Portland State University

PDXScholar

$5-2009$

\title{
Impacts of Climate Change and Urban Development on Water Resources in the Tualatin River Basin
}

Sarah Praskievicz

Portland State University

Follow this and additional works at: https://pdxscholar.library.pdx.edu/open_access_etds

Part of the Nature and Society Relations Commons, Physical and Environmental Geography Commons, Urban Studies Commons, and the Urban Studies and Planning Commons Let us know how access to this document benefits you.

\section{Recommended Citation}

Praskievicz, Sarah, "Impacts of Climate Change and Urban Development on Water Resources in the Tualatin River Basin" (2009). Dissertations and Theses. Paper 2248.

https://doi.org/10.15760/etd.2246

This Thesis is brought to you for free and open access. It has been accepted for inclusion in Dissertations and Theses by an authorized administrator of PDXScholar. Please contact us if we can make this document more accessible: pdxscholar@pdx.edu. 


\section{THESIS APPROVAL}

The abstract and thesis of Sarah Praskievicz for the Master of Science in Geography were presented May 8, 2009, and accepted by the thesis committee and the department.

COMMITTEE APPROVALS:

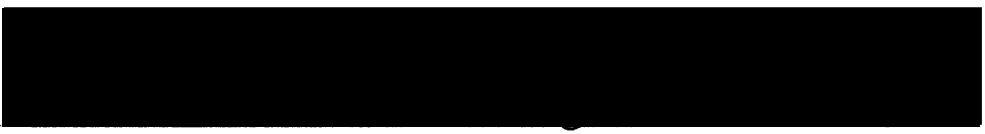

Heejun Chang, Chair

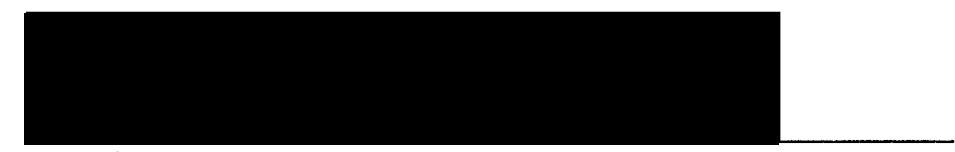

Jiunn-Der Duh

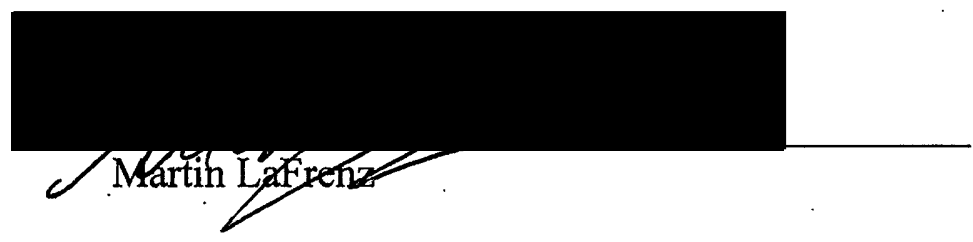

DEPARTMENT APPROVAL:

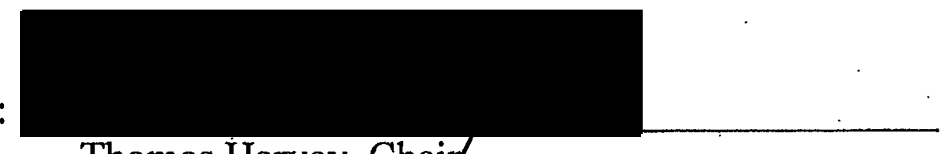

Thomas Harvey, Chair

Department of Geography 


\begin{abstract}
An abstract of the thesis of Sarah Praskievicz for the Master of Science in Geography presented May 8, 2009.
\end{abstract}

Title: Impacts of Climate Change and Urban Development on Water Resources in the Tualatin River Basin.

Potential impacts of climate change on the water resources of the Pacific Northwest of the United States include earlier peak runoff, reduced summer flows, and increased winter flooding. An increase in impervious surfaces, accompanied by urban development, is known to decrease infiltration and increase surface runoff.

Alterations of flow amount and pathways can alter water quality through dilution or flushing effects. I used the United States Environmental Protection Agency's Better Assessment Science Integrating Point and Nonpoint Sources (BASINS) modeling system to investigate the relative importance of future climate change and land use change in determining the quantity and quality of freshwater resources in northwestern Oregon's Tualatin River Basin. The basin was chosen for this study because it is rapidly urbanizing and representative of other low-elevation basins in the region. BASINS models were calibrated and validated using historic flow and water quality data from 1.991 to 2006 . The goodness-of-fit for the calibrated hydrology, suspended sediment, and orthophosphate models was high, with coefficients of determination ranging from 0.72 to 0.93 in the calibration period. The calibrated models were run 
under a range of eight downscaled climate change, two regional land use change, and four combined scenarios. Results included average increases in winter flows of ten percent, decreases in summer flows of thirty-seven percent, and increases in fifthpercentile flows of up to eighty percent as a result of climate change in the Tualatin River Basin. For land use change, the results included an increase in annual flows of twenty-one percent for the development-oriented scenario and a decrease of sixteen percent for the conservation-oriented scenario, with amplified changes at the sub-basin scale, including more than doubled winter flow. For combined scenarios of climate change and urban development, there is a projected increase in winter flows of up to seventy-one percent and decrease in summer flows of up to forty-eight percent.

Changes in suspended sediment and orthophosphate loading broadly tracked hydrological changes, with winter increases and summer decreases. The results are relevant to regional planners interested in the long-term response of water resources to climate change and land use change at the basin scale. 
' IMPACTS OF CLIMATE CHANGE AND URBAN DEVELOPMENT ON WATER RESOURCES IN THE TUALATIN RIVER BASIN'

by

SARAH PRASKIEVICZ

A thesis submitted in partial fulfillment of the requirements for the degree of

MASTER OF SCIENCE

in

GEOGRAPHY

Portland State University

2009 


\section{ACKNOWLEDGEMENTS}

A number of people and organizations made the completion of this thesis possible. First, I would like to thank my adviser, Dr. Heejun Chang, for his tireless guidance and support. I would also like to thank the other members of my committee, Dr. Geoffrey Duh and Dr. Martin LaFrenz, for providing valuable suggestions and feedback. Jan Miller of Clean Water Services provided the observed flow and water quality data. Dr. Eric Saláthe of the Climate Impacts Group provided the downscaled climate change scenario data; and Dr. Il-Won Jung wrote me a program for processing the scenario data: I am also grateful to Carolyn and Bob Perry and to John Rockie for funding scholarships that supported my work, and to the PSU chapter of the American Society for Photogrammetry and Remote Sensing (ASPRS) for providing me with financial assistance to present my research at the annual meeting of the Association of American Geographers in Las Vegas. Finally, I want to thank the faculty and my fellow students in the Department of Geography, for their friendship and moral support. 


\section{TABLE OF CONTENTS}

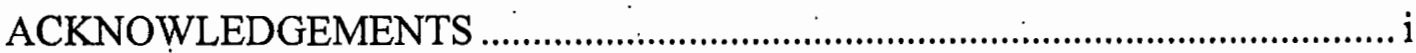

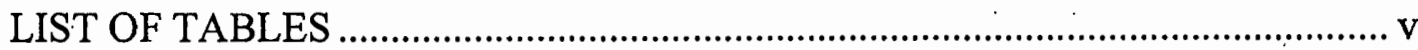

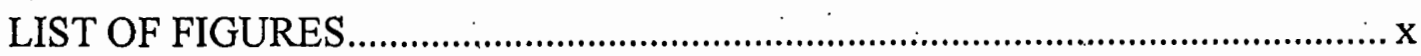

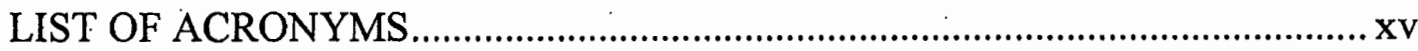

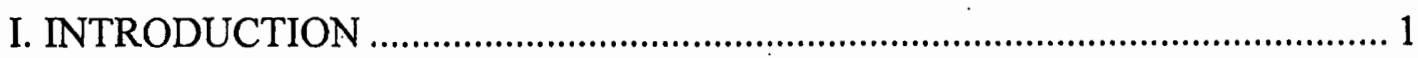

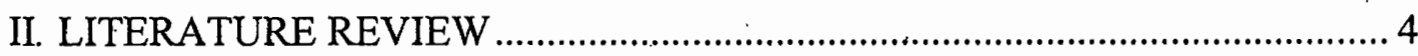

1. Impacts of Climate Change on Hydrology ……................................................. 5

A. Impacts of Uncertainty on Climate Impact Modeling ................................. 5

B. Global and Continental Scale Impacts ...................................................... 7

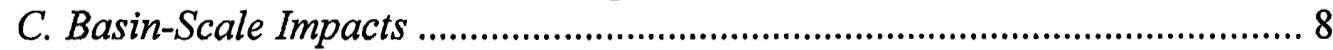

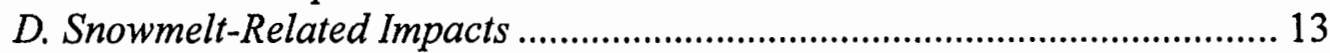

E. Extreme Events ......................................................... 14

2. Impacts of Climate Change on Water Quality .............................................. 16

3. Impacts of Urban Development on Hydrology ................................................ 19

4. Impacts of Urban Development on Water Quality..........................20

A. Empirical Studies ...................................................20

B. Modeling Studies...................................................22

5. Combined Impacts of Climate Change and Urban Development on Water Resources............................................................ 23

6. Implications for Water Management....................................28

A. Adaptation in the Water Sector .......................................28

B. Modeling Water Management ........................................28

7. Conclusion........................................................... 30

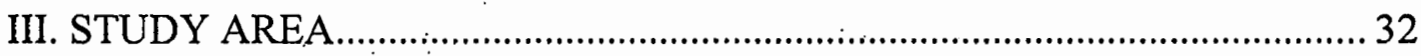

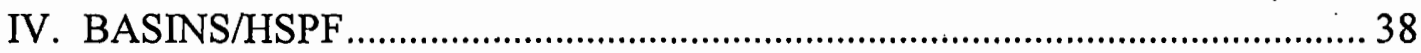

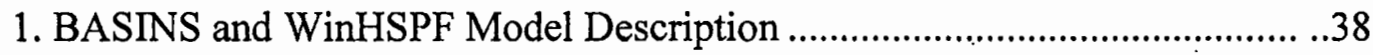

2. Previous Applications of BASINS/HSPF ........................................................ 48

A. Evaluative Studies.....................................................48

B. Scenario Modeling.................................................55

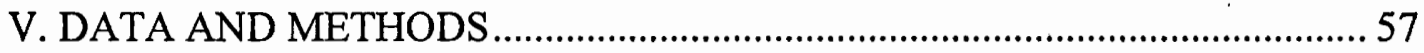

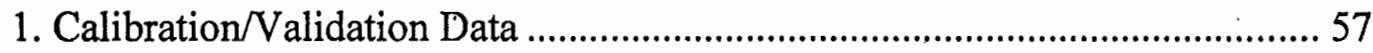

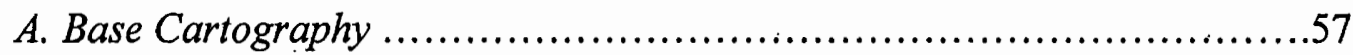

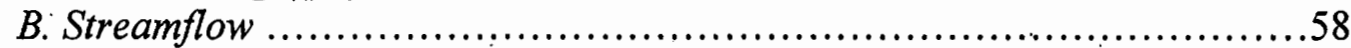

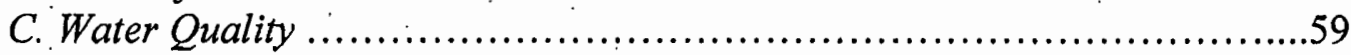

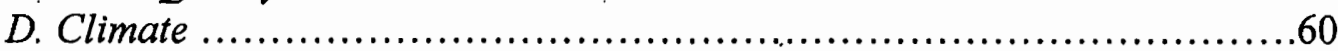

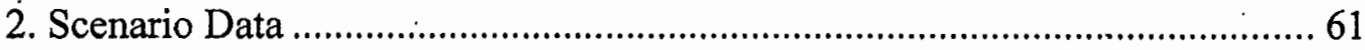

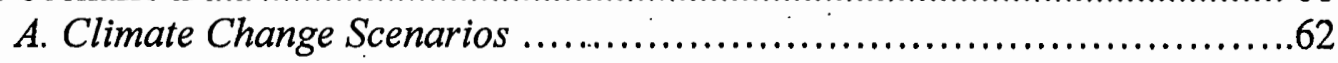


B. Urban Development Scenarios .............................................66

C. Combined Scenarios ....................................................68

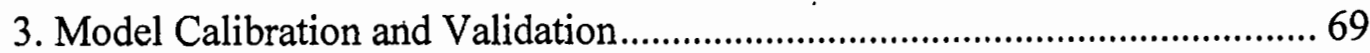

A. Hydrology Calibration and Validation....................................................... 71

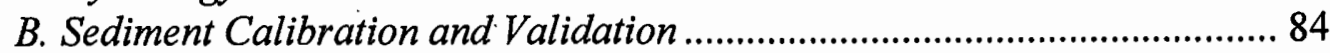

C. Nutrient Calibration and Validation .......................................88

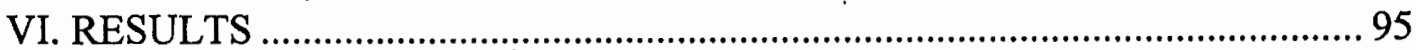

1. Impacts of Climate Change on Hydrology ……............................................... 95

A. Mean Hydrology ..........................................................95

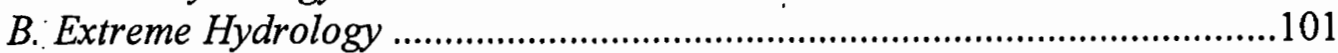

C. Soil Moisture Deficit and Flow Partitioning ..............................104

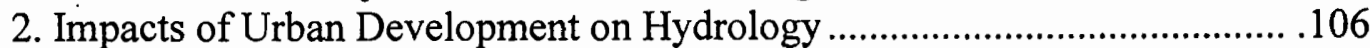

A. Basin-Scale Mean Hydrology ..............................................106

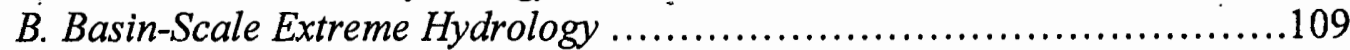

C. Basin-Scale Flow Partitioning ........................................ 110

D. Sub-Basin Impacts .................................................111

3. Combined Impacts of Climate Change and Urban Development on

Hydrology ............................................................ 117

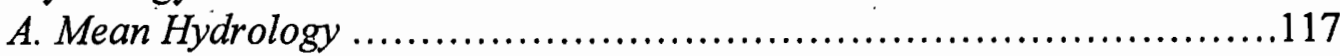

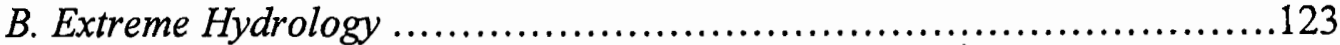

C. Flow Partitioning .................................................... 125

4. Impacts of Climate Change on Sediment Loading...........................127

5. Impacts of Urban Development on Sediment Loading........................131

6. Combined Impacts of Climate Change and Urban Development on Sediment

Loading..................................................................133

7. Impacts of Climate Change on Nutrient Loading.............................136

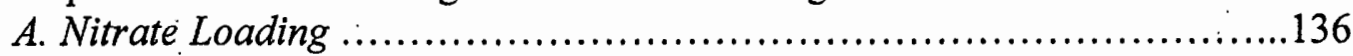

B. Orthophosphate Loading ............................................ 140

8. Impacts of Urban Development on Nutrient Loading.........................144

A. Nitrate Loading ....................................................... 144

B. Orthophosphate Loading ...........................................145

9. Combined Impacts of Climate Change and Urban Development on Nutrient

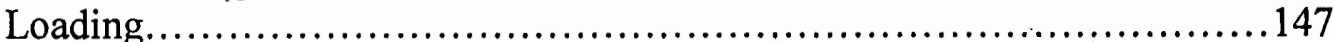

A. Nitrate Loading ....................................................... 147

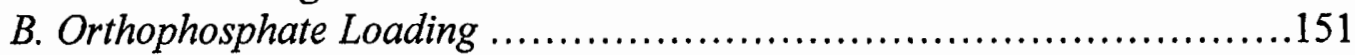

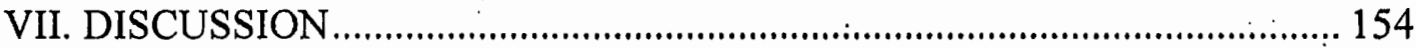

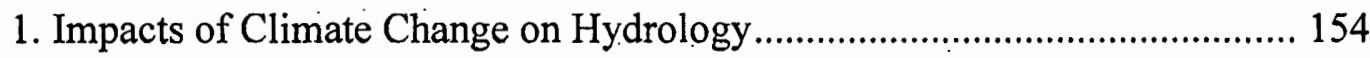

2. Impacts of Urban Development on Hydrology .......................................... 157

3. Combined Impacts of Climate Change and Urban Development on

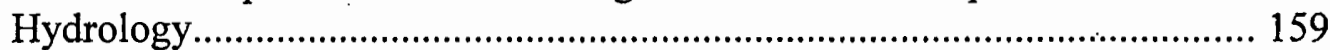

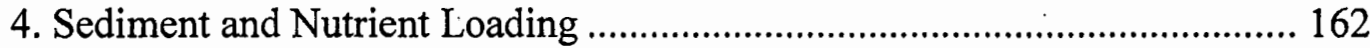

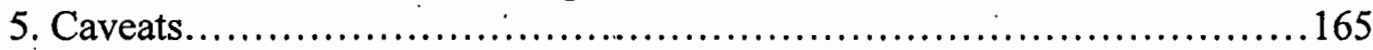


VII. CONCLUSIONS

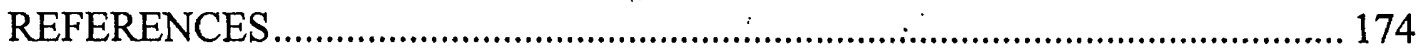




\section{LIST OF TABLES}

Table 2.1: Previous basin-scale modeling studies of impacts of climate change on hydrology................................................................ 8

Table 2.2: Previous basin-scale modeling studies of impacts of climate change on water quality ......................................................... 17

Table 2.3: Previous basin-scale modeling studies of impacts of urban development on hydrology ............................................................19

Table 2.4: Previous basin-scale modeling studies of impacts of urban development on water quality .............................................................

Table 2.5: Previous basin-scale modeling studies of combined impacts of climate change and urban development on water resources................................26

Table 2.6: Previous basin-scale modeling studies of impacts of climate change on

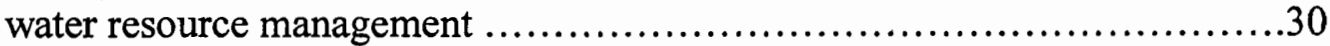

Table 4.1: Hydrology calibration parameters for WinHSPF ..........................44

Table 4.2: Previous evaluative studies using BASINS/HSPF .........................49

Table 4.3: Scenario modeling studies using BASINS/HSPF........................53

Table 5.1: Summary of datasets used for hydrological and water quality modeling...57

Table 5.2: Clean Water Services streamflow and water quality gage locations, lengths of time series, and sub-basin characteristics................................59

Table 5.3: Summary of climate change, urban development, and combined scenarios.................................................................61

Table 5.4: Summary of characteristics of GCMs used for climate change scenario modeling.

Table 5.5: Observed and modeled annual flows for the initial run during the

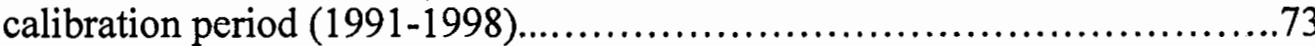

Table 5.6: Initial and final values of calibrated hydrology parameters for the Tualatin River Basin........................................................... 74

Table 5.7: Modeled and observed annual flows for the final run during the calibration period (1991-1998).....................................................76

Table 5.8: Comparison of hydrology model evaluation parameters between the initial and final runs for the calibration (1991-1998) and validation (1999-2006) periods for the Tualatin River Basin.........................................77

Table 5.9: Initial and final values of calibrated hydrology parameters for the Upper Tualatin River sub-basin.

Table 5.10: Hydrology model evaluation parameters for the calibration (1991-1998) and validation (1999-2006) periods for the Upper Tualatin River sub-basin. .82

Table 5.11: Hydrology model evaluation parameters for the calibration (2003-2004) and validation (2005-2006) periods for the Rock Creek sub-basin.............83

Table 5.12: Initial and final values of calibrated sediment parameters................84 Table 5.13: Sediment model evaluation parameters for the calibration (1991-1998) and validation (1999-2006) periods. 
Table 5.14: Modeled and observed annual sediment loads for the final run during the

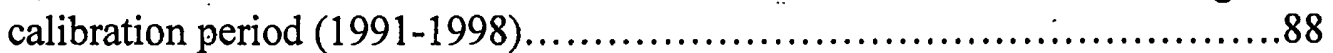

Table 5.15: Initial and final values of calibrated nitrate parameters.................88

Table 5.16: Nitrate model evaluation parameters for the calibration (1991-1998) and validation $(1999-2006)$ periods...........................................92

Table 5.17: Orthophosphate model evaluation parameters for the calibration (1991$1998)$ and validation $(1999-2006)$ periods.................................94

Table 6.1: Percent changes in monthly flow, averaged for all eight climate change scenarios, for the 2040s and 2070s.......................................97

Table 6.2: Results of two-tailed t-test for significance of changes in flow compared to the baseline for the eight climate change scenarios............................98

Table 6.3: Two-tailed t-test results from multiple paired comparisons of differences in flow among the eight climate change scenarios for the 2040s, with significance assessed using the false discovery rate......................................98

Table 6.4: Two-tailed t-test results from multiple paired comparisons of differences in flow among the eight climate change scenarios for the 2070s, with significance assessed using the false discovery rate ....................................99

Table 6.5: Percent changes in seasonal flow, averaged for all eight climate change scenarios, for the 2040s and 2070s....................................101

Table 6.6: Percent changes in five-percent highest flows for the 2040s and 2070s resulting from the high- and low-change climate scenarios..........................104

Table 6.7: Results of two-tailed t-test for significance of changes in fifth-percentile flows compared to the baseline for low-change and high-change climate scenarios.

Table 6.8: Percent changes in monthly flow resulting from the development and conservation land use scenarios for the Tualatin River Basin....................108

Table 6.9: Results of two-tailed t-test for significance of changes in flow compared to the baseline for the development and conservation scenarios for the Tualatin River Basin 108

Table 6.10: Percent changes in seasonal flow resulting from the development and conservation land use scenarios for the Tualatin River Basin.................109

Table 6.11: Percent changes in five-percent highest flows resulting from the development and conservation land use scenarios

Table 6.12: Results of two-tailed t-test for significance of changes in five-percent highest flows compared to the baseline for development and conservation land use scenarios.

Table 6.13: Percent changes in monthly flow resulting from the development and conservation land use scenarios for the Upper Tualatin River sub-basin.......113

Table 6.14: Percent changes in seasonal flow resulting from the development and conservation land use scenarios for the Upper Tualatin River sub-basin......113

Table 6.15: Results of two-tailed t-test for significance of changes in flow compared to the baseline for the development and conservation scenarios in the Upper Tualatin River sub-basin............................................114 
Table 6.16: Percent changes in monthly flow resulting from the development and conservation land use scenarios in the Rock Creek sub-basin.

Table 6.17: Percent changes in seasonal flow resulting from the development and conservation land use scenarios in the Rock Creek sub-basin.................116

Table 6.18: Results of two-tailed t-test for significance of changes in flow compared to the baseline for the development and conservation scenarios in the Rock Creek sub-basin.

Table 6.19: Percent changes in monthly flow resulting from the combined climate change and urban development scenarios for the 2040s....................120

Table 6.20: Percent changes in monthly flow resulting from the combined climate change and urban development scenarios for the 2070s.....................120

Table 6.21: Results of two-tailed t-test for significance of changes in flow compared to the baseline for the four combined climate change and urban development scenarios.

Table 6.22: Two-tailed t-test results from paired multiple comparisons of differences in flow among the four combined climate change and urban development scenarios for the 2040s, with significance assessed using false discovery rate.

Table 6.23: Two-tailed t-test results from paired multiple comparisons of differences in flow among the four combined climate change and urban development scenarios for the 2070 s, with significance assessed using false discovery rate................................................................. 121

Table 6.24: Percent changes in seasonal flow resulting from the combined climate change and urban development scenarios for the 2040s.

Table 6.25: Percent changes in seasonal flow resulting from the combined climate change and urban development scenarios for the 2070s.

Table 6.26: Percent changes in five-percent highest flows resulting from the four combined climate change and urban development scenarios.................125

Table 6.27: Results of two-tailed t-test for significance of changes in five-percent highest flows compared to the baseline for the four combined climate change and urban development scenarios.......................................125

Table 6.28: Two-tailed t-test results from multiple paired comparisons of differences in five-percent highest flows among the four combined climate change and urban development scenarios for the 2040s, with significance assessed using the false discovery rate................................................125

Table 6.29: Two-tailed t-test results from multiple paired comparisons of differences in five-percent highest flows among the four combined climate change and urban development scenarios for the 2070s, with significance assessed using the false discovery rate .............................................125

Table 6.30: Results of two-tailed t-test for significance of changes in suspended sediment load compared to the baseline for the eight climate change scenarios.

Table 6.31: Percent changes in seasonal suspended sediment load, averaged for all eight climate change scenarios, for the 2040s and 2070s 
Table 6.32: Percent changes in seasonal suspended sediment load resulting from the development and conservation land use scenarios.

Table 6.33: Results of two-tailed t-test for significance of changes in suspended sediment load compared to the baseline for the development and conservation scenarios....

Table 6.34: Percent changes in seasonal suspended sediment load resulting from the combined climate change and urban development scenarios for the $2040 \mathrm{~s}$.

Table 6.35: Percent changes in seasonal suspended sediment load resulting from the combined climate change and urban development scenarios for the $2070 \mathrm{~s}$

Table 6.36: Results of two-tailed t-test for significance of changes in suspended sediment load compared to the baseline for the four combined climate change and urban development scenarios.

Table 6.37: Percent changes in seasonal nitrate load, averaged for all eight climate change scenarios, for the 2040s and 2070s...

Table 6.38: Results of two-tailed t-test for significance of changes in nitrate load compared to the baseline for the eight climate change scenarios...

Table 6.39: Percent changes in seasonal orthophosphate load, averaged for all eight climate change scenarios, for the 2040s and 2070s.

Table 6.40: Results of two-tailed t-test for significance of changes in orthophosphate load compared to the baseline for the eight climate change scenarios....

Table 6.41: Percent change in seasonal nitrate load resulting from the development and conservation land use scenarios.

Table 6.42: Results of two-tailed t-test for significance of changes in nitrate load compared to the baseline for the development and conservation scenarios... 145

Table 6.43: Percent changes in seasonal orthophosphate load resulting from the development and conservation land use scenarios

Table 6.44: Results of two-tailed t-test for significance of changes in orthophosphate load compared to the baseline for the development and conservation scenarios.

Table 6.45: Percent changes in seasonal nitrate load resulting from the combined climate change and urban development scenarios for the $2040 \mathrm{~s}$

Table 6.46: Percent changes in seasonal nitrate load resulting from the combined climate change and urban development scenarios for the $2070 \mathrm{~s}$

Table 6.47: Results of two-tailed t-test for significance of changes in nitrate load compared to the baseline for the four combined climate change and urban development scenarios.

Table 6.48: Percent changes in seasonal orthophosphate load resulting from the combined climate change and urban development scenarios for the $2040 \mathrm{~s}$

Table 6.49: Percent changes in seasonal orthophosphate load resulting from the combined climate change and urban development scenarios for the $2070 \mathrm{~s}$ 
Table 6.50: Results of two-tailed t-test for significance of changes in orthophosphate load compared to the baseline for the four combined climate change and urban development scenarios. 


\section{LIST OF FIGURES}

Figure 3.1. Location of the Tualatin River Basin within the state of Oregon...........32

Figure 3.2. Average annual hydrograph of the Tualatin River at West Linn (site \#

14207500) for 1976-2006. Source: USGS (2008a)..........................34

Figure 3.3: Changes in land use type in the Tualatin River Basin between 1992 and 2001. Source: USEPA (2008)..........................................36

Figure 3.4: 2001 land use in the Tualatin River Basin. Source: USEPA (2008).......36

Figure 4.1: HSPF model structure for simulating water balance on pervious land surfaces. Source: USEPA (2001) ......................................42

Figure 4.2. HSPF model structure for simulating water balance on impervious land surfaces.................................................................42

Figure 4.3. HSPF model structure for simulating sediment transport..................45

Figure 4.4. HSPF model structure for simulating nutrient transport..................46

Figure 5.1: Tualatin River sub-basins delineated in ArcHydro.......................58

Figure 5.2: Observed Tualatin River flow, 1991-2006, and a) suspended sediment, below flows of $8 \mathrm{cms}$; b) suspended sediment, above flows of $8 \mathrm{cms}$; c) nitrate; and d) orthophosphate.................................................60

Figure 5.3: Absolute change from baseline in average monthly temperature for the 2040 s according to eight climate change scenarios.........................64

Figure 5.4: Absolute change from baseline in average monthly temperature for the 2070s according to eight climate change scenarios.........................65

Figure 5.5: Percent change from baseline in total monthly precipitation for the 2040s according to eight climate change scenarios....

Figure 5.6: Percent change from baseline in total monthly precipitation for the 2070s according to eight climate change scenarios................................66

Figure 5.7: Land use/land cover in the Tualatin River Basin for the 2040s according to the conservation and development scenarios.............................67

Figure 5.8: Changes from baseline in percent land use according to the two urban development scenarios................................................68

Figure 5.9: Annual average flows for the Tualatin River at West Linn (USGS site number 14207500) as departures from the mean annual flow for 19782007.....................................................................

Figure 5.10: Observed flows versus modeled flows for the initial run, 1991-2006, at the Weiss Bridge site, Tualatin River....................................72

Figure 5.11: Hydrograph of observed and modeled flows for the initial run, 1991-2006, at the Weiss Bridge site, Tualatin River..................................72

Figure 5.12: Observed flows versus modeled flows for the final run in the calibration

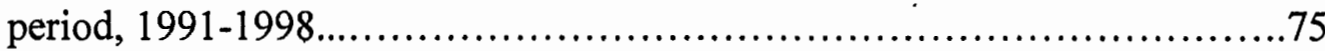

Figure 5.13: Hydrograph of observed and modeled flows for the final run in the calibration period, 1991-1998, for the Tualatin River Basin...................75

Figure 5.14: Observed flows versus modeled flows for the final run in the validation

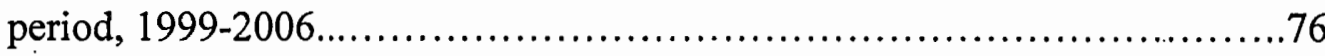


Figure 5.15: Hydrograph of observed and modeled flows during the final run in the validation period, 1999-2006, for the Tualatin River Basin....................77

Figure 5.16: Annual hydrograph of average monthly observed and simulated flow for

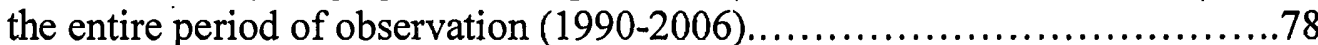

Figure 5.17: Land use in the Upper Tualatin River sub-basin under the baseline, development, and conservation scenarios..................................79

Figure 5.18: Land use in the Rock Creek sub-basin under the baseline, development, and conservation scenarios............................................... 80

Figure 5.19: Hydrograph of observed and modeled flows for the final run in the calibration period, 1991-1998, for the Upper Tualatin River sub-basin........82

Figure 5.20: Hydrograph of observed and modeled flows for the final run in the validation period, 1999-2006, for the Upper Tualatin River sub-basin.........82

Figure 5.21: Hydrograph of observed and modeled flows for the final run in the calibration period (2003-2004), for the Rock Creek sub-basin................83

Figure 5.22: Hydrograph of observed and modeled flows for the final run in the validation period (2005-2006), for the Rock Creek sub-basin................83

Figure 5.23: Observed versus modeled suspended sediment load for the final run in the

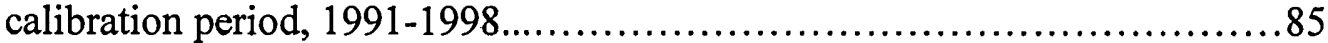

Figure 5.24: Time series of observed and modeled suspended sediment loads for the

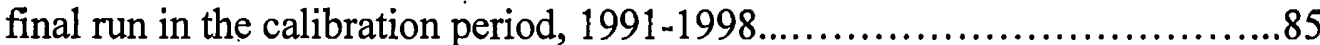

Figure 5.25: Observed versus modeled suspended sediment load for the final run in the validation period, $1999-2006$ .86

Figure 5.26: Time series of observed and modeled suspended sediment loads for the

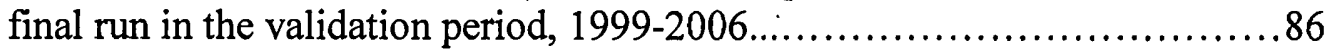

Figure 5.27: Observed versus modeled nitrate load for the final run in the calibration

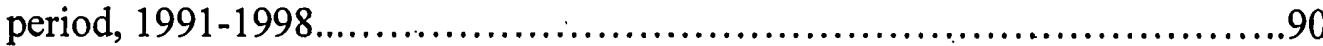

Figure 5.28: Observed versus modeled nitrate load for the final run in the validation

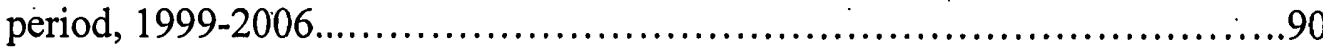

Figure 5.29: Observed flow and nitrate concentration samples for the entire observed data period, 1991-2006.

Figure 5.30: Time series of observed and modeled nitrate loads for the final run in the

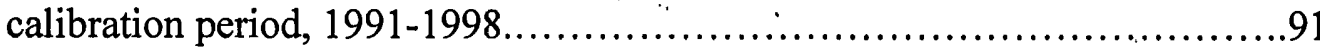

Figure 5.31: Time series of observed and modeled nitrate loads for the final run in the

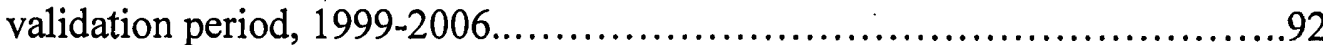

Figure 5.32: Observed versus modeled orthophosphate load for the final run in the

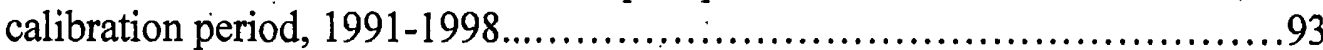

Figure 5.33: Observed versus modeled orthophosphate load for the final run in the validation period, $1999-2006$

Figure 5.34: Time series of observed and modeled orthophosphate loads for the final run in the calibration period, 1991-1998.

Figure 5.35: Time series of observed and modeled orthophosphate loads for the final run in the validation period, 1999-2006.

Figure 6.1: Absolute changes in monthly flow resulting from the eight climate change

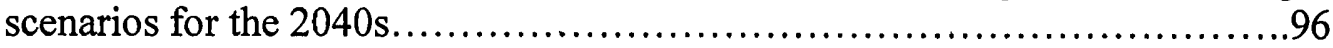


Figure 6.2: Absolute changes in monthly flow resulting from the eight climate change scenarios for the 2070 s...............................................96

Figure 6.3: Absolute changes in monthly flow, averaged for all eight climate change scenarios, for the 2040 s and 2070 s.

Figure 6.4: Absolute changes in seasonal flow resulting from the eight climate change scenarios for the 2040s. 100

Figure 6.5: Absolute changes in seasonal flow resulting from the eight climate change scenarios for the $2070 \mathrm{~s}$. 100

Figure 6.6: Absolute changes in seasonal flow, averaged for all eight climate change scenarios, for the 2040s and 2070s......................................101

Figure 6.7: Daily flow duration curves for baseline and future periods resulting from the high-change climate scenario, plotted with a logarithmic scale.............102

Figure 6.8: Daily flow duration curves for baseline and future periods resulting from the low-change climate scenario, plotted with a logarithmic scale ............102

Figure 6.9: Flow duration curves for the baseline and future period five-percent highest flows resulting from the high-change climate scenario.................103

Figure 6.10: Flow duration curves for the baseline and future period five-percent highest flows resulting from the low-change climate scenario..................103

Figure 6.11: Precipitation and potential evapotranspiration for the baseline and highchange climate scenario

Figure 6.12: Precipitation and potential evapotranspiration for the baseline and lowchange climate scenario

Figure 6.13: Surface and groundwater flows for the baseline and high-change climate scenario 106

Figure 6.14: Surface and groundwater flows for the baseline and low-change climate scenario....

Figure 6.15: Absolute changes in monthly flow resulting from the development and conservation land use scenarios for the Tualatin River Basin.

Figure 6.16: Absolute changes in seasonal flow resulting from the development and conservation land use scenarios for the Tualatin River Basin.

Figure 6.17: Flow duration curves for the baseline, development, and conservation land use scenarios.

Figure 6.18: Surface and groundwater flows for the baseline, development, and conservation land use scenarios.......................................111

Figure 6.19: Absolute changes in monthly flow resulting from the development and conservation land use scenarios for the Upper Tualatin River sub-basin......112

Figure 6.20: Absolute changes in seasonal flow resulting from the development and conservation land use scenarios for the Upper Tualatin River sub-basin......113

Figure 6.21: Percent changes in land use in the Upper Tualatin River sub-basin under the development and conservation scenarios

Figure 6.22: Absolute changes in monthly flow resulting from the development and conservation land use scenarios in the Rock Creek sub-basin

Figure 6.23: Absolute changes in seasonal flow resulting from the development and conservation land use scenarios in the Rock Creek sub-basin.................116 
Figure 6.24: Percent changes in land use in the Rock Creek sub-basin under the development and conservation scenarios..............................117

Figure 6.25: Absolute changes in monthly flow resulting from the combined climate change and urban development scenarios for the 2040s....................119

Figure 6.26: Absolute changes: in monthly flow resulting from the combined climate change and urban development scenarios for the 2070s.....................119

Figure 6.27: Absolute changes in seasonal flow resulting from the combined climate change and urban development scenarios for the 2040s....................122

Figure 6.28: Absolute changes in seasonal flow resulting from the combined climate change and urban development scenarios for the 2070s...................122

Figure 6.29: Flow duration curves for the baseline and future periods resulting from the four combined climate change and urban development scenarios for the $2040 \mathrm{~s}$

Figure 6.30: Flow duration curves for the baseline and future periods resulting from the four combined climate change and urban development scenarios for the $2070 \mathrm{~s}$

Figure 6.31: Surface and groundwater flows for the baseline and four combined climate change and urban development scenarios for the 2040s.............126

Figure 6.32: Surface and groundwater flows for the baseline and four combined climate change and urban development scenarios for the 2070s.............127

Figure 6.33: Absolute changes in monthly suspended sediment load resulting from the eight climate change scenarios for the 2040 s................................128

Figure 6.34: Absolute changes in monthly suspended sediment load resulting from the eight climate change scenarios for the 2070 s...............................128

Figure 6.35: Absolute changes in seasonal suspended sediment load resulting from the eight climate change scenarios for the 2040 s.............................. 130

Figure 6.36: Absolute changes in seasonal suspended sediment load resulting from the eight climate change scenarios for the 2070s..............................130

Figure 6.37: Absolute changes in seasonal suspended sediment load, averaged for all eight climate change scenarios, for the 2040s and 2070s.....................131

Figure 6.38: Absolute changes in monthly suspended sediment load resulting from the development and conservation land use scenarios...........................132

Figure 6.39: Absolute changes in seasonal suspended sediment load resulting from the development and conservation land use scenarios............................132

Figure 6.40: Absolute changes in monthly suspended sediment load resulting from the combined climate change and urban development scenarios for the 2040s...134

Figure 6.41: Absolute changes in monthly suspended sediment load resulting from the combined climate change and urban development scenarios for the 2070 s..................................................................... 134

Figure 6.42: Absolute changes in seasonal suspended sediment load resulting from the combined climate change and urban development scenarios for the 2040 s......................................................................135

Figure 6.43: Absolute changes in seasonal suspended sediment load resulting from the combined climate change and urban development scenarios for the 2070 s...135 
Figure 6.44: Absolute changes in monthly nitrate load resulting from the eight climate change scenarios for the 2040 s........................................ 137

Figure 6.45: Absolute changes in monthly nitrate load resulting from the eight climate change scenarios for the 2070 s........................................ 138

Figure 6.46: Absolute changes in seașonal nitrate load resulting from the eight climate change scenarios for the 2040s.........................................138.

Figure 6.47: Absolute changes in seasonal nitrate load resulting from the eight climate change scenarios for the 2070s..........................................139

Figure 6.48: Absolute changes in seasonal nitrate load, averaged for all eight climate change scenarios, for the 2040s and 2070s...............................139

Figure 6.49: Absolute changes in monthly orthophosphate load resulting from the eight climate change scenarios for the 2040 s................................ 141

Figure 6.50: Absolute changes in monthly orthophosphate load resulting from the eight climate change scenarios for the 2070 s............................... 141

Figure 6.51: Absolute changes in seasonal orthophosphate load resulting from the eight climate change scenarios for the 2040s.................................142

Figure 6.52: Absolute changes in seasonal orthophosphate load resulting from the eight climate change scenarios for the $2070 \mathrm{~s}$

Figure 6:53: Absolute changes in seasonal orthophosphate load, averaged for all eight climate change scenarios, for the 2040s and 2070s...........................143

Figure 6.54: Absolute changes in monthly nitrate load resulting from the development and conservation land use scenarios.......................................144

Figure 6.55: Absolute changes in seasonal nitrate load resulting from the development and conservation land use scenarios..................................145

Figure 6.56: Absolute changes in monthly orthophosphate load resulting from the development and conservation land use scenarios.........................146

Figure 6.57: Absolute changes in seasonal orthophosphate load resulting from the development and conservation land use scenarios...........................147

Figure 6.58: Absolute changes in monthly nitrate load resulting from the combined climate change and urban development scenarios for the 2040 s...............148

Figure 6.59: Absolute changes in monthly nitrate load resulting from the combined climate change and urban development scenarios for the 2070s...............149

Figure 6.60: Absolute changes in seasonal nitrate load resulting from the combined climate change and urban development scenarios for the 2040s.

Figure 6.61: Absolute changes in seasonal nitrate load resulting from the combined climate change and urban development scenarios for the 2070s..............150

Figure 6.62: Absolute changes in monthly orthophosphate load resulting from the combined climate change and urban development scenarios for the 2040s...151

Figure 6.63: Absolute changes in monthly orthophosphate load resulting from the combined climate change and urban development scenarios for the 2070 s...152

Figure 6.64: Absolute changes in seasonal orthophosphate load resulting from the combined climate change and urban development scenarios for the 2040s...152

Figure 6.65: Absolute changes in seasonal orthophosphate load resulting from the combined climate change and urban development scenarios for the 2070 s...153 


\section{LIST OF ACRONYMS}

\begin{tabular}{|c|c|}
\hline Acronym & Definition \\
\hline ARM & Agricultural Runoff Management \\
\hline AVGWLF & ArcView Generalized Watershed Loading Function \\
\hline BASINS & $\begin{array}{l}\text { Better Assessment Science Integrating Point and Nonpoint } \\
\text { Sources }\end{array}$ \\
\hline BCCR & Bjerknes Center for Climate Research \\
\hline BOD & Biological oxygen demand \\
\hline CAT & Climate Assessment Tool \\
\hline $\operatorname{CCSM}$ & Community Climate System Model \\
\hline CGCM & Coupled Global Climate Model \\
\hline CHARM & Climate and Human Activities-sensitive Runoff Model \\
\hline CIG & Climate Impacts Group \\
\hline CNRM & Centre National de Recherches Meteorologiques \\
\hline COD & Chemical oxygen demand \\
\hline CVMod & Central Valley Model \\
\hline CWS & Clean Water Services \\
\hline DEM & Digital Elevation Model \\
\hline DHSVM & Distributed Hydrology-Soil-Vegetation Model \\
\hline ECHAM & European Centre Hamburg Model \\
\hline EPA & Environmental Protection Agency \\
\hline GCM & General Circulation Model \\
\hline GHG & Greenhouse gas \\
\hline GIS & Geographic Information Systems \\
\hline HBV & Hydrologiska Byråns Vattenbalansavdelning \\
\hline $\mathrm{HCHL}$ & High climate change/high land use change scenario \\
\hline HCLL & High climate change/low land use change scenario \\
\hline HEC-HMS & Hydrologic Engineering Center Hydrologic Modeling System \\
\hline HSPEXP & HSPF Expert Calibration \\
\hline HSPF & Hydrologic Simulation Program - Fortran \\
\hline HUC & Hydrologic Unit Code \\
\hline $\begin{array}{l}\text { Hydro- } \\
\text { BEAM }\end{array}$ & Hydrological River Basin Environmental Assessment Tool \\
\hline IPCC & Intergovernmental Panel on Climate Change \\
\hline IPSL & Institut Pierre Simon Laplace \\
\hline IQQM & Integrated Quantity-Quality Model \\
\hline LCHL & Low climate change/high land use change scenario \\
\hline LCLL & Low climate change/low land use change scenario \\
\hline L-THIA & Long-Term Hydrological Impact Assessment \\
\hline LTM & Land Transformation Model \\
\hline NAM & Nedbor-Afstromings Model \\
\hline NHD & National Hydrography Dataset \\
\hline NLCD & National Land Cover Dataset \\
\hline NPS & NonPoint Source \\
\hline OCS & Oregon Climate Service \\
\hline PCM & Parallel Climate Model \\
\hline
\end{tabular}




\begin{tabular}{|c|c|}
\hline PCSWMM & Personal Computer - Storm Water Management Model \\
\hline PEST & Parameter Estimation \\
\hline PET & Potential evapotranspiration \\
\hline $\begin{array}{l}\text { PNW- } \\
\text { ERC }\end{array}$ & Pacific Northwest Ecosystem Research Consortium \\
\hline PRMS & Precipitation-Runoff Modeling System \\
\hline RCM & Regional Climate Model \\
\hline $\begin{array}{l}\text { SHE- } \\
\text { TRAN }\end{array}$ & Systéme hydrologique Européen TRANsport \\
\hline SMHI & Swedish Meteorological and Hydrological Institute \\
\hline SWAT & Soil and Water Assessment Tool \\
\hline SWM & Stanford Watershed Model \\
\hline TMDL & Total Maximum Daily Load \\
\hline TRB & Tualatin River Basin \\
\hline UBC & University of British Columbia \\
\hline USGS & United States Geological Survey \\
\hline USLE & Universal Soil Loss Equation \\
\hline VIC & Variable Infiltration Capacity \\
\hline WDM & Watershed Data Management \\
\hline WBUDG & Water Budget \\
\hline
\end{tabular}




\section{INTRODUCTION}

Regional water quantity and quality are affected by a variety of natural and anthropogenic factors. Some of the most important of these are climate and land use, which together account for much of a drainage basin's hydrological and water quality characteristics. Because of the significance of their impacts on water resources, and the projected changes in climate and land use during the twenty-first century in many world regions, studying the separate and combined influences of these two variables is important for sustainable water resource management.

Anthropogenic climate change is expected to affect the quantity and quality of global water resources and to necessitate changes in the way these resources are managed (Oki and Kanae 2006; Kundzewicz et al. 2007). In the Pacific Northwest, where most precipitation falls during the winter, the most significant projected result of climate change is a reduction in snowpack, which is a major source of summer flows (Mote et al. 2003). Over the past fifty years, peak spring runoff in snowmeltdominated and transient basins in the western United States has been occurring earlier, because of reduced snowpack and warmer spring temperatures (Regonda et al. 2005, Barnett et al. 2008).

Climate change also has the potential to affect water quality. Higher water temperatures resulting from increases in air temperature promote the growth of algal blooms and decrease dissolved oxygen, lowering ecological productivity (Kumagai et al. 2002). In areas where rainfall amount and intensity are expected to increase, more pollutants may be flushed from land surfaces into water bodies, although this may be 
countered by an increase in dilution (Murdoch et al. 2000, Chang et al. 2001). Lower summer flows can increase the concentration of pollutants because of reduced dilution effects (Kundzewicz et al. 2007).

In addition to climate change, water quantity and quality are affected by land use changes. As relatively permeable forest and agricultural land is converted to highly impermeable urban land cover, less water infiltrates the soil to recharge aquifers (Rose and Peters 2001). Additionally, the lower infiltration rates of urban land cover cause higher surface runoff, increasing flood risk (Nirupama and Simonovic 2007). Urban development impairs water quality by adding both point sources of pollution such as wastewater treatment and industrial effluent, as more facilities are built to serve a growing population, and nonpoint source urban pollution (Atasoy et al. 2006).

Because of the dynamic interactions between climate and land cover, numerous integrated watershed modeling studies have examined the relations among climate change, land use change, and water resources (Mimikou et al. 2000, Chang 2003, Maximov 2003, Sharma 2003, Chang 2004, Chen et al. 2005, Samaniego and Bardossy 2006, Wilby et al. 2006, Davis Todd et al. 2007, Ducharne et al. 2007, Franczyk and Chang 2009). The hydrological models used in these studies are capable of simulating responses to climatic and land cover inputs to project runoff and water quality outcomes. The watershed is a natural unit with which to model regional water resources for planning purposes. Although there are previous studies examining combined impacts of climate change and land use change on water resources, most of 
these studies focused on one or two scenarios and few modeled impacts on both runoff and water quality at the basin scale.

This research examines the relative importance of future climate change and land use change in determining the quantity and quality of freshwater resources in the Tualatin River Basin (TRB). It uses a Geographic Information Systems (GIS)-based hydrological model to investigate these relationships and project future impacts on water resources under a range of climatic and land use scenarios. The modeling framework is the Environmental Protection Agency's (EPA) Better Assessment Science Integrating Point and Nonpoint Sources (BASINS).

This research has three primary objectives. The first is to contribute to the body of knowledge about the separate and combined influences of climate change and urban development on water quantity and quality. The second objective is to test the application of the BASINS modeling framework in a meso-scale, low-elevation basin in the Pacific Northwest. The third objective is to make recommendations for the management of water resources in the TRB.

The specific research questions can be divided into the following sections: 1) impacts of climate change on hydrology; 2) impacts of climate change on water quality; 3) impacts of urban development on hydrology; 4) impacts of urban development on water quality; 5) combined impacts of climate change and urban development on water resources; and 6) implications of projected changes for sustainable water resource management in the TRB. 


\section{II: LITERATURE REVIEW}

In a world in which the consensus view predicts substantial impacts of anthropogenic climate change on global water resources in the near-term and distant future (Kundzewicz et al. 2007), hydrologic impact analysis has become a thriving area of research. Understanding potential climate-related impacts is especially necessary given that these changes may interact in complex ways with other elements of global change, notably urban development. These two driving forces of future hydrologic change are likely to affect both water quantity and quality, at global, continental, regional, and basin scales, in geographically disparate areas around the world. Not only are changes in mean hydrology expected, but also changes in hydrologic variability, which are particularly significant for water resource management. Further complicating these issues is the inherent uncertainty present at every stage in the methods and techniques used by researchers to predict future changes.

I begin this review by describing some issues related to modeling impacts of climate change on hydrology, namely sources of uncertainty, modeling at the global/continental and basin scale, impacts specifically related to snowmelt-dominated areas, and hydrologic variability. An overview follows of research examining the impacts of climate change on water quality, and then impacts of urban development on hydrology. Next I focus on empirical and modeling studies of the impacts of urban development on water quality. The next section examines the combined modeling of climate change and urban development impacts on water quantity and quality, and I 
end by discussing implications of this research for adaptation in the water resources sector.

\section{Impacts of Climate Change on Hydrology}

\section{A. Uncertainty in Climate Change Impact Modeling}

A typical study examining impacts of climate change on water resources consists of a series of linked models. It begins with one or more greenhouse gas (GHG) emissions scenarios, usually from the Intergovernmental Panel on Climate Change's (IPCC) Special Report on Emissions Scenarios (SRES). These scenarios are used in General Circulation Models (GCMs), which use large-scale simulations of the coupled ocean-atmosphere system to predict the response of the climate to the projected increase in GHG concentrations. Because the outputs from these models are at too large a scale to be useful for most hydrological applications, they must be downscaled using either a regional climate model (RCM), which simulates local topographic and other influences on climate, or a statistical downscaling technique, which alters historic climate records according to the projected future change. Finally, the downscaled climate change scenarios can be used as inputs to basin-scale hydrological models. The outputs from these models can be further used in water resource management models to take the socioeconomic aspects of the hydrologic system into account. At each stage of this modeling chain, assumptions must be made and error is inevitable, leading to amplified uncertainty throughout the modeling process. 
Wood et al. (2004) compared three statistical downscaling methods, using the Variable Infiltration Capacity (VIC) macroscale hydrological model. The most accurate method was bias correction and spatial disaggregation. Salathé et al. (2007) found significant differences in regional climate response in the Pacific Northwest using statistical downscaling versus an RCM, with the RCM more accurately reproducing the historical climate. Dibike and Coulibaly (2005) used output from a GCM to compare two downscaling methods, regression analysis and a stochastic weather generator, and two hydrological models, Hydrologiska Byråns Vattenbalansavdelning (HBV) and CEQUEAU, in their ability to project runoff impacts in a Québec basin. The weather generator performed better when estimating the length of wet spells in the historical period. Graham et al. (2007) compared a set of eleven RCMs' ability to simulate hydrologic impacts of climate change in the Baltic and Rhine basins. They found that the modeling results were more sensitive to the GCM used than to the emissions scenario or the RCM. This is likely because different emissions scenarios do not begin to diverge significantly until late in the twenty-first century, and RCMs are more affected by the boundary conditions provided by the GCM than by the local topographic and other regional climatic conditions that they simulate.

These studies indicate that the greatest source of uncertainty in the climate impact modeling chain is the GCM. Because they all model atmospheric conditions and feedbacks, differently, GCMs vary widely in their projections, particularly for precipitation. There is some evidence that the HadCM2 model may be more effective 
than other GCMs at simulating historical precipitation in the midlatitudes (Graham et al. 2007). The choice of emission scenario is less important, because most scenarios show very similar levels of emissions through the 2050s. In terms of downscaling methods, RCMs and other dynamic techniques are generally more successful because they replicate regional climate systems, but also require more data and time to implement than the simpler statistical techniques.

\section{B. Global and Continental Scale Impacts}

Oki and Kanae (2006) and Huntington (2006) found that climate change is likely to accelerate the global hydrologic cycle. The implications of this acceleration for water resources vary by region. Some areas, particularly in tropical regions and the higher latitudes, may have increased access to water resources as a result of more precipitation. This may have negative implications for flood risk in these regions. In other areas, especially those that are already experiencing water stress, such as Mediterranean and semi-arid climates, increased hydrologic variability may decrease water availability. Modeling studies by Manabe et al. (2004), Milly et al. (2005), and Nohara et al. (2006) found increases in the runoff of Arctic and many tropical and midlatitude rivers, with decreases in semiarid regions, particularly during the dry season.

Arnell (2003a) modeled hydrologic impacts of climate change in nearly 1200 basins around the world. He used six GCMs, driven by IPCC emissions scenarios A1, $\mathrm{A} 2, \mathrm{~B} 1$, and B2, to run a conceptual macroscale hydrological model for the $2020 \mathrm{~s}$, 2050s, and 2080s. The results included a general increase in annual and peak runoff in 
the middle and high latitudes, increased interannual variability in runoff, and an increase in the frequency of the contemporary ten-year low flow. In this study, results were far more sensitive to the choice of GCM than to the emissions scenario, also a finding of Graham et al. (2007). Future water stress will be influenced not only by changes in climate, but also by increase in water demand fueled by population growth and economic development, and in many regions these socioeconomic factors may be more significant than climatic factors (Vörösmarty et al. 2000, Alcamo et al. 2007).

\section{Basin-Scale Impacts}

Drainage basins are natural hydrologic units, each with its own water balance. Accordingly, basins are ideal spatial units for hydrological modeling, and many climate change impact studies are at this scale (Table 2.1). An added benefit of basinscale modeling is that many water resource management plans are made at this scale, which facilitates the application of modeling results to real-world decision-making.

Table 2.1: Previous basin-scale modeling studies of impacts of climate change on hydrology.

\begin{tabular}{|c|c|c|c|c|c|}
\hline Author(s) & $\begin{array}{l}\text { Study } \\
\text { Area }\end{array}$ & GCM(s) & $\begin{array}{l}\text { Study } \\
\text { Period }\end{array}$ & $\begin{array}{l}\text { Hydrological } \\
\text { Model }\end{array}$ & Results \\
\hline $\begin{array}{l}\text { Frei et al. } \\
(2002)\end{array}$ & New York & $\begin{array}{l}\text { HadCM2; } \\
\text { CGCMa1 }\end{array}$ & $2080 \mathrm{~s}$ & $\begin{array}{l}\text { Thornthwaite } \\
\text { conceptual } \\
\text { water } \\
\text { balance } \\
\text { model }\end{array}$ & $\begin{array}{l}\text { Increase of } 10 \% \text { to } \\
\text { decrease of } 30 \% \text { in } \\
\text { runoff }\end{array}$ \\
\hline $\begin{array}{l}\text { Loukas et al } \\
(2002 \mathrm{~b})\end{array}$ & $\begin{array}{l}\text { British } \\
\text { Columbia }\end{array}$ & CGCMa1 & $\begin{array}{l}2080- \\
2100\end{array}$ & $\begin{array}{l}\text { UBC } \\
\text { Watershed } \\
\text { Model }\end{array}$ & $\begin{array}{l}\text { Rainfall-dominated } \\
\text { basin; increased } \\
\text { fall/winter runoff, } \\
\text { decreased } \\
\text { spring/summer } \\
\text { runoff; Snowmelt- } \\
\text { dominated } \\
\text { basin: earlier spring } \\
\text { peak, increased } \\
\text { winter runoff } \\
\end{array}$ \\
\hline $\begin{array}{l}\text { Menzel and } \\
\text { Bürger } \\
(2002)\end{array}$ & Germany & $\begin{array}{l}\text { ECHAM4/ } \\
\text { OPYC3 }\end{array}$ & $2100 \mathrm{~s}$ & HBV & $\begin{array}{l}\text { Decrease in mean } \\
\text { annual runoff }\end{array}$ \\
\hline
\end{tabular}




\begin{tabular}{|c|c|c|c|c|c|}
\hline $\begin{array}{l}\text { Eckhardt and } \\
\text { Ulbrich } \\
(2003)\end{array}$ & $\begin{array}{l}\text { Central } \\
\text { Europe }\end{array}$ & $\begin{array}{l}\text { Ensemble } \\
\text { of } 5\end{array}$ & $2090 \mathrm{~s}$ & SWAT & $\begin{array}{l}\text { Increased winter } \\
\text { runoff; earlier } \\
\text { spring peak; } \\
\text { decreased summer } \\
\text { runoff and } \\
\text { groundwater } \\
\text { recharge }\end{array}$ \\
\hline $\begin{array}{l}\text { Christensen } \\
\text { et al. (2004) }\end{array}$ & $\begin{array}{l}\text { Colorado } \\
\text { River Basin }\end{array}$ & PCM & $2090-$ & VIC & $\begin{array}{l}17 \% \text { decrease in } \\
\text { runoff }\end{array}$ \\
\hline Jha (2005) & $\begin{array}{l}\text { Upper } \\
\text { Mississippi } \\
\text { River Basin }\end{array}$ & $\begin{array}{l}\text { HadCM2; } \\
\text { CGCMa1 }\end{array}$ & $2040 \mathrm{~s}$ & SWAT & $\begin{array}{l}51 \% \text { increase in } \\
\text { annual streamflow; } \\
43 \% \text { increase in } \\
\text { groundwater } \\
\text { recharge; } 50 \% \\
\text { increase in total } \\
\text { water yield }\end{array}$ \\
\hline $\begin{array}{l}\text { Andreásson } \\
\text { et al. (2004) }\end{array}$ & Sweden & $\begin{array}{l}\text { HadCM2; } \\
\text { ECHAM4I } \\
\text { OPYC3; } \\
\text { HadAM3H }\end{array}$ & $2030 \mathrm{~s}$ & HBV & $\begin{array}{l}\text { Southern Sweden: } \\
\text { decreased annual } \\
\text { runoff; Northern } \\
\text { Sweden: increased } \\
\text { annual runoff }\end{array}$ \\
\hline $\begin{array}{l}\text { Graham } \\
(2004)\end{array}$ & $\begin{array}{l}\text { Baltic Sea } \\
\text { Basin }\end{array}$ & $\begin{array}{l}\text { ECHAM4I } \\
\text { OPYC3; } \\
\text { HadAM3H }\end{array}$ & $\begin{array}{l}2071- \\
2100\end{array}$ & HBV & $\begin{array}{l}\text { Decrease of } 30 \% \text { to } \\
\text { increase of } 40 \% \text { in } \\
\text { runoff }\end{array}$ \\
\hline $\begin{array}{l}\text { Thodsen } \\
(2007)\end{array}$ & Denmark & $\begin{array}{l}\text { HIRHAM } \\
\text { RCM }\end{array}$ & $\begin{array}{l}2071- \\
2100\end{array}$ & NAM & $\begin{array}{l}\text { Increase of } 12 \% \text { in } \\
\text { mean annual } \\
\text { runoff; increase in } \\
100-y r \text { flood peak } \\
\text { of } 11 \%\end{array}$ \\
\hline $\begin{array}{l}\text { Bae et al. } \\
(2008)\end{array}$ & $\begin{array}{l}\text { South } \\
\text { Korea }\end{array}$ & $\begin{array}{l}\text { ECHO-G; } \\
\text { NCAR/MM } \\
5\end{array}$ & $\begin{array}{l}1960- \\
2100\end{array}$ & PRMS & $\begin{array}{l}\text { Decreased runoff in } \\
\text { spring and } \\
\text { summer; increased } \\
\text { runoff in fall and } \\
\text { winter. }\end{array}$ \\
\hline $\begin{array}{l}\text { Fujihara et al. } \\
(2008)\end{array}$ & Turkey & $\begin{array}{l}\text { MRI- } \\
\text { CGCM2; } \\
\text { CCSR- } \\
\text { MIROC }\end{array}$ & $2070 \mathrm{~s}$ & Hydro-BEAM & $\begin{array}{l}\text { Decrease in annual } \\
\text { runoff of } 52-61 \% \text {. }\end{array}$ \\
\hline
\end{tabular}

Note: $U B C=$ University of British Columbia; $H B V=$ Hydrologiska Byråns

Vattenbalansavdelning; $S W A T=$ Soil and Water Assessment Tool; VIC $=$ Variable Infliltration Capacity; NAM = Nedbor-Afstromings Model; $P R M S=$ PrecipitationRunoff Modeling System; Hydro-BEAM = Hydrological River Basin Environmental Assessment Tool.

The projected impacts of climate change on basin hydrology obviously depend on the geography of the study area. For example, humid midlatitude basins may experience increased runoff. Jha (2005) used HadCM2 output, downscaled with an 
RCM, to drive SWAT in order to project impacts of climate change through the 2040 s on the hydrology of the Upper Mississippi River Basin. The results include a fifty-one percent increase in annual streamflow, a forty-three percent increase in groundwater recharge; and a fifty percent increase in total water yield. Thodsen (2007) used the lumped conceptual hydrological model NAM, driven by the HIRHAM RCM under the IPCC's A2 emissions scenario, to simulate impacts of climate change on runoff in five Danish basins. They found that mean annual runoff will increase by twelve percent by the end of the twenty-first century. Eckhardt and Ulbrich (2003) used the physicallybased semi-distributed hydrological model Soil and Water Assessment Tool (SWAT), developed by the US Department of Agriculture, to project impacts of two climate change scenarios on streamflow and groundwater recharge in a central European basin where snowmelt is an important part of the water cycle. They modified the SWAT model to include the effects of stomatal conductance, which reduces plant transpiration under conditions of increased atmospheric carbon dioxide. Inclusion of the stomatal conductance improved the model performance for their humid midlatitude study area, but may not make a difference in more arid regions. The results include little change in annual runoff, but increased winter runoff, earlier peak spring flow, and decreased summer runoff and groundwater recharge, findings similar to those in other snowmelt-dominated basins, like those in the western United States (Barnett et al. 2005). Menzel and Bürger (2002) used HBV, a conceptual semidistributed model developed by the Swedish Meteorological and Hydrological Institute (SMHI), to simulate impacts of climate change on daily runoff in a German 
basin. The results included a decrease in mean annual runoff in the basin of approximately fifty percent with larger decreases in the summer and fall, a contrast to the findings of many other midlatitute climate change impact modeling studies. These changes are the likely the result of a general decrease in regional precipitation predicted by the climate scenario used in the study.

Arid and semi-arid basins are more likely to experience a decrease in annual runoff. For example, Fujihara et al. (2008) modeled the hydrological impacts of climate change in Turkey's Seyhan River Basin, using the Hydrological River Basin Environmental Assessment Model (Hydro-BEAM) driven by two GCMs. The results include a decrease in annual runoff of fifty-two to sixty-one percent.

Even within a nation in a humid temperate climate, differences in latitude may determine basin-scale hydrological response. Andreásson et al. (2004) investigated potential impacts of climate change on water resources in six Swedish basins, using two RCMs to drive HBV. Results differed according to the latitude of the basin, with southern Sweden mostly experiencing decreases in annual runoff and northern Sweden experiencing increases, particularly in autumn. Similarly, Graham (2004), using four climate change scenarios to drive $\mathrm{HBV}$ in the Baltic Sea region, found annual changes in runoff ranging from a decrease of thirty percent to an increase of forty percent, generally with decreases in the south and increases in the north. Bae et al. (2008) assessed potential impacts of climate change on runoff amount and timing in South Korea's 139 drainage basins. They used scenarios from two GCMs, downscaled through a stochastic weather generator, to drive the hydrological model PRMS. The 
results suggest that the changes in runoff will vary seasonally and regionally within the nation, with increases in the north and decreases in the south.

In addition to whether the basin is located in a relatively humid or arid region, basins located near one another may also differ in their hydrological response. One important factor is elevation and, accordingly, whether the basin is dominated by rainfall or snowmelt. Loukas et al. (2002b) used GCM scenarios to drive the University of British Columbia's conceptual Watershed Model, in order to determine climate-driven changes in runoff in two British Columbia basins. In the rainfalldominated basin, which has similar characteristics to the TRB, the results indicate that total runoff will increase in fall and winter and decrease in spring and summer, while the snowmelt-dominated basin is projected to experience an earlier spring peak and a nearly eighteen percent increase in winter runoff. Christensen et al. (2004) examined future hydrologic impacts of climate change in the Colorado River Basin using statistically downscaled scenarios from the Parallel Climate Model (PCM), a climate model developed by the United States Department of Energy and National Center for Atmospheric Research. They used these scenarios to drive the Variable Infiltration Capacity (VIC) hydrological model. Under a business-as-usual emissions scenario, the model projects a seventeen percent decrease in annual basin runoff by 2098 , because of increased evapotranspiration and decreased precipitation.

Climate change modeling studies often do not produce consistent outcomes among scenarios. Different emissions scenarios and climate models may result in different projections of hydrological change. Frei et al. (2002) investigated the 
impacts of climate change on water resources in two basins in New York's Catskill Mountains, which contribute to the municipal water supply of New York City. The results included potential changes in water supply in both basins ranging from an increase of ten percent to a decrease of thirty percent by 2080 , because of differences in precipitation projections among the climate models and emission scenarios. Similar ranges in potential future water availability, dependent on scenario choice, have been found in global-scale studies (Arnell 2004). The outcomes of basin-scale modeling studies are dependent on both the modeling approach used and the characteristics of the basin.

\section{Snowmelt-Related Impacts}

Barnett et al. (2005) determined that, in snowmelt-dominated basins, climate change is likely to cause a shift in the timing of peak runoff to earlier in the spring, consequently lowering flows during the summer, when demand for water is highest. In a follow-up study, Barnett et al. (2008) analyzed trends in and causes of observed changes in snowpack, timing of peak runoff, and average January through March daily minimum temperatures for the western United States from 1950 to 1999. The results indicate that anthropogenic greenhouse gas emissions are responsible for up to sixty percent of the observed hydroclimatic changes, a finding similar to that of Hamlet and Lettenmaier (2007). Likewise, Regonda et al. (2005) found that, between 1950 and 1999 , there has been an advance in the timing of the peak spring flow, a decrease in snow water equivalent, and an increase in winter rainfall in snowmelt-dominated basins in the western United States, particularly in lower-elevation basins in the 
Pacific Northwest, with a possible threshold elevation of approximately 2500 meters. Dettinger et al. (2004) also found earlier peak runoff in three Sierra Nevada basins averaging in elevation from approximately 1250 to 2800 meters, a trend that hydrological modeling suggests will continue throughout the twenty-first century. Stewart et al. (2004), using regression modeling, found similar results for the mountainous regions of the western United States. Knowles and Cayan (2004), in investigating the impacts of climate change on hydrology in the San Francisco Bay basin, found that snowmelt-driven changes in timing of peak runoff are dependent on elevation, with the most significant effects in the range of 1300 to 2700 meters. Morrison et al. (2002), modeling British Columbia's Fraser River Basin, project a shift in peak flow to twenty-four days earlier in the year and an eighteen percent decrease in average peak flow, despite an average annual flow increase of five percent by 2099 , relative to the 1961 to 1990 baseline. Severe declines in runoff as a result of glacial retreat have also been projected for other world regions, such as a decrease of up to ninety-four percent by 2100 in the Himalayan area (Akhtar et al. 2008).

\section{E. Extreme Events}

Arnell (2003b) examined the impacts of climate change on hydrologic variability in six basins in the United Kingdom through the twenty-first century, with results including a slight increase in mean monthly flow and a decrease in low flow amount of up to forty percent by the 2080s, with a corresponding increase in interannual hydrologic variability. Palmer and Raisanen (2002) predict that heavy winter rainfall events in the United Kingdom and summer monsoons in Asia may 
increase by a factor of five during the twenty-first century. Kleinen and Petschel-Held (2007) estimated, using statistically downscaled climate change-driven alterations of a water balance equation, that up to twenty percent of the global population lives in river basins that may experience greater flooding as a result of climate change by 2100 . In a continental-scale modeling study, Lehner et al. (2006) predicted increases in flood frequencies for northern Europe and drought frequencies for southern Europe. Kundzewicz et al. (2005) found that past and projected future large floods in central Europe may be related to anthropogenic climate change. Kay et al. (2006), using a conceptual model driven by high-resolution RCM outputs through the 2080s, found increases in flood frequency and magnitude for most of their fifteen study basins in the United Kingdom. In six Australian basins, Evans and Schreider (2002), using a conceptual hydrological model driven by stochastic weather generator outputs, found an increase in the magnitude of floods, despite a decrease in mean annual runoff. Kim (2005) used regional climate models to predict more than one hundred percent increases in ninety-fifth percentile runoff in mountainous regions of the western United States. Mote et al. (2003) also predict increases in winter flooding in the Pacific Northwest, particularly in smaller rainfall-dominated and transient basins, because of increases in temperature and precipitation. Milly et al. (2002) found an increase in the observed frequency of large floods in major world river basins through the twentieth century.

In an Ontario basin, however, Cunderlik and Simonovic (2005), using the US Army Corps of Engineers' Hydrologic Engineering Center Hydrologic Modeling 
System (HEC-HMS) driven by a stochastic weather generator under two scenarios from the Canadian Centre for Climate Modeling and Analysis, found a decrease in the severity of high and low flow events as a result of climate change. In British Columbia, Loukas et al. (2002a) predicted an increase in flood frequency and magnitude in a rainfall-dominated basin and a decrease in a snowmelt-dominated basin. These contrasts in results indicate that different regions may respond to climate change with varying impacts on the frequency and severity of hydrological extremes, because of differences between the basins in runoff generation processes. Snowmeltdominated basins are highly sensitive to changes in temperature, while rainfalldominated basins are mostly influenced by changes in precipitation. Additionally; basins with significant groundwater resources may be less sensitive to changes in climate in the near term (Tague et al. 2008). Modeling changes in soil moisture and subsurface processes as a result of climate change is an ongoing area of research.

\section{Impacts of Climate Change on Water Quality}

Although water quality will probably be affected by climate change, fewer studies (Table 2.2) have modeled these impacts than have modeled runoff and other hydrological parameters, perhaps because it is more difficult to obtain comprehensive water quality data in many regions and because modeling complexity increases with the inclusion of water quality parameters (Whitehead et al. 2009). Because of the uncertainty involved in the modeling process, the dynamics of water quality response to climate change are not well-known. For water quality studies, the spatial scale of the basin is especially important, because pollutant loadings are governed by local 
land-surface characteristics as well as by the more regional climatic processes.

Accordingly, the study basins referred to in Table 2.2 are all meso-scale basins, with areas ranging from approximately one thousand to three thousand square kilometers, in order to facilitate comparison with the similarly-sized TRB.

Table 2.2: Previous basin-scale modeling studies of impacts of climate change on water quality.

\begin{tabular}{|c|c|c|c|c|c|}
\hline Author(s) & $\begin{array}{l}\text { Study } \\
\text { Area }\end{array}$ & GCM(s) & $\begin{array}{l}\text { Study } \\
\text { Period }\end{array}$ & $\begin{array}{l}\text { Hydrological } \\
\text { Model }\end{array}$ & Results \\
\hline $\begin{array}{l}\text { Mimikou et } \\
\text { al. }(2000)\end{array}$ & Greece & HadCM2; UKHI & $2050 \mathrm{~s}$ & WBUDG & $\begin{array}{l}\text { Decrease in runoff } \\
\text { and DO; increase } \\
\text { in BOD and } \\
\text { ammonium }\end{array}$ \\
\hline $\begin{array}{l}\text { Varanou et } \\
\text { al. (2002). }\end{array}$ & Greece & $\begin{array}{l}\text { HadCM2; } \\
\text { ECHAM; } \\
\text { CSIRO; CGCM }\end{array}$ & $2080 \mathrm{~s}$ & SWAT & $\begin{array}{l}\text { Decrease in runoff } \\
\text { and nutrient } \\
\text { transport }\end{array}$ \\
\hline $\begin{array}{l}\text { Bouraoui et } \\
\text { al. }(2004)\end{array}$ & Finland & $\begin{array}{l}\text { None } \\
\text { (retrospective) }\end{array}$ & $\begin{array}{l}1965- \\
1998\end{array}$ & SWAT & $\begin{array}{l}\text { Increase in winter } \\
\text { runoff; increase in } \\
\text { annual/winter } \\
\text { nutrient transport }\end{array}$ \\
\hline $\begin{array}{l}\text { Arheimer et } \\
\text { al. (2005) }\end{array}$ & Sweden & $\begin{array}{l}\text { HadAM3H; } \\
\text { HADCM2; } \\
\text { ECHAM4/OPY } \\
\text { C3 }\end{array}$ & $\begin{array}{l}2071- \\
2100\end{array}$ & HBV & $\begin{array}{l}\text { Increase in nutrient } \\
\text { loadings of } 10-33 \%\end{array}$ \\
\hline $\begin{array}{l}\text { Imhoff et } \\
\text { al. (2007) }\end{array}$ & Maryland & ECHAM4 & $\begin{array}{l}2010- \\
2039\end{array}$ & CAT & $\begin{array}{l}\text { Increase in nutrient } \\
\text { loadings of } 10 \%\end{array}$ \\
\hline
\end{tabular}

Note: $W B U D G=$ Water Budget; SWAT = Soil and Water Assessment Tool; HBV = Hydrologiska Byråns Vattenbalansavdelning; CAT = Climate Assessment Tool.

Mimikou et al. (2000) used the physical hydrological model WBUDG and the point source water quality model R-Qual to simulate impacts of climate change on runoff, biological oxygen demand (BOD), dissolved oxygen (DO), and ammonium in a Greek basin. Because the climate scenarios included increased temperatures and decreased precipitation, the results were decreased mean monthly runoff, particularly in summer. Varanou et al. (2002) used SWAT to model the impacts of climate change, derived from six GCMs, on runoff and water quality in a Greek basin. Because of 
reduced flows, concentrations of some pollutants may increase as a result of climate change, particularly in the summer months, a finding similar to that of Mimikou et al. (2000). In a retrospective study, Bouraoui et al. (2004) modeled runoff, suspended solids, total nitrogen, and total phosphorus in a Finnish basin with SWAT, using thirty-four years of historic climate data. They then removed the trends in temperature and precipitation, finding that observed climate change has resulted in increased winter runoff and increased annual and winter nutrient transport of up to eighty-five percent, as a result of higher precipitation and associated flushing of the soil matrix. Arheimer et al. (2005) modeled the impacts of climate change on nitrogen and phosphorus levels in a Swedish basin. Climate scenarios with increased precipitation projected higher average river flows while others with decreased precipitation projected decreased flows, but the average overall nitrogen loading in the basin for all scenarios increased by ten to thirty-three percent by 2100 . In a forecasting study, Imhoff et al. (2007) used the Climate Assessment Tool (CAT), driven by regional climate scenarios, to project changes in nutrient loadings as a result of climate change for the period 2010-2039 in a Maryland basin. There were significant differences among land use types in their sensitivity to climate change, with agricultural land experiencing larger-climate-driven increases in nutrient export than forest land, findings that are similar to those of Chang et al. (2001). Overall, the water quality results are closely tied to basin hydrology in terms of flushing and dilution responses, and cannot be examined independently. 


\section{Impacts of Urban Development on Hydrology}

It is well known that an increase in impervious surface area accompanied by urban development significantly alters hydrological response, in particular by increasing the "flashiness" or quickness to and magnitude of peak flow from rainfall events (Dunne and Leopold 1978). One major research question that has been explored is whether there exist thresholds of impervious surface area above which the hydrologic response is characteristically urban. Several studies have modeled the hydrological response of basins to historical or potential future urban development (Table 2.3).

Table 2.3: Previous basin-scale modeling studies of impacts of urban development on hydrology.

\begin{tabular}{|l|l|l|l|l|l|}
\hline Author(s) & $\begin{array}{l}\text { Study } \\
\text { Area }\end{array}$ & $\begin{array}{l}\text { Basin } \\
\text { Size* }\end{array}$ & $\begin{array}{l}\text { Study } \\
\text { Period }\end{array}$ & $\begin{array}{l}\text { Hydrological } \\
\text { Model }\end{array}$ & $\begin{array}{l}1974- \\
\text { Results }\end{array}$ \\
\hline $\begin{array}{l}\text { Wang } \\
(2006)\end{array}$ & Texas & Small & $\begin{array}{l}\text { Object- } \\
\text { oriented GIS }\end{array}$ & $\begin{array}{l}\text { Increase in 100-yr flood } \\
\text { peak of 20\% }\end{array}$ \\
\hline $\begin{array}{l}\text { Nirupama } \\
\text { and } \\
\begin{array}{l}\text { Simonovic } \\
(2007)\end{array}\end{array}$ & Ontario & Medium & & & \\
\hline & & $\begin{array}{l}1974- \\
2000\end{array}$ & $\begin{array}{l}\text { None (trend } \\
\text { analysis) }\end{array}$ & \\
$\begin{array}{l}\text { Cao et al. } \\
(2008)\end{array}$ & $\begin{array}{l}\text { New } \\
\text { Zealand }\end{array}$ & & $\begin{array}{l}1990- \\
\text { Increase in flood risk }\end{array}$ \\
\hline
\end{tabular}

Note: GIS = Geographic Information System; SWAT = Soil and Water Assessment Tool.

*A small basin is defined as $<1000 \mathrm{~km}^{2}$; a medium basin is $1000-10,000 \mathrm{~km}^{2}$.

Wang (2006) conducted a retrospective analysis of the impacts of urban development on flood risk in an approximately four hundred square kilometer Texas basin, using both thirty-meter digital elevation models and high-resolution Light Detection and Ranging (LiDAR) data. He found that, from 1974 to 2002, the basin impervious surface area increased from approximately ten percent to over thirty-eight 
percent, with an accompanying increase in the hundred-year flood peak of twenty percent. In another retrospective analysis, Nirupama and Simonovic (2007) used data on land use, meteorology, and hydrology to estimate the increase in flood risk caused by urban development in London, Ontario. This study demonstrates that approximately fifteen percent impervious surface area may be a threshold above which basin hydrology exhibits the typical urban flashiness. Also, basin size influences hydrologic sensitivity to urban development, with smaller basins experiencing relatively greater impacts than larger ones. Runoff does not increase linearly with rainfall, and the amount and location of basin impervious surfaces affects the relation between these variables (Dunne and Leopold 1978).

Cao et al. (2008) used SWAT to model runoff for past, present, and potential future land cover scenarios in a New Zealand basin. They found that the current land cover, which is dominated by plantation forests and pasture, results in higher mean and low flows than either the past scenario, with mostly native forests, or the potential future scenario, which included an increase in the area of plantation forests. While this study did not model urban development, it illustrates the effects of different vegetation communities on runoff, and that any changes between forest and agriculture land uses can also be significant for hydrology.

\section{Impacts of Urban Development on Water Quality}

\section{A. Empirical Studies}

Much of the existing research of the impacts of urban development on water quality is either empirical or statistical. In a study of forty-two sub-basins in 
Washington's Puget Sound lowland, ranging in area from four to sixty-nine square kilometers, Alberti et al. (2007) found that both greater amount and connectivity of impervious surface area degrade water quality and biotic integrity, as measured by indices of benthic macroinvertebrate diversity. In another empirical case study, Almeida et al. (2007) found that values of total fecal coliform bacteria, Escherichia coli, total heterotrophic bacteria, chemical oxygen demand (COD), BOD, and phosphate were significantly higher in urban areas than at undeveloped sites in an Argentinean basin, particularly during the wet season, illustrating the negative impact of urban development on water quality. In three New Jersey basins with a combined area of approximately 1200 square kilometers, Conway (2007) determined that a threshold of impervious surface area of 2.4 to 5.1 percent results in negative water quality impacts, as measured by $\mathrm{pH}$ and specific conductance. Rose (2007) found that solute concentrations in the baseflow of a Georgia basin increased along a rural-tourban gradient, indicating increasing levels of nonpoint source pollution in urban areas. Tu et al. (2007) found that, in their Massachusetts study area, per capita developed land use was a strong predictor of specific conductance, dissolved ions, and dissolved solids. Boeder and Chang (2008) conducted a multi-scale empirical analysis of trends in DO, COD, and nitrogen levels. in Oregon's Rock Creek basin, a sub-basin of the Tualatin, from the mid-1990s to 2003 and found that forest cover is negatively correlated with $\mathrm{COD}$ at the basin scale and positively correlated with nitrogen at the local scale. All these results suggest that the scale of analysis significantly affects the determination of land cover impacts on water quality parameters. 


\section{B. Modeling Studies.}

In addition to establishing empirical relations between level of urban development and water quality, researchers have also modeled the response of water quality parameters to land use change (Table 2.4). Tong and Chen (2002) used BASINS to model the relation between land use and water quality in an Ohio basin and found that agricultural and urban lands were associated with high levels of nitrogen, phosphorus, and fecal coliform bacteria. Im et al. (2003) compared the ability of two hydrological models, SWAT and HSPF, to simulate historical impacts of urban development on hydrology, sediment, and nutrient transport in a Virginia basin, finding that observed water quality can be reasonably reproduced using these models, and that nutrient and sediment loading was associated with higher levels of urban development. Tang et al. (2005) used the Land Transformation Model (LTM), a land use change model, in combination with the Long-Term Hydrologic Impact Assessment (L-THIA), a physically-based hydrological model, to project land use change impacts on runoff and nonpoint source water pollution in the Muskegon River watershed in Michigan, and found that increases in pollutant loading were more significant in some urbanizing sub-basins than at the scale of the entire basin. This scale issue is related to the concept of urbanization thresholds, because basins where the relative change in impervious surface area is greater may exhibit more sensitivity to additional urban development. The location of development may also be significant; increased impervious surface area in headwater regions tends to have more impact than development further downstream (Tang et al. 2005). 
Table 2.4: Previous basin-scale modeling studies of impacts of urban development on water quality.

\begin{tabular}{|l|l|ll|l|l|}
\hline Author(s) & $\begin{array}{l}\text { Study } \\
\text { Area }\end{array}$ & $\begin{array}{l}\text { Basin } \\
\text { Size* }\end{array}$ & $\begin{array}{l}\text { Study } \\
\text { Period }\end{array}$ & $\begin{array}{l}\text { Hydrological } \\
\text { Model }\end{array}$ & Results \\
\hline $\begin{array}{l}\text { Tong and } \\
\text { Chen } \\
(2002)\end{array}$ & & Medium & & & $\begin{array}{l}\text { Higher. levels of nitrogen, } \\
\text { phosphorus, and fecal } \\
\text { coliform bacteria on } \\
\text { urban/agricultural lands }\end{array}$ \\
\hline $\begin{array}{l}\text { Tang et al. } \\
\text { (2005) }\end{array}$ & Ohio & & $\begin{array}{l}1988- \\
1994\end{array}$ & BASINS & $\begin{array}{l}\text { Bichigan } \\
\text { nutrient transport, and oils } \\
\text { and heavy metals }\end{array}$ \\
\hline $\begin{array}{l}\text { Im et al. } \\
(2003)\end{array}$ & & Medium & $\begin{array}{l}1995- \\
2040\end{array}$ & L-THIA & $\begin{array}{l}\text { Both models accurately } \\
\text { simulated runoff, sediment, } \\
\text { and nutrient transport }\end{array}$ \\
\hline
\end{tabular}

Note: BASINS = Better Assessment Science Integrating Point and Nonpoint Sources; L-THIA = Long-Term Hydrologic Impact Assessment; SWAT = Soil and Water Assessment Tool; HSPF = Hydrologic. Simulation Program - Fortran.

${ }^{*}$ A small basin is defined as $<1000 \mathrm{~km}^{2}$; a medium basin is $1000-10,000 \mathrm{~km}^{2}$.

\section{Combined Impacts of Climate Change and Urban Development on Water}

\section{Resources}

Because both climate change and urban development are expected in many regions, an increasing number of basin-scale hydrological modeling studies take both changes into account in order to improve understanding of their interactions (Table 2.5). Herron et al. (2002) used the Integrated Quantity-Quality Model (IQQM), driven by outputs from a regional climate scenario generator, to simulate impacts of climate change and proposed increase in forest cover for 2030 on runoff in an Australian basin and found that a ten percent increase in forest cover results in a seventeen percent decrease in runoff, while the climate change scenario only reduces runoff by five percent. Chang (2003) modeled impacts of climate change and urban development on runoff in a Pennsylvania basin, using the hydrochemical model ArcView Generalized Watershed Loading Function (AVGWLF) and found that impacts were more significant in small urban basins, illustrating the importance of scale in modeling 
studies, a finding replicated in Chang (2004). Chen et al. (2005) used SWAT and the lumped Climate and Human Activities-sensitive Runoff Model (CHARM) to simulate the effects of climate variation and land cover change over the past four decades in China's Suomo River Basin and found that climate variation explains sixty to eighty percent, and land-cover change explains twenty percent, of the changes in runoff. Samaniego and Bárdossy (2006) developed a set of nonlinear mathematical models, linked to a stochastic land use/land cover change model, to simulate impacts of climate and land use on runoff in a German basin and found, using their worst-case climate change and land use scenarios, an increase in winter runoff of seventeen to forty-four percent by 2025. Davis Todd et al. (2007) used the Variable Infiltration Capacity (VIC) model to attribute observed changes in baseflow, streamflow, and peak runoff to climatic change and urban development in Indiana, using fifty years of historic data, finding an increase in monthly baseflow and streamflow, but not in precipitation, indicating that non-climatic factors may be more significant. Similarly, Cuo et al.(2009) investigated twentieth-century land cover change and climate change on Puget Sound Basin hydrology using the spatially distributed hydrological model Distributed Hydrology-Soil-Vegetation Model (DHSVM), identifying that both land cover and temperature change are important in upland areas, while land cover change is the primary driving force of hydrology in lowlands. Harrison et al. (2008) assessed the impacts of climate change and urban development on wetland ecosystems in the United Kingdom, finding that climate change affects the distribution of both high and 
low flows, and that urbanization increases the flow sensitivity of wetland ecosystems, particularly by increasing the severity of low flows.

Several studies have examined the combined impacts of climate change and urban development on both water quantity and quality. Maximov (2003) used HSPF to model impacts of climate change and land use change on hydrology and nutrient transport in Ohio's Great Miami River. The hydrology results included an increase in phosphate concentrations of forty to fifty percent as a result of projected climatic and land use changes. Ducharne et al. (2007) examined the separate and combined impacts of climate change, land cover change, and agricultural practices on the water quality of France's Seine River, finding that climate change increases or slightly decreases mean annual runoff, depending on the climate model used, and increases nutrient concentrations by up to twenty percent, but that this increase can be mitigated by improved agricultural practices, illustrating the importance of potential adaptation measures in resource management. Beighley et al. (2008) simulated runoff and nutrient transport for historic and future climate variability and land use in a coastal basin in southern California and found that, with an increase in basin urban area from thirty-nine to fifty percent, the mean event runoff will increase by two hundred percent by 2050 , El Niño years will be five times more likely than non-El Niño years to produce large runoff events, and nitrate and phosphate concentrations will increase to five to ten times greater than baseline levels. 


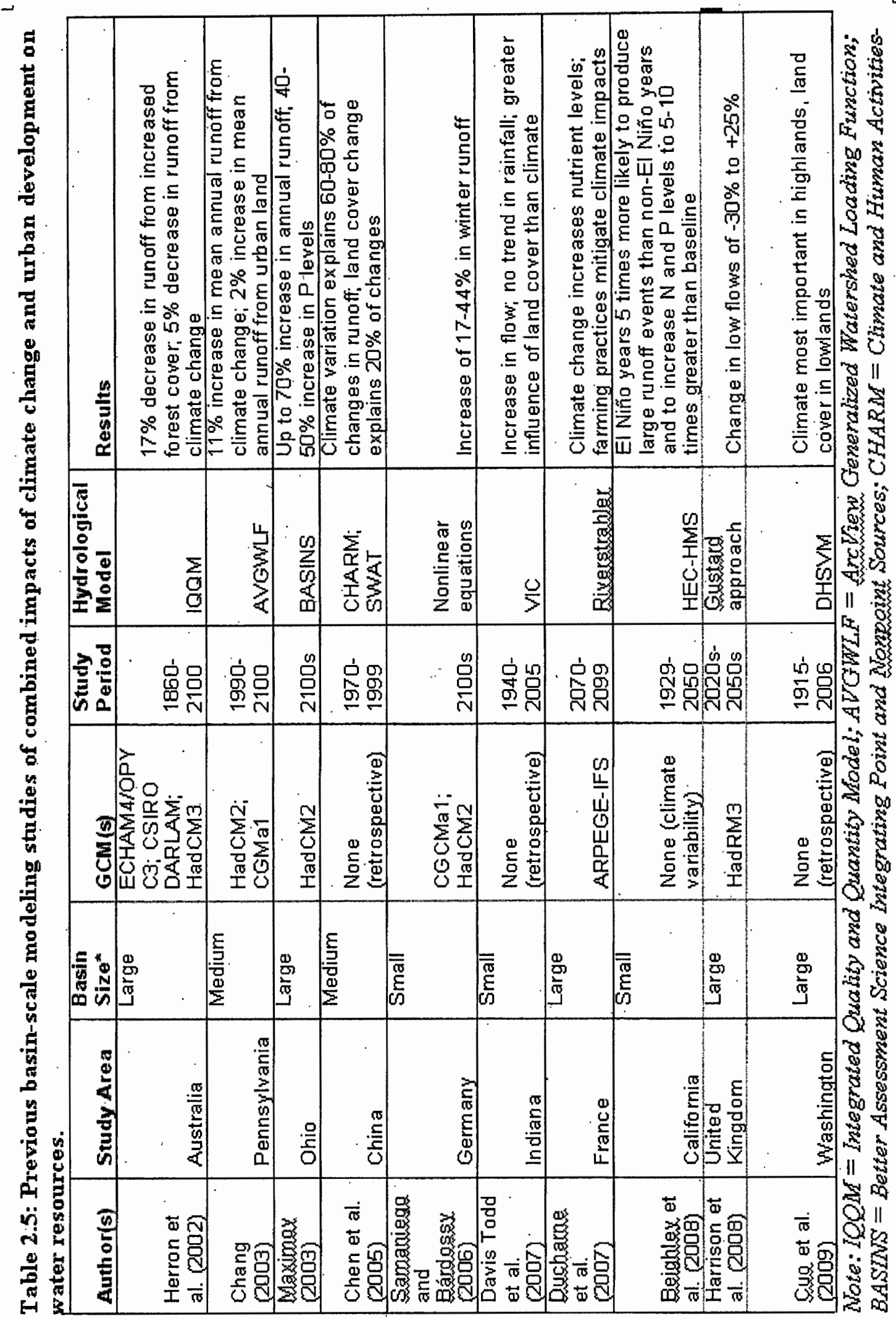




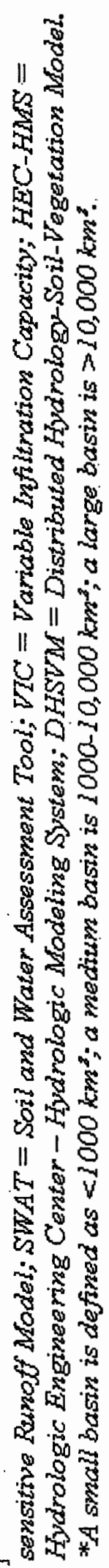




\section{Implications for Water Management}

\section{A. Adaptation in the Water Sector}

Nelson et al. (2007) define adaptation to environmental change as "an adjustment in ecological, social, or economic systems in response to observed or expected changes in environmental stimuli and their effects and impacts in order to alleviate adverse impacts of change." The related concept of resilience refers to the ability of a system to withstand change. Different regions and different sectors vary in their resilience, and therefore in their capacity for adaptation (Arnell 2000).

Milly et al. (2008) argue that climate change has undermined the principle of stationarity; a central concept in water resource management which holds that future hydrologic events will be within the range of past variability. Currently, water managers make decisions based on probability density functions, which are generated with observed data on the inverse relation between the frequency of an occurrence and its magnitude. Because climate change is likely to change both the mean conditions and the variability of hydrologic regimes, basing long-term management decisions on these functions is highly problematic, a reality increasingly acknowledged by water resource managers.

\section{B. Modeling Water Management}

A few studies have gone beyond asking merely what the potential hydrological impacts of future changes are likely to be, to attempting to model potential adaptation responses of water resource managers to these impacts (Table 2.6). Waters et al. (2003) used the water resource model Personal Computer - Storm Water Management 
Model (PCSWMM), driven by a synthetic climate change scenario, to simulate the management actions needed to maintain peak discharge at current levels under a fifteen-percent increase in rainfall intensity in an urban basin in Ontario. Payne et al. (2004) used a macro-scale hydrological model, driven by dynamically downscaled scenarios from the United States Department of Energy and National Center for Atmospheric Research Parallel Climate Model (PCM), to evaluate climate change adaptation options in the water management sector of the Columbia River Basin and found that by shifting the timing of reservoir releases to earlier in the season, they were able to meet in-stream flow targets necessary for salmon habitat, but with a decrease in hydropower production of nine to thirty-five percent. VanRheenen et al. (2004) used a water resource model, driven by outputs from a macroscale hydrological model perturbed by statistically downscaled PCM scenarios, to examine the impacts of climate change on water management in California's Sacramento and San Joaquin basins. They found that the modeled adaptation measures could meet only up to ninety-six percent of environmental flow requirements in the Sacramento River Basin and less than eighty percent in the San Joaquin River Basin by 2099. Fowler et al. (2007) used the Mospa water management model, driven by the UKCIP02 SRES A2 regional climate change scenario, to determine twenty-first century impacts of climate change on the water supply system of northwestern England. They found that overall available yield will decrease by eighteen percent, but that existing water infrastructure and management practices should be sufficient to meet future demand. O'Hara and Georgakakos (2008) assessed the water supply system in San Diego, California, as a 
case study to develop a methodology for evaluating the need for changes in water storage capacity as a result of climate change, finding an increase in future storage costs under climate change, exacerbated by population growth.

Table 2.6: Previous basin-scale modeling studies of impacts of climate change on water resource management.

\begin{tabular}{|c|c|c|c|c|c|}
\hline Author(s) & $\begin{array}{l}\text { Study } \\
\text { Area }\end{array}$ & GCM(s) & $\begin{array}{l}\text { Study } \\
\text { Period }\end{array}$ & $\begin{array}{l}\text { Hydrological } \\
\text { Model }\end{array}$ & Results \\
\hline $\begin{array}{l}\text { Waters et al. } \\
(2003)\end{array}$ & Ontario & CGCM2 & $2090 \mathrm{~s}$ & SWMM & $\begin{array}{l}\text { Flooding can be } \\
\text { mitigated with } \\
\text { disconnected drains, } \\
\text { bioswales, and green } \\
\text { streets }\end{array}$ \\
\hline $\begin{array}{l}\text { Payne et al. } \\
(2004)\end{array}$ & $\begin{array}{l}\text { Columbia } \\
\text { River } \\
\text { Basin }\end{array}$ & PCM & $\begin{array}{l}2070- \\
2098\end{array}$ & VIC & $\begin{array}{l}\text { Decrease in } \\
\text { hydropower production } \\
\text { of } 9-35 \%\end{array}$ \\
\hline $\begin{array}{l}\text { VanRheenen } \\
\text { et al. (2004) }\end{array}$ & California & PCM & $\begin{array}{l}1995- \\
2099\end{array}$ & CVmod & $\begin{array}{l}96 \% \text { of instream flow } \\
\text { targets met in the } \\
\text { Sacramento basin and } \\
<80 \% \text { in the San } \\
\text { Joaquin basin }\end{array}$ \\
\hline $\begin{array}{l}\text { Fowler et al. } \\
\text { (2007) } \\
\text { O'Hare and } \\
\text { Georgakakos } \\
(2008) \\
\end{array}$ & England. & $\begin{array}{l}\text { HadCM3 } \\
\text { CGCM2; } \\
\text { HadCM3, } \\
\text { ECHAM4 }\end{array}$ & $\begin{array}{l}2070- \\
2100 \\
2006- \\
2030\end{array}$ & Mospa & $\begin{array}{l}\text { Decrease of } 18 \% \text { in } \\
\text { overall water yield } \\
\text { Expected increase in } \\
\text { water storage costs of } \\
100-200 \text { million dollars }\end{array}$ \\
\hline
\end{tabular}

$S W M M=$ Storm Water Management Model; VIC = Variable Infiltration Capacity; CVmod $=$ Central Valley model

\section{Conclusion}

As the trends of climate change and urban development continue throughout the twenty-first century, there will be increasing demands by governments and other institutions for reliable projections of how water resources may be affected. Although uncertainty will never be eradicated from what is necessarily a probabilistic exercise, ongoing developments in the science and technology of hydrological impact analysis may improve researchers' ability to generate realistic scenarios that will be of use to the water resource sector as it adapts to these changes. What is needed in particular 
are improved methods for reconciling the climate models' precipitation forecasts, downscaling from GCMs to the regional and basin scales, including water quality impacts in modeling studies, integrating the effects of climate change and urban development, and quantifying uncertainty in modeling outcomes. These issues will be a rich source of questions for researchers in a variety of disciplines in the years to come. 


\section{(4)}

\section{III: STUDY AREA}

My study area is the $1,800-\mathrm{km}^{2}$ Tualatin River Basin (TRB), located to the southwest of Portland, Oregon, and including portions of the cities of Beaverton, Hillsboro, Lake Oswego, and Tigard (Figure 3.1). It originates in the Coast Range and flows for a length of 134 kilometers before entering the Willamette River near West Linn. Elevations range from 140 meters at the river's source to 26 meters at its mouth, with very little elevation change in the lower reaches (TRWC 1999).

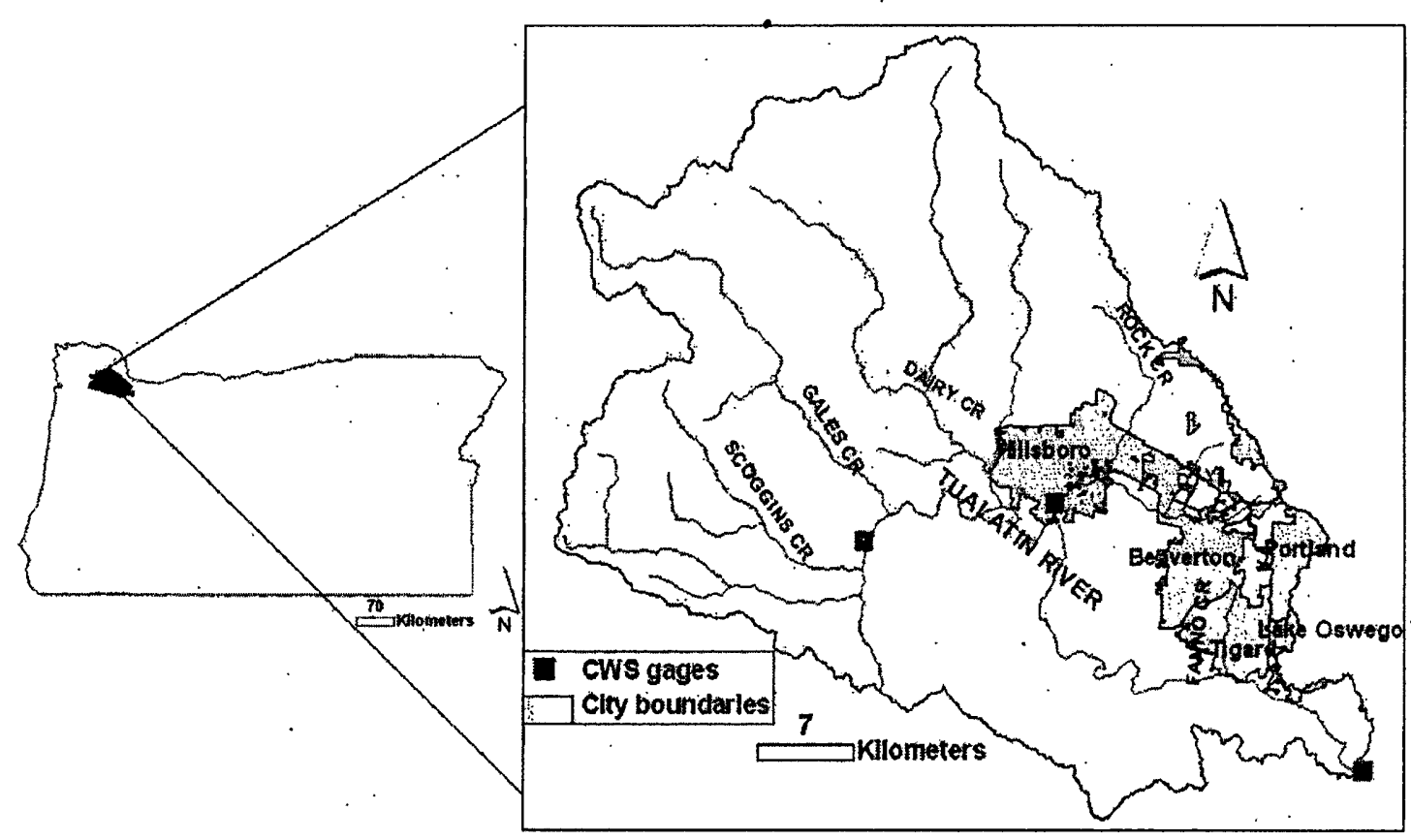

Figure 3.1. Location of the Tualatin River Basin within the state of Oregon.

The Tualatin River Basin was selected as the study area for several reasons.

First, previous research on climate change impacts in the Pacific Northwest suggests the potential for significant hydrological changes in low-elevation basins, including the Tualatin, as a result of increased evapotranspiration from higher temperatures (Palmer et al. 2004). Second, the basin is located in rapidly urbanizing Washington 
County, one of the fastest-growing regions of Oregon, making it an ideal area for studying the impacts of urban development. Finally, the basin's moderate size and rich availability of flow and water quality data enable the successful application of the Better Assessment Science Integrating Point and Nonpoint Sources (BASINS) modeling system.

The Coast Range, where the headwaters of the Tualatin River are located, was formed by seafloor uplift approximately forty million years ago. The middle and lower reaches are characterized by the gentle topography of the Tualatin Plains. The predominant soil type in the basin is the Cascade series, which is a clay loam with moderate to high erosive potential and high phosphorus levels (USGS 2008b).

The marine west coast climate of the basin is characterized by moderate yearround temperatures (mean winter low of $0^{\circ} \mathrm{C}$ and high of $17^{\circ} \mathrm{C}$; mean summer low of $5^{\circ} \mathrm{C}$ and high of $28^{\circ} \mathrm{C}$ ). Average annual precipitation is approximately 965 millimeters at Hillsboro, of which over seventy-five percent falls during the winter months of November through April (OCS 2008). Snowfall is limited, because of the basin's modest elevations.

Average annual discharge at the mouth of the Tualatin River is approximately 43 cubic meters per second. The annual distribution of flows generally follows that of precipitation, with a winter peak and low flows of as little as four cubic meters per second during the dry summer (Figure 3.2). An annual total of as much as five cubic meters per second of water is withdrawn from the Tualatin River by the Joint Water Commission for municipal supply, the Tualatin Valley Irrigation District for irrigation, 
and the Lake Oswego Corporation for hydropower generation. Two wastewater treatment plants operated by Clean Water Services each discharge approximately 0.65 cubic meters of effluent per day into the Tualatin River during the wet season. A dam on Scoggins Creek, a major tributary of the Tualatin River, stores irrigation water in Henry Hagg Lake, which has a capacity of over fifteen million cubic meters and also releases water for summer flow augmentation (USGS 2008b). The Oregon Department of Environmental Quality has listed the Tualatin River or its tributaries as impaired under Section 303(d) of the Clean Water Act for dissolved oxygen, temperature, bacteria, and phosphorus (ODEQ 1998).

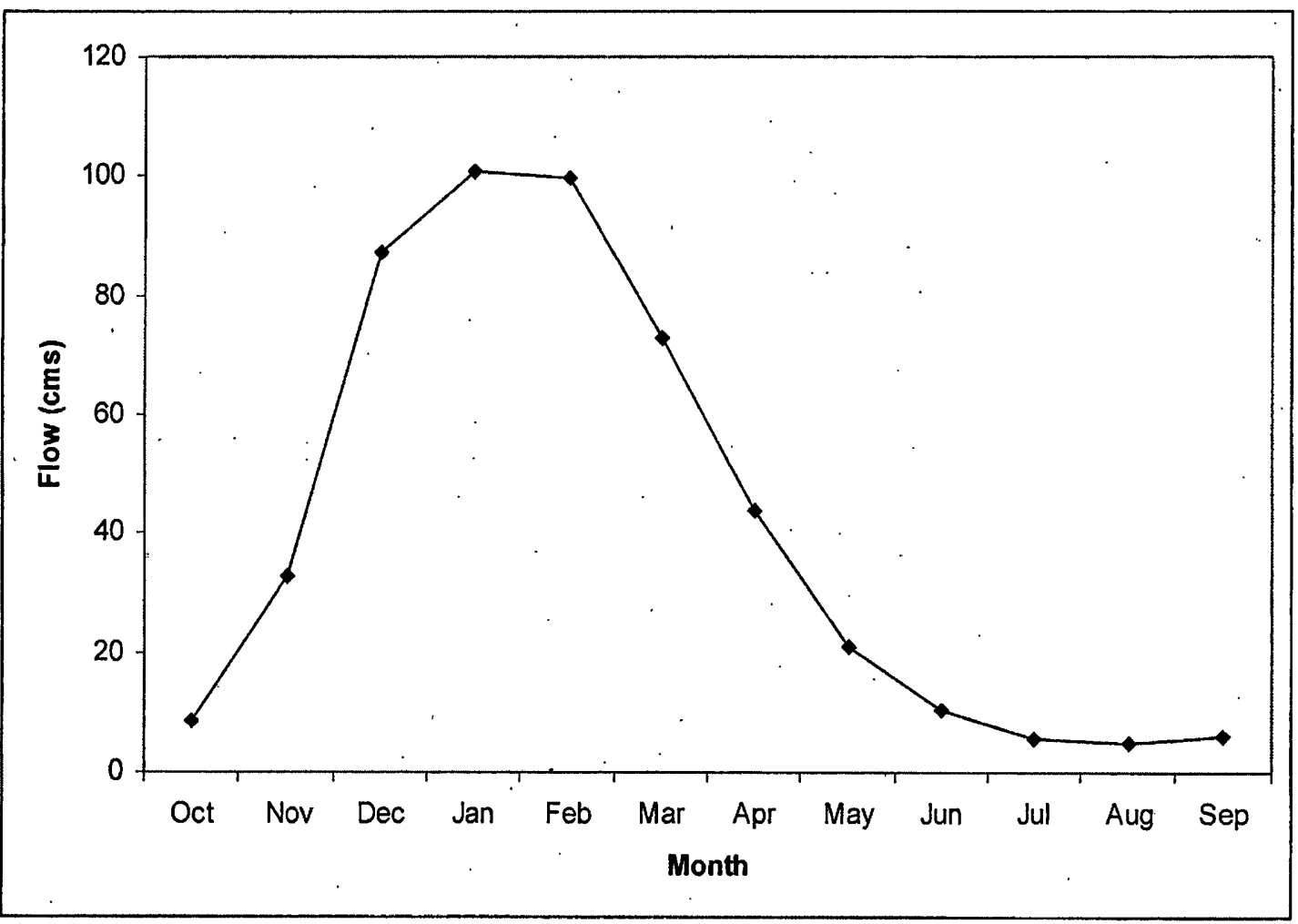

Figure 3.2. Average annual hydrograph of the Tualatin River at West Linn (site \# 14207500) for 1976-2006. Source: USGS (2008a). 
The TRB has experienced significant land use changes during the 1990s and 2000 s, with a growth in urban area at the expense of forested and agricultural land (Figure 3.3). The water category increases between the two time periods because of changes in the class aggregation scheme between the 1992 and 2001 National Land Cover Dataset. The current land use is approximately forty-six percent agriculture, seventeen percent forest, and twenty-five percent urban (Figure 3.4). Washington County, where the basin is located, is one of the fastest-growing counties in Oregon, with an estimated population increase of sixty-seven percent from 1990 to 2007 (USCB 2007). The two largest cities in the basin, Hillsboro and Beaverton, have also experienced significant growth, with Beaverton growing by 10.7 percent and Hillsboro by 20.3 percent between 2000 and 2006, making them the current fifth and sixth largest cities, respectively, in the state (OSOS 2008): This growth is expected to continue and to fuel further urban development in the basin. 


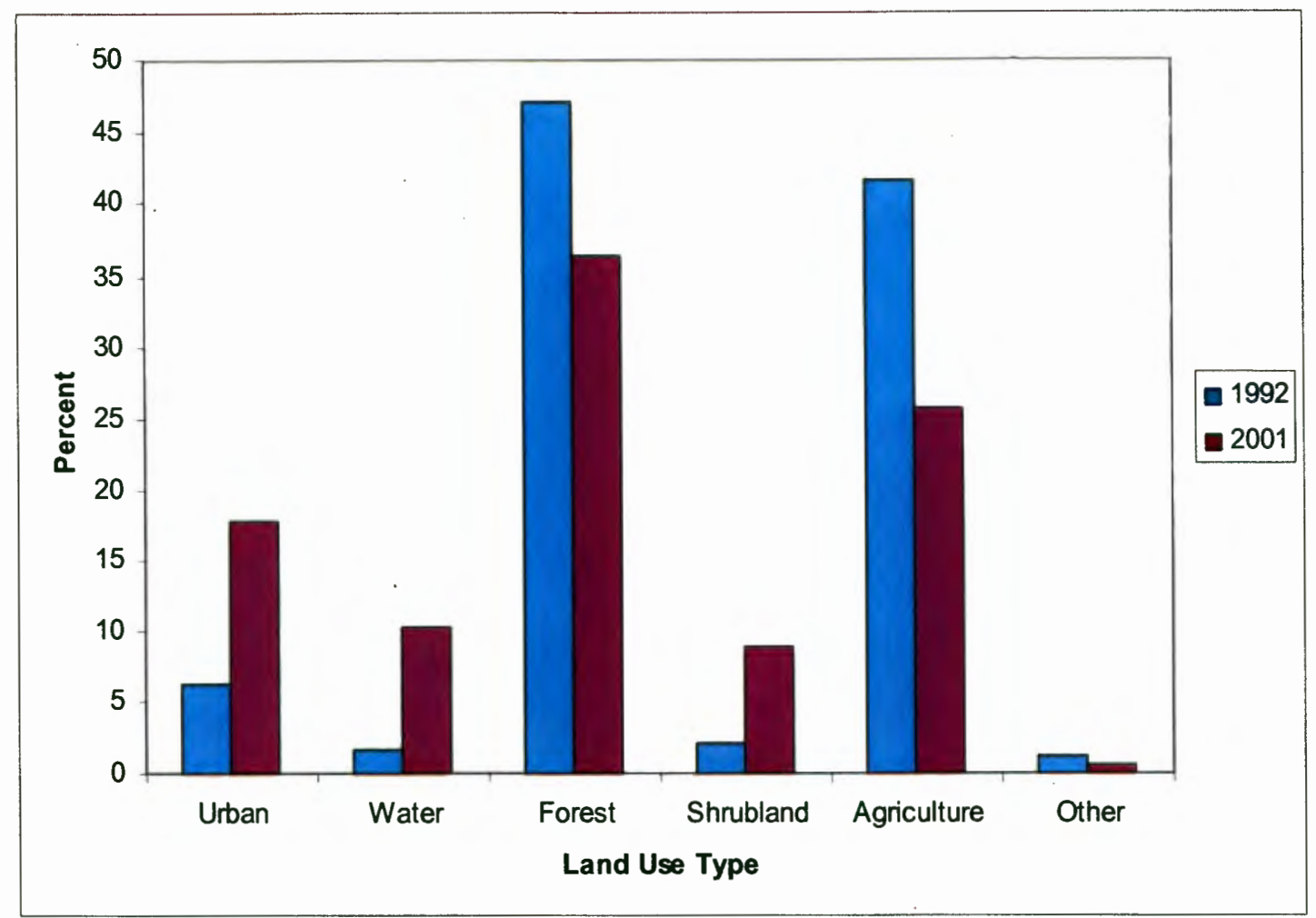

Figure 3.3: Changes in land use type in the Tualatin River Basin between 1992 and 2001. Source: USEPA (2008).

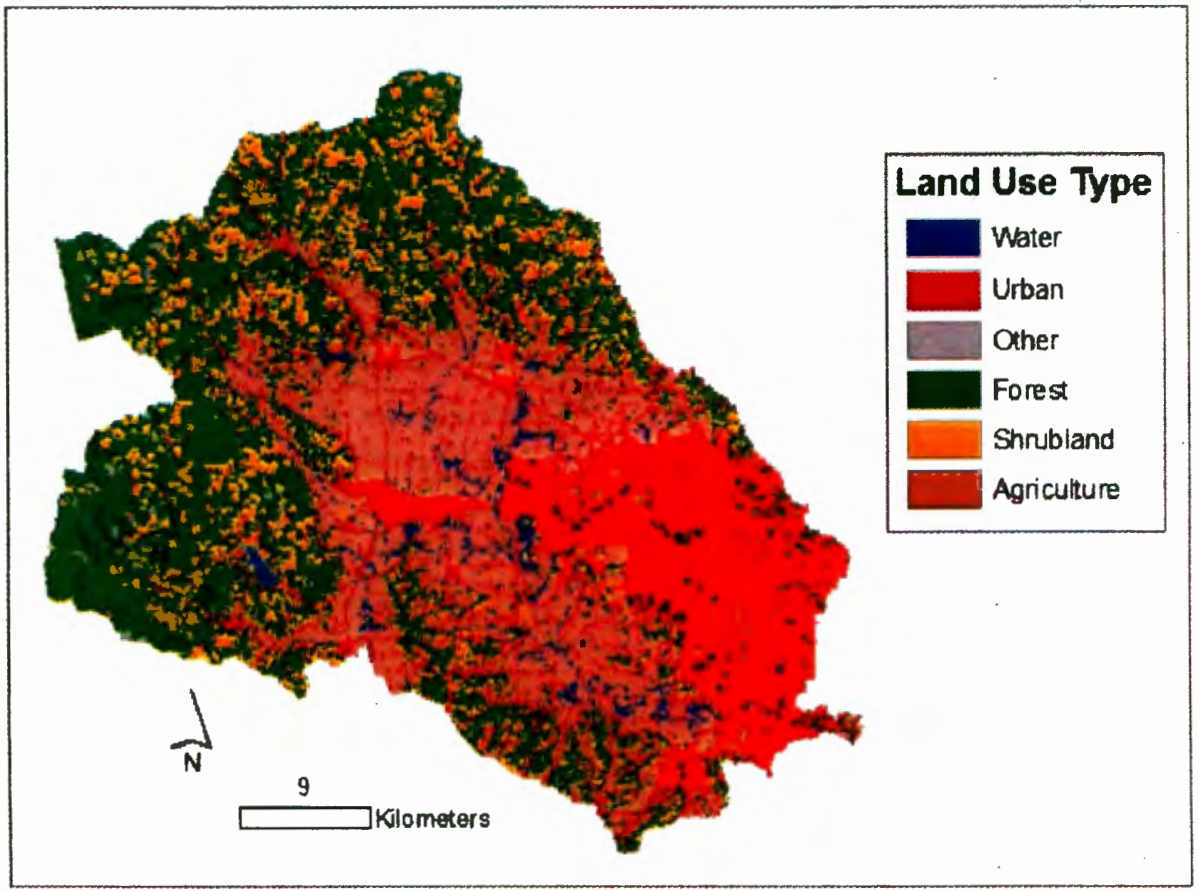

Figure 3.4: 2001 land use in the Tualatin River Basin. Source: USEPA (2008). 
In addition to the economic value provided to the cities and farms in the region, the water resources of the TRB also have significant ecological, cultural, and aesthetic values. Winter steelhead, a federally listed threatened species, is found in the Tualatin River and its tributaries (TRWC 1999). Remnant wetlands are protected in the Tualatin River National Wildlife Refuge and Jackson Bottom Wetlands Preserve. Boating, fishing, hiking, and wildlife viewing are popular recreational activities in the basin. 


\section{IV: BASINS/HSPF}

\section{BASINS and WinHSPF Model Description}

Better Assessment Science Integrating Point and Nonpoint Sources (BASINS)

is an integrated environmental analysis system originally developed by the United States Environmental Protection Agency (EPA) in 1994 for use in evaluating compliance with Total Maximum Daily Loads (TMDLs) of pollutants and simulating hydrologic impacts of management decisions (Donigian et al. 1995). BASINS is not in itself a model, but includes a number of sub-models, the most important of which is the Windows-based Hydrologic Simulation Program - Fortran (WinHSPF). The most recent version of BASINS includes a new Climate Assessment Tool (CAT), which was designed specifically to investigate impacts of climate change on runoff and water quality at the basin scale (Imhoff et al. 2007). BASINS also includes WDMUtil, a program for managing time-series data, and $\mathrm{GenScn}$, a post-processing tool used to display and evaluate results generated by WinHSPF and other BASINS programs.

The precursor to WinHSPF was the Stanford Watershed Model (SWM), developed in the 1960s as one of the first continuous hydrological models used by civil engineers (Donigian and Imhoff 2002). SWM was succeeded by the Hydrocomp Simulation Program (HSP), which simulated water quality loadings in addition to hydrology. During the 1970s, the EPA developed agricultural and nonpoint source pollution models, including the Agricultural Runoff Management (ARM) and Nonpoint Source (NPS) models. The culmination of these efforts was HSPF, which 
combined the functions of HSP, ARM, and NPS into one user-friendly program, first publicly released in 1980 .

Other programs now included in BASNS were originally developed by the United States Geological Survey (USGS). For example, the Watershed Data Management (WDM) time series data file format, the output post-processor GenScn, and the autocalibration program HSPF Expert Calibration (HSPEXP) were developed by the USGS during the 1980s and later (Donigian and Imhoff 2002). In 1994, these USGS tools, along with HSPF as the core hydrology model, were integrated to create the first version of BASINS. Today, BASINS/WinHSPF is one of the most common hydrological modeling frameworks used by federal agencies, including the EPA, USGS, and US Army Corps of Engineers, in additional to academic and private sector researchers [eg., Nasr et al. (2007), Al-Abed and Al-Sharif (2008), Ribarova et al: (2008)].

This widespread use of BASINS/WinHSPF is one of the main benefits of using these programs. Because of the relatively large user community, technical support and example applications are readily available. Another advantage of BASINS/WinHSPF is its focus on integration of data and techniques from different government agencies. The BASINS Data Download tool, for example, allows users to easily obtain data from numerous sources in one convenient application. This availability of data streamlines the modeling process and, to some extent, standardizes the types of data used in different regions of the United States. 
The BASINS/WinHSPF modeling framework, while one of the most comprehensive environmental analysis systems available to the public, has great potential for further improvements in the future. For example, explicit modeling of habitat characteristics, further incorporation of land management practices, and greater use of remotely sensed data may enhance the usefulness of BASINS/WinHSPF for understanding processes and making policy decisions. Such refinements are planned for future releases of the software (Donigian and Imhoff 2002).

The main BASINS application is a Geographic Information Systems (GIS)based viewer. The GIS platform is the open-source program MapWindow (USEPA 2001). In this application, most of the pre-processing steps are completed, including download of spatial and time-series data from the BASINS server using the Data Download tool. The default layers for a given Hydrological Unit Code (HUC) include basin boundaries, a digital elevation model (DEM), National Land Cover Dataset (NLCD) grids, and National Hydrography Dataset (NHD) flowlines. GIS data from other sources can also be added in the form of shapefiles or grids. Another function of the BASINS viewer is the ability to automatically or manually delineate watersheds; a necessary pre-processing step for modeling hydrology with WinHSPF. Finally, the BASINS viewer includes basic GIS tools for editing and displaying spatial data.

Time-series data used by WinHSPF are in the WDM format (USEPA 2001). BASINS includes WDMUtil, a program for creating, editing, and exporting WDM files. The major type of time series data necessary for running WinHSPF is hourlyscale meteorological data. At a minimum, the program needs precipitation and 
evapotranspiration data, but other meteorological variables, including maximum and minimum temperatures, wind speeds, and cloud cover, may also be included. These meteorological data can be accessed for many weather stations in the United States through the BASINS Data Download tool or imported from text files. WDMUtil is also the program used to store output time series from WinHSPF, including modelgenerated flow and hydrological calibration parameters. Time series data can be viewed and edited in WDMUtil or exported to other programs.

WinHSPF is generally classified as a lumped conceptual hydrological model, because it represents physical processes based on idealized system behavior, and reports output for the entire watershed defined by user-specified points (Watts 1997). It calculates a water balance for selected points based on inputs of precipitation, with hydrological parameters for different land cover classes (USEPA 2001). WinHSPF uses separate water balance equations to calculate runoff on pervious and impervious land surfaces (Figure 4.1, Figure 4.2). 


\section{PWATER STRUCTURE CHART}

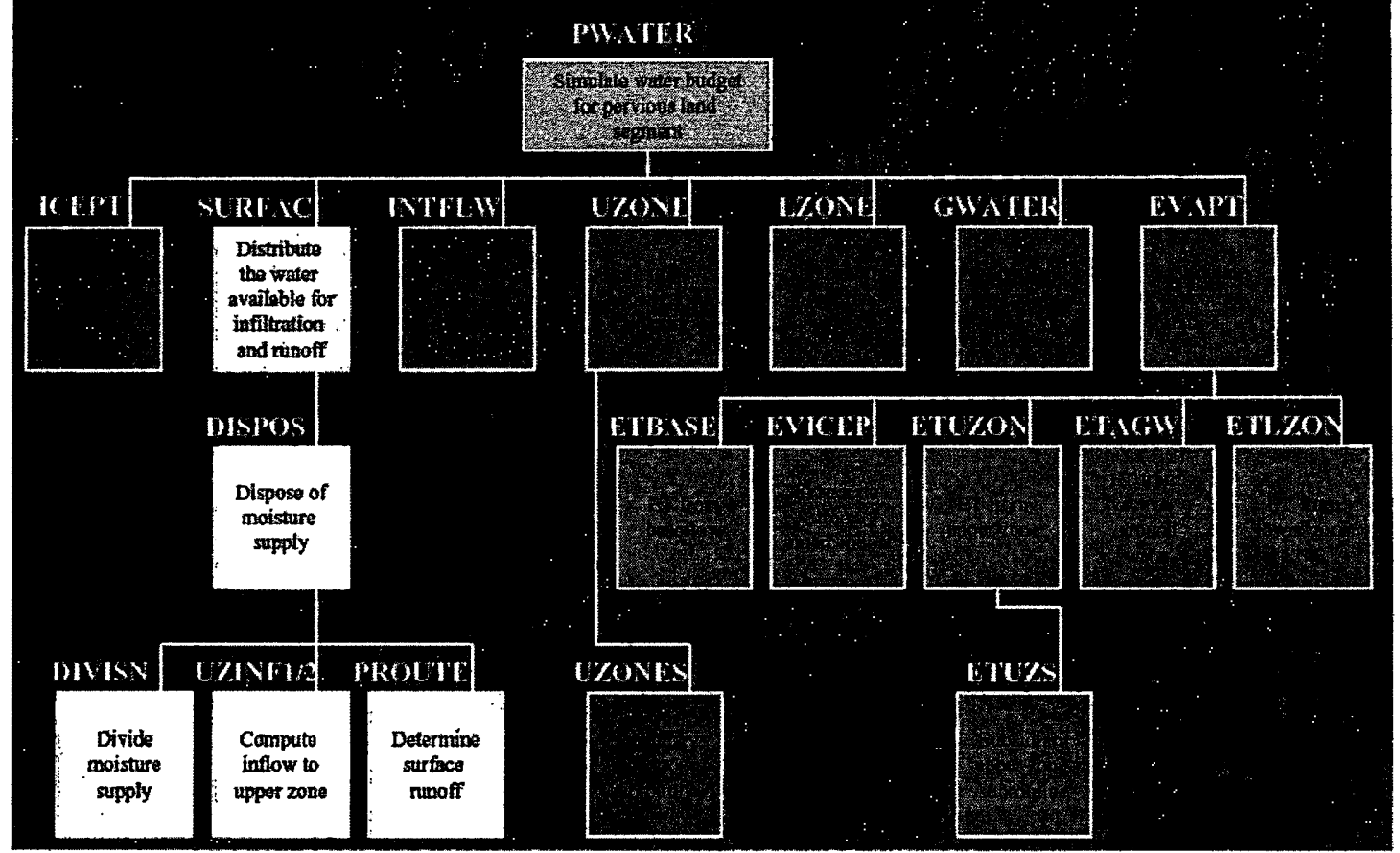

Figure 4.1: HSPF model structure for simulating water balance on pervious land surfaces. Source: USEPA (2001).

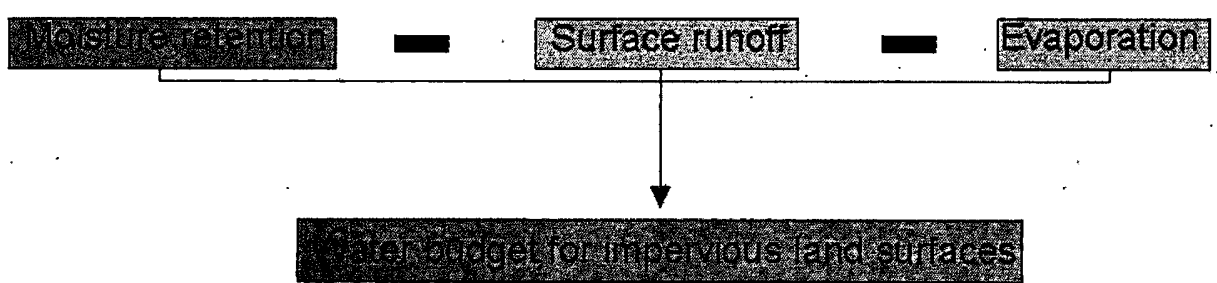

Figure 4.2. HSPF model structure for simulating water balance on.impervious land surfaces.

The WinHSPF module that simulates pervious land hydrology is called PWAT. Hydrological behavior is determined by several dozen parameters that are initially estimated by WinHSPF based on the basin's climatic, topographic, and land cover characteristics, then adjusted manually or with the aid of an autocalibration program to optimize model performance (USEPA 2000). Some of the major adjustable 
parameters include lower and upper zone soil moisture storage, soil infiltration rate, length and slope of overland flow path, groundwater and interflow recession rates, evaporation coefficients, groundwater zone partitioning, vegetation interception, and Manning's n roughness coefficient (Table 4.1). Evaporation parameters are estimated based on vegetation type using crop coefficients. Initial soil moisture characteristics are based on calibrated parameters originally derived from the Stanford Watershed Model, estimated in humid climates by taking one-eighth of the mean annual rainfall and adding four inches (USEPA 2000). Other model parameters, such as length and slope of the overland flow plane, are initially estimated from the DEM. Slope of the overland flow plane, for example, is initially estimated by dividing the basin area by twice the length of all streams in the basin (USEPA 2000). 
Table 4.1: Hydrology calibration parameters for WinHSPF.

\begin{tabular}{|l|l|l|l|}
\hline Name & Definition & Units & Determining Variables \\
\hline FOREST & Fraction forest cover & none & Forest cover \\
\hline LZSN & $\begin{array}{l}\text { Sower Zone Nominal Soil Moisture } \\
\text { Storage }\end{array}$ & inches & Soils, climate \\
\hline INFILT & Index to Infiltration Capacity & in/hr & Soils, land use \\
\hline LSUR & Length of overland flow & feet & Topography \\
\hline SLSUR & Slope of overland flow plane & ftft & Topography \\
\hline KVARY & Variable groundwater recession & 1/inches & $\begin{array}{l}\text { Baseflow recession } \\
\text { variation }\end{array}$ \\
\hline AGWRC & Base groundwater recession & none & Baseflow recession \\
\hline PETMAX & Temp below which ET is reduced & deg. F & Climate, vegetation \\
\hline PETMIN & Temp below which ET is set to zero & deg.F & Climate, vegetation \\
\hline INFEXP & Exponent in infiltration equation & none & Soils variability \\
\hline INFILD & $\begin{array}{l}\text { Ratio of max/mean infiltration } \\
\text { capacities }\end{array}$ & none & Soils variability \\
\hline DEEPFR & $\begin{array}{l}\text { Fraction of GW inflow to deep } \\
\text { recharge }\end{array}$ & none & Geology, GW recharge \\
\hline BASETP & $\begin{array}{l}\text { Fraction of remaining ET from } \\
\text { baseflow }\end{array}$ & none & Riparian vegetation \\
\hline AGWET & $\begin{array}{l}\text { Fraction of remaining ET from active } \\
\text { PW }\end{array}$ & none & Marsh/wetlands extent \\
\hline CEPSC & Interception storage capacity & inches & $\begin{array}{l}\text { Vegetation type/density, } \\
\text { land use }\end{array}$ \\
\hline UZSN & $\begin{array}{l}\text { Upper zone nominal soil moisture } \\
\text { storage }\end{array}$ & inches & $\begin{array}{l}\text { Surface soil conditions, } \\
\text { land use }\end{array}$ \\
\hline NSUR & $\begin{array}{l}\text { Manning's n (roughness) for overland } \\
\text { flow }\end{array}$ & none & $\begin{array}{l}\text { Surface conditions, } \\
\text { residue, etc. }\end{array}$ \\
\hline INTFW & Interflow inflow parameter & none & $\begin{array}{l}\text { Soils, topography, land } \\
\text { use }\end{array}$ \\
\hline IRC & Interflow recession parameter & none & $\begin{array}{l}\text { Soils, topography, land } \\
\text { use }\end{array}$ \\
\hline LZETP & Lower zone ET parameter & $\begin{array}{l}\text { Vegetation type/density, } \\
\text { root depth }\end{array}$ \\
\hline
\end{tabular}

In additional to simulating hydrology, WinHSPF also calculates mass balances for selected water quality constituents. As with runoff, sediment loading is simulated in HSPF with separate equations for pervious and impervious surfaces (Figure 4.3). Sediment loading in WinHSPF generally follows the Universal Soil Loss Equation (USLE):

$$
A=R * K * L * S * C * P(1)
$$


where $\mathrm{A}=$ annual soil loss in tons per acre per year, $\mathrm{R}=$ rainfall erosivity factor, $\mathrm{K}=$ soil erodibility factor, $\mathrm{L}=$ slope length factor, $\mathrm{S}=$ slope gradient factor, $\mathrm{C}=$ cover management factor, and $\mathrm{P}=$ erosion control practice factor (Meyer and Wischmeier 1969).

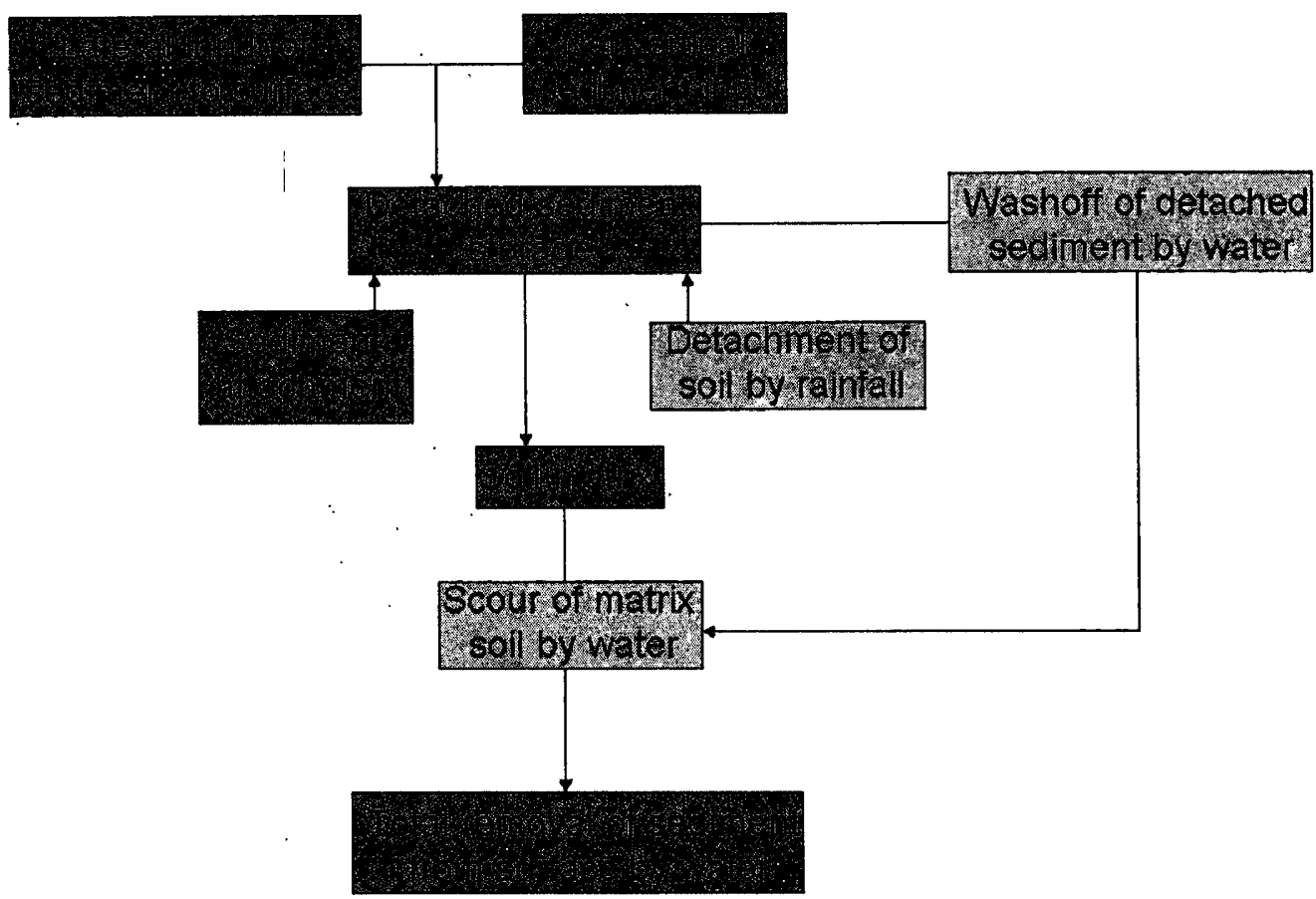

Figure 4.3. HSPF model structure for simulating sediment transport.

The output of the sediment balance is the total sediment load transported (USEPA 2006). Major adjustable parameters that determine sediment processes include coefficients for sediment washoff, soil matrix scour, solids washoff, and solids accumulation rate, which are initially estimated and then adjusted during the calibration process. Initial values are estimated from the input sediment load size fractions, determined by soil type, and shear stress in the flow plane, a function of topography (USEPA 2006). 
Another major water quality constituent modeled by WinHSPF is nutrient loading, including total nitrogen and total phosphorus. They are both simulated in HSPF by a nutrient transport equation (Figure 4.4), which takes the form:

$$
\mathrm{N}=\mathrm{NSTOR}+\mathrm{ADFX}+\mathrm{PREC} * \text { ADCN (2) }
$$

where $\mathrm{N}=$ nutrient load, NSTOR = storage of nutrient species in the soil layer in mass per area, $\mathrm{ADFX}=$ dry atmospheric deposition flux in mass per area per interval, PREC $=$ precipitation in depth per interval, and $\mathrm{ADCN}=$ concentration of nutrient species in rainfall in mass per volume (Bicknell et al. 2001). The output of the nutrient balance equation is the total load, which can be combined with runoff volume in order to determine nitrogen and phosphorus concentrations (Bicknell et al: 2001).

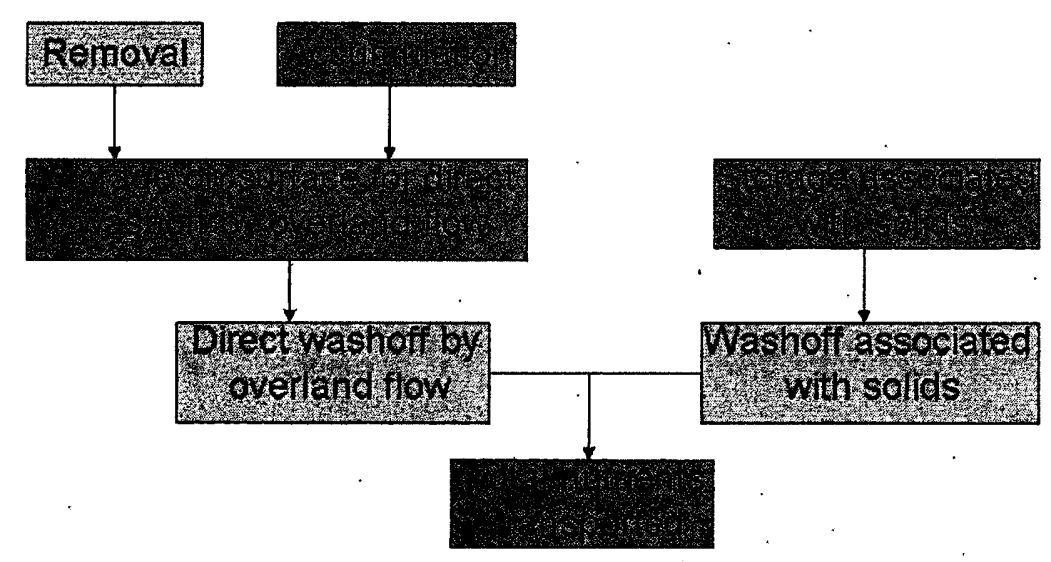

Figure 4.4. HSPF model structure for simulating nutrient transport.

The nitrogen species modeled by WinHSPF are nitrate, ammonia, and organic nitrogen (Bicknell et al. 2001). 'Initial nitrogen storage is determined by soil nitrogen content, a function of soil type and land cover, dry atmospheric deposition, and nitrogen rainfall concentration and amount of precipitation. Vegetation dynamics are simulated by an equation for plant uptake of ammonium and nitrate and return of 
organic nitrogen to the soil. Nitrogen fluxes, translated to export coefficients, are then calculated as a function of soil nitrogen concentration and temperature-corrected reaction rate:

$$
\mathrm{FLUX}=\mathrm{KK} * \mathrm{CONC} /(\mathrm{CS}+\mathrm{CONC})(3)
$$

where FLUX = amount of flux in milligrams per liter per time interval, $\mathrm{KK}=$ temperature-corrected maximum rate in milligrams per liter per time interval, CONC $=$ concentration of nitrogen species in soil layer in milligrams per liter, and CS $=$ the half-saturation constant in milligrams per liter (Bicknell et al. 2001).

Phosphorus is simulated in WinHSPF in the forms of organic phosphorus and adsorbed orthophosphate with sediment and as phosphate in solution (Bicknell et al. 2001). As with nitrogen, initial phosphorus storage is modeled as a function of soil content, dry deposition, and rainfall input. Phosphorus fluxes are determined by adsorption, mineralization, immobilization, and plant uptake reactions.

The final program in the BASINS/WinHSPF modeling process is GenScn, where output time series from WinHSPF, including flow and other hydrological parameters and sediment and nutrient loadings, may be viewed (USEPA 2001). GenScn includes the capability to create hydrographs, flow duration curves, and comparisons of observed and modeled flow. Output time series can also be exported as text files from GenScn for use in other applications.

I. chose to use BASINS/HSPF for this research for three primary reasons. First, as one of the most commonly used public domain hydrological modeling systems, BASINS has a large user community with abundant case study examples and technical 
support. Second, HSPF has an advantage over many other hydrological models in that it simulates loadings of several water quality constituents in addition to hydrology, thus allowing for comprehensive assessment of impacts on both water quality and quantity. Finally, unlike related models such as SWAT, which was developed primarily for agricultural watersheds, HSPF was intended for use in meso-scale, mixed land use basins, similar to the TRB.

\section{Previous Applications of BASINS/HSPF}

Although BASINS/HSPF was originally developed by the United States Environmental Protection Agency (USEPA) for the purpose of evaluating pollutant Total Maximum Daily Loads (TMDLs), its user-friendly interface and comprehensive approach to modeling basin-scale hydrology and water quality has enabled researchers to adapt it for a variety of applications (Donigian et al. 1995). These research areas include modeling the impacts of climate change, land use, and land management scenarios on various hydrological and water quality parameters, including flow, sediments, nutrients, and agricultural runoff. Other research applications focus not on basin response to future scenarios, but on evaluating the model's performance based on observed data.

\section{A. Evaluative Studies}

In order to ensure that models are able to produce reliable scenarios for research applications, it is necessary to evaluate their ability to simulate different parameters under a wide variety of conditions, a task undertaken by a number of studies for BASINS/HSPF (Table 4.2). These studies achieved a wide range of fitness 
values, indicating that model performance is highly dependent on the parameters being modeled, the conditions of the study basin, and the quality of observed data available. To assess the performance of HSPF in simulating runoff and sediment loading, Hayashi et al. (2004) used observed daily-scale data from China's Upper Changjiang River to compare with modeled output, in order to facilitate study of logging practices in this forested basin. They found that, although the model predicted flow well, with a calibration $\mathrm{R}^{2}$ of 0.69 , it was less successful at simulating sediment, with underestimations of up to seventy-nine percent of the suspended sediment load at some locations, probably because the model is not optimized to perform at a daily time step.

Table 4.2: Previous evaluative studies using BASINS/HSPF.

\begin{tabular}{|c|c|c|c|c|}
\hline Author(s) & $\begin{array}{l}\text { Study } \\
\text { Area }\end{array}$ & $\begin{array}{l}\text { Basin } \\
\text { Size }\end{array}$ & $\begin{array}{l}\text { Study } \\
\text { Period }\end{array}$ & Results \\
\hline $\begin{array}{l}\text { Hayashi et } \\
\text { al. (2004) }\end{array}$ & China & $\begin{array}{l}536,780 \\
\mathrm{~km}^{2}\end{array}$ & $1987-1988$ & $\begin{array}{l}\text { Model underestimated daily sediment } \\
\text { runoff volume, with calibration and } \\
\text { validation } R^{2} \text { of } .69 \text { and } .68\end{array}$ \\
\hline $\begin{array}{l}\text { Wang and } \\
\text { Linker } \\
(2006)\end{array}$ & Maryland & $\begin{array}{l}165,759 \\
\mathrm{~km}^{2}\end{array}$ & $1985-1994$ & $\begin{array}{l}\text { Developed synthetic modification of } \\
\text { HSPF } N \text { simulation to improve } \\
\text { modeling of dissolved inorganic } \\
\text { nitrogen }\end{array}$ \\
\hline $\begin{array}{l}\text { Kim et al. } \\
(2007)\end{array}$ & Virginia & $973 \mathrm{~km}^{2}$ & $1985-2003$ & $\begin{array}{l}\text { Achieved flow calibration } R^{2} \text { of } 0.51 \\
\text { for autocalibration and } 0.49 \text { for } \\
\text { manual calibration }\end{array}$ \\
\hline $\begin{array}{l}\text { Jeon et al. } \\
(2007)\end{array}$ & $\begin{array}{l}\text { South } \\
\text { Korea }\end{array}$ & $2523 \mathrm{~km}^{2}$ & $1995-2004$ & $\begin{array}{l}\text { Achieved calibration and validation } \\
R^{2} \text { of } 0.97 \text { and } 0.98 \text { for monthly flow }\end{array}$ \\
\hline $\begin{array}{l}\text { Nasr et al. } \\
(2007)\end{array}$ & Ireland & $\begin{array}{l}15-96 \\
\mathrm{~km}^{2}\end{array}$ & $2000-2002$ & $\begin{array}{l}\text { HSPF achieved best model } \\
\text { performance for mean daily } \\
\text { discharge and SWAT for } P \text { loading }\end{array}$ \\
\hline $\begin{array}{l}\text { Al-Abed } \\
\text { and Al- } \\
\text { Sharif } \\
(2008)\end{array}$ & Jordan & $3300 \mathrm{~km}^{2}$ & 1988-1998 & $\begin{array}{l}\text { Achieved calibration and validation } \\
R^{2} \text { of } 0.81 \text { and } 0.76 \text { for monthly flow }\end{array}$ \\
\hline $\begin{array}{l}\text { Iskra and } \\
\text { Droste } \\
\text { (2008) }\end{array}$ & Ontario & $3810 \mathrm{~km}^{2}$ & 00 & $\begin{array}{l}95 \% \text { confidence intervals of } \\
\text { parameter uncertainty correspond to } \\
10 \% \text { variation in spring maximum } \\
\text { flow }\end{array}$ \\
\hline
\end{tabular}


Another water quality constituent that is problematic to model with HSPF is nitrogen, particularly because of the complex dynamics involved with plant uptake during the growing season. Wang and Linker (2006) sought to address this limitation by developing an algorithm that improves the simulation of the relation between soil moisture and plant nitrogen uptake, using a synthetic method that combines concentration- and mass-based functions. This algorithm may be a useful tool in modeling applications focused on the export of dissolved organic nitrogen from a basin.

Model calibration is an often time-consuming process, the success of which ultimately determines the reliability of modeling results. Accordingly, Kim et al. (2007) compared the performance of a model manually calibrated in HSPF and one autocalibrated using the BASINS tool Parameter Estimation (PEST). The autocalibration model results were somewhat closer in fit to observed data, with an $\mathrm{R}^{2}$ of 0.51 , than the manually calibrated model, with an $R^{2}$ of 0.49 , suggesting that such a method of calibration is useful in obtaining more reliable and objective results.

Because it is necessary to test models in a wide range of conditions to be confident in their broad applicability, research applications in areas outside the original development regions are of interest (Diaz-Ramirez et al. 2008). Jeon et al. (2007) adapted the HSPF algorithms to simulate flow and water quality in South Korean rice paddies. The modified model was able to reasonably reproduce observed flow and water quality, with an $\mathrm{R}^{2}$ of 0.97 at the monthly scale, providing an example 
of the adaptability of HSPF in modeling areas with different hydrology from which the model was originally developed.

Another example of applying HSPF in a geographical region different from the basins for which it was primarily developed is a study by Al-Abed and Al-Sharif (2008), who calibrated HSPF for flow in Jordan's Zarqa River Basin. The model's goodness-of-fit was relatively high, demonstrating HSPF's success in simulating hydrology in arid regions. The ability of HSPF to perform well in areas as diverse as rice paddies and deserts illustrates its high level of adaptability and suggests that its flow equations are generally applicable and not limited to a particular type of hydrological regime.

Another type of research useful for model evaluation is comparison of different models. Nasr et al. (2007) assessed the relative ability of HSPF, the Soil and Water Assessment Tool (SWAT), and Systéme hydrologique Européen TRANsport (SHETRAN) for modeling flow and phosphorus export from three Irish basins. While HSPF most accurately simulated basin hydrology, SWAT was the most successful of the three models in simulating daily phosphorus loads. The authors believe HSPF's relatively inferior performance may be because it has fewer adjustable parameters in its phosphorus module than SWAT, limiting its calibration ability. HSPF models organic phosphorus, sediment-adsorbed orthophosphate, and phosphate in solution through a simplified function of soil content, dry deposition, and rainfall input. Its fluxes are determined by adsorption, mineralization, immobilization, and plant uptake. 
Finally, it is useful to understand how parameter uncertainty during the calibration process affects modeling results. Iskra and Droste (2008) performed a sensitivity analysis of independent model calibrations using method of moments, Monte Carlo simulation, and response surface methods. They found that ninety-five percent confidence intervals for model parameters correspond to ten percent variations in maximum spring flows. This study demonstrates that, even with a high amount of confidence in calibrated parameters, there is still a significant amount of uncertainty in HSPF modeling results.

\section{B. Scenario Modeling}

While model evaluation studies are necessary, the real purpose of such research is to enable applications of the model for studying hydrological processes and projecting impacts of management decisions (Table 4.3). For example, Laroche et al. (1996) used HSPF to assess how different application levels of the herbicide atrazine affect stream water quality in a Québec agricultural basin. Through their modeling results, they were able to determine the threshold level of application that would negatively impact aquatic life. 
Table 4.3: Scenario modeling studies using BASINS/HSPF.

\begin{tabular}{|c|c|c|c|c|}
\hline Author(s) & Study Area & $\begin{array}{l}\text { Basin } \\
\text { Size }\end{array}$ & $\begin{array}{l}\text { Study } \\
\text { Period }\end{array}$ & Results \\
\hline $\begin{array}{l}\text { Laroche et } \\
\text { al. (1996) }\end{array}$ & Québec & $\begin{array}{l}0.78 \\
\mathrm{~km}^{2}\end{array}$ & $\begin{array}{l}1991- \\
1993\end{array}$ & $\begin{array}{l}\text { Atrazine application rates of } \geq 4.5 \\
\mathrm{~kg} / \mathrm{ha} \text { result in concentrations that } \\
\text { could negatively impact aquatic life }\end{array}$ \\
\hline $\begin{array}{l}\text { Albek et } \\
\text { al. (2004) }\end{array}$ & Turkey & $\begin{array}{l}414 \\
\mathrm{~km}^{2}\end{array}$ & $\begin{array}{l}1991- \\
1994\end{array}$ & $\begin{array}{l}\text { Annual mean temperature increase of } \\
3^{\circ} \mathrm{C} \text { decreases annual flow by } 21 \% ; \\
\text { maximum vegetation cover } \\
\text { decreases flow by } 37 \% \text { and minimum } \\
\text { cover increases it by } 40 \%\end{array}$ \\
\hline $\begin{array}{l}\text { Imhoff et } \\
\text { al. (2007) }\end{array}$ & Maryland & $\begin{array}{l}1900 \\
\mathrm{~km}^{2}\end{array}$ & $\begin{array}{l}2010 \\
2039\end{array}$ & $\begin{array}{l}\text { Increased temperature and } \\
\text { precipitation in climate change } \\
\text { scenario increased } N \text { loadings by } \\
10.7 \%\end{array}$ \\
\hline $\begin{array}{l}\text { Choi and } \\
\text { Deal } \\
(2008) \\
\end{array}$ & Illinois/Wisconsin & $\begin{array}{l}3528 \\
\mathrm{~km}^{2}\end{array}$ & $\begin{array}{l}1988- \\
1994\end{array}$ & $\begin{array}{l}\text { Highest-change urban development } \\
\text { scenario (urban area increases from } \\
2.9 \% \text { to } 6.0 \% \text { increased annual } \\
\text { runoff by } 1.7 \% \text { and surface flow by } \\
38.5 \%\end{array}$ \\
\hline $\begin{array}{l}\text { Göncu } \\
\text { and Albek } \\
\text { (2008) }\end{array}$ & Turkey & $\begin{array}{l}1000 \\
\mathrm{~km}^{2}\end{array}$ & $\begin{array}{l}2004- \\
2050\end{array}$ & $\begin{array}{l}\text { Annual temperature increase of } \\
1.57^{\circ} \mathrm{C} \text { and annual precipitation } \\
\text { increase of } 20 \% \text { increases annual } \\
\text { sediment load by } 5 \text { tons/yr and } \\
\text { chloride concentration by } 9 \% \text { on } \\
\text { barren land; sediment increases by a } \\
\text { ton/yr and chloride by } 6 \% \text { on } \\
\text { coniferous forest land }\end{array}$ \\
\hline $\begin{array}{l}\text { Hunter } \\
\text { and } \\
\text { Walton } \\
(2008) \\
\end{array}$ & Australia & $\begin{array}{l}1602 \\
\mathrm{~km}^{2}\end{array}$ & $\begin{array}{l}1958- \\
1996\end{array}$ & $\begin{array}{l}91 \% \text { of suspended sediment and } \\
84 \% \text { of } P \text { exported during } Q 10 \text { flows; } \\
\text { loading of nitrate } 6 \text { times higher than } \\
\text { natural conditions }\end{array}$ \\
\hline $\begin{array}{l}\text { Ribarova } \\
\text { et al. } \\
\text { (2008) } \\
\text { Chung } \\
\text { and Lee } \\
\text { (2009) }\end{array}$ & Bulgaria & $\begin{array}{l}1040 \\
\mathrm{~km}^{2} .\end{array}$ & $\begin{array}{l}2000- \\
2003\end{array}$ & $\begin{array}{l}\text { Post-flooding } N \text { loads increased by a } \\
\text { factor of } 6 \text { and } P \text { by a factor of } 7 \\
\text { Using groundwater increases number } \\
\text { of day in-stream flow requirement is } \\
\text { met from } 150 \text { to } 175 \text {; using inter- } \\
\text { basin transfers increases it to } 203 \text {. }\end{array}$ \\
\hline
\end{tabular}

Albek et al (2004) is an example of an HSPF modeling study that estimates changes in flow resulting from both climate change and land use change scenarios, for a small sub-basin in Turkey. As a result of a synthetic climate change scenario that includes a $3^{\circ} \mathrm{C}$ increase in mean annual temperature, annual flows in the sub-basin were projected to decrease by twenty-one percent. The land use scenarios resulted in 
more significant changes in flow in this sub-basin, with a decrease in annual flow of thirty-seven percent resulting from a scenario of maximum vegetation cover and an increase of forty percent for minimum vegetation cover, as a result of changes in evapotranspiration.

Because climate change impacts is a growing area of important research, the latest version of BASINS includes a Climate Assessment Tool (CAT) specifically designed to assist researchers in generating and evaluating the impacts of climate change scenarios. Imhoff et al. (2007) demonstrated CAT's use in simulating flow and nitrogen loading impacts of climate change in a Maryland basin, with summer temperature changes of plus or minus $2{ }^{\circ} \mathrm{C}$ and annual precipitation changes of plus of minus ten percent of the historical average. Through a sensitivity analysis, they were able to project the amount of nitrogen loading increase that would result from a series of changes in temperature and precipitation.

Choi and Deal (2008) used HSPF in combination with a dynamic spatial model of urban growth to estimate hydrological changes in a basin in the Midwestern United States resulting from a range of urban development scenarios. For the highest-change urban development scenario, in which urban area increases from nearly three to six percent, total runoff increases by less than two percent. The change in surface flow, however, is more significant, with an increase of over thirty-eight percent.

Göncü and Albek (2008) created hypothetical watersheds with differing land use types and simulated sediment and chloride loading for these watersheds using a climate change scenario for Turkey in which annual temperature increases by $1.57^{\circ} \mathrm{C}$ 
and annual precipitation by twenty millimeters. In the watershed with barren land, annual sediment load increased by five tons per year and chloride concentrations by nine percent. The increase in sediment load in the coniferous forest watershed was smaller, at one ton per year, because of the lower runoff and increased soil stability of the forested watershed. The increase in chloride concentrations was higher for the barren watershed, at nine percent, than the six percent increase for the forested watershed, because of both the lower erosion rate and higher buffering capacity of the forest land.

Hunter and Walton (2008) conducted a retrospective modeling study to examine the impacts of different land use types on loading of suspended sediment and nutrients in a tropical Australian basin. They found that the ten percent highest flow events account for ninety-one percent of the suspended sediment load and eighty-four percent of the total phosphorus load, but much less of the total nitrogen load, illustrating that sediment and phosphorus are much more strongly controlled by surface erosion and flushing processes. Another significant finding was that nitrate loading was approximately six times higher under contemporary land use than in predevelopment conditions, and that most of the nitrate originated on sugar cane plantations.

A potential area for increased research applications in HSPF is event-scale nutrient loading. While most HSPF studies use a monthly time scale or longer, Ribarova et al. (2008) modeled how nutrient and phosphorus concentrations in a Bulgarian river respond to "first floods", a rainfall event that occurs after a long dry 
period. Using observed data, they were able to calculate the increases in nutrient loading following these events and project the amount of additional loading that would occur after precipitation events of varying magnitude and intensity. They found that these first flood events increased nitrogen loading by a factor of six and phosphorus loading by a factor of seven over baseline conditions. Under a scenario of increased precipitation intensity under anthropogenic climate change, these results could mean significant changes to basin-scale nutrient dynamics, with a greater proportion of export occurring during fewer storms, causing pulses of nutrient-rich runoff, with potential negative implications for water quality.

Finally, Chung and Lee (2009) used HSPF to model impacts of a number of water resource management actions for a basin in South Korea. Under the baseline no-action scenario, the number of days per year in which the in-stream flow target is met is 150 . By supplementing demand with groundwater withdrawals, however, this number can be increased to 175 , and use of inter-basin transfers increases it to 203 . This study provides a rare example of HSPF being used to directly model water management policies. 


\section{V: DATA AND METHODS}

\section{Calibration/Validation Data}

To calibrate and validate the hydrology and water quality models, I obtained several categories of data. These include elevation, soils, the watershed boundary, land cover, streamflow, water quality, and climate. The characteristics of these datasets are summarized below (Table 5.1).

Table 5.1: Summary of datasets used for hydrological and water quality modeling.

\begin{tabular}{|l|l|l|l|}
\hline Datasets & Format & Resolution & Source \\
\hline Digital Elevation Model (DEM) & Raster & $10 \mathrm{~m}$ & USGS (2004) \\
\hline Soil Layer & Shapefile & $1: 20,000$ & NRCS (2001) \\
\hline Watershed Boundary & Shapefile & N/A & USGS (2006) \\
\hline Land cover & Raster & $30 \mathrm{~m}$ & NLCD (2001) \\
\hline Streamflow gage data &. $\mathrm{txt}$ & $\mathrm{N} / \mathrm{A}$ & CWS (2008) \\
\hline Water quality data &. $\mathrm{txt}$ & $\mathrm{N} / \mathrm{A}$ & CWS (2008) \\
\hline Forest Grove climate data &. $\mathrm{wdm}$ & $\mathrm{N} / \mathrm{A}$ & OCS (2007) \\
\hline
\end{tabular}

\section{A. Base Cartography}

Most of the base cartography data layers were obtained directly through the BASINS Data Download tool. These included a soil shapefile from the State Soil Geographic Database (NRCS 2001), the Hydrologic Unit Code (HUC) Sub-basin Level watershed boundary for the TRB (17090010), and flowlines from the National Hydrography Dataset (NHDPlus 2007). Although a thirty-meter Digital Elevation Model (DEM) was available through the Data Download tool, I decided that this spatial resolution was too coarse for accurate watershed delineation in the relatively low-relief TRB. Accordingly, I imported a ten-meter DEM from the United States Geological Survey (USGS 2004) into ArcMap 9.2, along with the HUC boundary and NHD flowlines, and used the ArcHydro Watershed Delineation tools to delineate two 
subbasins, in addition to the entire basin, using the seven available streamflow and water quality gages as output points (Figure 5.1). I then imported this sub-basin layer into BASINS for further analysis of the entire TRB, Upper Tualatin River sub-basin, and Rock Creek sub-basin.
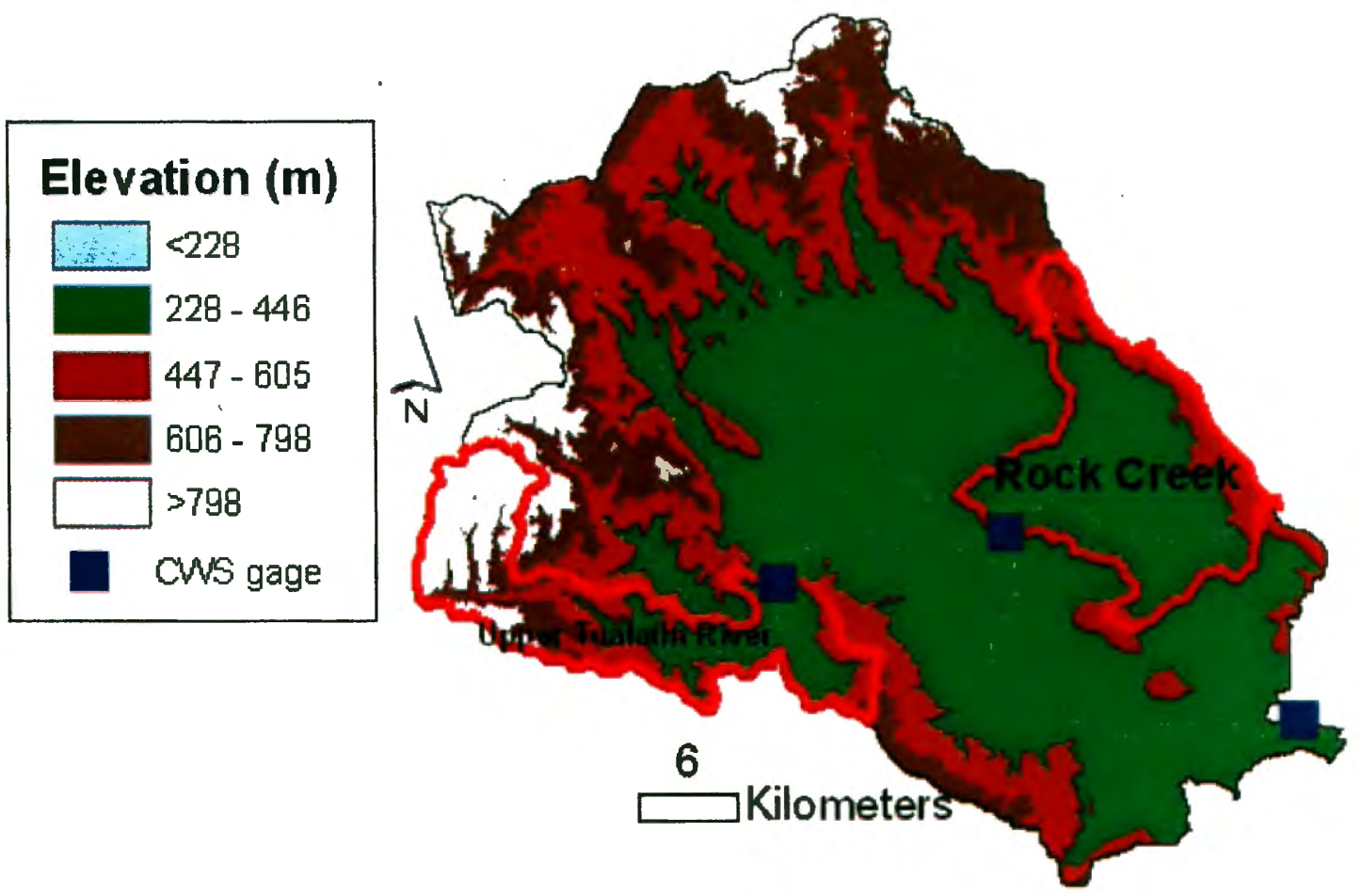

Figure 5.1: Tualatin River sub-basins delineated in ArcHydro.

\section{B. Streamflow}

I obtained historical daily average streamflow data for three gages in the basin from Clean Water Services (Table 5.2). The lengths of the complete data records varied among gages. For analysis, I converted the flows from cubic feet to cubic meters per second. 
Table 5.2: Clean Water Services streamflow and water quality gage locations, lengths of time series, and sub-basin characteristics.

\begin{tabular}{|l|l|l|l|l|l|l|l|}
\hline Station ID & Location & $\begin{array}{l}\text { Time } \\
\text { Series }\end{array}$ & Latitude & Longitude & $\begin{array}{l}\text { Basin } \\
\text { Size } \\
\left(\mathrm{km}^{2}\right)\end{array}$ & $\begin{array}{l}\text { Basin } \\
\text { Elevation } \\
(\mathrm{m})\end{array}$ & $\begin{array}{l}\text { Basin } \\
\text { Slope } \\
\left.\mathrm{\rho}^{\circ}\right)\end{array}$ \\
\hline 3701002 & $\begin{array}{l}\text { Tualatin } \\
\text { (lower) }\end{array}$ & $1991-2006$ & $123^{\circ} 7^{\prime} 32^{\prime \prime}$ & $45^{\circ} 28^{\prime} 29^{\prime \prime}$ & 1730 & 501 & 23 \\
\hline 3701612 & $\begin{array}{l}\text { Tualatin } \\
\text { (upper) }\end{array}$ & $1991-2006$ & $122^{\circ} 39^{\prime} 18^{\prime \prime}$ & $45^{\circ} 20^{\prime} 22^{\prime \prime}$ & 282 & 629 & 32 \\
\hline 3820012 & Rock & $2003-2006$ & $122^{\circ} 56^{\prime} 52^{\prime \prime}$ & $45^{\circ} 30^{\prime} 8^{\prime \prime}$ & 192 & 415 & 15 \\
\hline
\end{tabular}

\section{Water Quality}

The instantaneous water quality data, also from Clean Water Services (CWS 2008), were for the same gage locations and time periods as in Table 5.2.

Instantaneous water quality data of flow in cubic feet per second and concentrations of dissolved sediment, nitrate, and orthophosphate in milligrams per liter were obtained from CWS for the three sites. Because these data were irregularly sampled at approximately two-week intervals, it was necessary to estimate continuous daily time series for calibration and validation purposes. Accordingly, I fitted power functions to the scatterplot relating flow to concentrations of the three constituents (Figure 5.2). In the case of suspended sediment, the non-linearity of the data required that two separate functions be fitted, one for flows below approximately eight cubic meters per second and one for flows above this threshold. I then used these functions to estimate daily concentrations of suspended sediment, nitrate, and orthophosphate, based on observed flows, to use for calibrating and validating the sediment and nutrient models. 


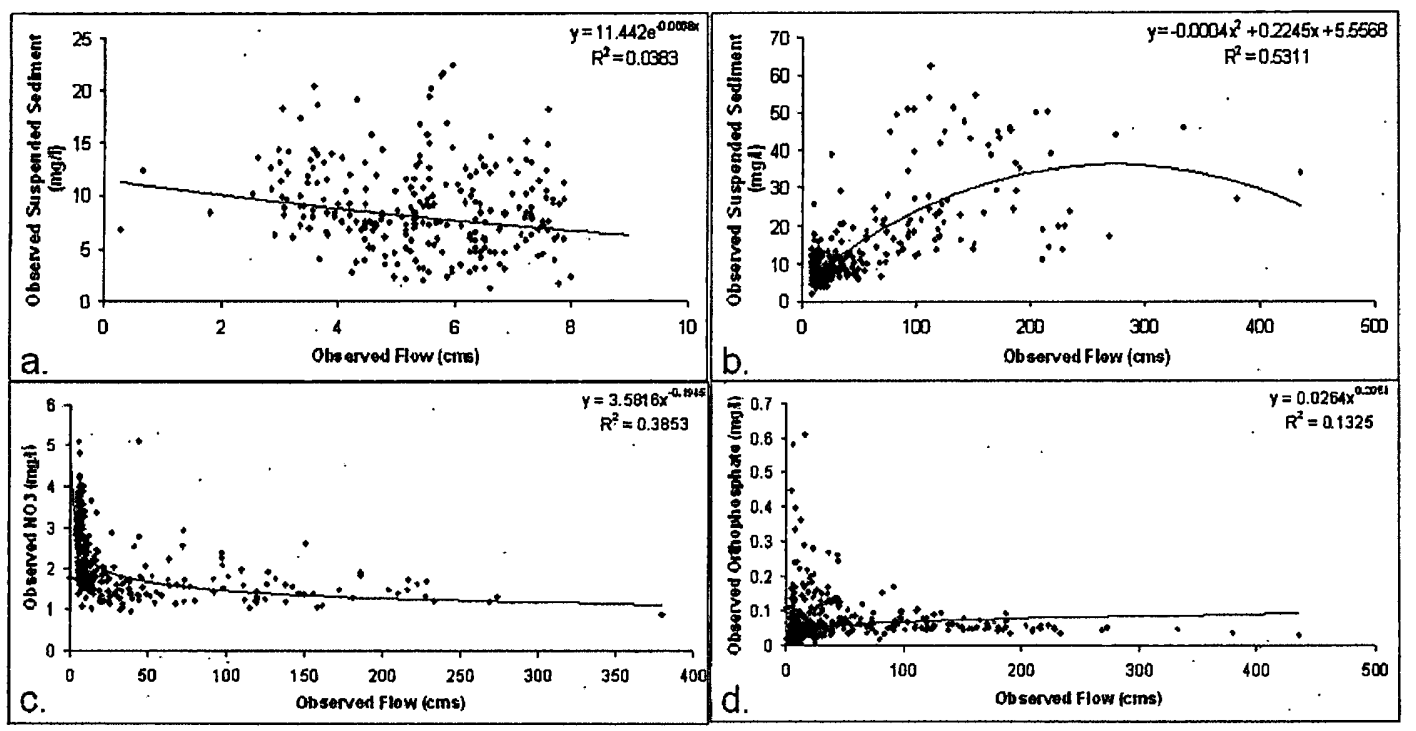

Figure 5.2: Observed Tualatin River flow, 1991-2006, and a) suspended sediment, below flows of $8 \mathrm{cms}$; b) suspended sediment, above flows of $8 \mathrm{cms}$; c) nitrate; and d) orthophosphate.

\section{Climate}

Using the BASINS Data Download tool, I obtained historical climate data for Forest Grove, including hourly average temperature and total precipitation, from 1970 to 2006 (OCS 2006). Because the elevation at Forest Grove (55 meters) is lower than the mean elevation for the basin (501 meters), I modified the precipitation by adding fifteen percent to each measurement for the TRB and Upper Tualatin River sub-basin, based on the regression of elevation versus precipitation in the Parameter-elevation Regressions on Independent Slopes (PRISM) dataset (OCS 2008). This step ensures that precipitation is not underestimated in the higher-elevation parts of the basin. For the lower-elevation Rock Creek sub-basin, I left the precipitation unmodified. 


\section{Scenario Data}

To simulate the effects of potential future conditions on water resources in the TRB, I selected several scenarios representing a range of climate change and urban development in the basin (Table 5.3). There were a total of eight climate change (Section 5.2.A) and two land use change (Section 5.2.B) scenarios, each of which I ran separately. In addition, I combined the highest-change and lowest-change climate scenarios with each of the two land use scenarios, for a total of four combined scenarios.

Table 5.3: Summary of climate change, urban development, and combined scenarios.

\begin{tabular}{|c|c|c|c|}
\hline Category & Scenario & Time Period & Source \\
\hline \multirow{8}{*}{$\begin{array}{l}\text { Climate } \\
\text { Change }\end{array}$} & BCCR A1B & \multirow[t]{8}{*}{$2040 \mathrm{~s} ; 2070 \mathrm{~s}$} & \multirow{8}{*}{ CIG } \\
\hline & CCSM 3 A1B & & \\
\hline & CGCM3 A1B & & \\
\hline & PCM1 A1B & & \\
\hline & CCsM3 B1 & & \\
\hline & CNRM3 B1 & & \\
\hline & ECHAM5 B1 & & \\
\hline & IPSL4 B1 & & \\
\hline \multirow{2}{*}{$\begin{array}{l}\text { Urban } \\
\text { Development }\end{array}$} & Development & \multirow[t]{2}{*}{$2040 s$} & \multirow{2}{*}{ PNW-ERC } \\
\hline & Conservation & & \\
\hline \multirow{4}{*}{ Combined } & $\mathrm{HCHL}$ & \multirow[t]{4}{*}{$2040 \mathrm{~s} ; 2070 \mathrm{~s}$} & \multirow{4}{*}{$\begin{array}{l}\text { CIG; PNW- } \\
\text { ERC }\end{array}$} \\
\hline & HCLL & & \\
\hline & LCHL & & \\
\hline & LCLL & & \\
\hline
\end{tabular}

Note: $B C C R=$ Bjerknes Center for Climate Research; $C C S M=$ Community Climate System Model; $C G C M=$ Coupled Global Climate Model; $P C M=$ Parallel Climate Model; $C N R M=$ Centre National de Recherches Meteorologiques; $E C H A M=$ European Centre Hamburg Model; IPSL = Institut Pierre Simon Laplace; CIG = Climate Impacts Group; PNW-ERC = Pacific Northwest Ecosystem Research Consortium; HCHL = high climate/high land use change; HCLL = high climate/low land use change; $L C H L=$ low climate/high land use change; $L C L L=$ low climate/low land use change. 


\section{A. Climate Change Scenarios}

Because different general circulation models (GCMs) can produce widely varying outcomes, I chose to use a total of seven GCMs to generate the climate change scenarios, in order to generate a range of possible results (Table 5.4). Three of these GCMs were driven by the Intergovernmental Panel on Climate Change's (IPCC) A1B emission scenario, three by the B1 emission scenario, and one, the Community Climate System Model (CCSM), by both the A1B and B1 scenarios, for a total of eight GCM/emission scenario combinations. The A1B scenario is based on the assumption that future economic growth will be rapid; global population will peak in the middle twenty-first century, and there will be a balance between fossil fuels and new alternative energy sources. The B1 scenario uses the same population projections as the AlB scenario, but assumes a shift in the global economy away from materialoriented industry towards services and information, and a higher level of adoption of alternative energy technology (IPCC 2000). I ran the eight climate scenarios for two time periods: 2030 to 2059 (2040s) and 2060 to 2099 (2070s). 
Table 5.4: Summary of characteristics of GCMs used for climate change scenario modeling.

\begin{tabular}{|c|c|c|c|}
\hline Name & Agency. & $\begin{array}{l}\text { Atmospheric } \\
\text { Resolution }\end{array}$ & $\begin{array}{l}\text { Oceanic } \\
\text { Resolution }\end{array}$ \\
\hline $\begin{array}{l}\text { Bjerknes Center } \\
\text { for Climate } \\
\text { Research } \\
\text { (BCCR) }\end{array}$ & University of Bergen, Norway & $2.8^{\circ}$ & $1.5^{\circ}$ \\
\hline $\begin{array}{l}\text { Community } \\
\text { Climate System } \\
\text { Model v.3 } \\
\text { (CCSM3) }\end{array}$ & $\begin{array}{l}\text { National Center for } \\
\text { Atmospheric Research, US }\end{array}$ & $1.4^{\circ}$ & $1.125^{\circ}$ \\
\hline $\begin{array}{l}\text { Coupled Global } \\
\text { Climate Model } \\
\text { v.3 (CGCM3) }\end{array}$ & $\begin{array}{l}\text { Canadian Centre for Climate } \\
\text { Modelling and Analysis, } \\
\text { Canada }\end{array}$ & $2.5^{\circ}$ & $1.8^{\circ}$ \\
\hline $\begin{array}{l}\text { Parallel Climate } \\
\text { Model (PCM) }\end{array}$ & $\begin{array}{l}\text { National Center for } \\
\text { Atmospheric Research, US }\end{array}$ & $2.8^{\circ}$ & $0.67^{\circ}$ \\
\hline $\begin{array}{l}\text { Centre National } \\
\text { de Recherches } \\
\text { Meteorologiques } \\
\text { v.3 (CNRM3) }\end{array}$ & Meteo France, France & $2.8^{\circ}$ & $1.875^{\circ} \times 2^{\circ}$ \\
\hline $\begin{array}{l}\text { European } \\
\text { Centre Hamburg } \\
\text { Model v. } 5 \\
\text { (ECHAM5) }\end{array}$ & $\begin{array}{l}\text { Max.Planck Institute for } \\
\text { Meteorology } y_{i} \text { Germany }\end{array}$ & $2.8^{\circ}$ & $1.5^{\circ}$ \\
\hline $\begin{array}{l}\text { Institut Pierre } \\
\text { Simon Laplace } \\
\text { v:4 (IPSL4) }\end{array}$ & $\begin{array}{l}\text { Institut Pierre Simon Laplace, } \\
\text { France }\end{array}$ & $2.5^{\circ} \times 3.75^{\circ}$ & $2^{\circ}$ \\
\hline
\end{tabular}

The outputs of GCMs are far too coarse for hydrologic impact analysis at the basin scale (Xu 1999). Accordingly, the GCM outputs were statistically downscaled for the Pacific Northwest by the Climate Impacts Group (CIG). Time series of maximum and minimum temperature, precipitation, and wind speed were provided by $\mathrm{CIG}$ at one-sixteenth degree resolution, and the area-weighted average for the grid cells comprising the TRB was computed. The resulting averaged time series became the input to HSPF for climate change scenario modeling.

Figures 5.3 and 5.4 show the change in average monthly temperature compared to the baseline 1970-1999 climate. There are increases in temperature in all months, 
higher in magnitude in the 2070s, particularly in the summer. Figures 5.5 and 5.6 show the percent change in precipitation from the baseline. While there is some variation among models in terms of the direction of change, generally there are increases in winter precipitation and decreases in summer precipitation, with a significant overall increase apparent in the 2070s.

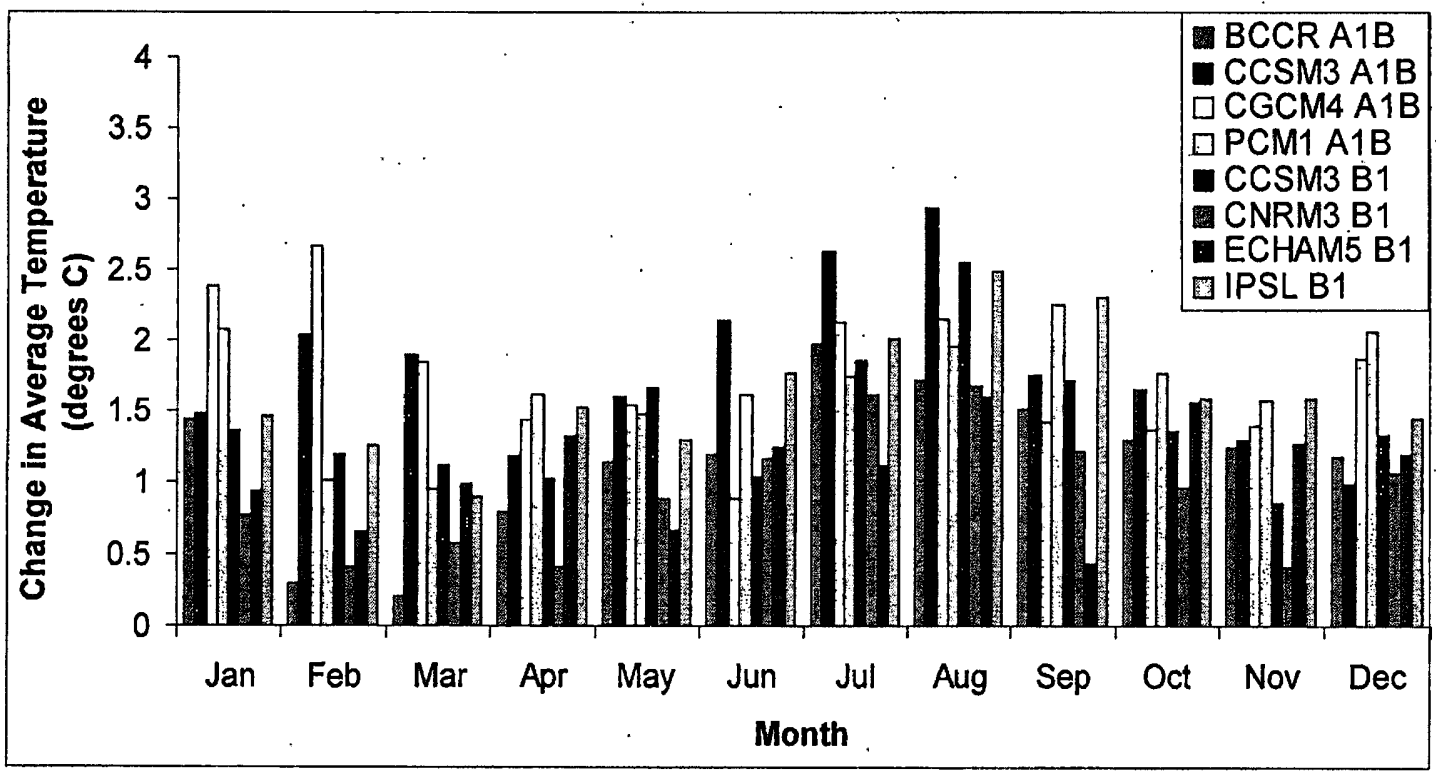

Figure 5.3: Absolute change from baseline in average monthly temperature for the 2040s according to eight climate change scenarios. 


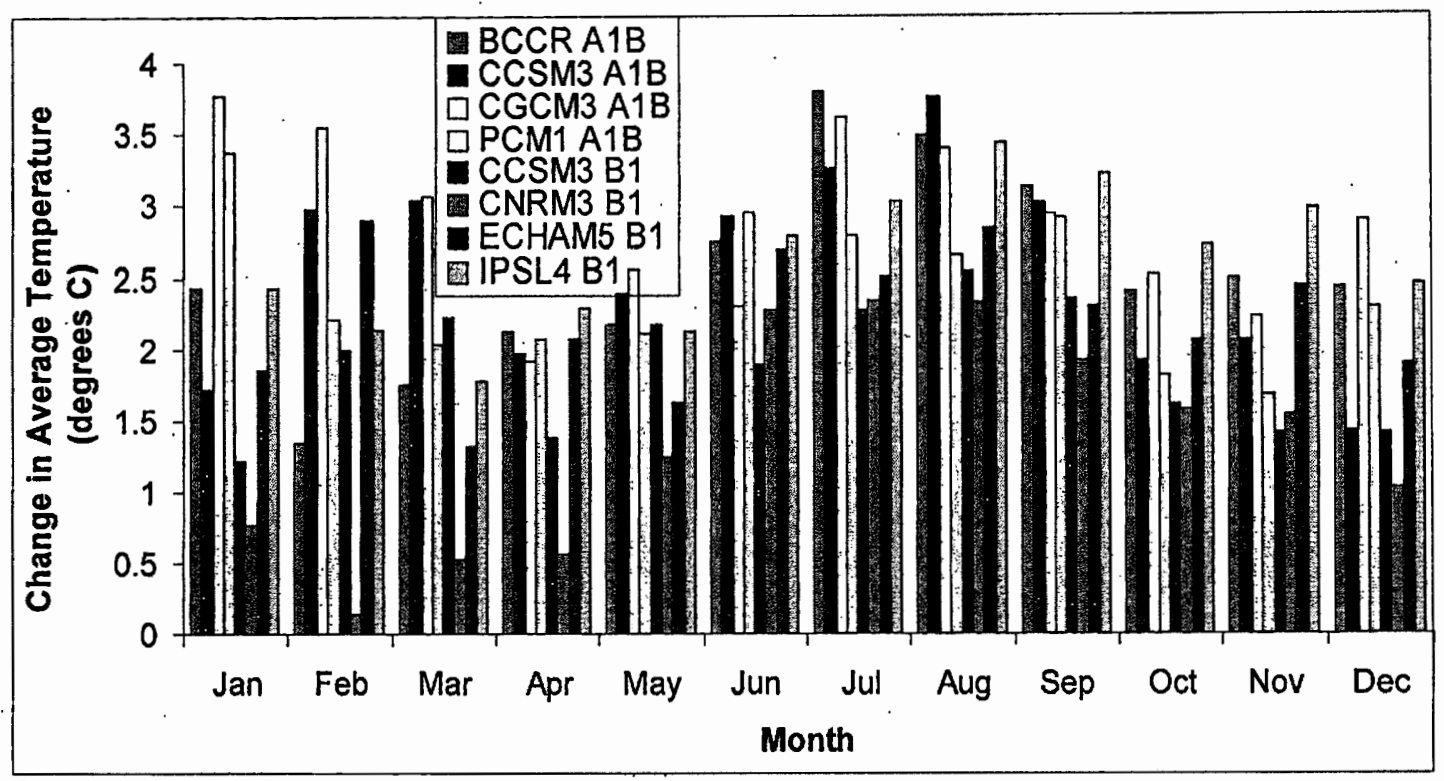

Figure 5.4: Absolute change from baseline in average monthly temperature for the 2070s according to eight climate change scenarios.

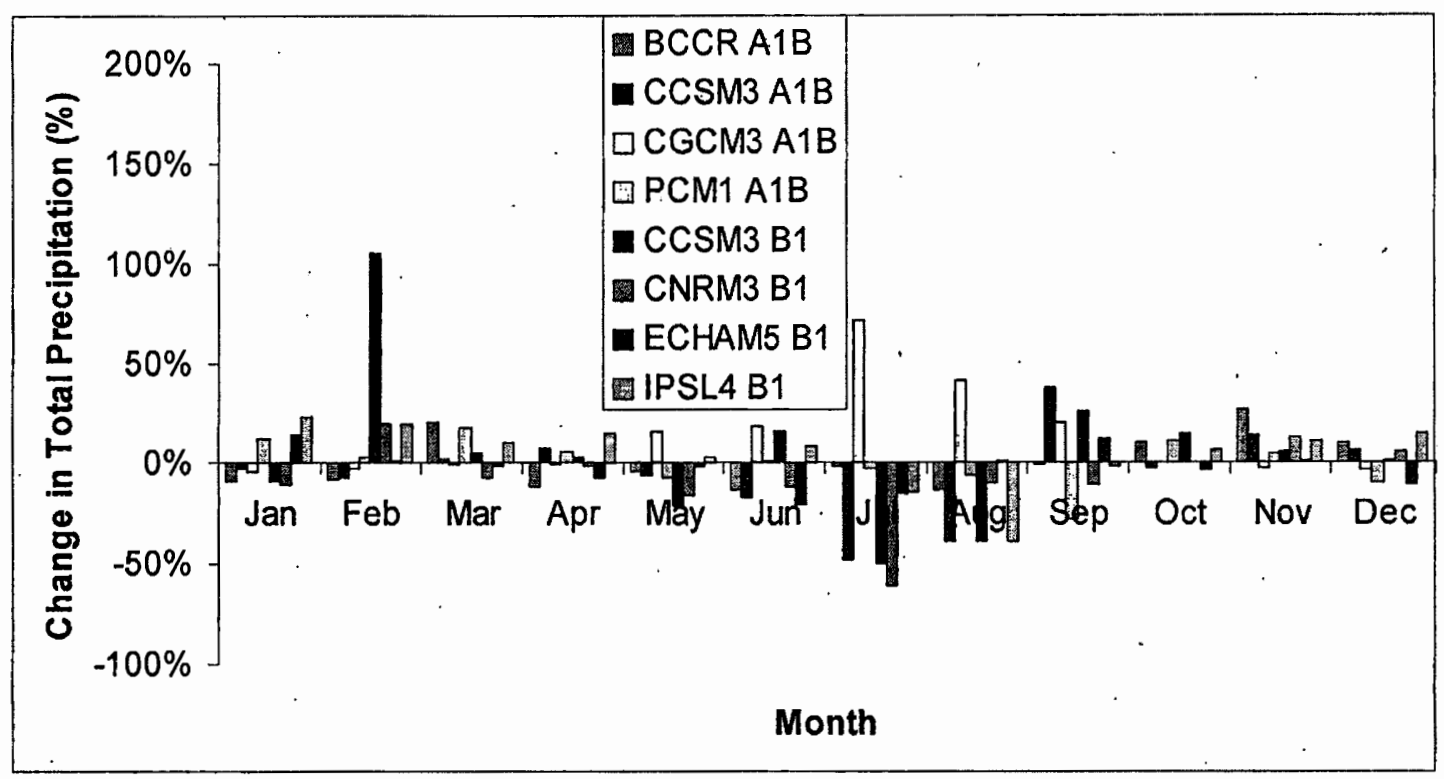

Figure 5.5: Percent change from baseline in total monthly precipitation for the 2040s according to eight climate change scenarios. 


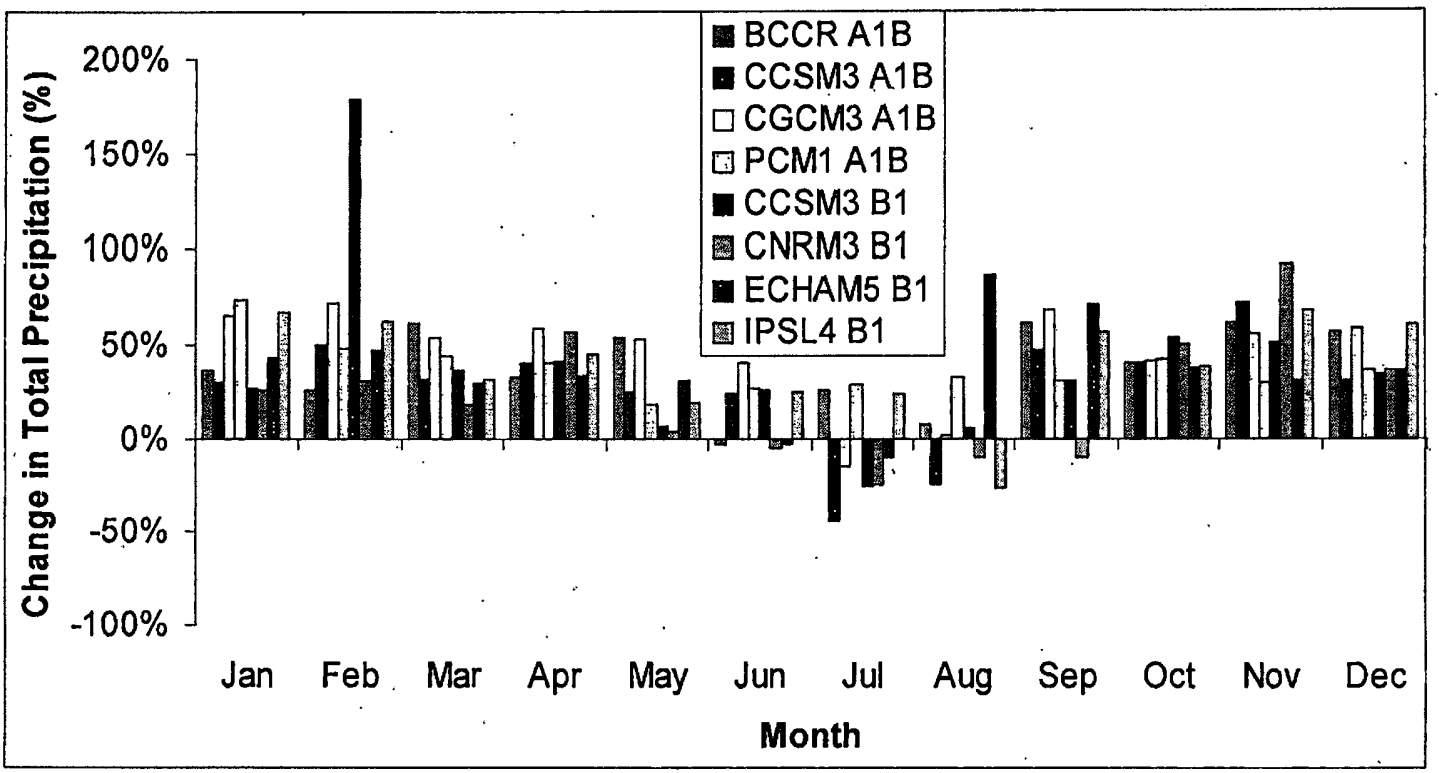

Figure 5.6: Percent change from baseline in total monthly precipitation for the 2070 s according to eight climate change scenarios.

B. Urban Development Scenarios

In order to simulate the impacts of urban development for the TRB, I used two scenarios of possible land use for the 2040s, developed by the Pacific Northwest Ecosystem Research Consortium (Figure 5.7). These took the form of thirty-meter raster layers with Anderson land cover classifications (Anderson et al. 1976). Both scenarios assume that the population of the Willamette River Basin, of which the Tualatin is a sub-basin, will grow to $3,900,000$, but the type of growth that occurs differs between the two scenarios. 

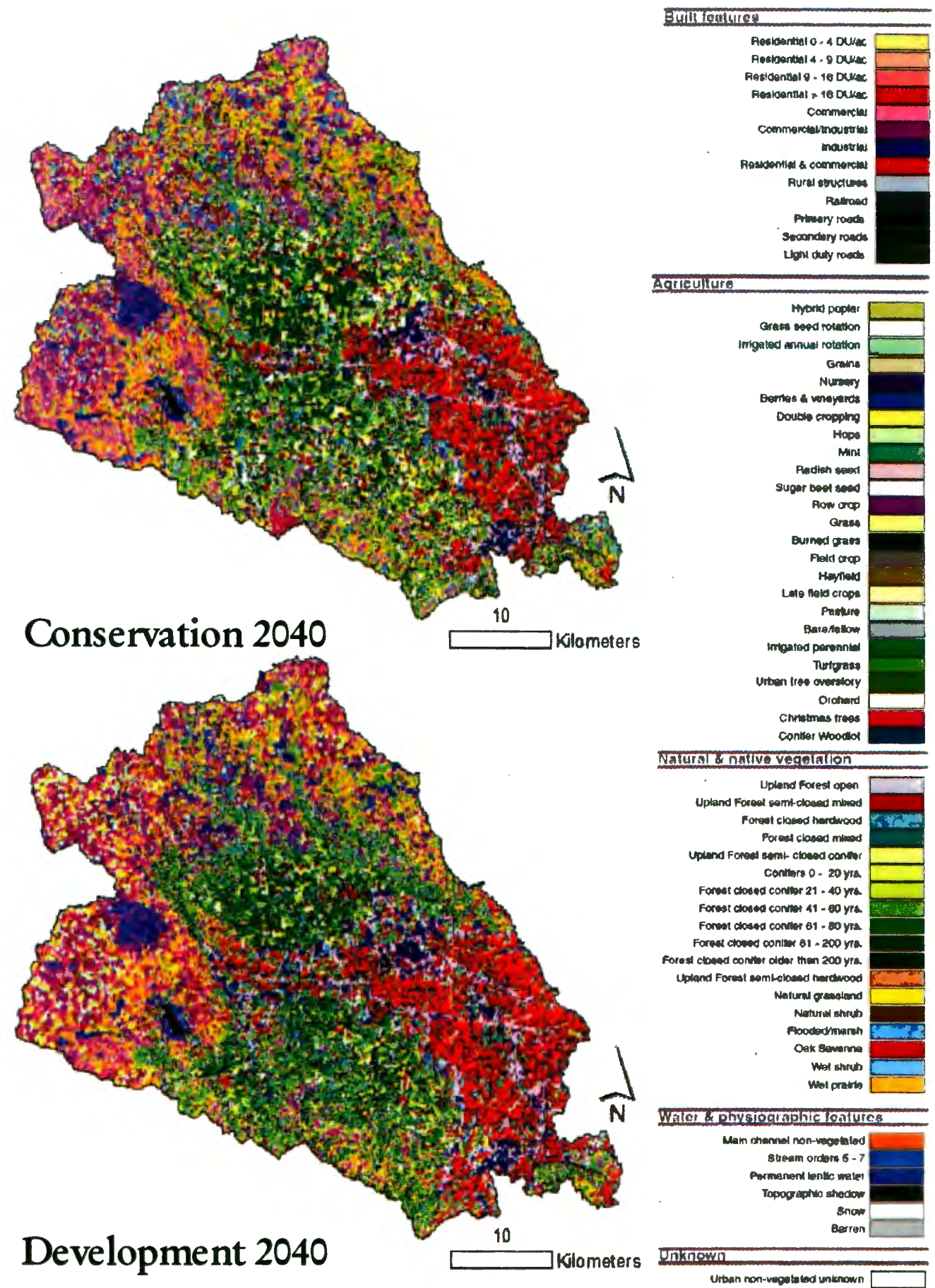

Agrreuliur:

2000

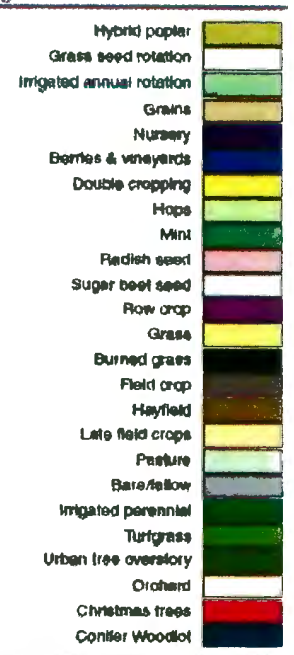

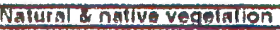
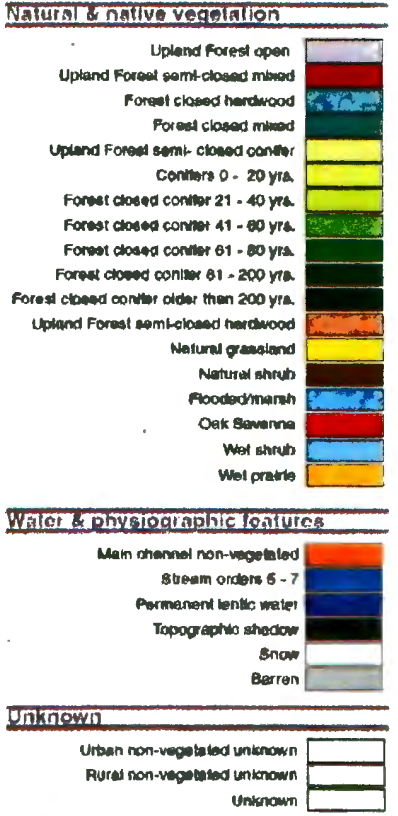

Figure 5.7: Land use/land cover in the Tualatin River Basin for the 2040s according to the Conservation and Development scenarios. 
The development scenario assumes that market-oriented solutions will dominate land use in the region. It relaxes many existing zoning regulations that protect rural areas from development and significantly expands the urban growth boundaries. In contrast, the conservation scenario assumes that the provision of ecological services will be the priority driving land use in the future. This scenario concentrates most population growth within existing urban areas, while conserving and restoring natural vegetation and wetlands. The differences between the two scenarios are illustrated in Figure 5.8, which shows that the development scenario has a higher increase in its urban area, while the conservation scenario includes a substantial increase in the water/wetland class as a result of restoration activities.

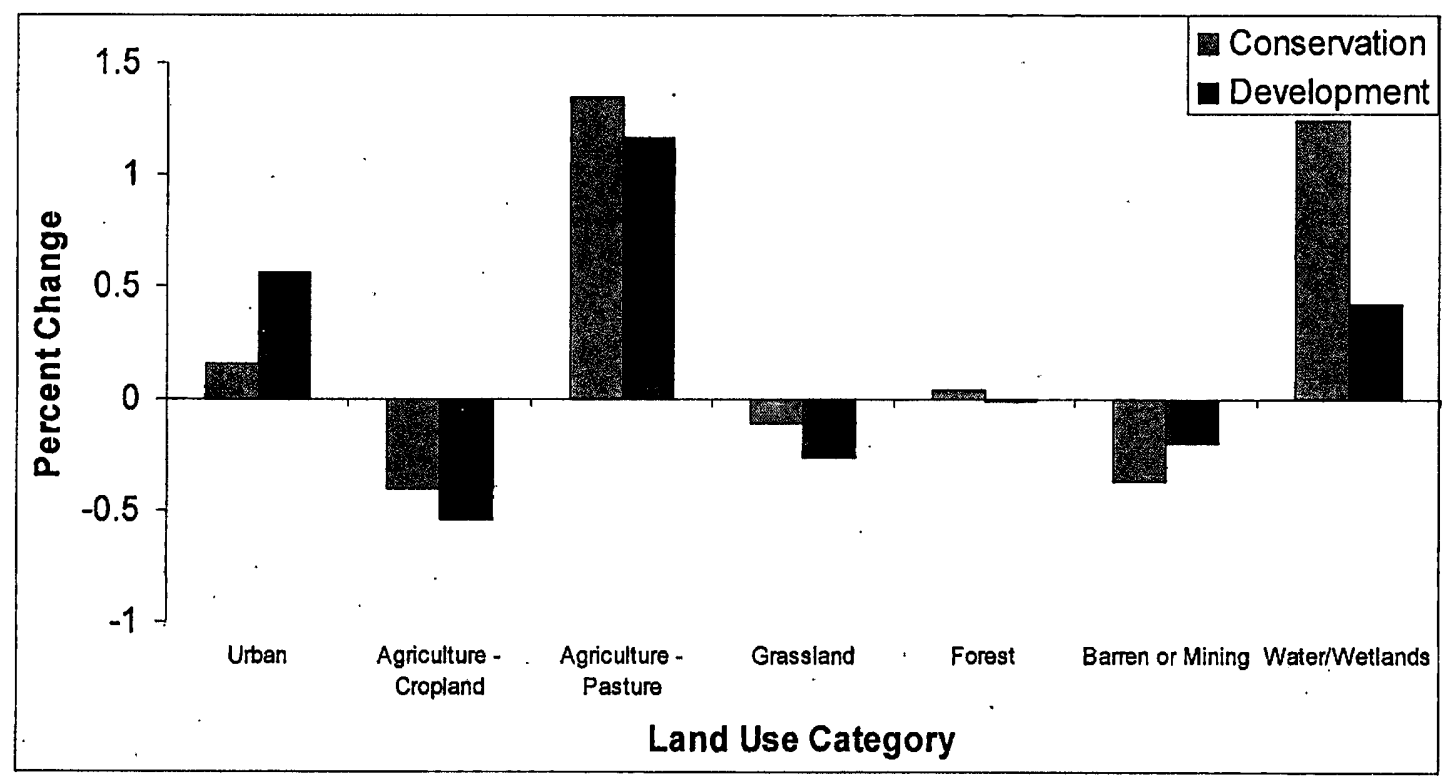

Figure 5.8: Changes from baseline in percent land use according to the two urban development scenarios.

\section{Combined Scenarios}

In addition to simulating the effects of climate change and urban development separately, I also modeled the combined impacts of these two changes. I selected the 
climate change scenario with the highest average change in basin runoff (IPSL B1, with an increase in annual runoff of sixteen percent) and the one with the lowest average runoff change (CCSM3 B1, with a decrease in annual runoff of six percent). I then ran each of these two climate change scenarios in combination with the development and conservation land use scenarios, for a total of four combined scenarios (high climate change/high land use change, high climate change/low land use change, low climate change/high land use change, and low climate change/low land use change).

\section{Model Calibration and Validation}

Hydrological models such as HSPF simulate a large number of parameters that determine the hydrological dynamics of a basin. The values of these parameters vary according to a basin's size, topography, climate, vegetation, land use, and other watershed characteristics (Sarooshian and Gupta 1995). To ensure that a hydrological model is simulating flows accurately in a particular basin, it must be calibrated and validated using observed flow data:

Several important rules guide the calibration and validation process. First, all adjustments to parameter values must have a valid physical basis, rather than being arbitrary changes that improve the model fit without regard to the basin's hydrological processes. Ignoring this rule results in models that may have a very high statistical goodness-of-fit, but do not actually capture the processes at work, and so are unlikely to yield realistic results when run under different conditions. Second, only one parameter should be adjusted at a time. It is essential to see the result of changing one 
parameter, without it being obscured by other unrelated changes. Finally, parameter values should be adjusted incrementally. This rule prevents the modeler from immediately making large changes that may be unnecessary and result in overparameterization of the model.

I ran BASINS-WinHSPF at a daily timestep for the period 1990 to 2006 at the Weiss Bridge station, near the mouth of the Tualatin River. The first year, 1990, serves as an initialization year and was not included in the evaluation of goodness-offit. I then divided the remaining modeled period (1991-2006) into two halves. The first half (1991-1998) serves as the calibration period, and the second half (1999-2006) is the validation period. Both periods contain a combination of wet, dry, and average years (Figure 5.9). I manually calibrated the model for hydrology using an iterative process, guided by USEPA (2000). To evaluate the model's goodness-of-fit, I used the coefficient of determination, or $\mathrm{R}^{2}$, one of the most commonly used statistical measures for model assessment (Węglarczyk 1998). It is based on a regression of the modeled flows on the observed flows. An $\mathrm{R}^{2}$ of 0 indicates no relationship between variables, while 1 means that the independent variable is a perfect predictor of the dependent variable. For hydrological modeling, an $\mathrm{R}^{2}$ of 0.8 has generally been accepted as the minimum for a good fit for the calibration period (Watts 1997). The appropriateness of using the coefficient of determination for model evaluation has been criticized, because this measure is sensitive to outliers and to systematic bias in the model (Legates and McCabe 1999). Accordingly, I supplemented the model evaluation by also calculating the Nash-Sutcliffe model efficiency, E, and the annual 
deviation of runoff volumes, or the percent difference between modeled and observed annual flow volume, to evaluate the model's water balance, as suggested by Watts (1997).

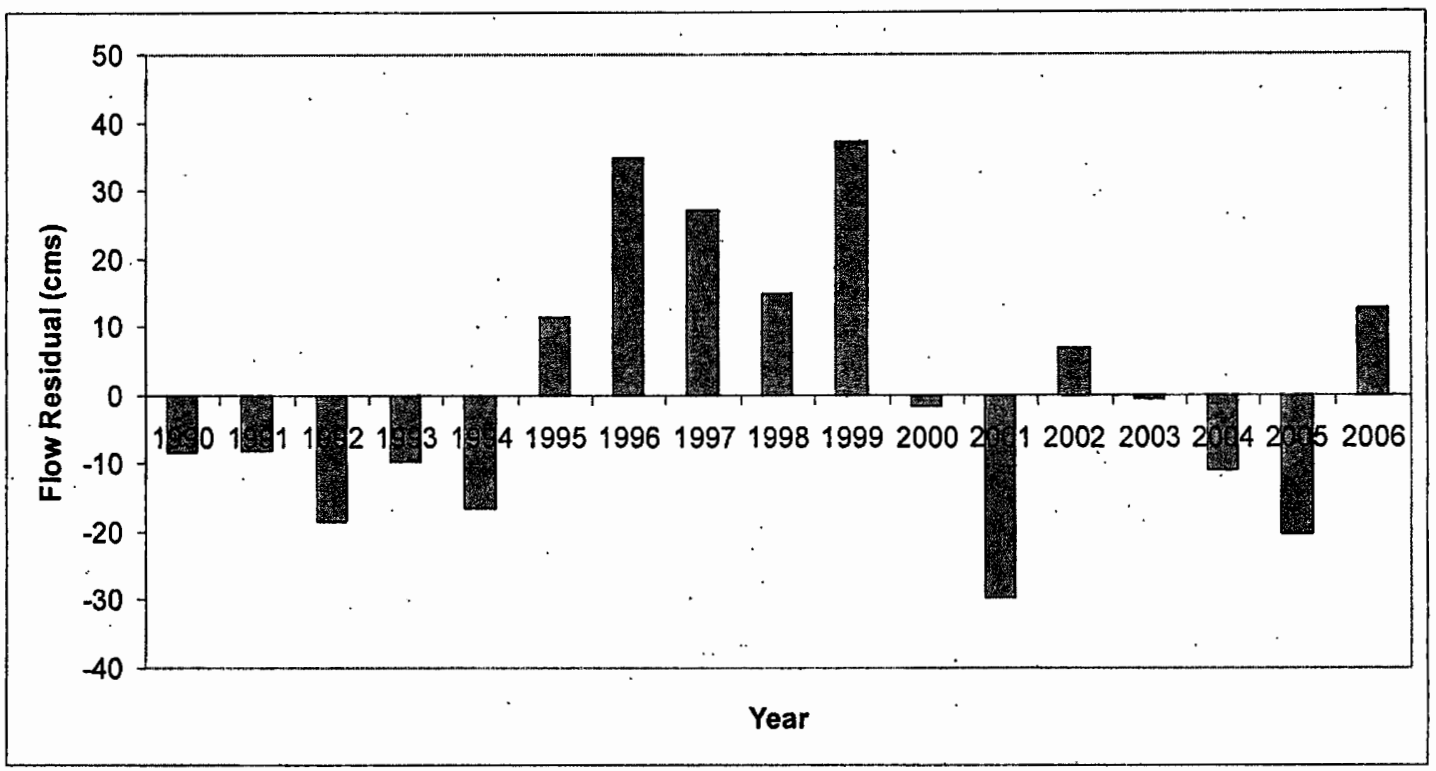

Figure 5.9: Annual average flows for the Tualatin River at West Linn (USGS site number 14207500) as departures from the mean annual flow for 1978-2007.

\section{Hydrology Calibration and Validation}

For the initial run in the calibration period (1991-1998), in which all parameters were kept at their default values, the $\mathrm{R}^{2}$ was 0.587 for the calibration period (1991-1998) and 0.578 for the validation period (1999-2006) (Figure 5.10). Figure 5.11 shows that the model overestimates peak flow in some years, while Table 5.5 indicates that the overall annual flow in the calibration period is underestimated by over nine percent. This fit is insufficient for simulating basin hydrology. 


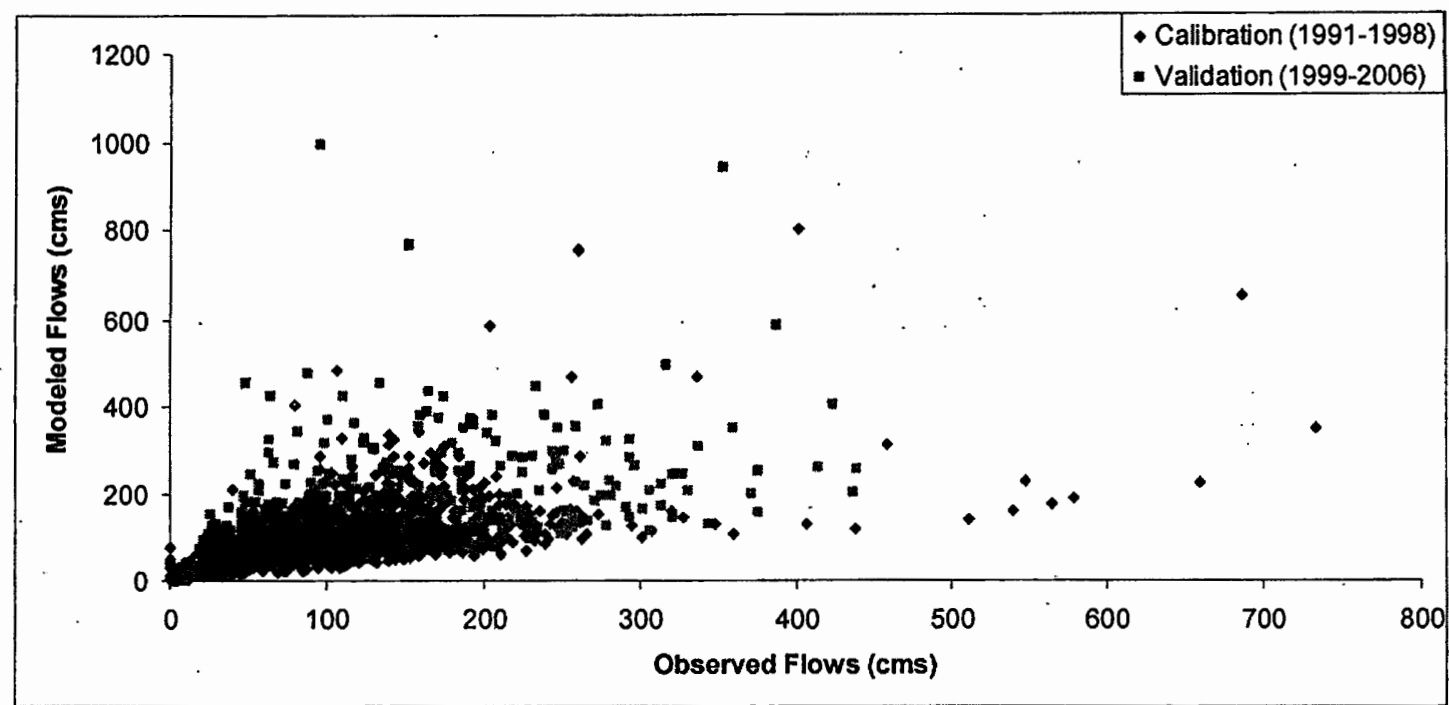

Figure 5.10: Observed flows versus modeled flows for the initial run, 1991-2006, at the Weiss Bridge site, Tualatin River.

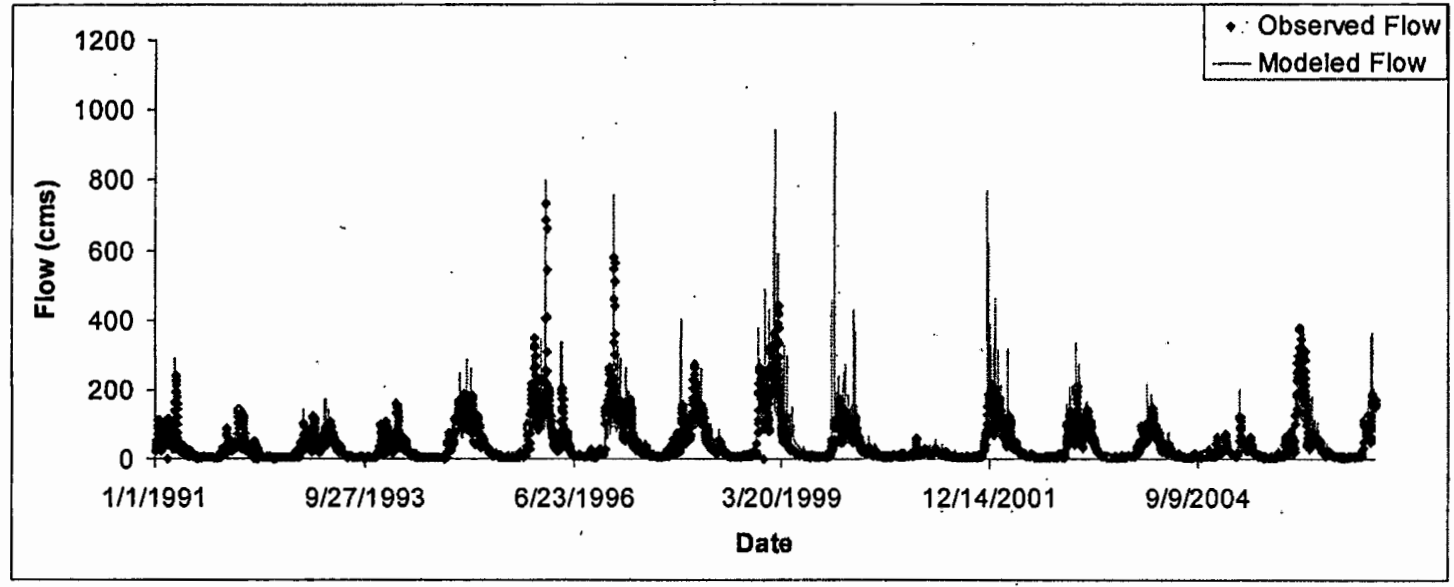

Figure 5.11: Hydrograph of observed and modeled flows for the initial run, 19912006, at the Weiss Bridge site, Tualatin River. 
Table 5.5: Observed and modeled annual flows for the initial run during the calibration period (1991-1998):

\begin{tabular}{|c|c|c|c|}
\hline Date & $\begin{array}{l}\text { Simulated Outflow (cubic } \\
\text { meters) }\end{array}$ & $\begin{array}{l}\text { Observed Outflow (cubic } \\
\text { meters) }\end{array}$ & $\begin{array}{l}\text { Percent } \\
\text { Difference }\end{array}$ \\
\hline 1991 & $860,600,280$ & $1,045,141,647$ & $-17.7 \%$ \\
\hline 1992 & $633,516,273$ & $776,970,883$ & $-18.5 \%$ \\
\hline 1993 & $1,034,644,567$ & $941,646,728$ & $9.9 \%$ \\
\hline 1994 & $713,445,896$ & $1,138,213,205$ & $-37.3 \%$ \\
\hline 1995 & $1,580,090,237$ & $1,881,451,134$ & $-16.0 \%$ \\
\hline 1996 & $2,268,373,104$ & $2,448,198,330$ & $-7.3 \%$ \\
\hline 1997 & $2,031,544,590$ & $1,952,236,257$ & $4.1 \%$ \\
\hline 1998 & $1,871,191,951$ & $1,928,013,574$ & $-2.9 \%$ \\
\hline Total & $10,993,406,899$ & $12,111,871,758$ & $-9.2 \%$ \\
\hline
\end{tabular}

To improve the goodness-of fit over the initial run, I iteratively adjusted model parameters. Table 5.6 contains the initial and final values of each parameter adjusted during the calibration process. The general intent of the calibration was to increase the overall surface flow, while reducing the magnitude of peak flows, in order to better match the observed data. I first adjusted the parameters identified as the most sensitive to calibration in USEPA (2000). This includes the lower zone nominal soil moisture storage, which is dependent on land cover type and determines the amount of water that can be held by the soil. After increase of this value, in line with the TRB soils' high silt and clay content, flashy surface runoff was decreased. Further reduction of peak flows was achieved by slightly increasing the index to infiltration capacity and interflow inflow parameter. Next, the base groundwater recession, or ratio of current groundwater flow to that from twenty-four hours before, was lowered, which had the effect of decreasing overall basin flows. The length of overland flow and Manning's $\mathrm{n}$ were increased to their maximum recommended values, to account for the surface roughness of the densely vegetated TRB. The fraction of groundwater inflow to deep recharge was reduced, thus leaving groundwater reserves in the upper 
zone to contribute to surface flow. The fraction of evapotranspiration from baseflow was reduced, forcing most evapotranspiration to come from stormflows. Finally, the interflow recession parameter was increased, making interflow behave more like baseflow than overland flow. The overall impact of these changes is to make the TRB's flows less flashy and more dependent on subsurface flow than in the initial run.

Table 5.6: Initial and final values of calibrated hydrology parameters for the Tualatin River Basin.

\begin{tabular}{|c|c|c|c|c|c|c|}
\hline Parameter & Description & $\begin{array}{l}\text { Recommended } \\
\text { Range }\end{array}$ & $\begin{array}{l}\text { Initial } \\
\text { Value }\end{array}$ & $\begin{array}{l}\text { Final } \\
\text { Value }\end{array}$ & Unit & $\begin{array}{l}\text { Effect } \\
\text { on } \\
\text { Runoff }\end{array}$ \\
\hline LZSN & $\begin{array}{l}\text { Lower zone } \\
\text { nominal soil } \\
\text { moisture storage }\end{array}$ & $3.0-8.0$ & $\begin{array}{l}4.0- \\
6.5 \\
\end{array}$ & $\begin{array}{l}6.0- \\
8.0\end{array}$ & in & $\downarrow$ \\
\hline INFILT & $\begin{array}{l}\text { Index to infiltration } \\
\text { capacity }\end{array}$ & $0.01-0.25$ & 0.16 & 0.19 & in $/ \mathrm{hr}$ & $\downarrow$ \\
\hline AGWRC. & $\begin{array}{l}\text { Base groundwater } \\
\text { recession }\end{array}$ & $0.92-0.99$ & 0.98 & 0.92 & ratio & $\downarrow$ \\
\hline INTFW & $\begin{array}{l}\text { Interflow inflow } \\
\text { parameter }\end{array}$ & $1.0-3.0$ & 0.75 & 2 & none & $\downarrow$ \\
\hline LSUR & $\begin{array}{l}\text { Length of overland } \\
\text { flow }\end{array}$ & $200-500$ & 400 & 500 & $\mathrm{ft}$ & $\downarrow$ \\
\hline DEEPFR & $\begin{array}{l}\text { Fraction of } \\
\text { groundwater inflow } \\
\text { to deep recharge }\end{array}$ & $0.0-0.2$ & 0.1 & 0 & ratio & $\uparrow$ \\
\hline BASETP & $\begin{array}{l}\text { Fraction of } \\
\text { remaining } \\
\text { evapotranspiration } \\
\text { from baseflow }\end{array}$ & $0.0-0.05$ & 0.02 & 0.01 & ratio & \\
\hline NSUR & $\begin{array}{l}\text { Manning's } n \\
\text { (roughness) for } \\
\text { overland flow }\end{array}$ & $0.015-0.035$ & 0.02 & 0.035 & none & \\
\hline IRC & $\begin{array}{l}\text { Interflow recession } \\
\text { parameter }\end{array}$ & $0.5-0.7$ & 0.5 & 0.7 & none & \\
\hline
\end{tabular}

*Note: Values of LZSN vary according to land use category.

After adjusting the model parameters as outlined in Table 5.6, I evaluated the model fit for the calibration period of 1991-1998 and found an $\mathrm{R}^{2}$ of 0.825 (Figure 5.12). Figure 5.13 shows that the problem of overestimation of peak flows has been substantially reduced. Table 5.7 indicates that the absolute error between observed 
and modeled annual flows has been reduced, so that the overall annual flow is now overestimated by approximately 3.5 percent.

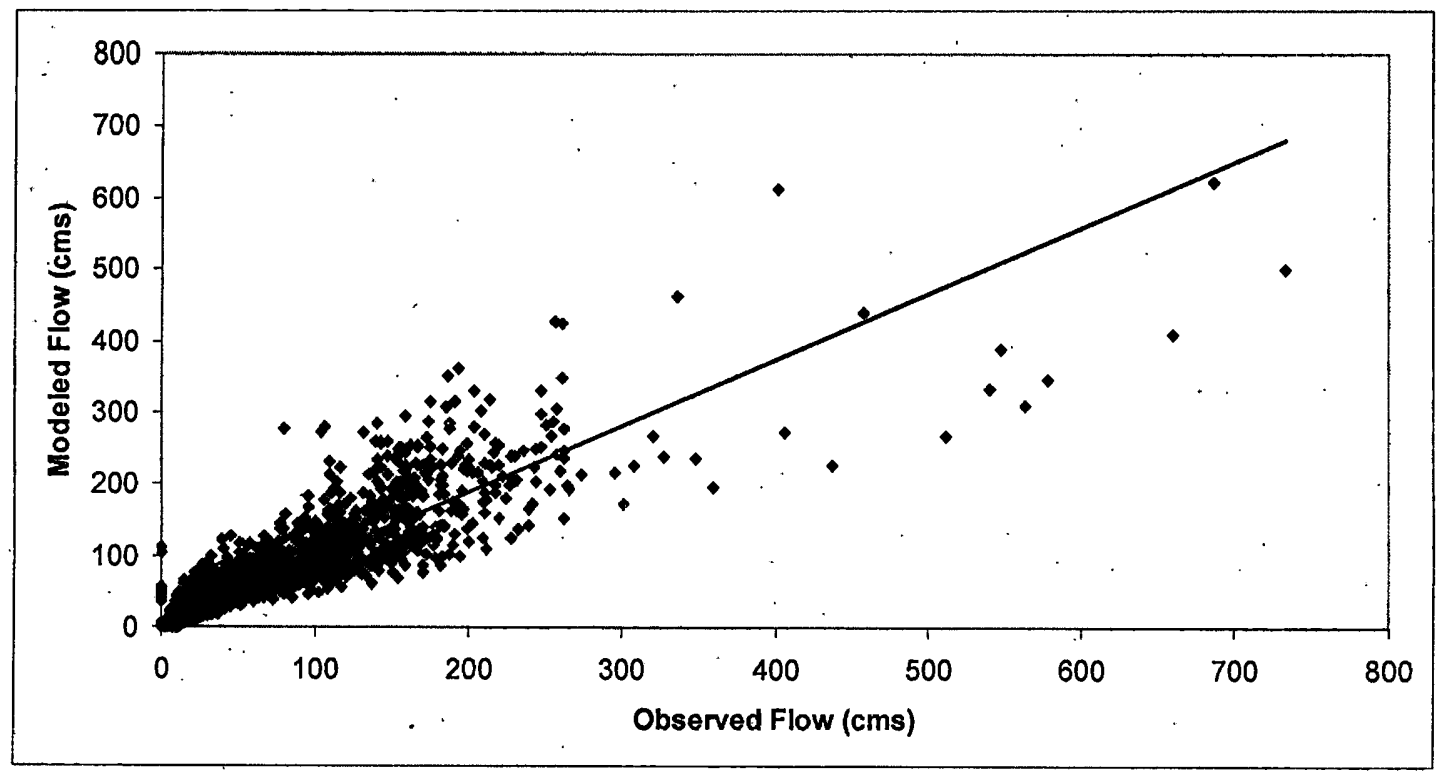

Figure 5.12: Observed versus modeled daily flows for the final run in the calibration period, 1991-1998.

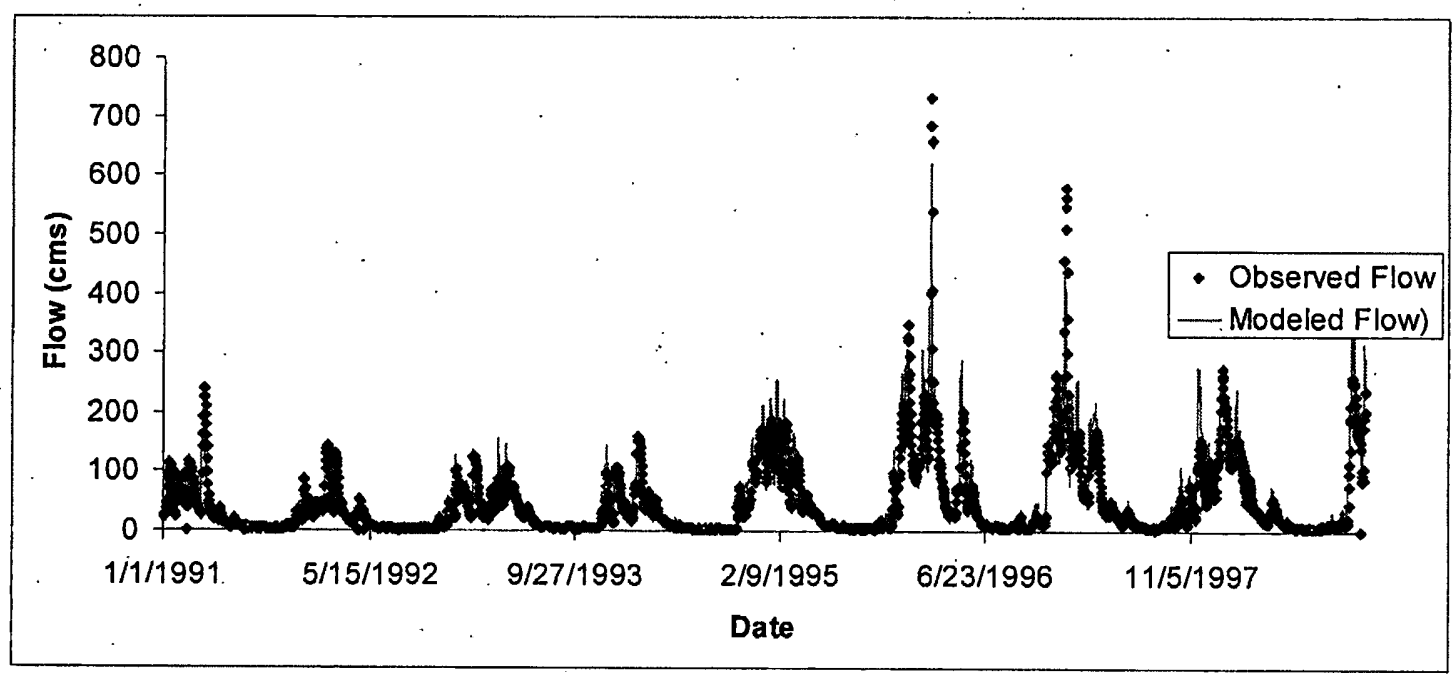

Figure 5.13: Hydrograph of observed and modeled flows for the final run in the calibration period, 1991-1998, for the Tualatin River Basin. 
Table 5.7: Modeled and observed annual flows for the final run during the calibration period (1991-1998).

\begin{tabular}{|c|r|r|r|}
\hline Date & $\begin{array}{l}\text { Simulated Outflow (cubic } \\
\text { meters) }\end{array}$ & $\begin{array}{l}\text { Observed Outflow (cubic } \\
\text { meters) }\end{array}$ & $\begin{array}{l}\text { Percent } \\
\text { Difference }\end{array}$ \\
\hline 1991 & $912,159,821$ & $1,045,141,647$ & $-12.7 \%$ \\
\hline 1992 & $824,705,958$ & $776,970,883$ & $6.1 \%$ \\
\hline 1993 & $1,024,406,668$ & $941,646,728$ & $8.8 \%$ \\
\hline 1994 & $1,149,728,423$ & $1,138,213,205$ & $1.0 \%$ \\
\hline 1995 & $1,883,526,770$ & $1,881,451,134$ & $0.1 \%$ \\
\hline 1996 & $2,526,170,808$ & $2,448,198,330$ & $3.2 \%$ \\
\hline 1997 & $2,064,848,600$ & $1,952,236,257$ & $5.8 \%$ \\
\hline 1998 & $2,147,491,883$ & $1,928,013,574$ & $11.4 \%$ \\
\hline Total & $12,533,038,932$ & $12,111,871,758$ & $3.5 \%$ \\
\hline
\end{tabular}

During the final run, the calibrated model had an $\mathrm{R}^{2}$ of 0.761 for the validation period (1999-2006) (Figure 5.14). Figure 5.15 shows that the model continues to overestimate peak flows during the validation period. The observed and modeled values are much closer to one another during moderate and low flows.

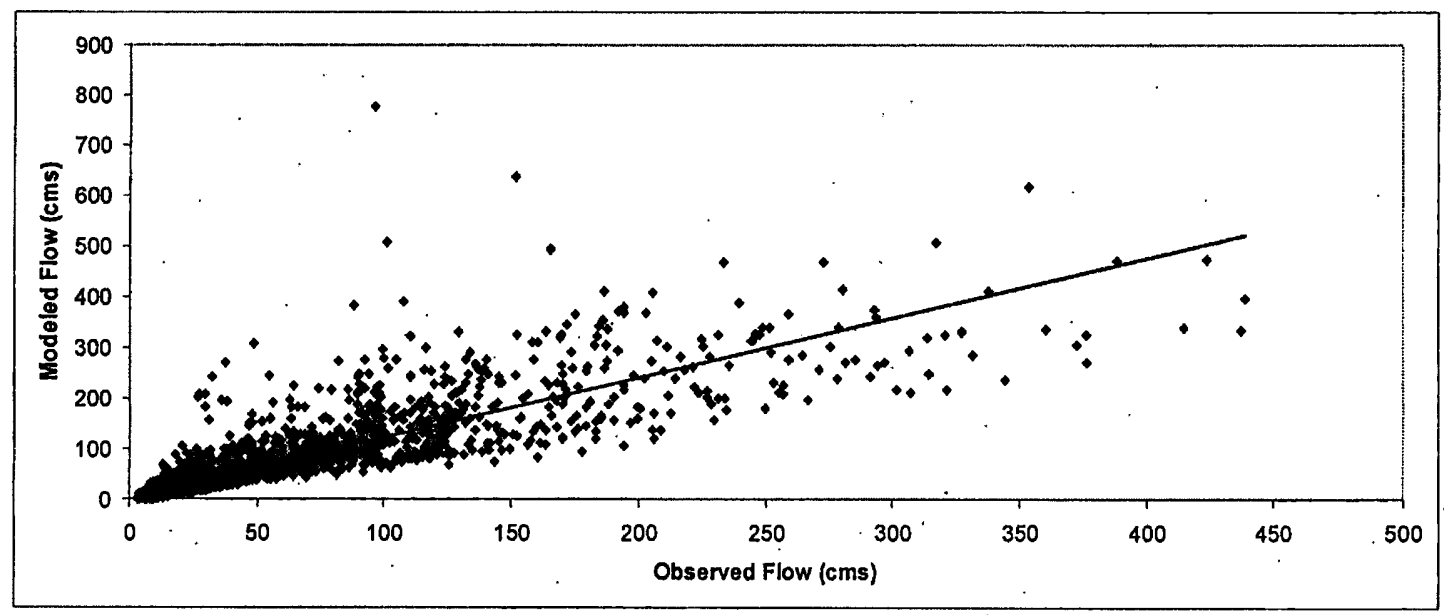

Figure 5.14: Observed versus modeled daily flows for the final run in the validation period, 1999-2006: 


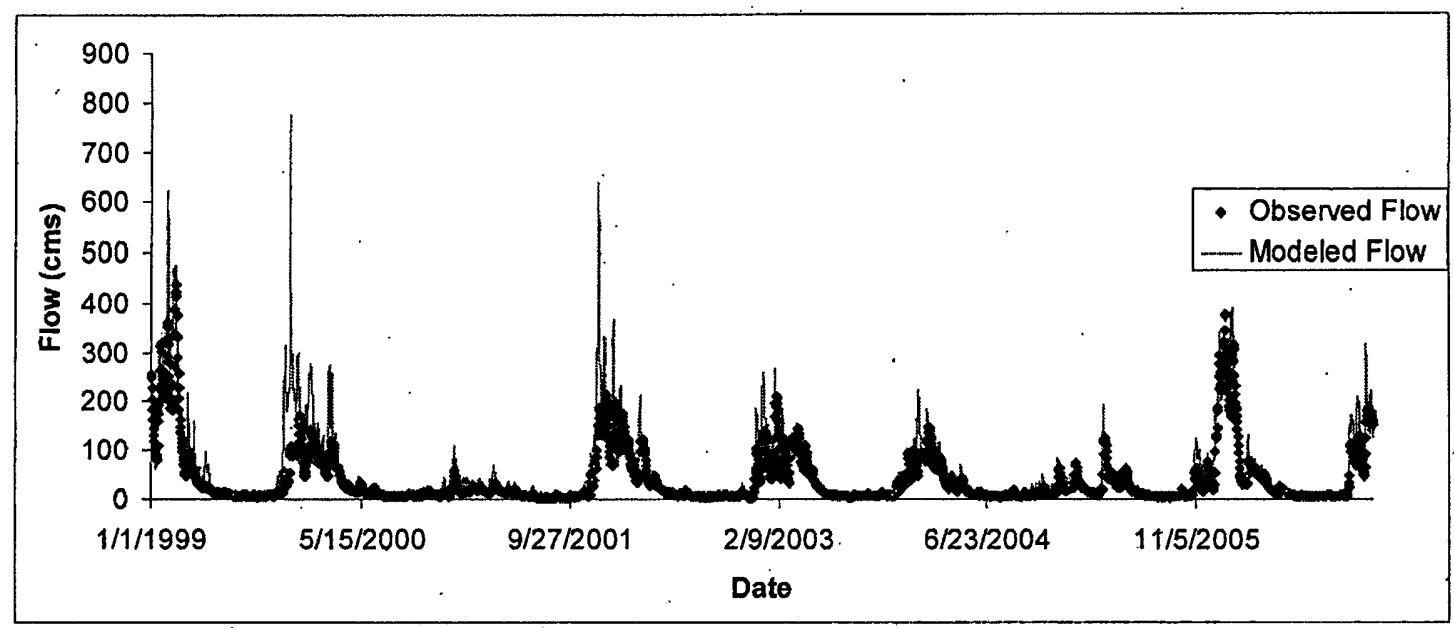

Figure 5.15: Hydrograph of observed and modeled flows during the final run in the validation period, 1999-2006, for the Tualatin River Basin.

The model performance improved significantly between the initial and final runs as a result of parameter adjustments made during calibration (Table 5.8). The annual hydrograph of the observed and modeled flow shows close agreement in most months, although the model overestimates winter flow (Figure 5.16). There is a lag in observed peak flow of about one month compared to modeled flow, a reflection of the model's tendency to overestimate the flashiness of basin runoff. Given the relatively high final $\mathrm{R}^{2}$ values, the model can be considered sufficiently calibrated. Accordingly, there are grounds for reasonable confidence in the accuracy of the model.

Table 5.8: Comparison of hydrology model evaluation parameters between the initial and final runs for the calibration (1991-1998) and validation (1999-2006) periods for the Tualatin River Basin.

\begin{tabular}{|l|c|c|c|c|}
\hline Run & Calibration $\mathrm{R}^{2}$ & Calibration E & Validation $\mathrm{R}^{2}$ & Validation E \\
\hline $\begin{array}{l}\text { Initial } \\
\text { Daily }\end{array}$ & 0.587 & 0.72 & 0.578 & 0.36 \\
\hline $\begin{array}{l}\text { Final } \\
\text { Daily }\end{array}$ & 0.825 & 0.81 & 0.761 & 0.49 \\
\hline $\begin{array}{l}\text { Final } \\
\text { Monthly }\end{array}$ & 0.942 & 0.94 & 0.878 & 0.65 \\
\hline
\end{tabular}




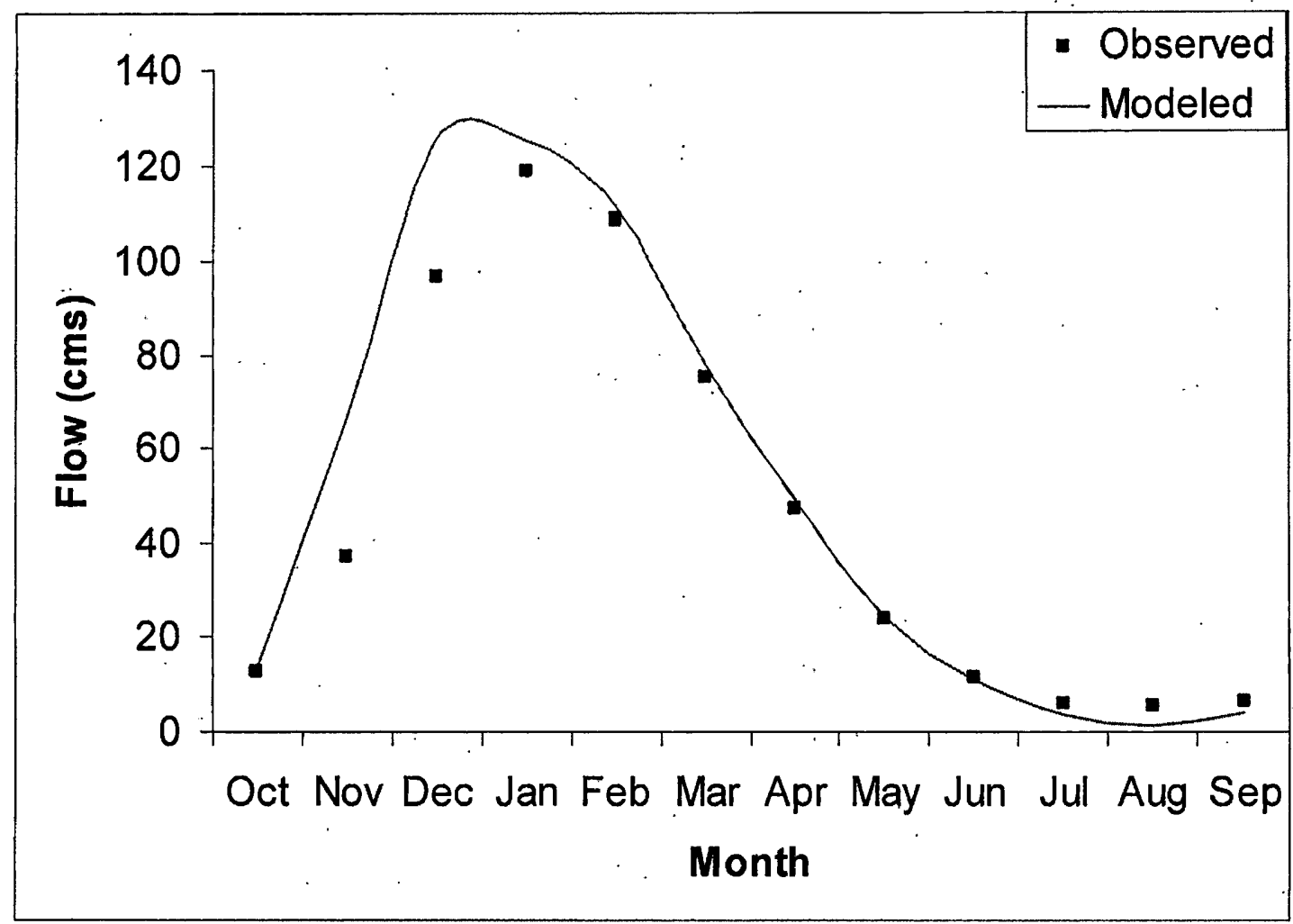

Figure 5.16: Annual hydrograph of average monthly observed and simulated flow for the entire period of observation (1990-2006).

In addition to modeling impacts of climate change and urban development for the entire TRB, I also modeled changes in hydrology resulting from the land use change scenarios for two sub-basins. The reason for the sub-basin modeling is that land use may have more localized effects than climate change, particularly if the subbasin in question passes some threshold level of urban development, which is why I examined sub-basin impacts only for urban development. I selected the two subbasins, the Upper Tualatin River above Springhill Road (CWS site \#3701612) and the tributary Rock Creek (CWS site \#3820012), based on their availability of observed data for calibration and validation purposes and the diversity in their current land use, which may determine their hydrologic sensitivity to future land use change. The 
Upper Tualatin sub-basin is predominantly forested (Figure 5.17), while the Rock

Creek sub-basin is highly urbanized (Figure 5.18).

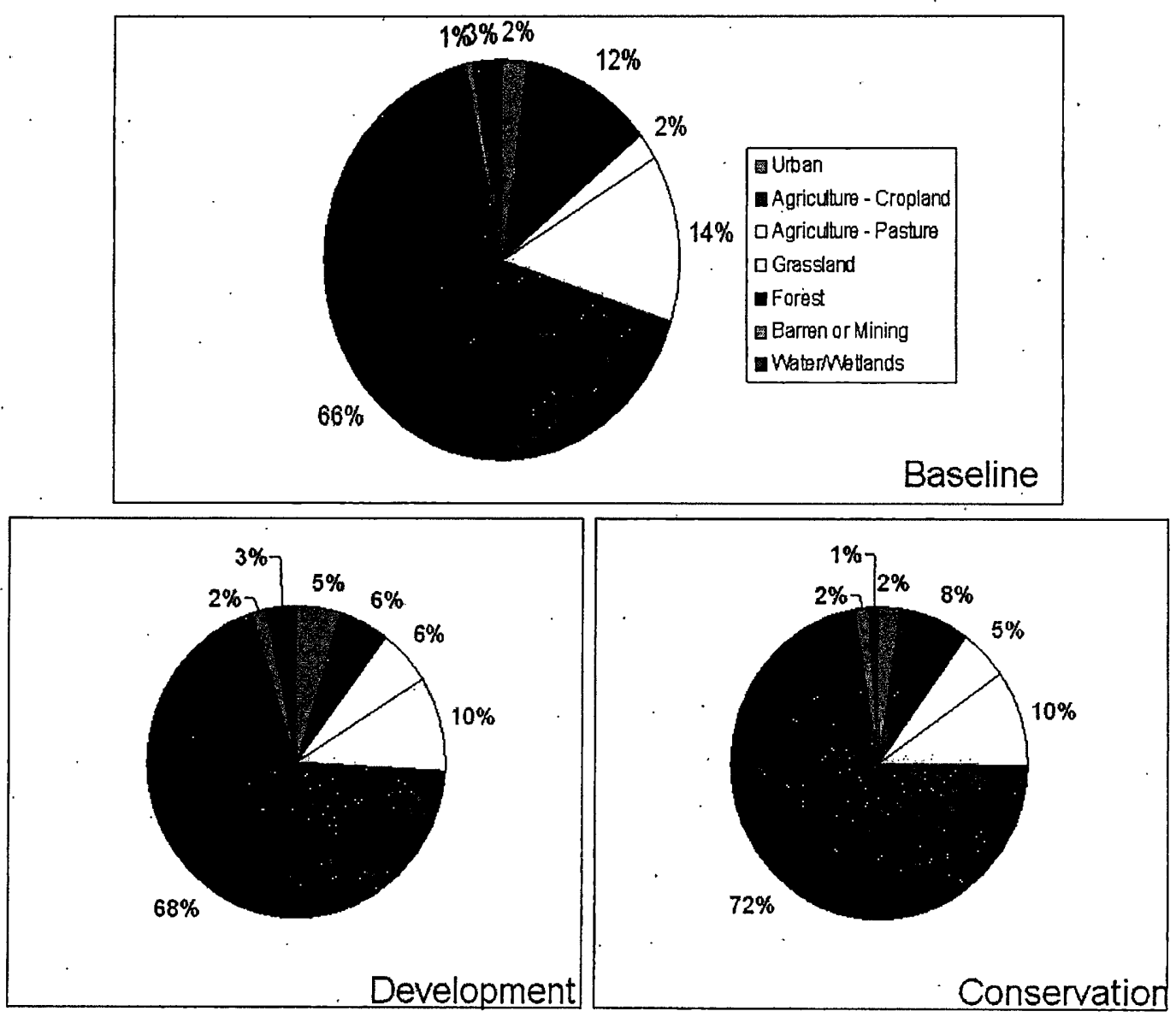

Figure 5.17: Land use in the Upper Tualatin River sub-basin for the baseline, development, and conservation scenarios. 

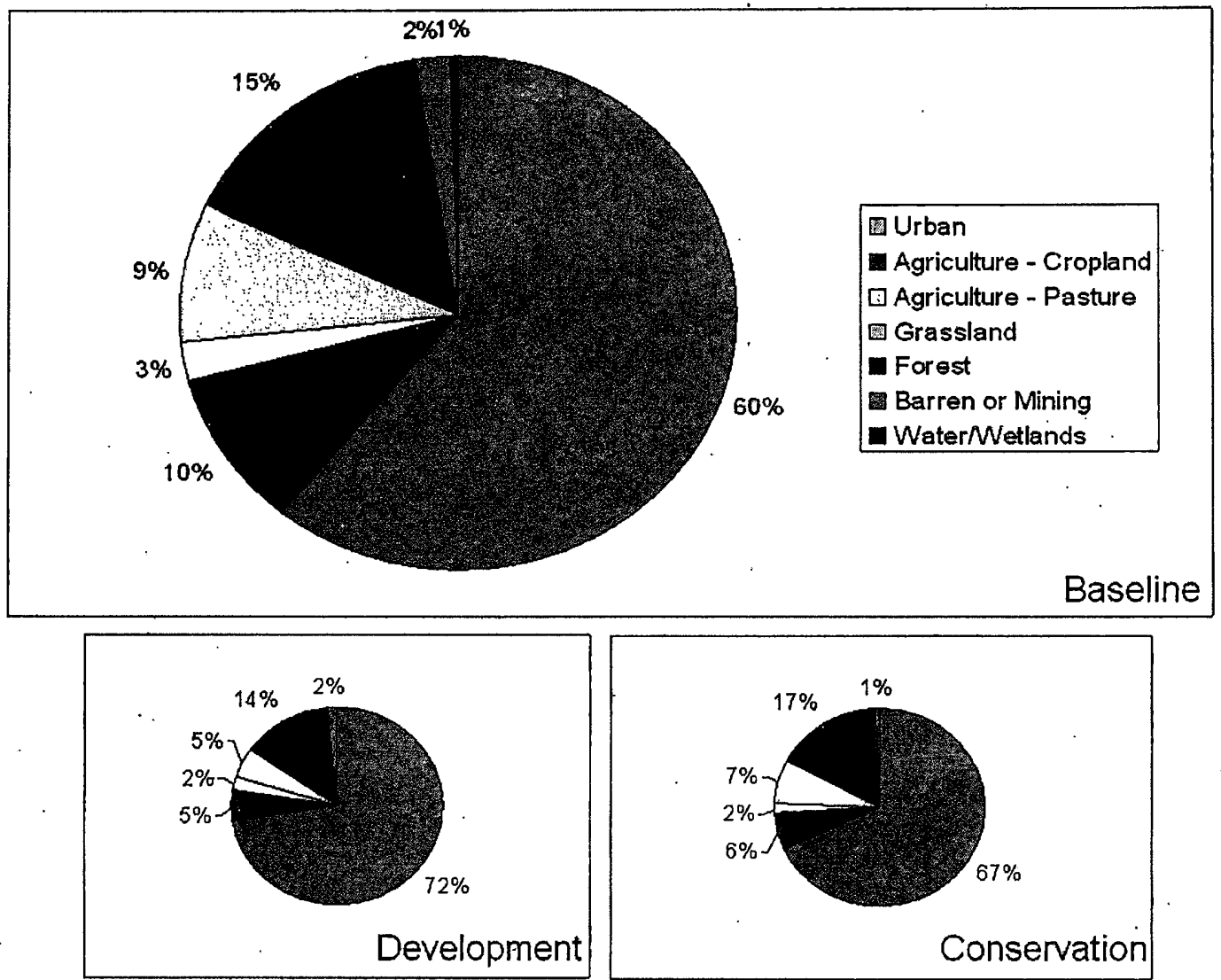

Figure 5.18: Land use in the Rock Creek sub-basin under the baseline, development, and conservation scenarios.

Because of a large number of missing values in the earlier part of the Rock Creek observed dataset, I used a calibration period of 2003-2004 and a validation period of 2005-2006, while using the same calibration (1991-1998) and validation (1999-2006) periods for the Upper Tualatin as for the main basin-scale model. I calibrated the two sub-basins' hydrologic models separately and found that the Rock Creek model had the best fit when parameters were the same as for the main TRB hydrology model. The Upper Tualatin River hydrology model calibration parameters are shown in Table 5.9. 
Table 5.9: Initial and final values of calibrated hydrology parameters for the Upper Tualatin River sub-basin.

\begin{tabular}{|l|l|l|r|r|r|r|}
\hline Parameter & Description & $\begin{array}{l}\text { Recommended } \\
\text { Range }\end{array}$ & $\begin{array}{l}\text { Initial } \\
\text { Value }\end{array}$ & $\begin{array}{l}\text { Final } \\
\text { Value }\end{array}$ & Unit & $\begin{array}{l}\text { Effect } \\
\text { on } \\
\text { Runoff }\end{array}$ \\
\hline INFILT & $\begin{array}{l}\text { Index to infiltration } \\
\text { capacity }\end{array}$ & $0.01-0.25$ & 0.16 & 0.17 & in/hr & $\downarrow$ \\
\hline AGWRC & $\begin{array}{l}\text { Base groundwater } \\
\text { recession }\end{array}$ & $0.92-0.99$ & 0.98 & 0.92 & ratio & $\downarrow$ \\
\hline INTFW & $\begin{array}{l}\text { Interflow inflow } \\
\text { parameter }\end{array}$ & $1.0-3.0$ & 0.75 & 2 & none & $\downarrow$ \\
\hline DEEPFR & $\begin{array}{l}\text { Fraction of } \\
\text { groundwater inflow } \\
\text { to deep recharge }\end{array}$ & $0.0-0.2$ & 0.1 & 0 & ratio & $\uparrow$ \\
\hline NSUR & $\begin{array}{l}\text { Manning's } \\
\text { (roughness) for } \\
\text { overland flow }\end{array}$ & $0.015-0.035$ & 0.02 & 0.035 & none & $\downarrow$ \\
\hline IRC & $\begin{array}{l}\text { Interflow recession } \\
\text { parameter }\end{array}$ & $0.5-0.7$ & 0.5 & 0.7 & none & $\downarrow$ \\
\hline
\end{tabular}

The Upper Tualatin model somewhat underestimates peak flows in the calibration (Figure 5.19) and validation (Figure 5.20) periods, probably because of the sub-basin's higher elevation, but the overall fit is reasonable (Table 5.10). The Rock Creek model, meanwhile, has a lower but still sufficient fit in the calibration period (Figure 5.21), with some missing observed data in the winter of 2006 during the validation period (Figure 5.22), but an adequate overall fit nonetheless (Table 5.11). The Rock Creek model somewhat overestimates peak flows, probably because of the sub-basin's high amount of urban land, which is uniformly modeled as impervious surface area, despite the existence of bioswales, permeable pavement, and other sustainable stormwater management techniques. Given the fit of these models, there are grounds for reasonable confidence in the accuracy of the modeling results at the sub-basin scale, although not as much as for the basin-scale model, because of the lower fit and relative scarcity of observed data. 


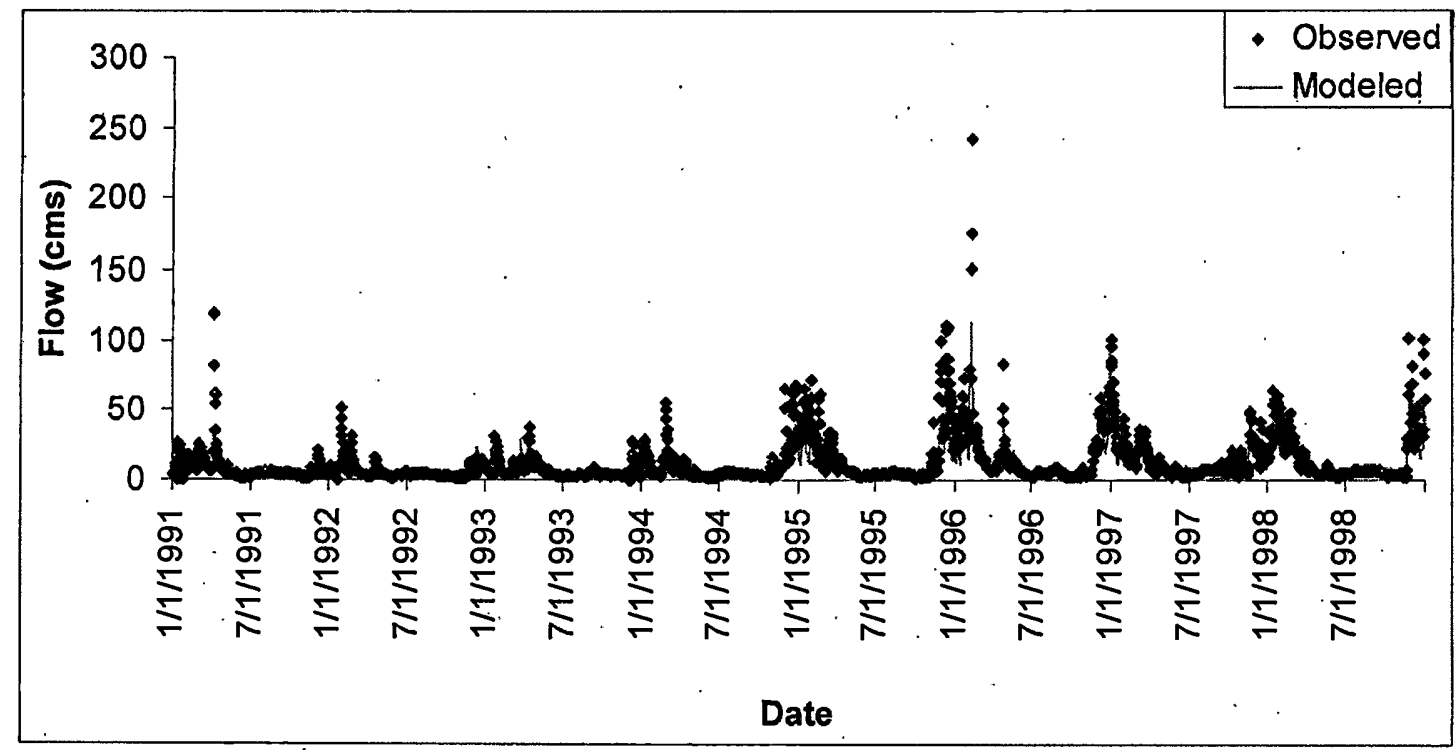

Figure 5.19: Hydrograph of observed and modeled flows for the final run in the calibration period, 1991-1998, for the Upper Tualatin River sub-basin.

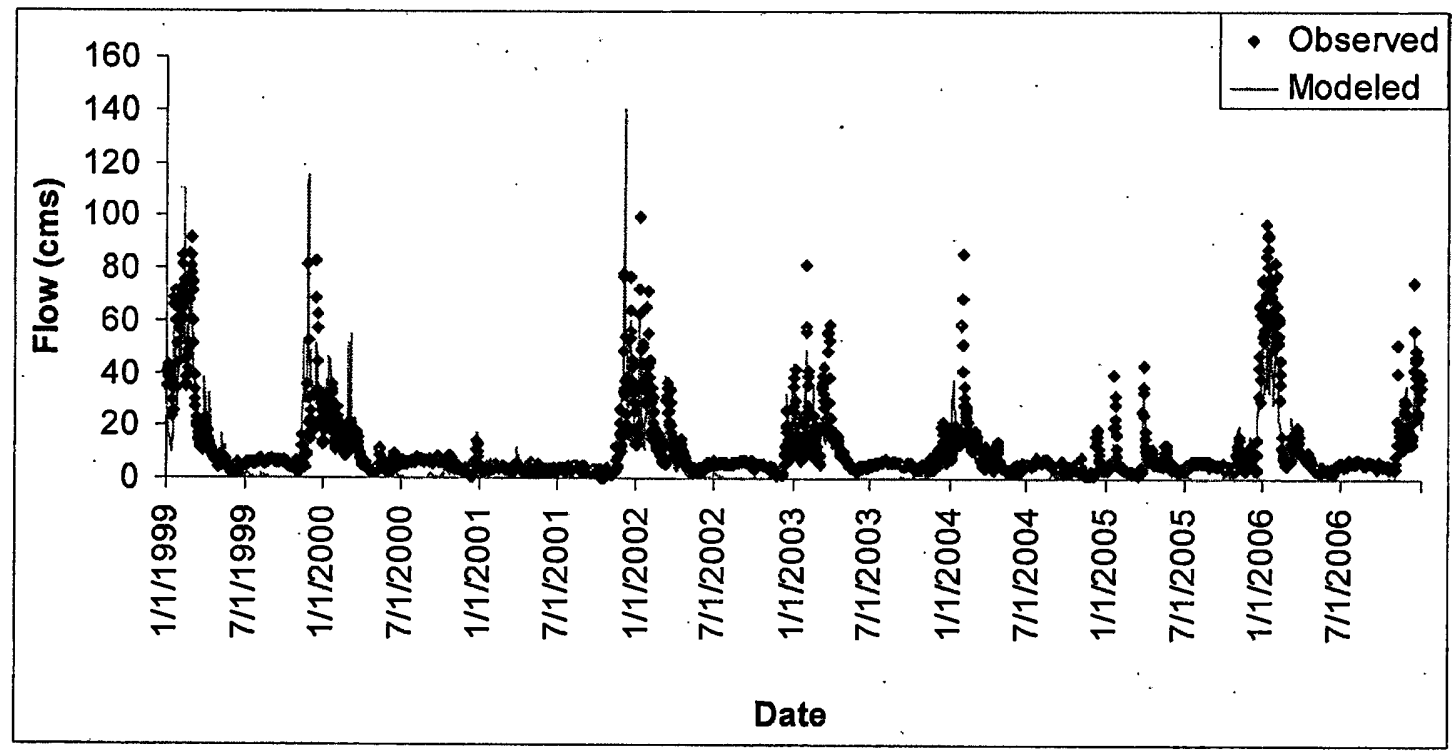

Figure 5.20: Hydrograph of observed and modeled flows for the final run in the validation period, 1999-2006, for the Upper Tualatin River sub-basin.

Table 5.10: Hydrology model evaluation parameters for the calibration (19911998) and validation (1999-2006) periods for the Upper Tualatin River sub-basin.

\begin{tabular}{|l|r|r|r|r|}
\hline Period & Daily R & Daily E & Monthly $\mathrm{R}^{2}$ & Monthly E \\
\hline Calibration & 0.79 & 0.70 & 0.89 & 0.77 \\
\hline Validation & 0.72 & 0.69 & 0.82 & 0.78 \\
\hline
\end{tabular}




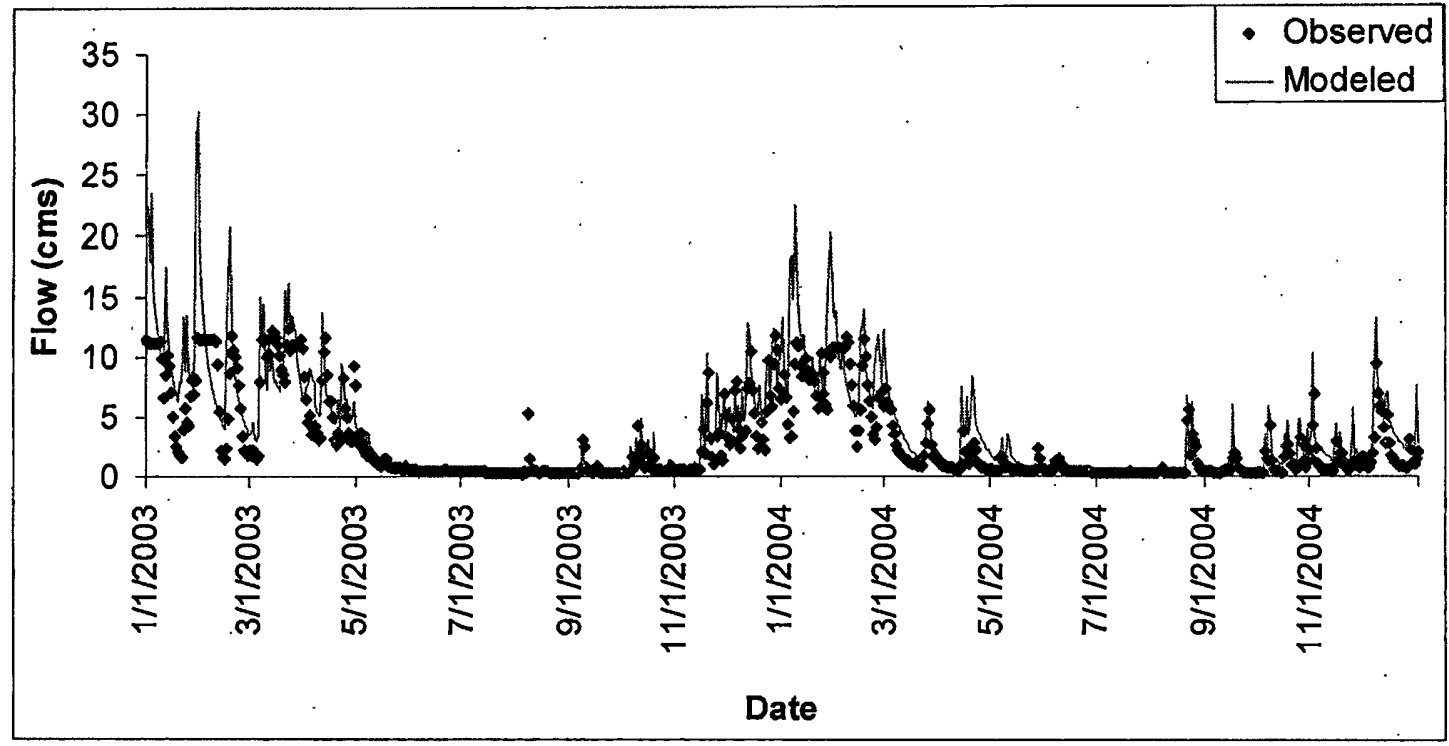

Figure 5.21: Hydrograph of observed and modeled flows for the final run in the calibration period (2003-2004), for the Rock Creek sub-basin.

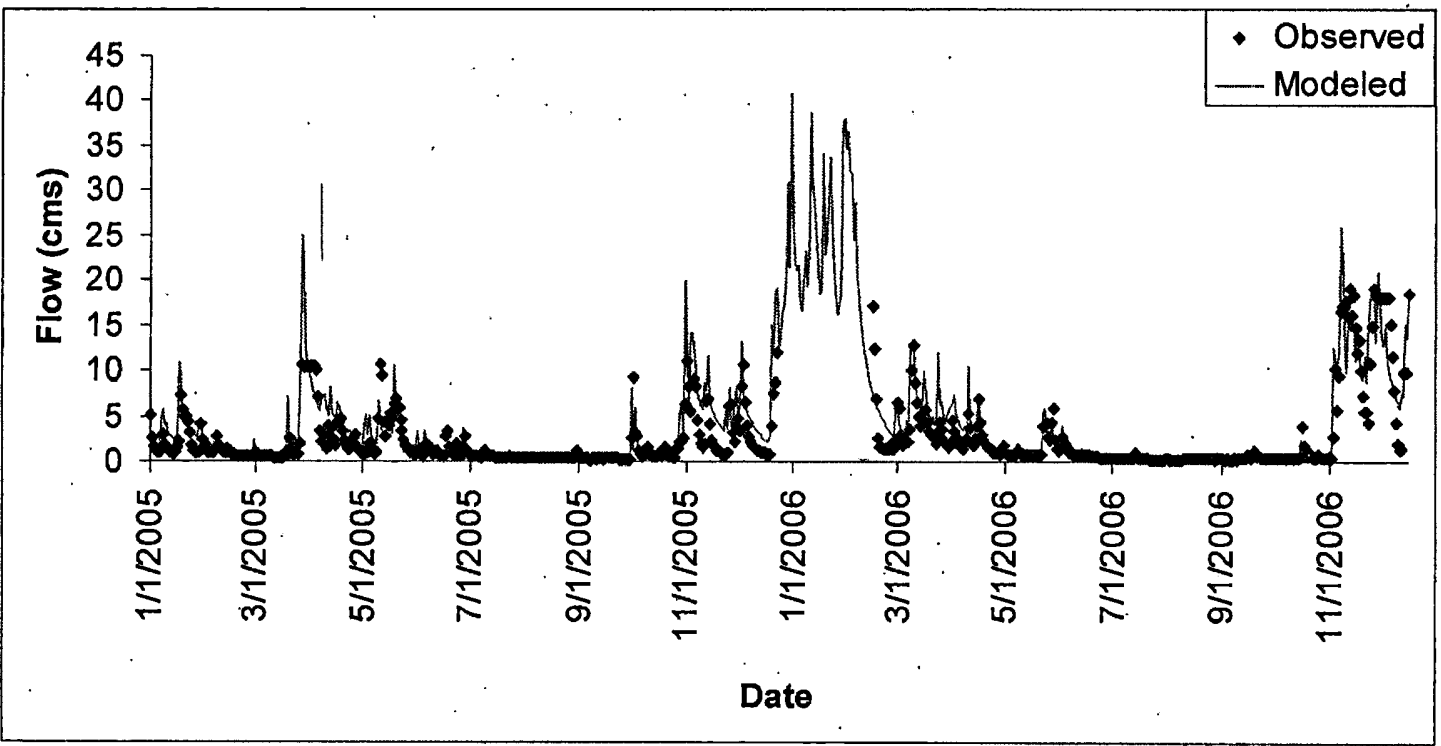

Figure 5.22: Hydrograph of observed and modeled flows for the final run in the validation period (2005-2006), for the Rock Creek sub-basin.

Table 5.11: Hydrology model evaluation parameters for the calibration (20032004) and validation (2005-2006) periods for the Rock Creek sub-basin.

\begin{tabular}{|c|c|c|c|c|}
\hline Period & Daily $\mathrm{R}^{2}$ & Daily E & $\begin{array}{l}\text { Monthly } \\
R^{2}\end{array}$ & $\begin{array}{l}\text { Monthly } \\
\text { E }\end{array}$ \\
\hline & 0.70 & 0.40 & 0.92 & 0.69 \\
\hline Validation & 0.75 & 0.34 & 0.94 & 0.84 \\
\hline
\end{tabular}




\section{Sediment Calibration and Validation}

I used a similar procedure to calibrate the sediment model as that used for hydrology. Table 5.12 shows the parameters adjusted during the calibration process. The major adjustments made were to the coefficient and exponent in the soil detachment equation, the daily reduction in detached sediment, the exponent in the sediment washoff equation, and the fraction of solids removed per day from impervious surfaces.

Table 5.12: Initial and final values of calibrated sediment parameters.

\begin{tabular}{|c|c|c|c|c|c|c|}
\hline Parameter & Description & Recommended Range & Initial Value & $\begin{array}{l}\text { Final } \\
\text { Value }\end{array}$ & Unit & $\begin{array}{l}\text { Effect } \\
\text { on } \\
\text { Load }\end{array}$ \\
\hline KRER & $\begin{array}{l}\text { Coefficient } \\
\text { in the soil } \\
\text { detachment } \\
\text { equation }\end{array}$ & $0.15-0.45$ & 0.325 & 0.15 & none & $\downarrow$ \\
\hline JRER & $\begin{array}{l}\text { Exponent } \\
\text { in the soil } \\
\text { detachment } \\
\text { equation }\end{array}$ & $1.5-2.5$ & 2 & 2.5 & none & $\uparrow$ \\
\hline AFFIX & $\begin{array}{l}\text { Daily } \\
\text { reduction in } \\
\text { detached } \\
\text { sediment }\end{array}$ & $0.03-0.1$ & 0.03 & 0.1 & ratio & 1 \\
\hline JSER & $\begin{array}{l}\text { Exponent } \\
\text { in the } \\
\text { sediment } \\
\text { washoff } \\
\text { equation }\end{array}$ & $1.5-2.5$ & 2 & 2.5 & none & $\uparrow$ \\
\hline REMSDP & $\begin{array}{l}\text { Fraction of } \\
\text { solids } \\
\text { removed } \\
\text { per day }\end{array}$ & $0.03-0.2$ & 0.03 & 0.2 & ratio & $\uparrow$ \\
\hline
\end{tabular}

After parameter adjustment, the final model fit in the calibration period was an $\mathrm{R}^{2}$ of approximately 0.72 (Figure 5.23). While the model fit is good for the lower amounts of sediment, the peak loadings are somewhat overestimated (Figure 5.24). This 
deficiency in the model is likely the result of the similar overestimation of peak flows in the hydrology model.

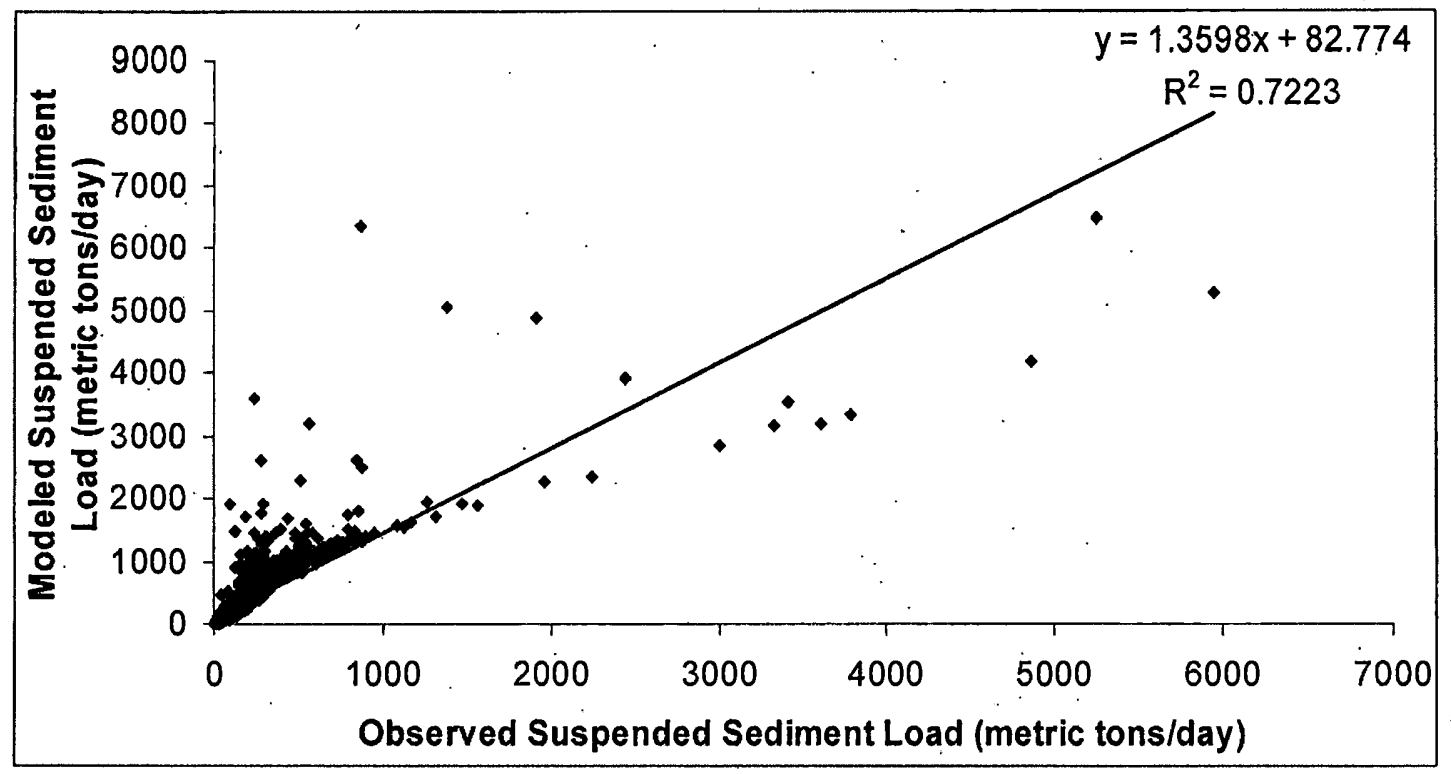

Figure 5.23: Observed versus modeled suspended sediment load for the final run in the calibration period, 1991-1998.

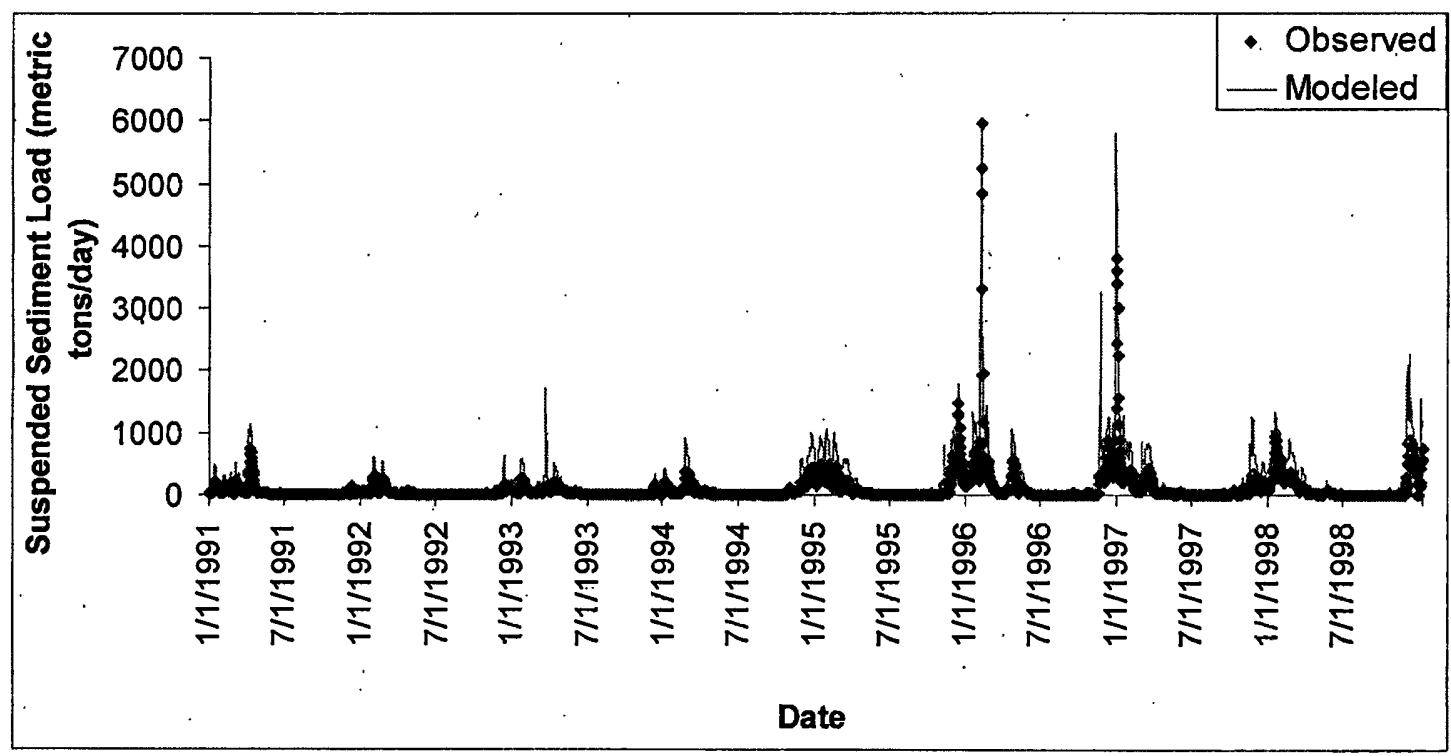

Figure 5.24: Time series of observed and modeled suspended sediment loads for the final run in the calibration period, 1991-1998. 
The $\mathrm{R}^{2}$ for the final run in the validation period was approximately 0.55

(Figure 5.25). This is lower than for the calibration period, as expected. The overestimation of peak loading is more severe for the validation period (Figure 5.26).

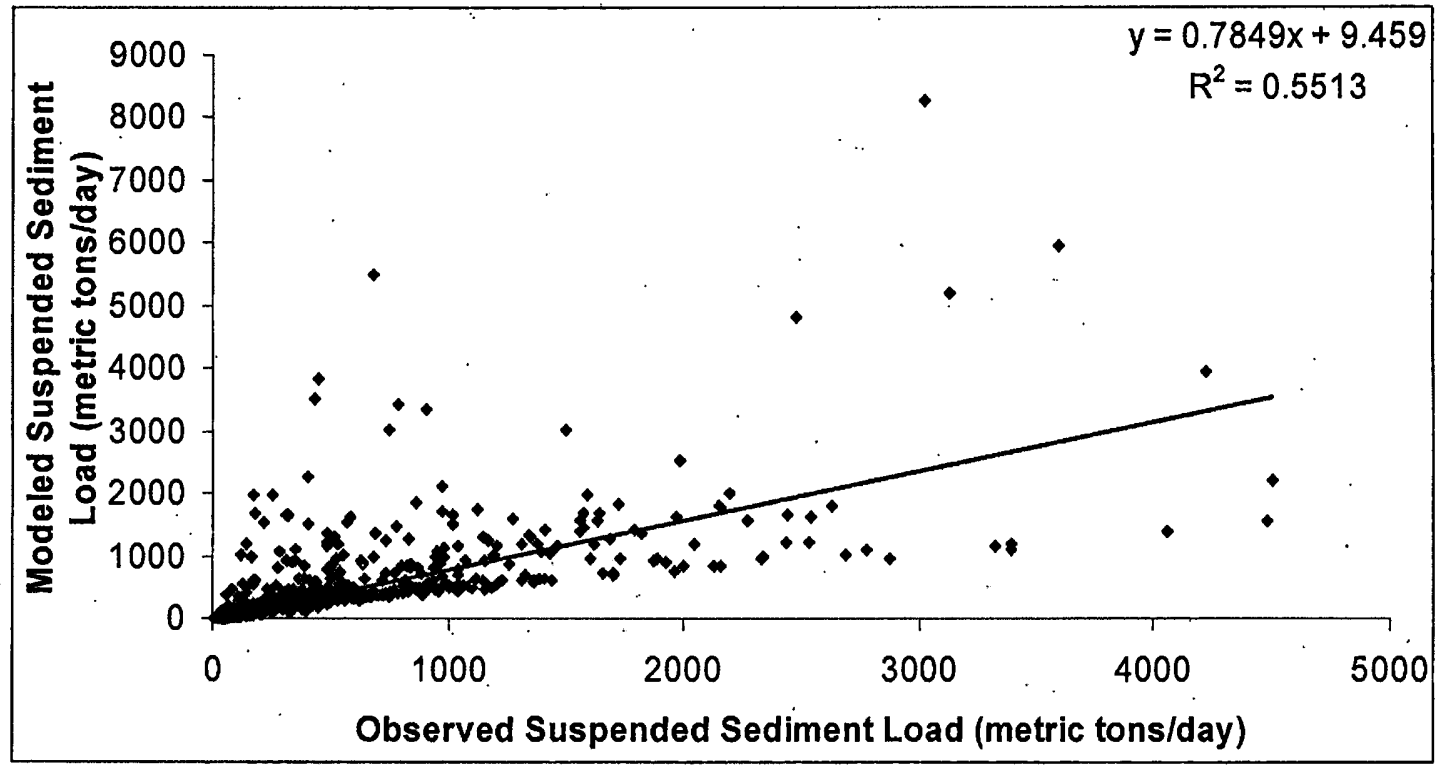

Figure 5.25: Observed versus modeled suspended sediment load for the final run in the validation period, 1999-2006.

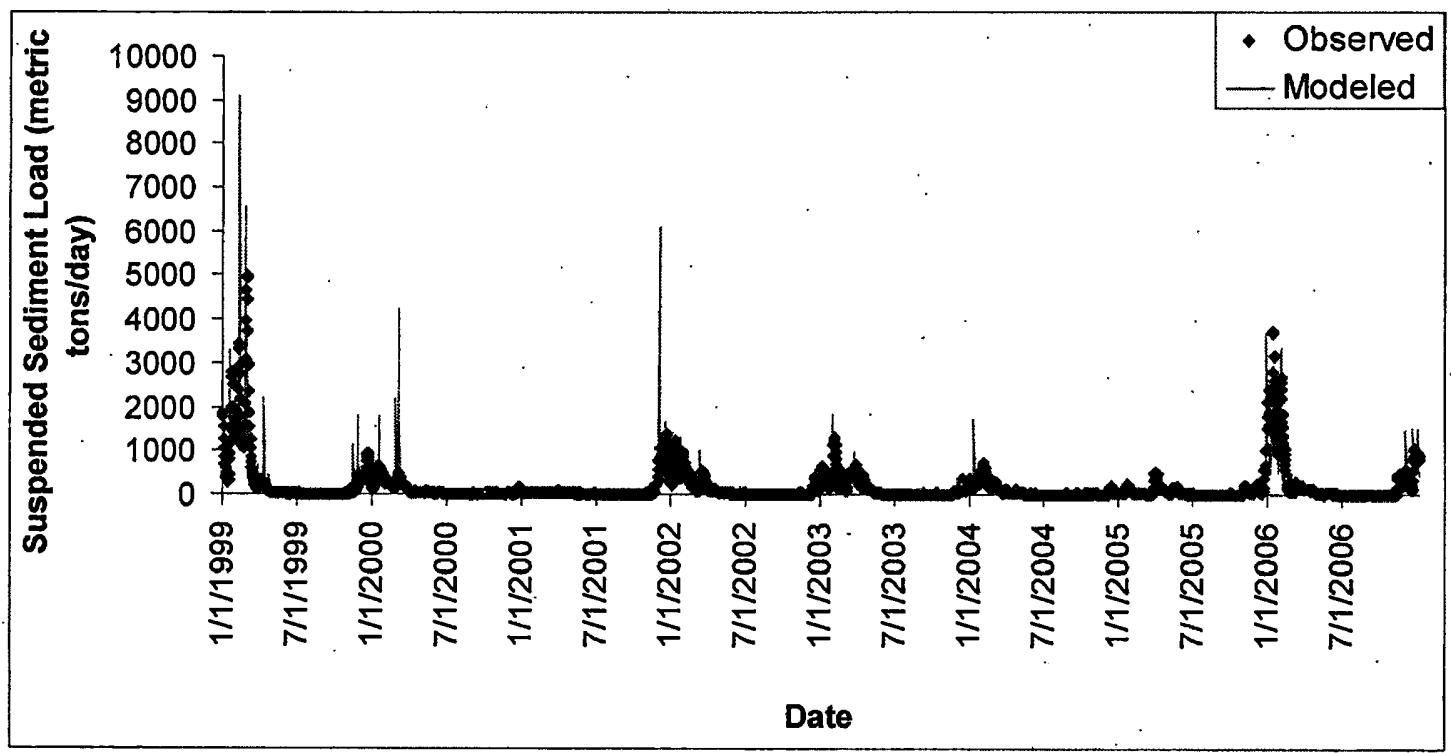

Figure 5.26: Time series of observed and modeled suspended sediment loads for the final run in the validation period, 1999-2006. 
Table 5.13 summarizes the model evaluation statistics for the calibration and validation periods. The $\mathrm{R}^{2}$ values fall below the target of 0.8 , and the Nash-Sutcliffe model efficiency values are also lower than desired, although they are positive, meaning the model does explain some of the variance in sediment loads. The relatively poorer performance of the sediment model can be explained by the fact that it includes all of the uncertainty of the hydrology model, plus additional uncertainty from the sediment transport equations, thus leading to cascading errors. Additionally, the observed sediment data are not as reliable as the observed hydrology data, because they are estimated from irregular samples rather than measured continuously, so it is inherently more difficult to match the modeled to the observed time series. The sediment model's performance is, however, adequate for average conditions; it is mainly in the higher loadings that the overestimations are significant. Accordingly, the peak loading results should be treated with caution, but the average loadings can be considered reasonably accurate (Table 5.14).

Table 5.13: Sediment model evaluation parameters for the calibration (1991-1998) and validation (1999-2006) periods.

\begin{tabular}{|l|r|r|r|r|}
\hline Period & \multicolumn{1}{|c|}{ Daily $\mathrm{R}^{2}$} & \multicolumn{1}{|l|}{ Daily $\mathrm{E}$} & \multicolumn{1}{l}{$\begin{array}{l}\text { Monthly } \\
\mathrm{R}^{2}\end{array}$} & \multicolumn{2}{l}{$\begin{array}{l}\text { Monthly } \\
\mathrm{E}\end{array}$} \\
\hline Calibration & 0.72 & 0.24 & 0.78 & 0.27 \\
\hline Validation & 0.55 & 0.45 & 0.59 & 0.49 \\
\hline
\end{tabular}


Table 5.14: Modeled and observed annual sediment loads for the final run during the calibration period (1991-1998).

\begin{tabular}{|r|r|r|r|}
\hline Year & $\begin{array}{l}\text { Observed Sediment Load (metric } \\
\text { tons) }\end{array}$ & $\begin{array}{l}\text { Modeled Sediment Load (metric } \\
\text { tons) }\end{array}$ & $\begin{array}{l}\% \\
\text { Difference }\end{array}$ \\
\hline 1991 & 19075.19 & 32457.87 & $70 \%$ \\
\hline 1992 & 12112.78 & 10931.03 & $-10 \%$ \\
\hline 1993 & 14551.71 & 17204.63 & $18 \%$ \\
\hline 1994 & 21417.38 & 20726.85 & $-3 \%$ \\
\hline 1995 & 46617.96 & 47919.51 & $3 \%$ \\
\hline 1996 & 79611.61 & 77507.20 & $-3 \%$ \\
\hline 1997 & 53152.63 & 49726.42 & $-6 \%$ \\
\hline 1998 & 47584.42 & 50872.32 & $7 \%$ \\
\hline Total & 294123.68 & 307345.82 & $4 \%$ \\
\hline
\end{tabular}

\section{Nutrient Calibration and Validation}

As with the hydrology and sediment models, I used an iterative procedure to adjust parameters in the nutrient loading model. I modeled two nutrient constituents: dissolved nitrate $\left(\mathrm{NO}_{3}{ }^{-}\right)$and total orthophosphate $\left(\mathrm{PO}_{4}\right)$. Compared to the hydrology and sediment models, fewer nutrient parameters were sensitive to calibration. Table 5.14 shows the calibration parameters for nitrate only. Orthophosphate load was simulated by making it a function of sediment load, because it readily adsorbs to sediments, with no further changes made to the calibrated hydrology and sediment parameters.

Table 5.15: Initial and final values of calibrated nitrate parameters.

\begin{tabular}{|l|l|l|r|r|}
\hline Parameter & Description & $\begin{array}{l}\text { Recommended } \\
\text { Range }\end{array}$ & $\begin{array}{l}\text { Initial } \\
\text { Value }\end{array}$ & $\begin{array}{l}\text { Final } \\
\text { Value }\end{array}$ \\
\hline ACQOP & Rate of NO3 accumulation & $0-1$ & 0 & 0.1 \\
\hline SQOLIM & NO3 storage & $0-10$ & 0 & 1 \\
\hline IOQC & $\begin{array}{l}\text { NO3 sub-surface } \\
\text { concentrations }\end{array}$ & $0-5$ & 0 & 1 \\
\hline
\end{tabular}

After parameter adjustment, the nitrate model achieved an $\mathrm{R}^{2}$ in the calibration period of 0.42 (Figure 5.27) and 0.50 in the validation period (Figure 5.27). The 
weakness of this model fit can be explained by several factors. First, as stated previously, few of the HSPF nitrate model parameters are sensitive to calibration and, unlike with orthophosphate, sediment cannot be used as a proxy for nitrate loading, because the two constituents do not correlate. This is an example of the relative weakness of HSPF in simulating nitrate as compared to other models, such as SWAT. Second, the relation between observed flow and nitrate concentration samples is negative (Figure 5.29). This indicates that, unlike with sediment and orthophosphate, increased flows have a dilution rather than flushing effect on nitrate concentrations. Accordingly, nitrate loading is predominantly controlled by factors other than flow, most likely vegetation growth and groundwater concentrations, and the ability of HSPF, which is primarily a surface runoff model, to accurately simulate these processes is limited. As can be seen in the time series for the calibration (Figure 5.30) and validation (Figure 5.31) periods, there are large discrepancies in both the magnitude and timing of peak nitrate loads. The evaluation statistics (Table 5.15) indicate that the fit is insufficient for confident modeling of scenarios. I have nevertheless continued with the nitrate scenario modeling, but the results should be treated with great caution. 


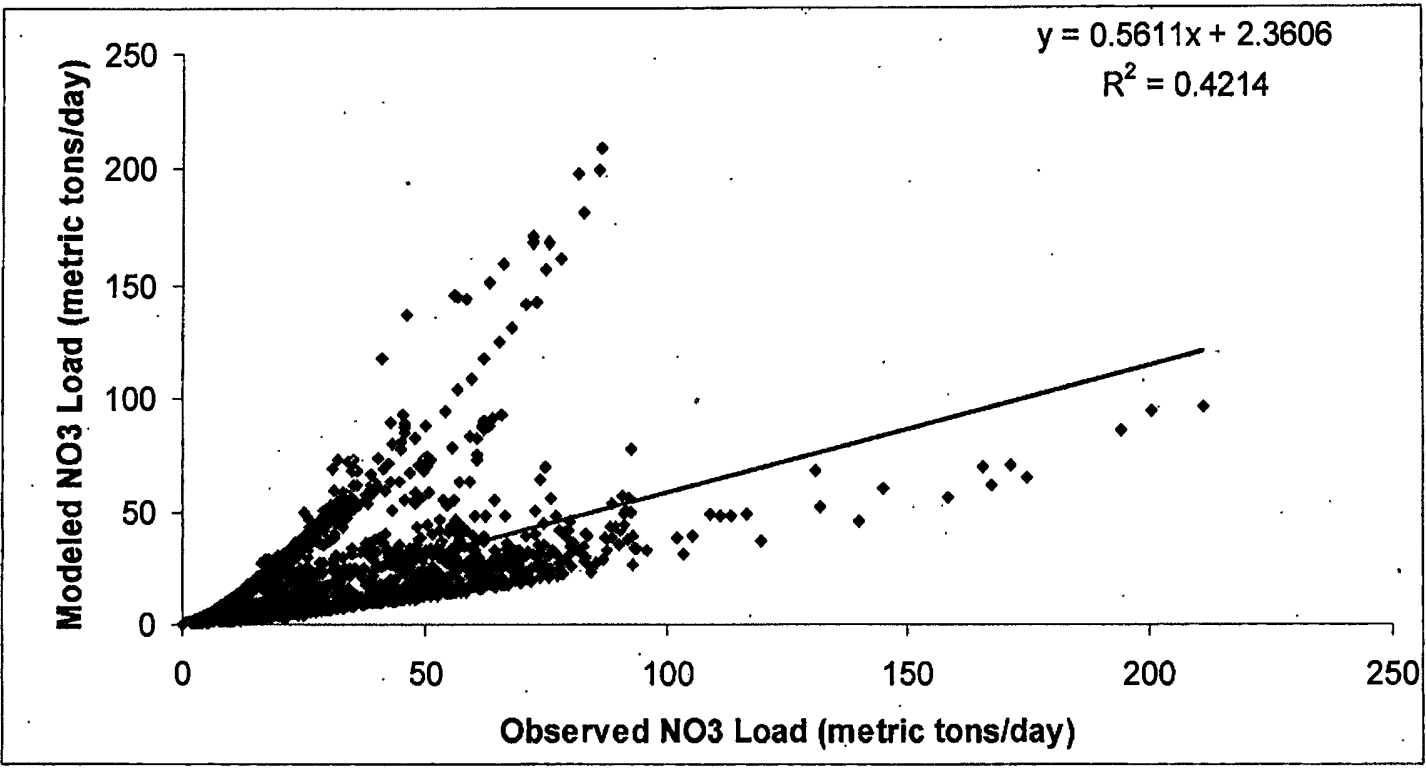

Figure 5.27: Observed versus modeled nitrate load for the final run in the calibration period, 1991-1998.

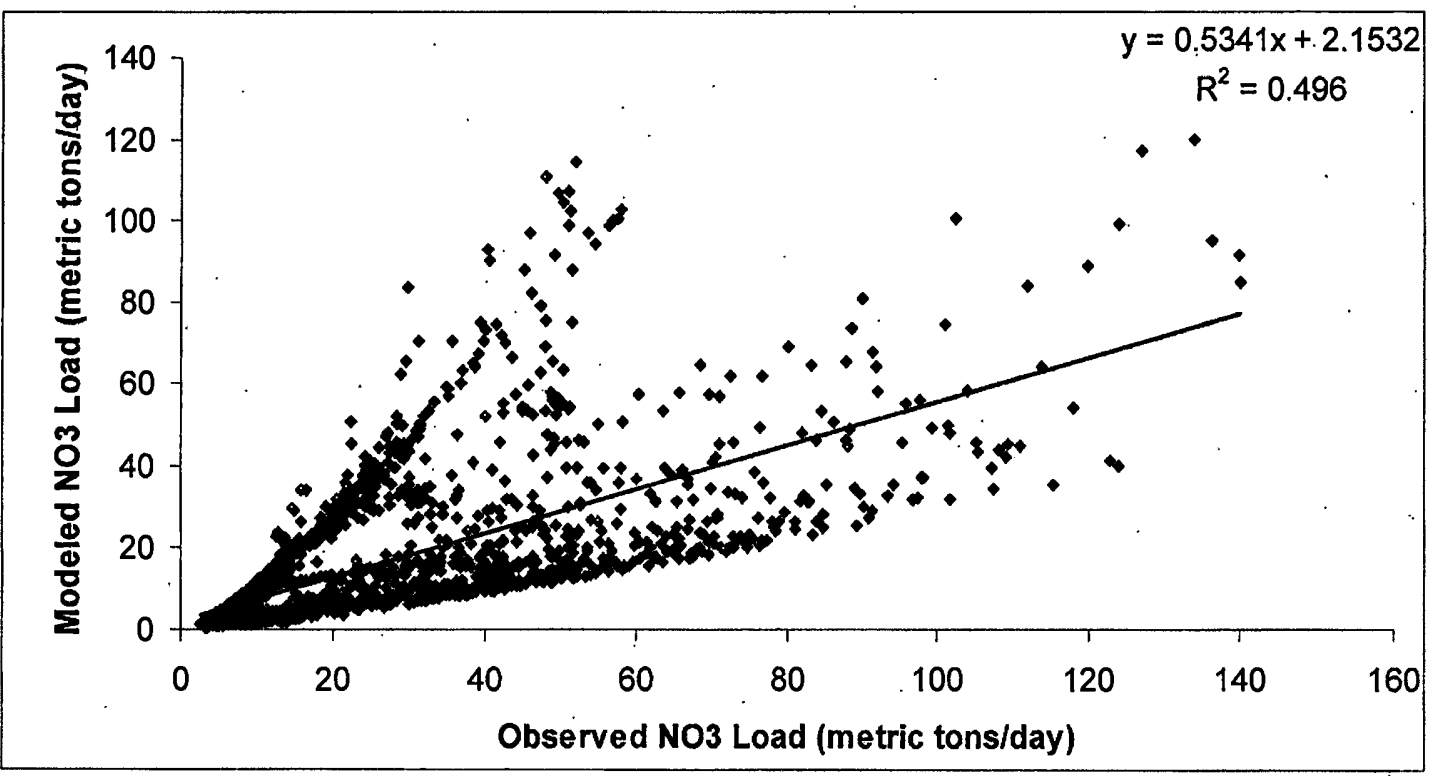

Figure 5.28: Observed versus modeled nitrate load for the final run in the validation period, 1999-2006. 


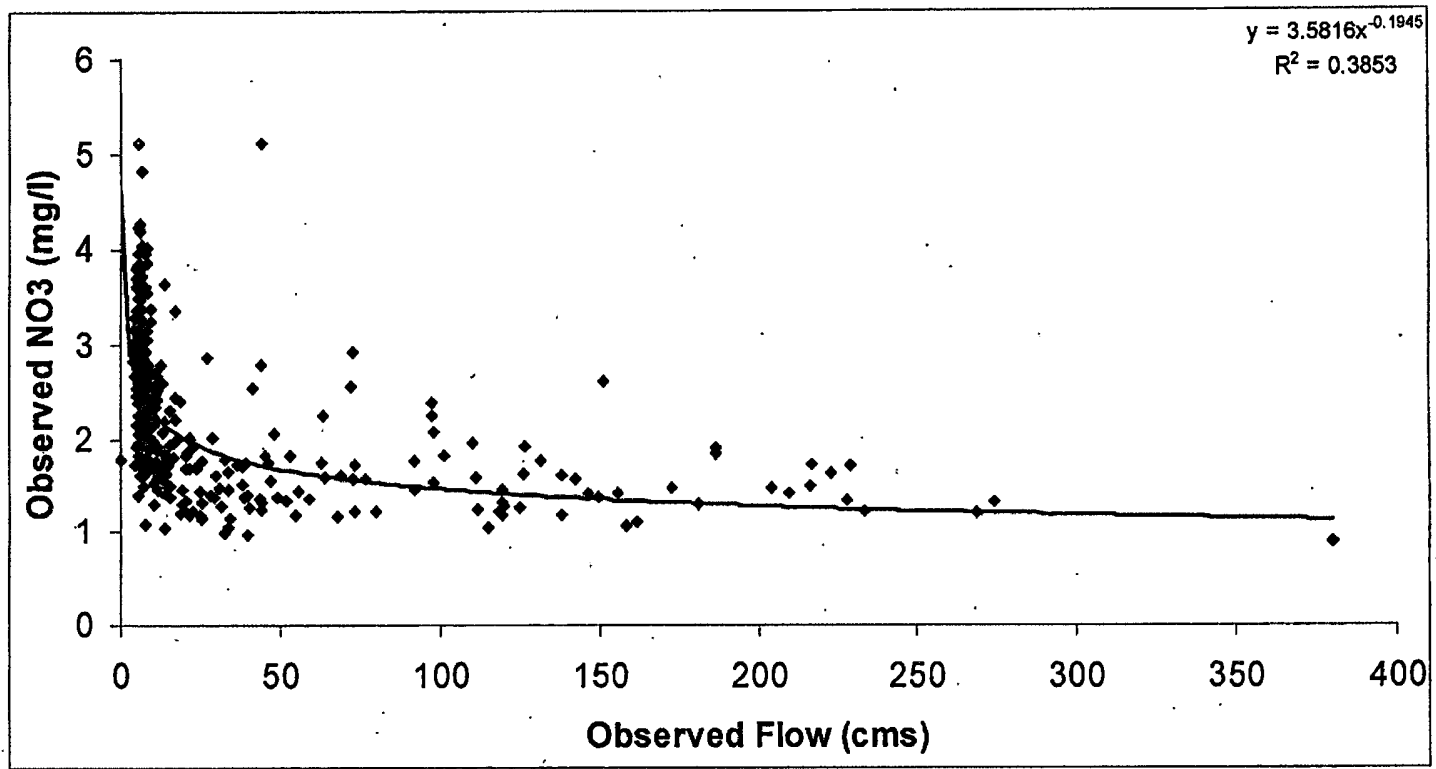

Figure 5.29: Observed flow and nitrate concentration samples for the entire observed data period, 1991-2006.

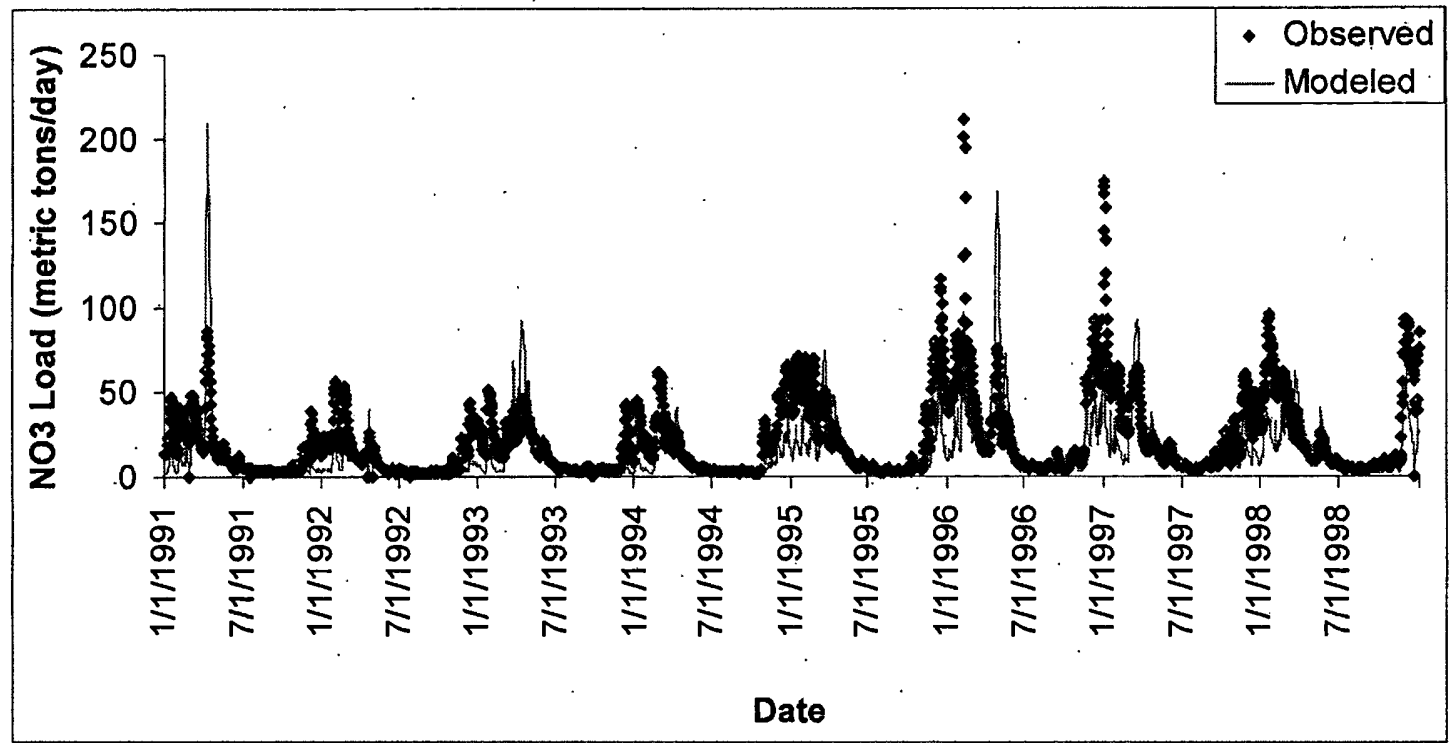

Figure 5.30: Time series of observed and modeled nitrate loads for the final run in the calibration period, 1991-1998. 


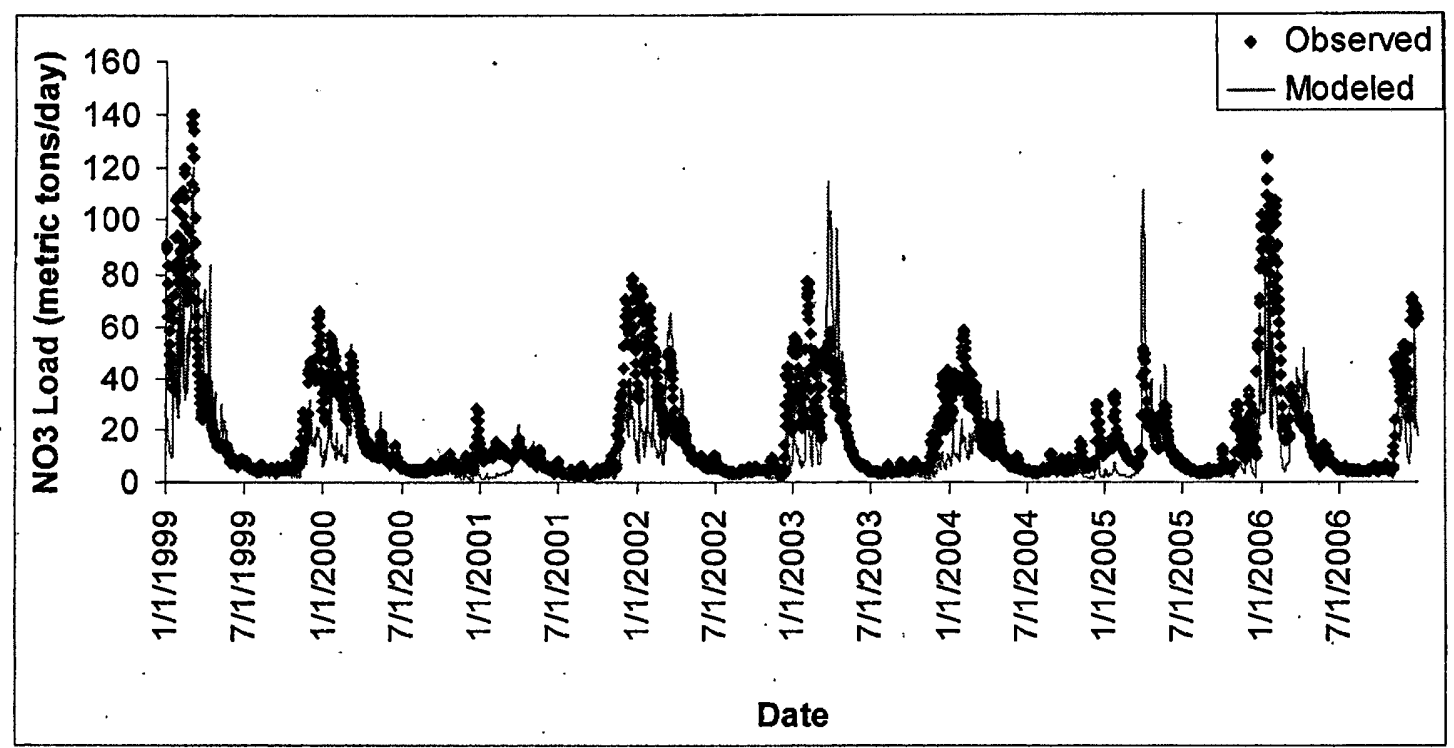

Figure 5.31: Time series of observed and modeled nitrate loads for the final run in the validation period, 1999-2006.

Table 5.16: Nitrate model evaluation parameters for the calibration (1991-1998) and validation (1999-2006) periods.

\begin{tabular}{|l|r|r|r|r|}
\hline Period & Daily $\mathrm{R}^{2}$ & \multicolumn{1}{|c|}{ Daily $\mathrm{E}$} & $\begin{array}{l}\text { Monthly } \\
\mathrm{R}^{2}\end{array}$ & \multicolumn{2}{l|}{$\begin{array}{l}\text { Monthly } \\
\mathrm{E}\end{array}$} \\
\hline Calibration & 0.42 & 0.25 & 0.47 & 0.32 \\
\hline Validation & 0.50 & 0.41 & 0.53 & 0.44 \\
\hline
\end{tabular}

The orthophosphate load, modeled as a function of sediment load, achieved an $\mathrm{R}^{2}$ of approximately 0.93 in both the calibration (Figure 5.32) and validation (Figure 5.33) periods. The calibration (Figure 5.34) and validation (Figure 5.35) time series show that the model somewhat underestimates peak loads. The model evaluation statistics, however, indicate that the fit is very good (Table 5.17), probably because orthophosphate is highly sensitive to the flushing effects of increased flow. Unlike nitrate, there are grounds for a high level of confidence in the scenario modeling results for orthophosphate. 


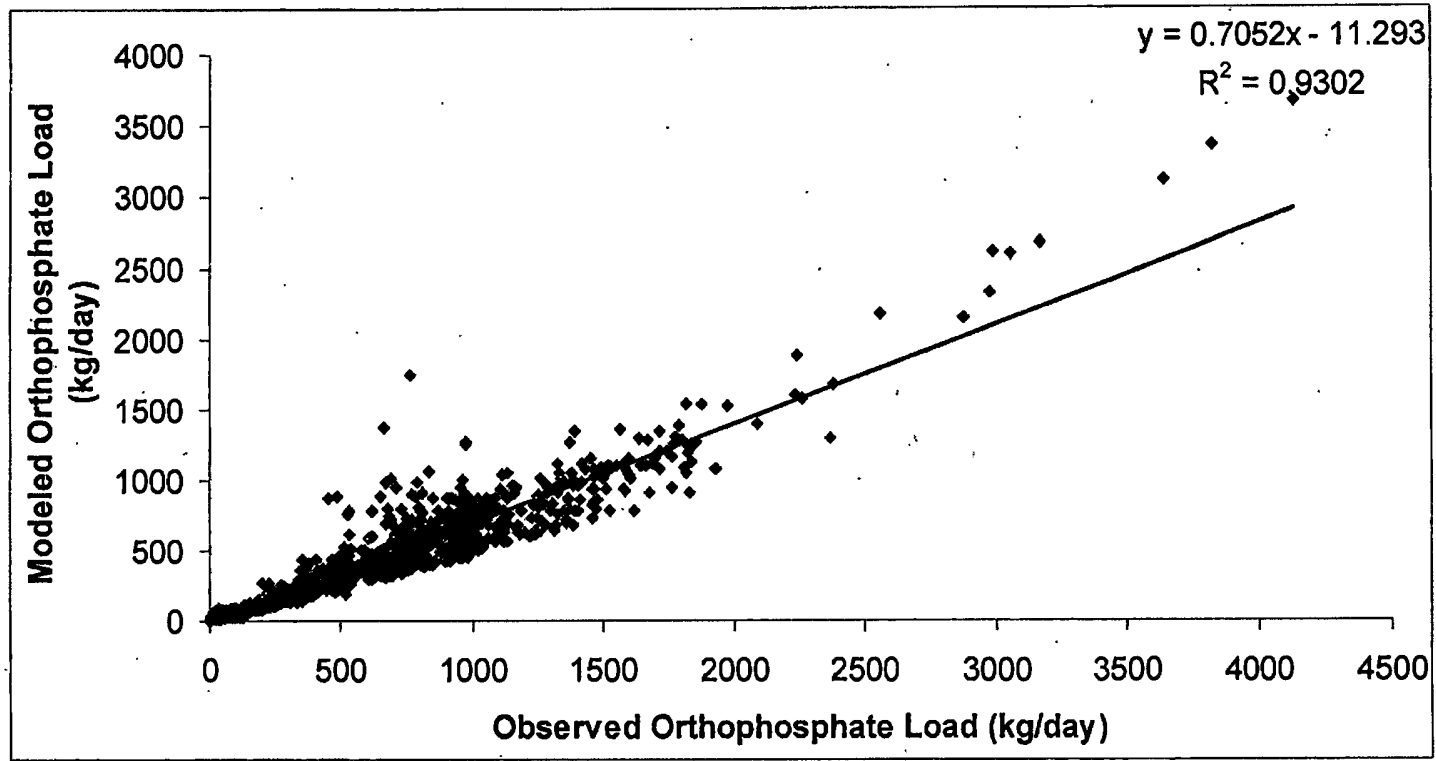

Figure 5.32: Observed versus modeled orthophosphate load for the final run in the calibration period, 1991-1998.

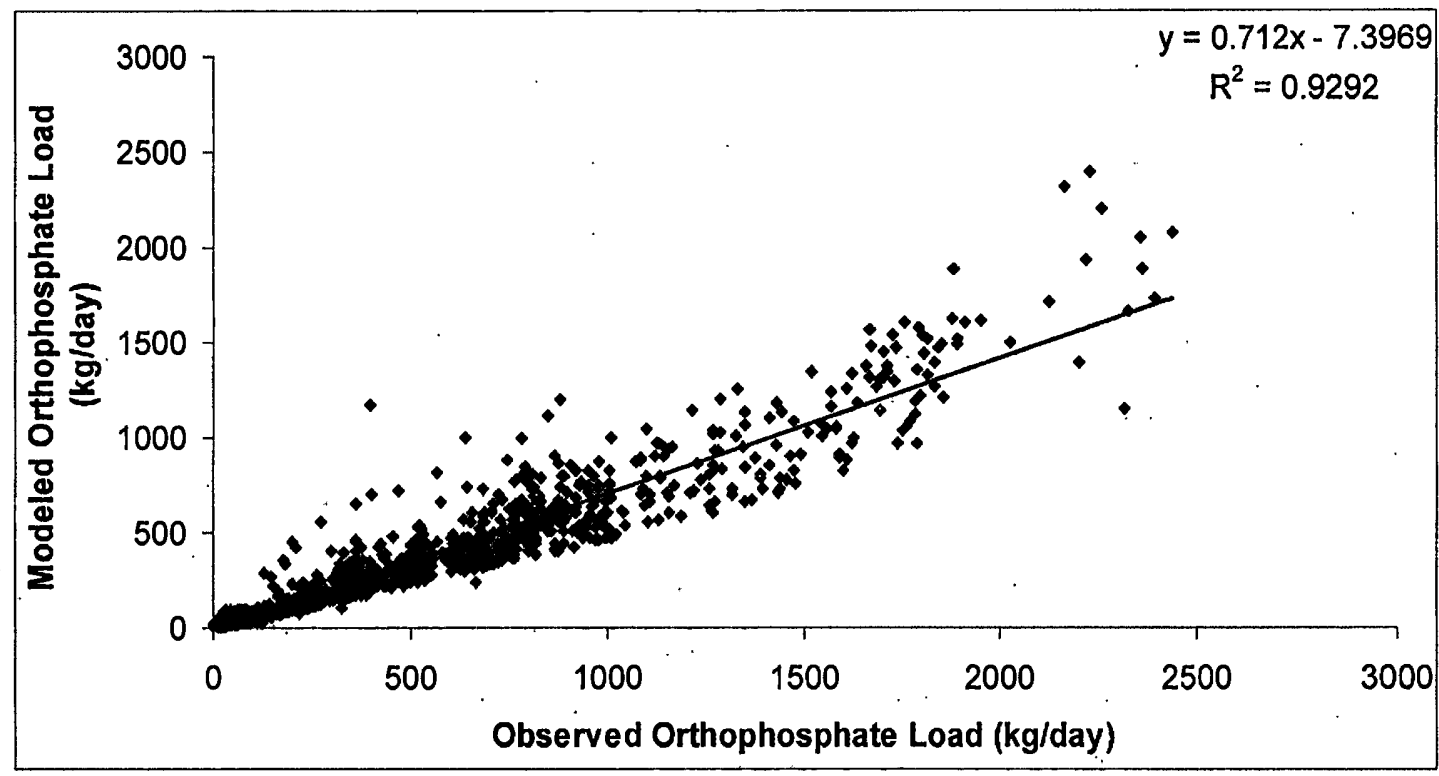

Figure 5.33: Observed versus modeled orthophosphate load for the final run in the validation period, 1999-2006. 


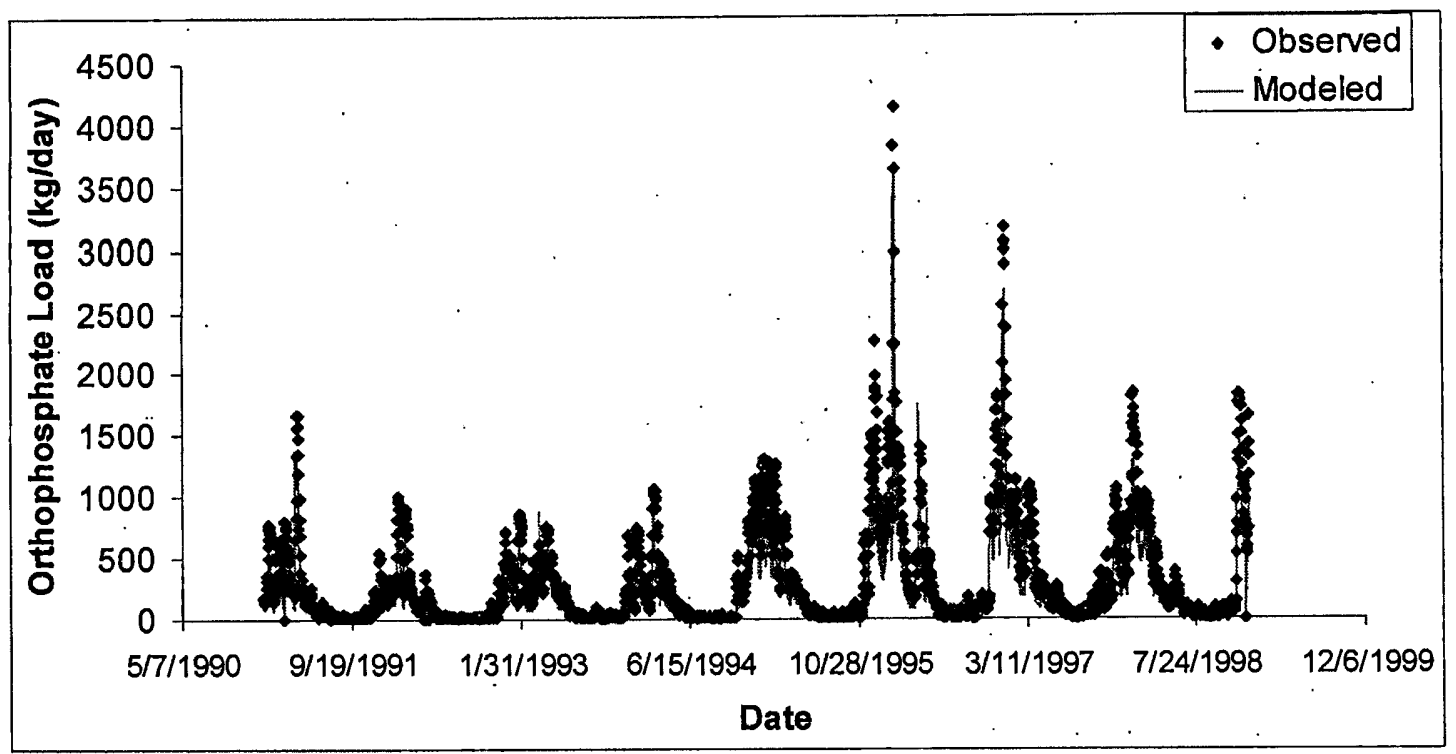

Figure 5.34: Time series of observed and modeled orthophosphate loads for the final run in the calibration. period, 1991-1998.

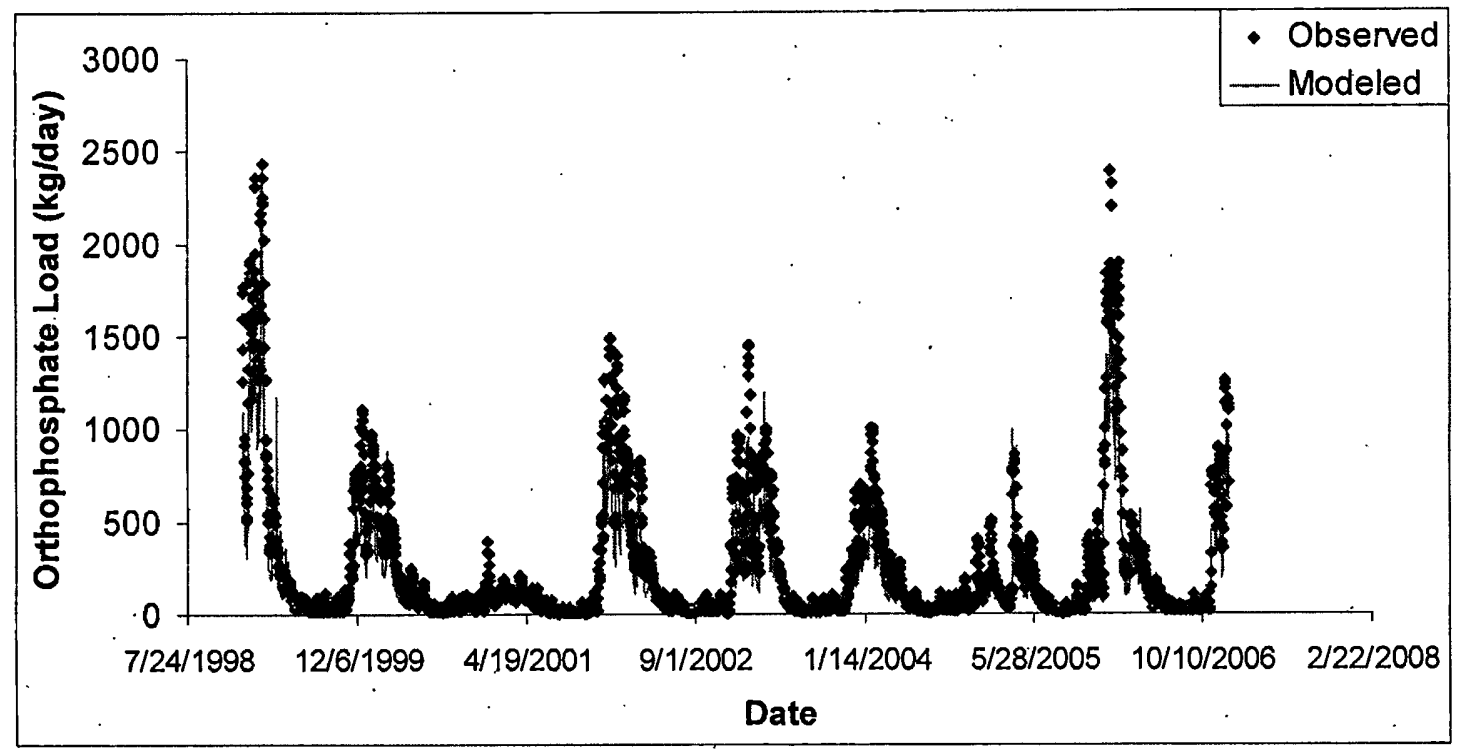

Figure 5.35: Time series of observed and modeled orthophosphate loads for the final run in the validation period, 1999-2006.

Table 5.17: Orthophosphate model evaluation parameters for the calibration (1991-1998) and validation (1999-2006) periods.

\begin{tabular}{|c|c|c|c|c|}
\hline Period & Daily $R^{2}$ & Daily $E$ & $\begin{array}{l}\text { Monthly } \\
\mathrm{R}^{2}\end{array}$ & $\begin{array}{l}\text { Monthly } \\
\text { E }\end{array}$ \\
\hline Calibration & 0.93 & 0.82 & 0.99 & 0.94 \\
\hline Validation & 0.93 & 0.83 & 0.99 & 0.95 \\
\hline
\end{tabular}




\section{VI: RESULTS}

\section{Impacts of Climate Change on Hydrology}

\section{A. Mean Hydrology}

Figures 6.1 and 6.2 show the changes in mean monthly flow from the baseline period (1970-1999) resulting from the eight climate change scenarios for the 2040s and 2070 s, respectively. Although there is some variation among the scenarios, the general pattern is increases in winter flow and decreases in summer flow, with somewhat greater changes in magnitude by the $2080 \mathrm{~s}$, as illustrated by Figure 6.3 , which shows the average changes from all eight scenarios for the 2040s and 2070s. Table 6.1 shows these average monthly changes as percent change from the baseline. The changes in flow are significant at the 0.05 level or higher for the BCCR A1B, CGCM3 A1B, CCSM3 B1, and IPSL4 B1 scenarios, according to a two-tailed t-test (Table 6.2). Table 6.3 shows a matrix of multiple paired comparisons of differences in flow among the eight climate scenarios for the 2040s, with significance assessed using the false discovery rate, following the procedure described in McBride (2005). Table 6.4 shows the same information for the $2070 \mathrm{~s}$. 


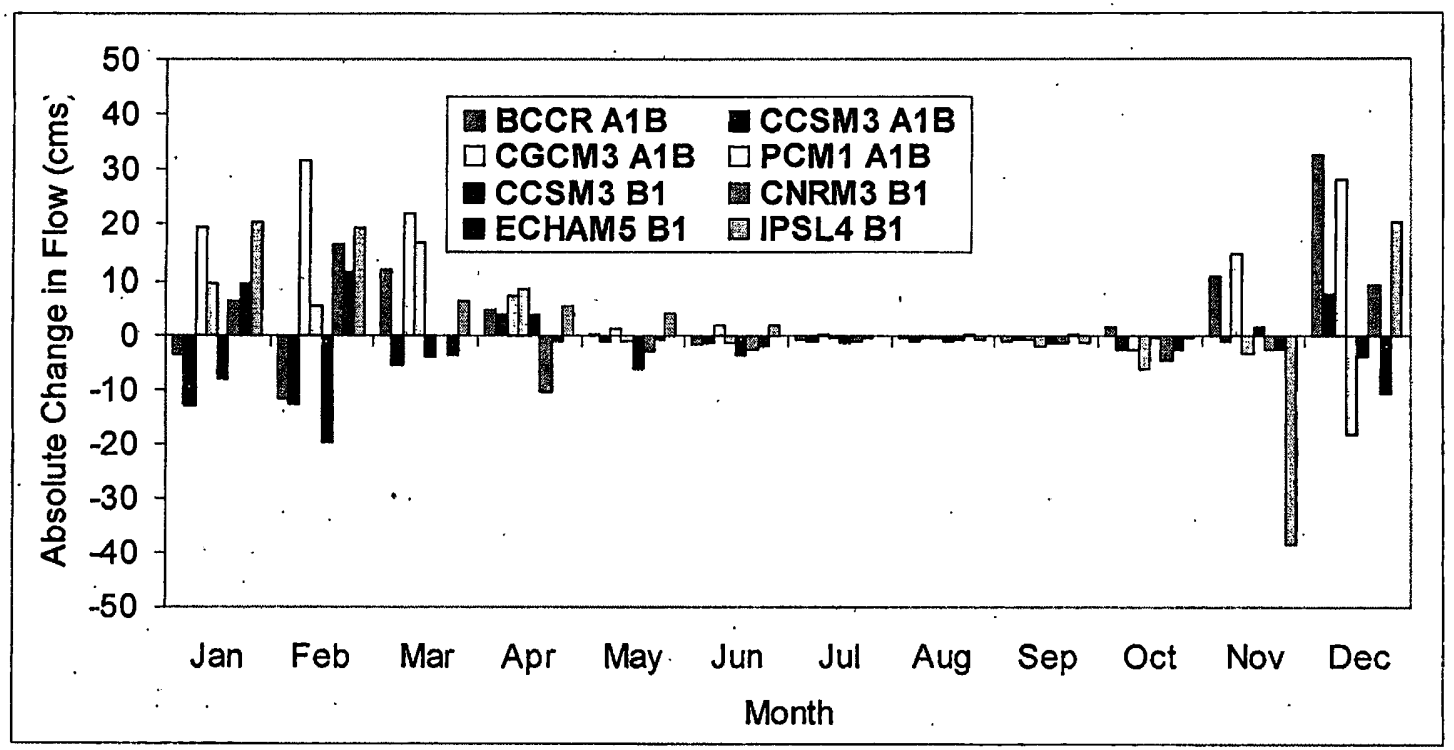

Figure 6.1: Absolute changes in monthly flow resulting from the eight climate change scenarios for the 2040s.

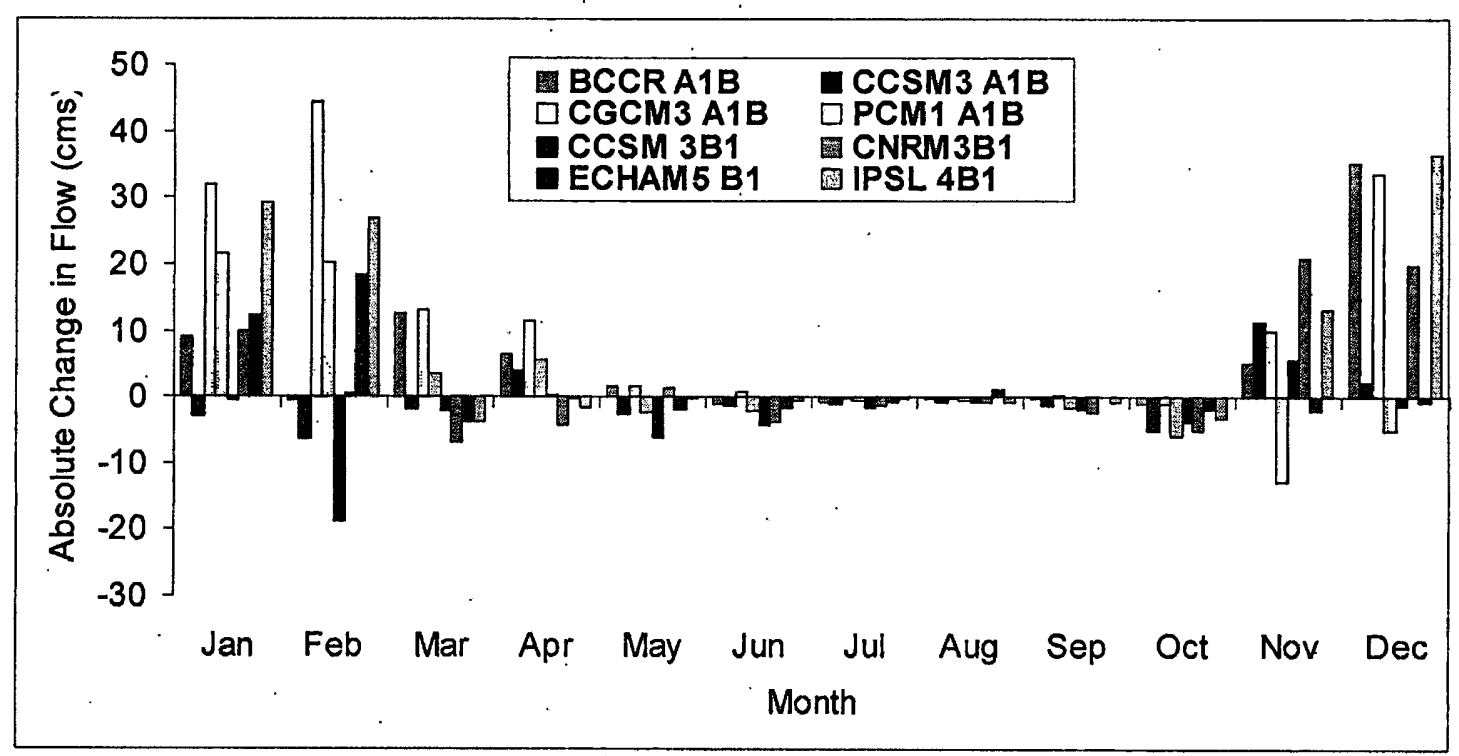

Figure 6.2: Absolute changes in monthly flow resulting from the eight climate change scenarios for the $2070 \mathrm{~s}$. 


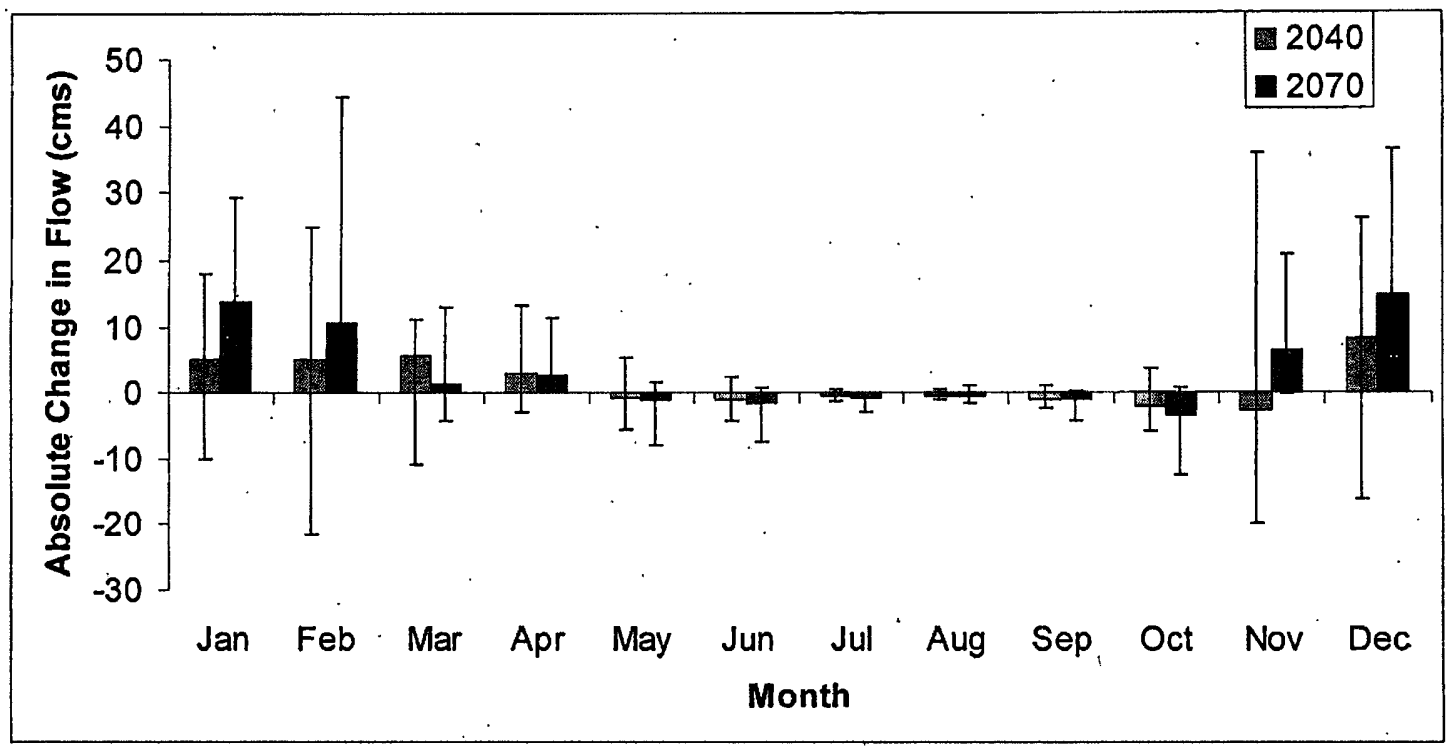

Figure 6.3: Absolute changes in monthly flow, averaged for all eight climate change scenarios, for the 2040s and 2070s.

Note: Error bars represent maximum and minimum changes in flow for each month.

Table 6.1: Percent changes in monthly flow, averaged for all eight climate change scenarios, for the 2040s and 2070s.

\begin{tabular}{|l|r|r|}
\hline Month & $\begin{array}{r}\text { Change } \\
\text { Chan }\end{array}$ & 2070 Change \\
\hline Jan & $3.97 \%$ & $10.74 \%$ \\
\hline Feb & $4.49 \%$ & $9.33 \%$ \\
\hline Mar & $7.13 \%$ & $1.72 \%$ \\
\hline Apr & $5.82 \%$ & $5.50 \%$ \\
\hline May & $-4.59 \%$ & $-6.72 \%$ \\
\hline Jun & $-15.28 \%$ & $-24.12 \%$ \\
\hline Jul & $-26.34 \%$ & $-39.91 \%$ \\
\hline Aug & $-35.00 \%$ & $-30.39 \%$ \\
\hline Sept & $-22.63 \%$ & $-22.76 \%$ \\
\hline Oct & $-11.37 \%$ & $-17.60 \%$ \\
\hline Nov & $-3.54 \%$ & $8.65 \%$ \\
\hline Dec & $6.92 \%$ & $12.68 \%$ \\
\hline
\end{tabular}


Table 6.2: Results of two-tailed t-test for significance of changes in flow compared to the baseline for the eight climate change scenarios.

\begin{tabular}{|l|l|l|}
\hline Scenario & 2040 & \multicolumn{1}{|c|}{2070} \\
\hline $\begin{array}{l}\text { BCCR } \\
\text { A1B }\end{array}$ & $-2.31^{* *}$ & $-4.03^{\star *}$ \\
\hline $\begin{array}{l}\text { CCSM3 } \\
\text { A1B }\end{array}$ & 0.73 & -1.06 \\
\hline $\begin{array}{l}\text { CGCM3 } \\
\text { A1B }\end{array}$ & 0.31 & $-9.64^{\star *}$ \\
\hline $\begin{array}{l}\text { PCM1 } \\
\text { A1B }\end{array}$ & -0.72 & -1.65 \\
\hline $\begin{array}{l}\text { CCSM3 } \\
\text { B1 }\end{array}$ & $2.07^{\star}$ & 1.48 \\
\hline $\begin{array}{l}\text { CNRM3 } \\
\text { B1 }\end{array}$ & -0.01 & -1.67 \\
\hline $\begin{array}{l}\text { ECHAM5 } \\
\text { B1 }\end{array}$ & 1.32 & -0.29 \\
\hline IPSL4 B1 & $-7.19^{\star *}$ & $-8.41^{\star *}$ \\
\hline
\end{tabular}

*Significant at the 0.05 level.

**Significant at the 0.01 level.

Table 6.3: Two-tailed t-test results from multiple paired comparisons of differences in flow among the eight climate change scenarios for the $2040 \mathrm{~s}$, with significance assessed using the false discovery rate.

\begin{tabular}{|c|c|c|c|c|c|c|c|c|}
\hline Model & $\begin{array}{l}\mathrm{BCCR} \\
\mathrm{AlB}\end{array}$ & $\begin{array}{l}\mathrm{CCSM} 3 \\
\mathrm{~A} 1 \mathrm{~B}\end{array}$ & $\begin{array}{l}\text { CGCM } \\
3 \mathrm{AlB}\end{array}$ & $\begin{array}{l}\text { PCM1 } \\
\text { AlB }\end{array}$ & $\begin{array}{l}\text { CCSM3 } \\
\text { B1 }\end{array}$ & $\begin{array}{l}\text { CNRM } \\
3 \mathrm{~B} 1\end{array}$ & $\begin{array}{l}\text { ECHA } \\
\text { M5 B1 } \\
\end{array}$ & $\begin{array}{l}\text { IPSL4 } \\
\text { B1 }\end{array}$ \\
\hline $\begin{array}{l}\text { BCCR } \\
\text { AlB }\end{array}$ & - & $5.40^{*}$ & $-5.15^{*}$ & $2.79^{*}$ & $6.65^{*}$ & $2.77^{*}$ & $3.62 *$ & $-2.69 *$ \\
\hline $\begin{array}{l}\text { CCSM3 } \\
\text { A } 1 \mathrm{~B}\end{array}$ & $5.40 *$ & - & $-10.59^{*}$ & $-2.94^{*}$ & 1.25 & $-2.50 *$ & $-2.05^{*}$ & $-8.27^{*}$ \\
\hline $\begin{array}{l}\text { CGCM } \\
3 \mathrm{AlB} \\
\end{array}$ & $-5.15^{*}$ & $-10.59 *$ & - & $8.22 *$ & $11.84^{*}$ & $7.84^{*}$ & $9.01^{*}$ & $2.58^{*}$ \\
\hline $\begin{array}{l}\mathrm{PCM} 1 \\
\mathrm{~A} 1 \mathrm{~B} \\
\end{array}$ & $2.79^{*}$ & $-2.94^{*}$ & $8.22 *$ & - & $4.28 *$ & 0.20 & 0.91 & $-5.73 *$ \\
\hline $\begin{array}{l}\text { CCSM3 } \\
\text { B1 }\end{array}$ & $6.65^{*}$ & 1.25 & $11.84^{*}$ & $4.28^{*}$ & - & $-3.71^{*}$ & $-3.38 *$ & $-9.56^{*}$ \\
\hline $\begin{array}{l}\text { CNRM } \\
3 \mathrm{~B} 1 \\
\end{array}$ & $2.77^{*}$ & $-2.50^{*}$ & $7.84^{*}$ & 0.20 & $-3.71^{*}$ & - & 0.63 & $-5.49 *$ \\
\hline $\begin{array}{l}\text { ECHA } \\
\text { M5 B1 }\end{array}$ & $3.62^{*}$ & $-2.05^{*}$ & 9.01 * & 0.91 & $-3.38 *$ & 0.63 & - & $-6.56^{*}$ \\
\hline $\begin{array}{l}\text { IPSL4 } \\
\text { B1 }\end{array}$ & $-2.69 *$ & $-8.27^{*}$ & $2.58 *$ & $-5.73^{*}$ & $-9.56 *$ & $-5.49 *$ & $-6.56^{*}$ & - \\
\hline
\end{tabular}

*Significant at the 0.05 level. 
Table 6.4: Two-tailed t-test results from multiple paired comparisons of differences in flow among the eight climate change scenarios for the 2070s, with significance assessed using the false discovery rate.

\begin{tabular}{|c|c|c|c|c|c|c|c|c|}
\hline Model & $\begin{array}{l}\mathrm{BCCR} \\
\mathrm{A} 1 \mathrm{~B} \\
\end{array}$ & $\begin{array}{l}\mathrm{CCSM} 3 \\
\mathrm{~A} 1 \mathrm{~B}\end{array}$ & $\begin{array}{l}\mathrm{CGCM} \\
3 \mathrm{~A} 1 \mathrm{~B} \\
\end{array}$ & $\begin{array}{l}\mathrm{PCM} 1 \\
\mathrm{~A} 1 \mathrm{~B}\end{array}$ & $\begin{array}{l}\text { CCSM3 } \\
\text { B1 }\end{array}$ & $\begin{array}{l}\text { CNRM } \\
3 \mathrm{~B} 1\end{array}$ & $\begin{array}{l}\text { ECHA } \\
\text { M5 B1 }\end{array}$ & $\begin{array}{l}\text { IPSL4 } \\
\text { B1 }\end{array}$ \\
\hline $\begin{array}{l}\mathrm{BCCR} \\
\mathrm{A} 1 \mathrm{~B}\end{array}$ & - & $5.99^{*}$ & $-5.50 *$ & $3.81^{*}$ & $8.43^{*}$ & $3.01 *$ & $4.10^{*}$ & $-2.06^{*}$ \\
\hline $\begin{array}{l}\text { CCSM3 } \\
\text { A1B }\end{array}$ & $5.99 *$ & 50 & $-11.42^{*}$ & $-2.31^{*}$ & $2.55^{*}$ & $-2.87^{*}$ & $-2.14^{*}$ & -8.27 \\
\hline $\begin{array}{l}\mathrm{CGCM} \\
3 \mathrm{AlB}\end{array}$ & $-5.50 *$ & $-11.42^{*}$ & - & $9.34 *$ & $13.74^{*}$ & $8.39 *$ & $9.72 *$ & $3.61 *$ \\
\hline $\begin{array}{l}\text { PCM1 } \\
\text { A1B }\end{array}$ & $3.81^{*}$ & $-2.31^{*}$ & $9.34^{*}$ & - & $4.87^{*}$ & -0.67 & 0.22 & $-6.04^{*}$ \\
\hline $\begin{array}{l}\text { CCSM3 } \\
\text { B1 }\end{array}$ & $8.43^{*}$ & $2.55^{*}$ & $13.74^{*}$ & $4.87^{*}$ & - & $-5.30^{*}$ & $-4.77^{*}$ & $-10.77^{*}$ \\
\hline $\begin{array}{l}\text { CNRM } \\
3 \mathrm{~B} 1\end{array}$ & $3.01^{*}$ & $-2.87^{*}$ & $8.39^{*}$ & -0.67 & $-5.30^{*}$ & - & 0.90 & $-5.14^{*}$ \\
\hline $\begin{array}{l}\text { ECHA } \\
\text { M5 B1 }\end{array}$ & $4.10^{*}$ & $-2.14^{*}$ & $9.72 *$ & 0.22 & $-4.77^{*}$ & 0.90 & - & $-6.39 *$ \\
\hline $\begin{array}{l}\text { IPSL4 } \\
\text { B1 }\end{array}$ & $-2.06^{*}$ & -8.27 & $3.61 *$ & $-6.04^{*}$ & $-10.77^{*}$ & $-5.14^{*}$ & $-6.39 *$ & - \\
\hline
\end{tabular}

*Significant at the 0.05 level.

Figures 6.4 and 6.5 show the seasonal changes in flow resulting from the eight climate change scenarios. Here, the nearly uniform declines in summer flow and increases in winter flow can be clearly seen. Figure 6.6 shows these seasonal changes averaged for all eight climate change scenarios. Table 6.5 shows the relative magnitude of the averaged changes, which includes a ten percent increase in winter flow and a thirty-seven percent decrease in summer flow by the 2070 s. 


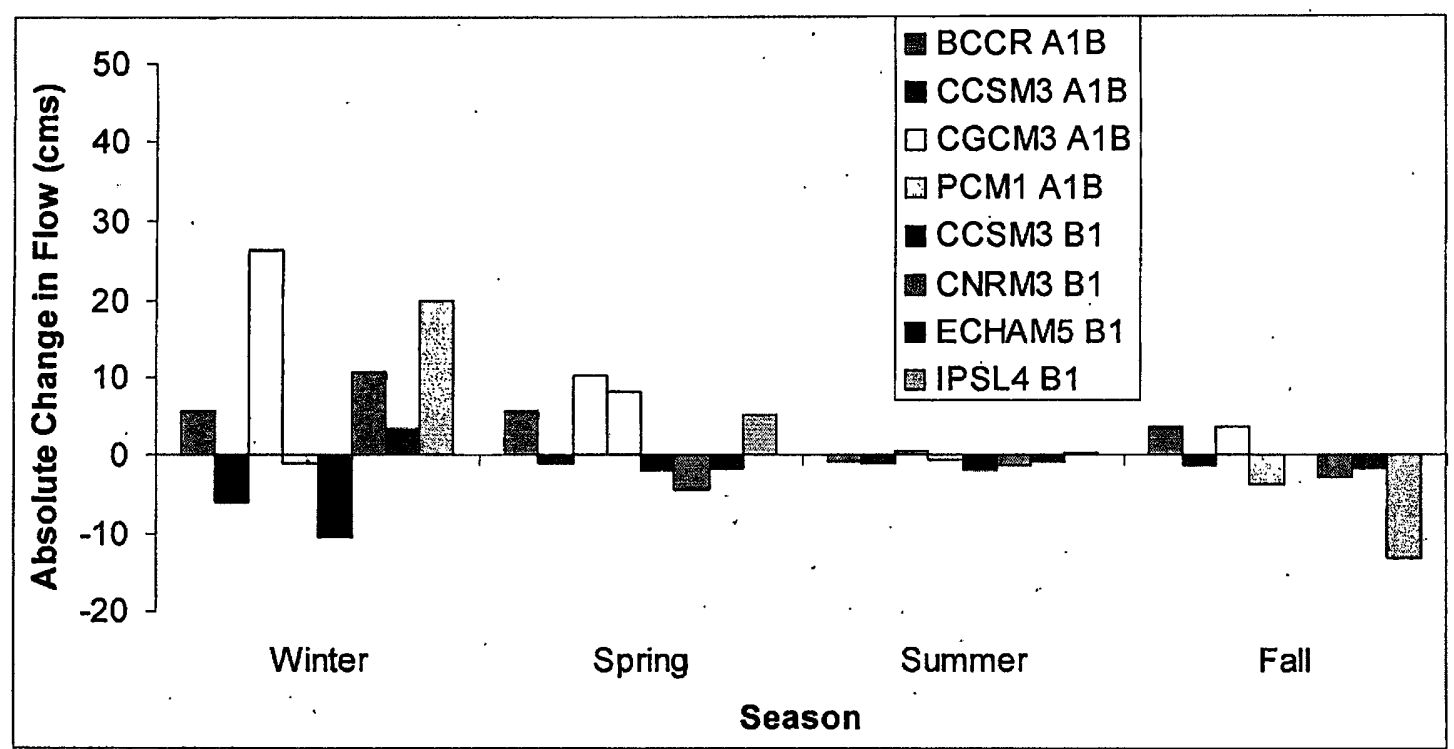

Figure 6.4: Absolute changes in seasonal flow resulting from the eight climate change scenarios for the 2040s.

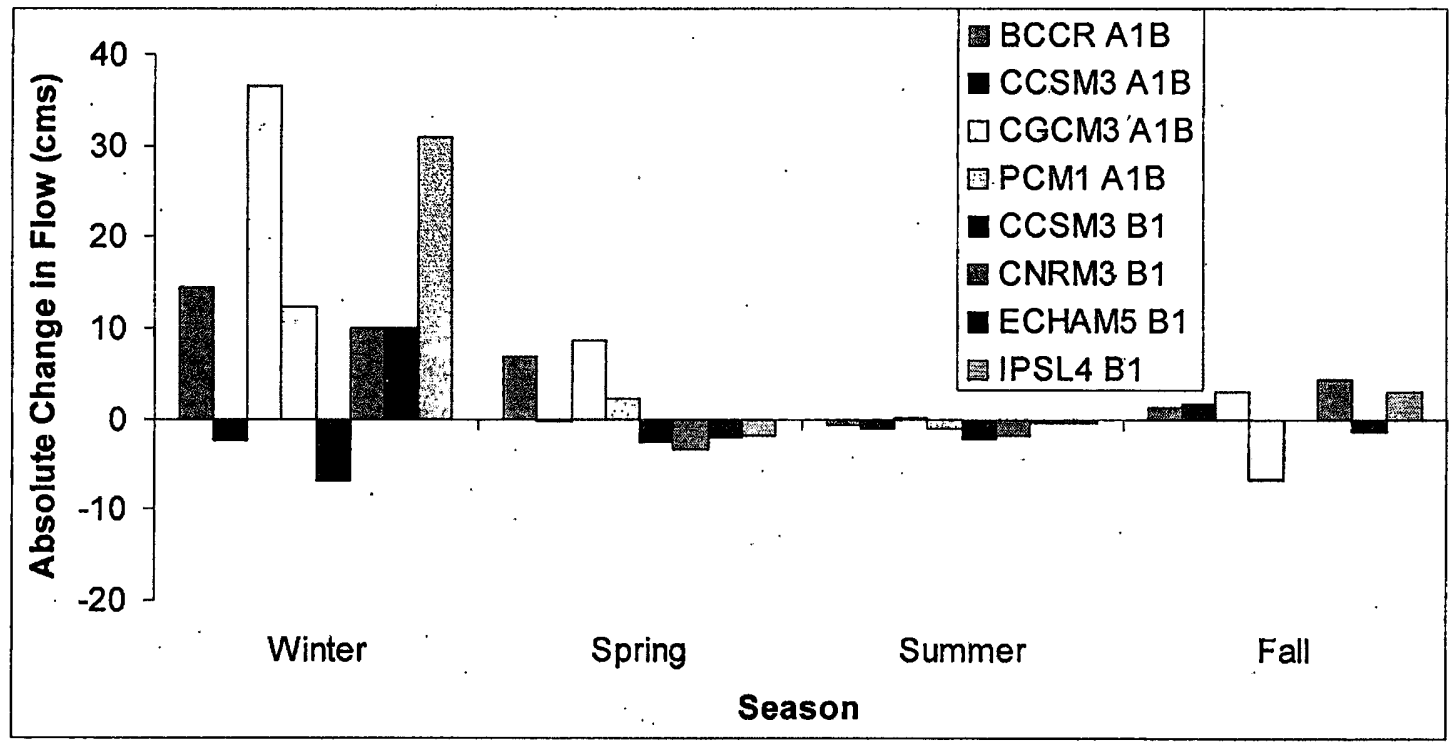

Figure 6.5: Absolute changes in seasonal flow resulting from the eight climate change scenarios for the $2070 \mathrm{~s}$. 


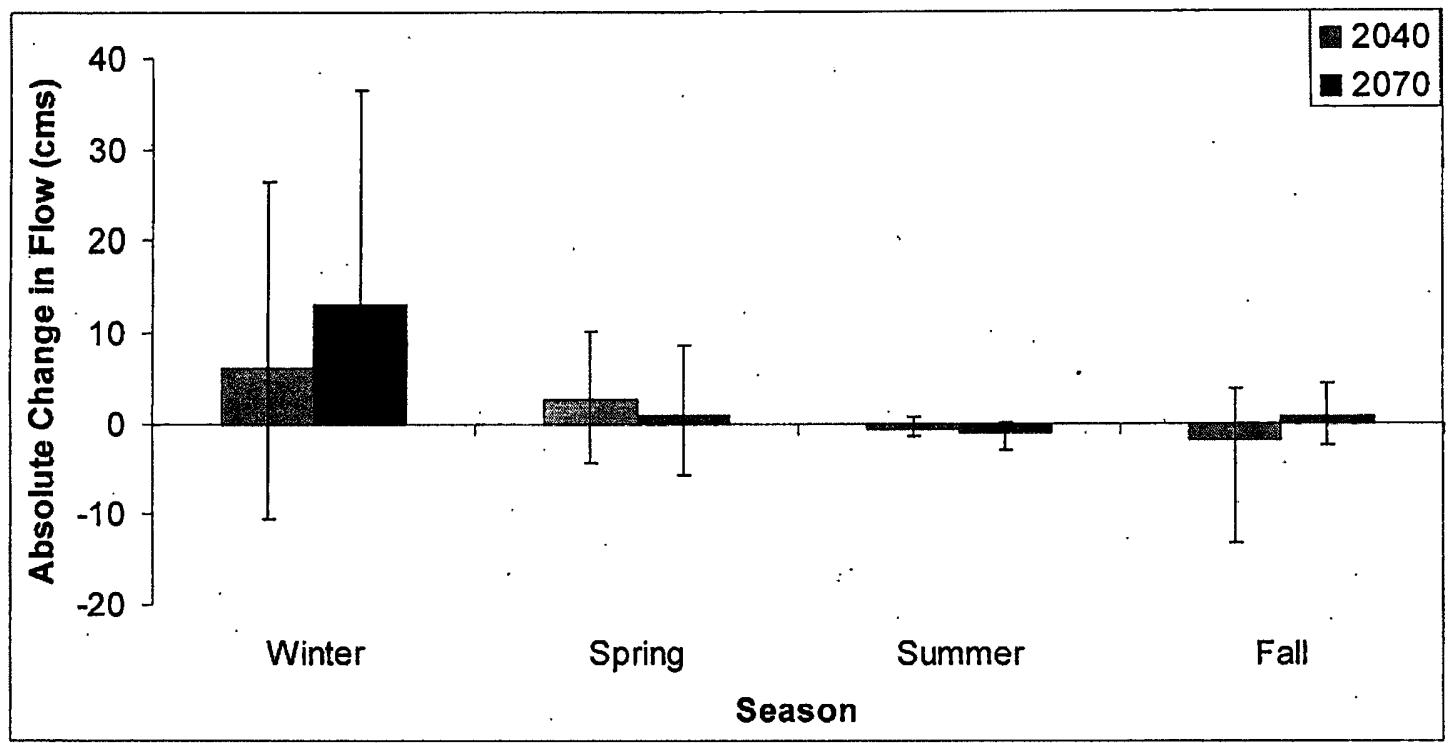

Figure 6.6: Absolute changes in seasonal flow, averaged for all eight climate change scenarios, for the 2040s and 2070s.

Table 6.5: Percent changes in seasonal flow, averaged for all eight climate change scenarios, for the 2040s and 2070s.

\begin{tabular}{|l|r|r|}
\hline Season & $\begin{array}{l}\text { 2040 } \\
\text { Change }\end{array}$ & $\begin{array}{l}\text { 2070 } \\
\text { Change }\end{array}$ \\
\hline Winter & $5.10 \%$ & $10.43 \%$ \\
\hline Spring & $5.40 \%$ & $1.88 \%$ \\
\hline Summer & $-19.97 \%$ & $-37.16 \%$ \\
\hline Fall & $-5.93 \%$ & $1.86 \%$ \\
\hline
\end{tabular}

B. Extreme Hydrology

In addition to modeling changes in the mean hydrology, I also examined potential changes in extreme hydrological events resulting from climate change.

Figures 6.7 and 6.8 show the modeled flow duration curves for the baseline, 2040s, and 20.70s, for the high-change (IPSL4 B1) and low-change (CCSM3 B1) climate scenarios, respectively. The lowest five percent of flows, those exceeded ninety-five percent or more of the time, are of lower magnitude under the climate change scenarios than the baseline. This means that, under climate change, lower low flows should be expected. 


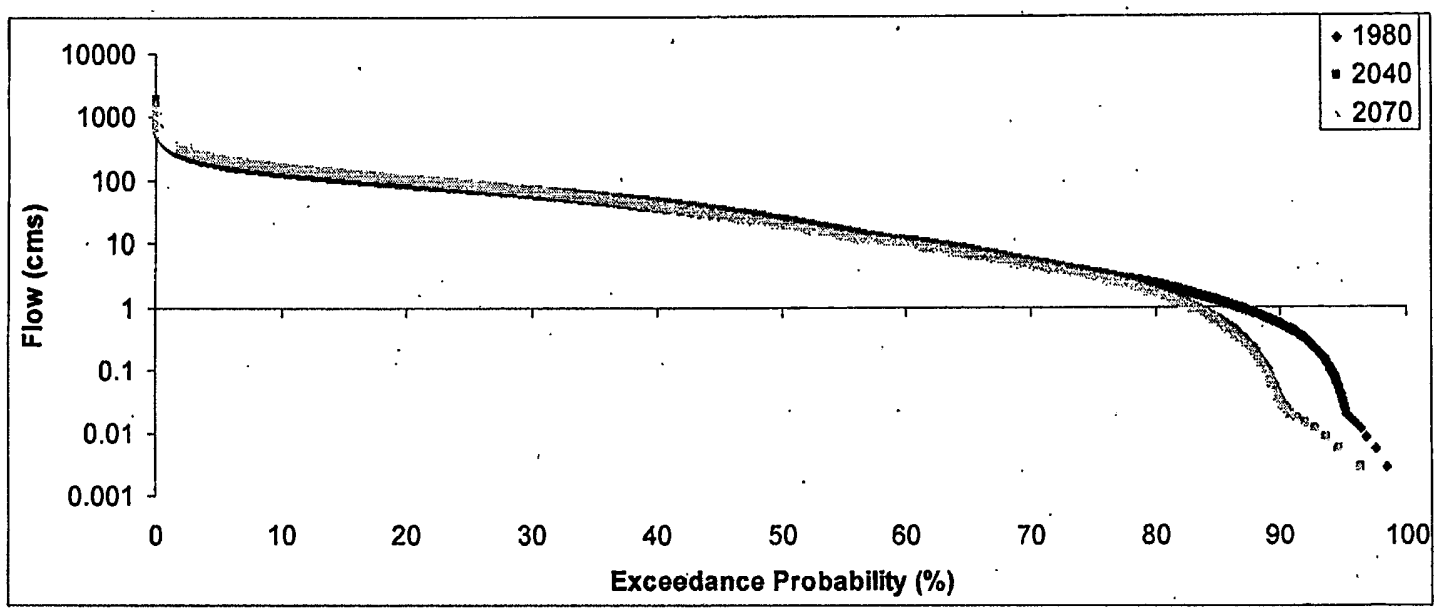

Figure 6.7: Daily flow duration curves for baseline and future periods resulting from the high-change climate scenario, plotted with a logarithmic scale.

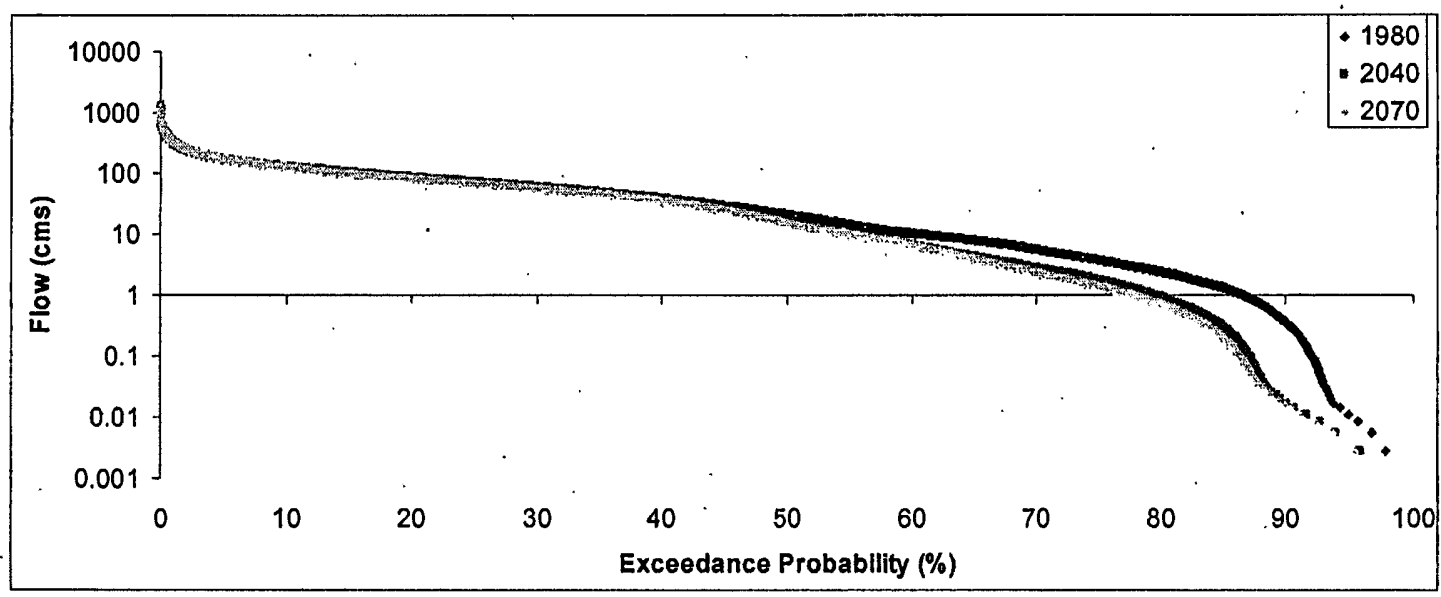

Figure 6.8: Daily flow duration curves for baseline and future periods resulting from the low-change climate scenario, plotted with a logarithmic scale.

It is not only the low flows that are likely to be affected by increased hydrologic variability under climate change. The flow duration curves for only the highest five percent of flows, those exceeded less than five percent of the time, show that these flows are higher in magnitude under climate change than the baseline for both the high-change and low-change climate scenarios (Figures 6.9 and 6.10). The magnitude of these increases in high flow ranges from sixty-nine to eighty percent for the high-change scenario and twenty-five to thirty-two percent for the low-change 
scenario (Table 6.6). Except for the low-change scenario in the 2040s, these changes are all significant at the 0.01 level (Table 6.7). This analysis indicates that the TRB is likely to experience increased hydrologic variability as a result of climate change, with lower low flows and higher high flows.

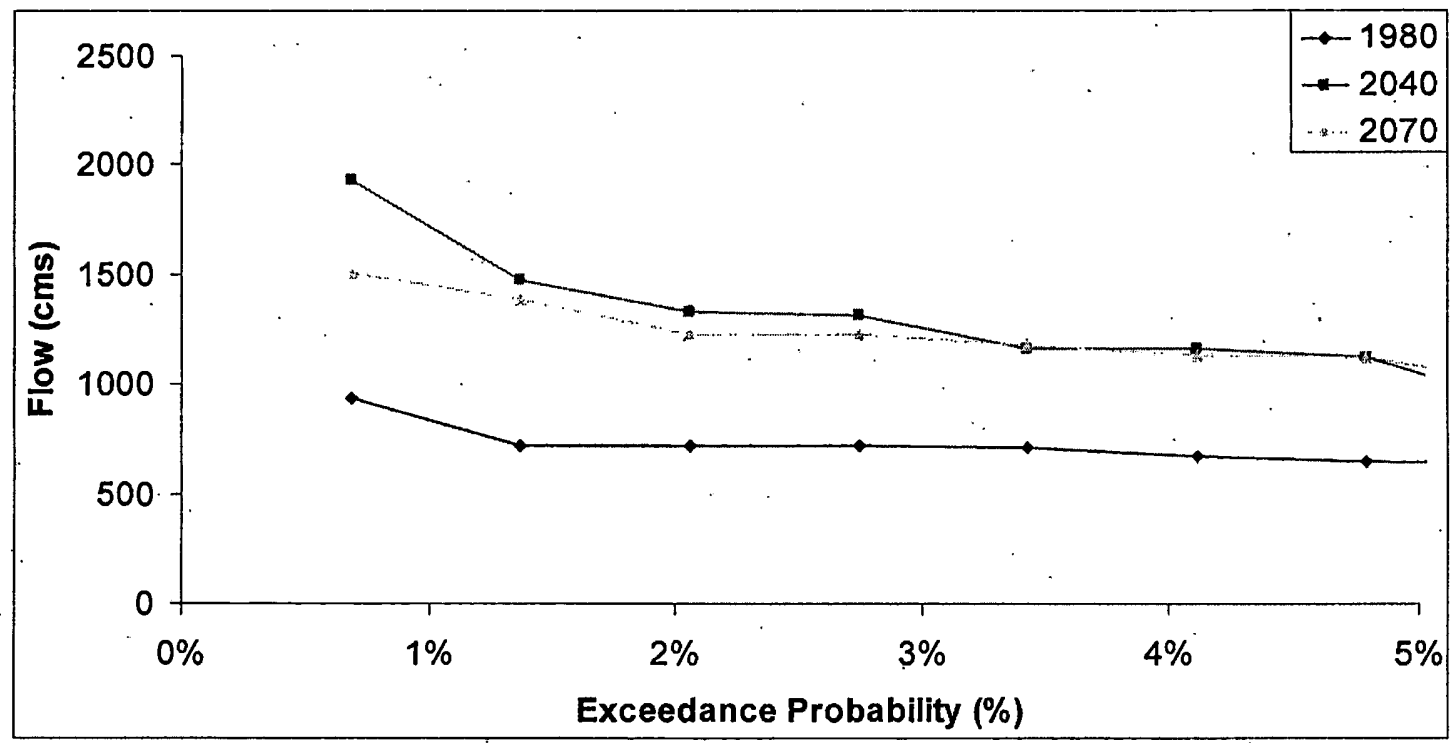

Figure 6.9: Flow duration curves for the baseline and future period five-percent highest flows resulting from the high-change climate scenario.

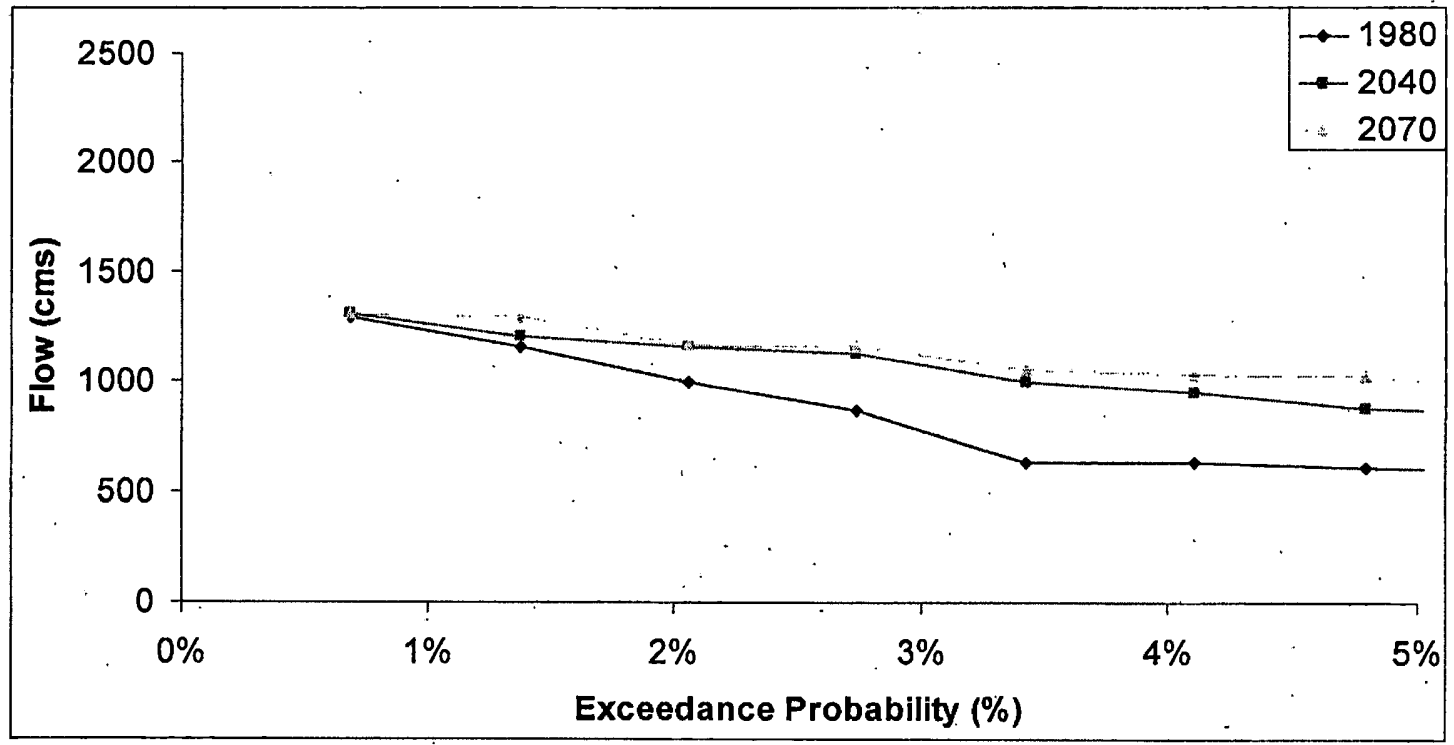

Figure 6.10: Flow duration curves for the baseline and future period five-percent highest flows resulting from the low-change climate scenario. 
Table 6.6: Percent changes in five-percent highest flows for the 2040s and 2070s resulting from the high- and low-change climate scenarios.

\begin{tabular}{|l|r|r|}
\hline Period & $\begin{array}{l}\text { High } \\
\text { Change }\end{array}$ & $\begin{array}{l}\text { Low } \\
\text { Change }\end{array}$ \\
\hline 2040 s & $80 \%$ & $25 \%$ \\
\hline 2070 s & $69 \%$ & $32 \%$ \\
\hline
\end{tabular}

Table 6.7: Results of two-tailed t-test for significance of changes in fifthpercentile flows compared to the baseline for low-change and high-change climate scenarios.

\begin{tabular}{|l|c|c|}
\hline Scenario & 2040 & 2070 \\
\hline $\begin{array}{l}\text { Low- } \\
\text { Change }\end{array}$ & -1.89 & $-3.68^{* *}$ \\
\hline $\begin{array}{l}\text { High- } \\
\text { Change }\end{array}$ & $-4.25^{\star *}$ & $-5.63^{\star *}$ \\
\hline
\end{tabular}

$* *$ Significant at the 0.01 level.

C. Soil Moisture Deficit and Flow Partitioning

In addition to mean and extreme runoff, I also modeled changes in several other hydrological parameters resulting from the climate change scenarios. Figures 6.11 and 6.12 show changes in potential evapotranspiration (PET) as it relates to precipitation for the high- and low-change climate scenarios, respectively. The summer soil moisture deficit, when PET exceeds precipitation, is projected to grow more severe as a result of climate change, because of decreasing precipitation and increasing PET from higher temperatures. Figures 6.13 and 6.14 show changes in the partitioning of runoff into surface flow and groundwater flow as a result of climate change for the high- and low-change scenarios. Currently, the dry summer conditions are ameliorated by a relatively steady input of groundwater, but as groundwater flows become more seasonally variable, these summer groundwater flows will decline.

Consequently, groundwater may not reliably supplement summer flows under a future of climate change. 


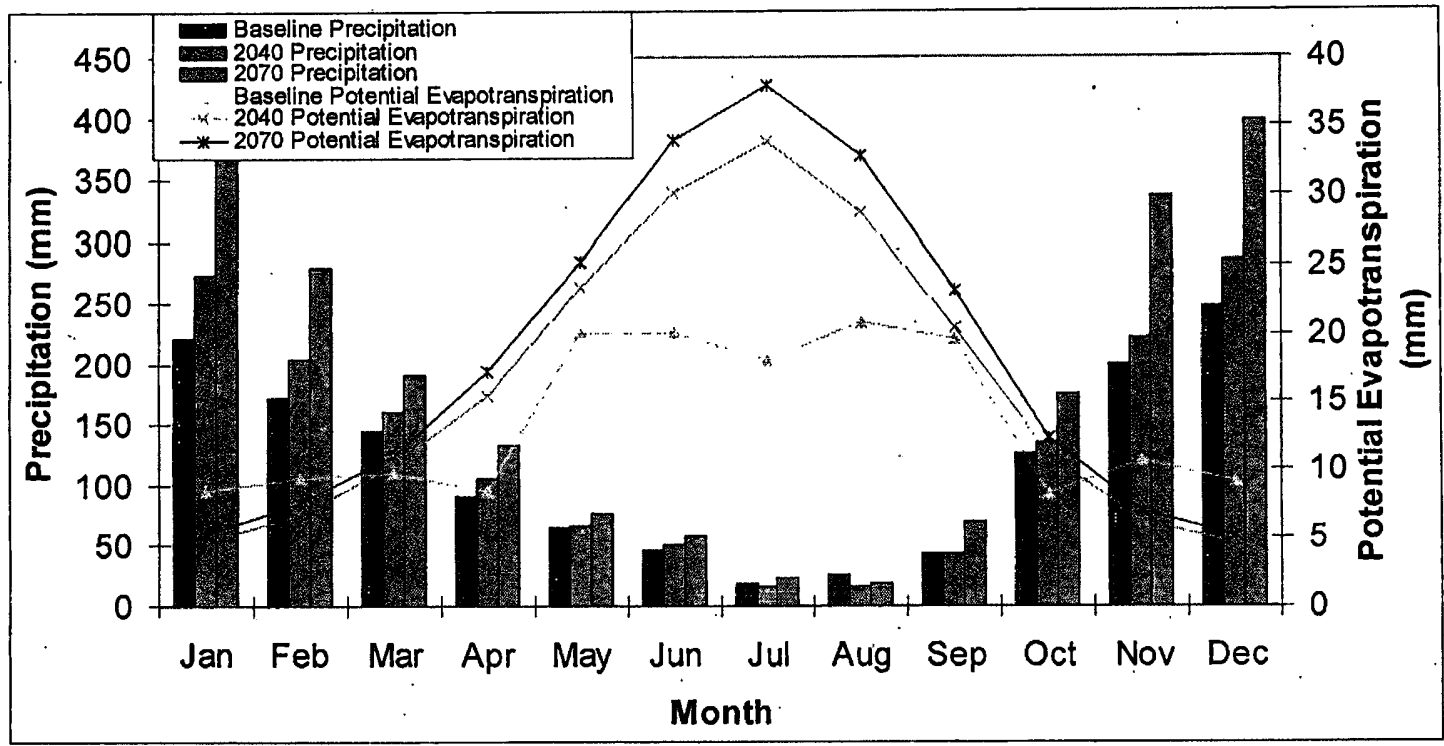

Figure 6.11: Precipitation and potential evapotranspiration for the baseline and high-change climate scenario.

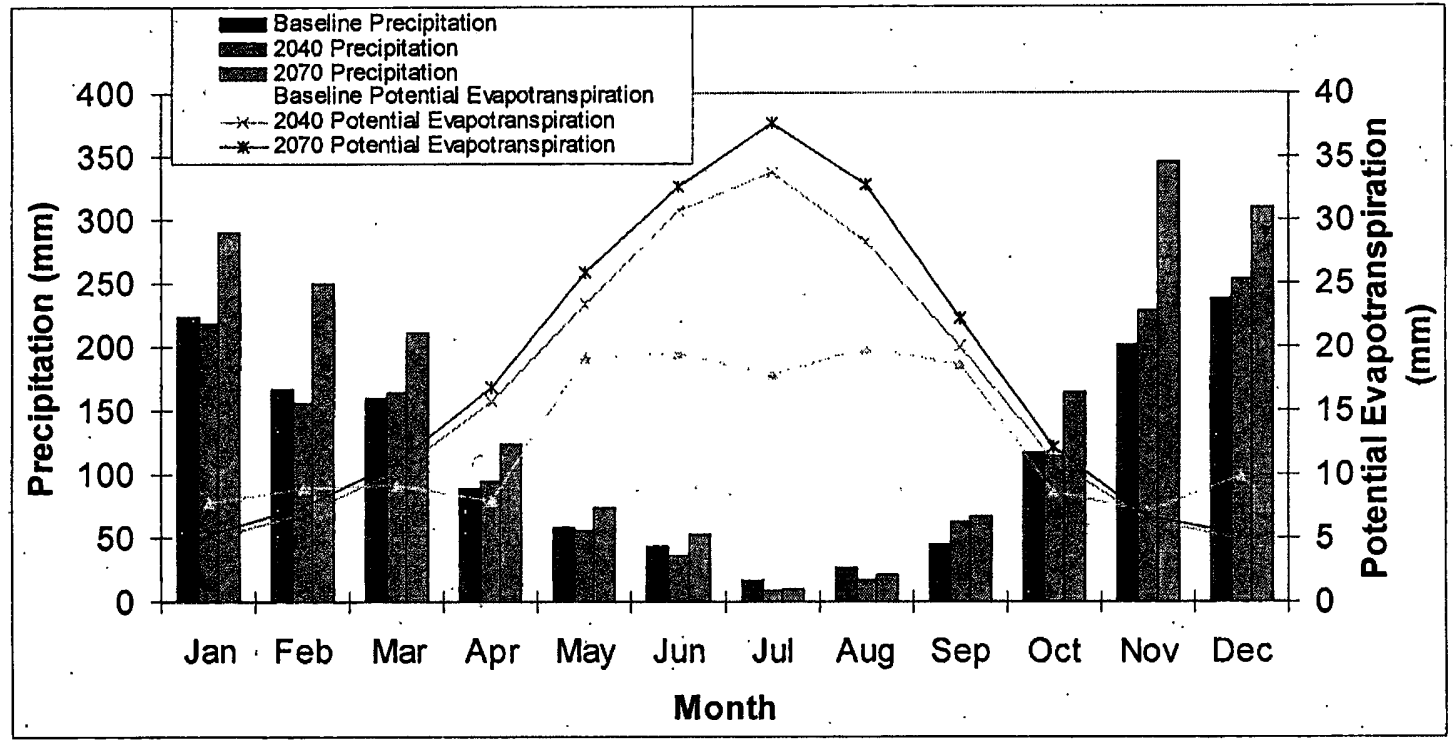

Figure 6.12: Precipitation and potential evapotranspiration for the baseline and low-change climate scenario. 


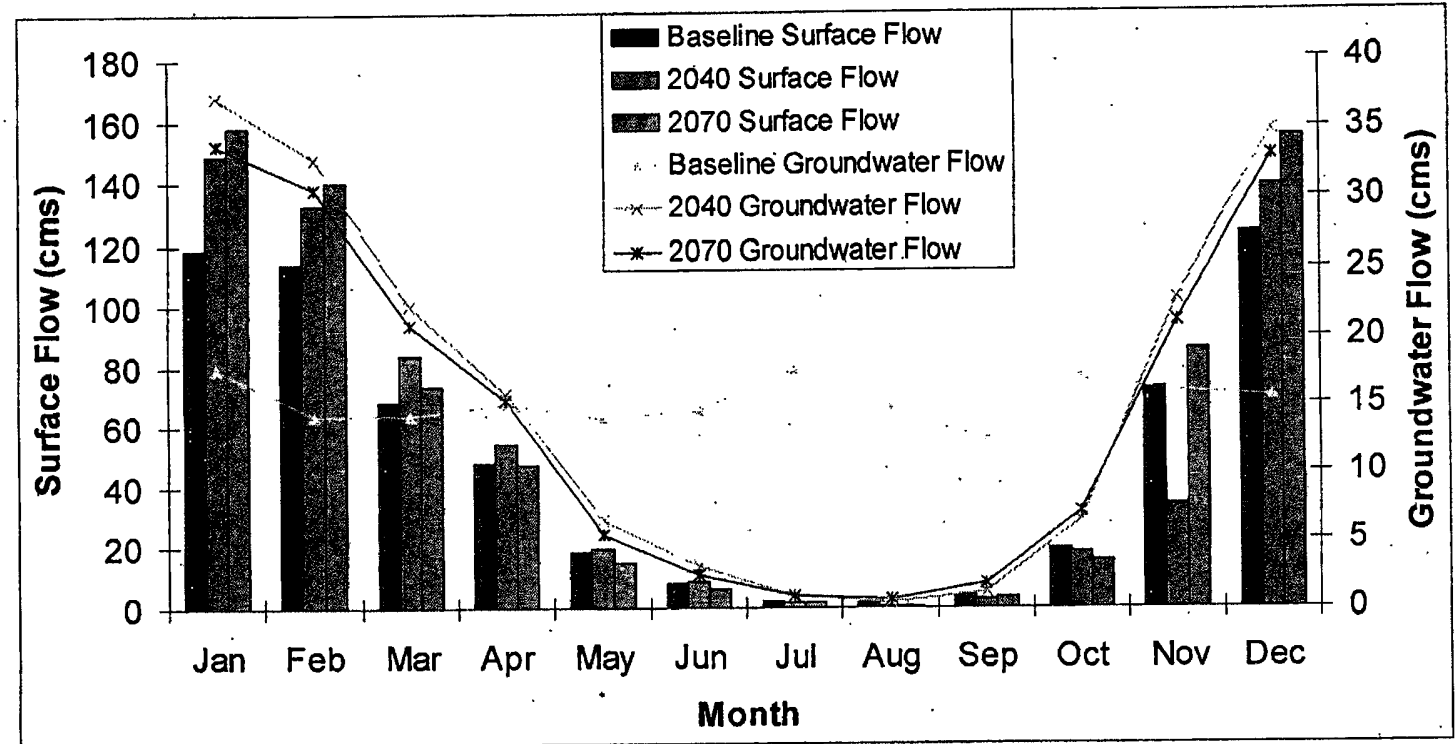

Figure 6.13: Surface and groundwater flows for the baseline and high-change climate scenario.

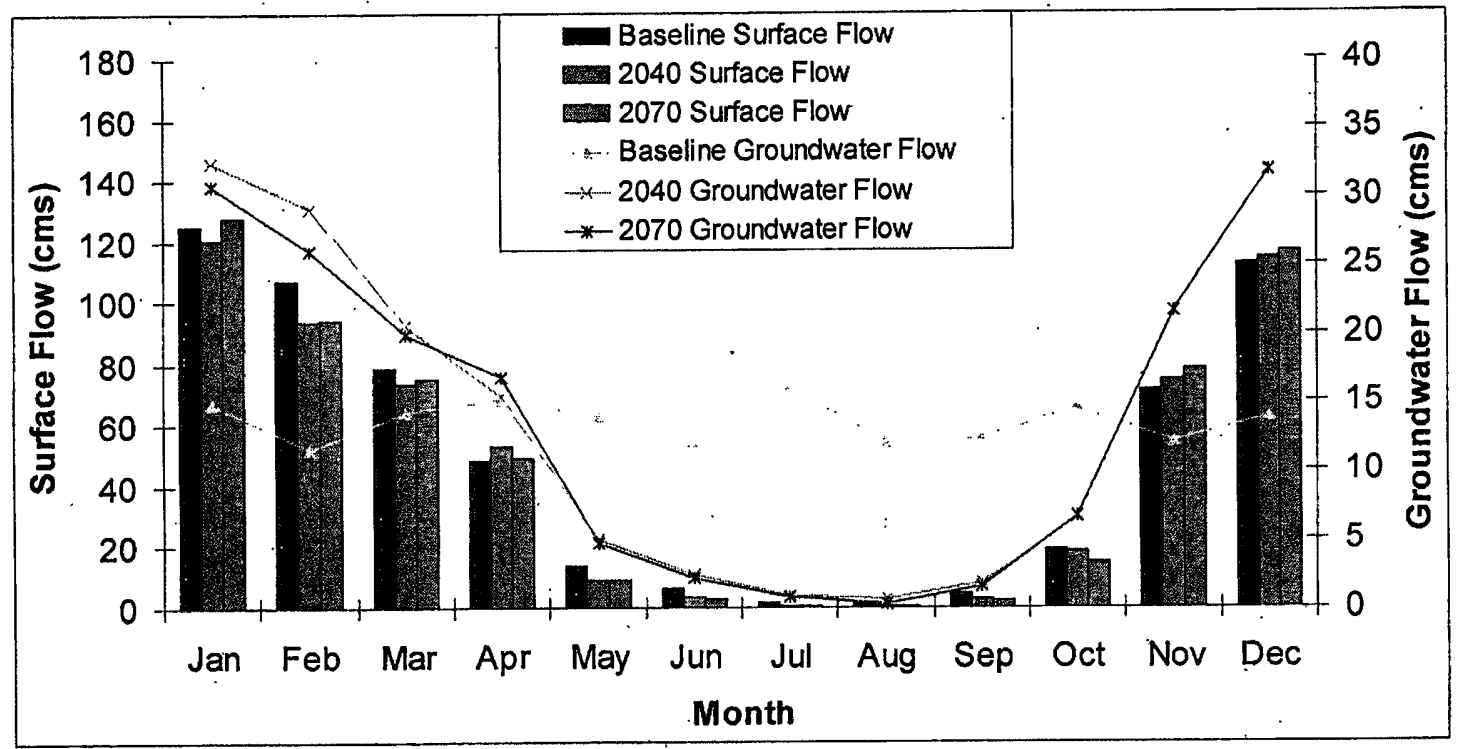

Figure 6.14: Surface and groundwater flows for the baseline and low-change climate scenario.

\section{Impacts of Urban Development on Hydrology}

\section{A. Basin-Scale Mean Hydrology}

Figure 6.15 shows the results of the development and conservation land use scenarios on monthly flow in the entire TRB. The development scenario results in 
increased flow in each month, while the conservation scenario decreases each month's flow. This is probably because the development scenario includes a large increase in urban land, with its associated impervious surfaces, while the conservation scenario includes increased wetland area because of restoration activities, resulting in increased storage of precipitation. Table 6.8 shows that that the average magnitude of these changes is approximately a twenty-one percent increase for the development scenario and a sixteen percent.decrease for the conservation scenario. These changes are significant at the 0.01 level for both scenarios (Table 6.9).

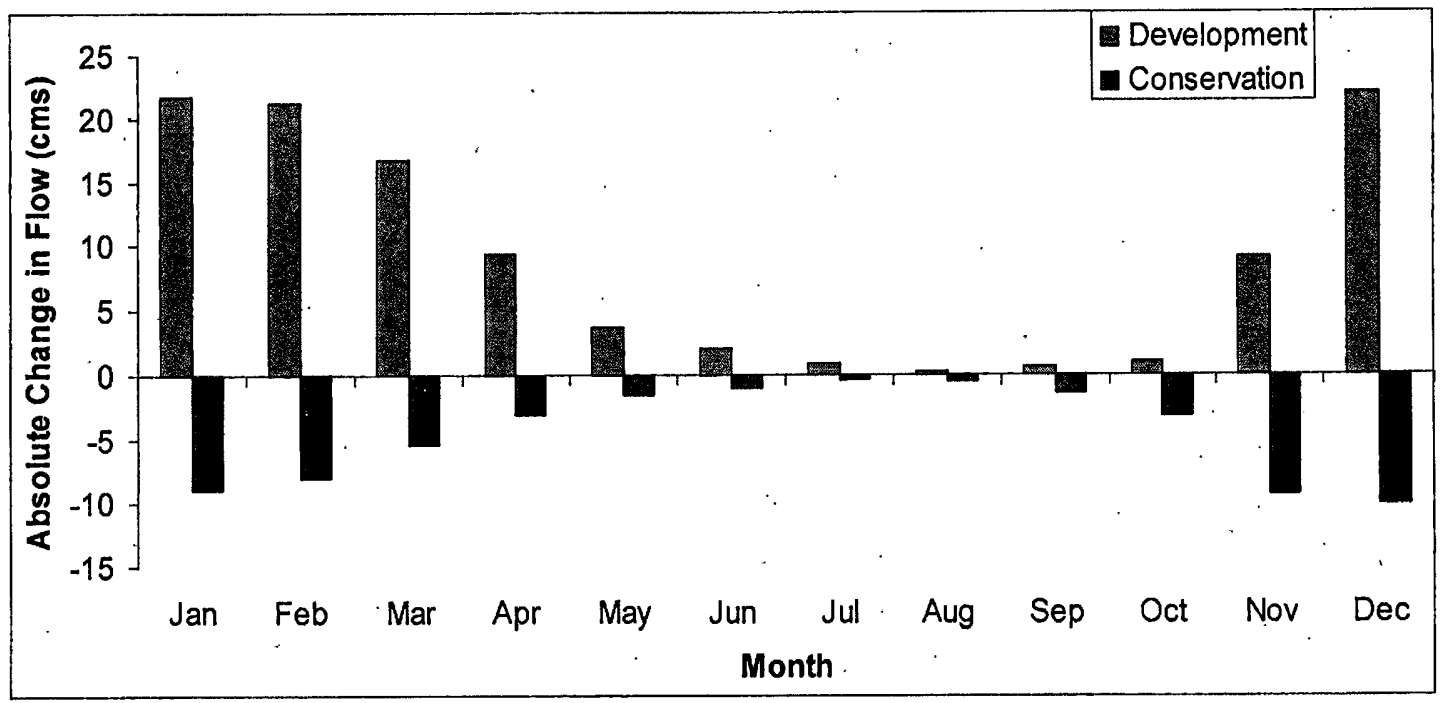

Figure 6.15: Absolute changes in monthly flow resulting from the development and conservation land use scenarios for the Tualatin River Basin. 
Table 6.8: Percent changes in monthly flow resulting from the development and conservation land use scenarios for the Tualatin River Basin.

\begin{tabular}{|l|r|r|}
\hline Month & Development & Conservation \\
\hline January & $25 \%$ & $-10 \%$ \\
\hline February & $26 \%$ & $-10 \%$ \\
\hline March & $27 \%$ & $-9 \%$ \\
\hline April & $27 \%$ & $-9 \%$ \\
\hline May & $25 \%$ & $-11 \%$ \\
\hline June & $24 \%$ & $-13 \%$ \\
\hline July & $27 \%$ & $-13 \%$ \\
\hline August & $10 \%$ & $-33 \%$ \\
\hline September & $11 \%$ & $-28 \%$ \\
\hline October & $9 \%$ & $-28 \%$ \\
\hline November & $18 \%$ & $-18 \%$ \\
\hline December & $25 \%$ & $-11 \%$ \\
\hline Average & $21 \%$ & $-16 \%$ \\
\hline
\end{tabular}

Table 6.9: Results of two-tailed t-test for significance of changes in flow compared to the baseline for the development and conservation scenarios for the Tualatin River Basin.

\begin{tabular}{|l|l|}
\hline Scenario & $t$ \\
\hline Development & $-11.54^{\star *}$ \\
\hline Conservation & $6.79^{\star \star}$ \\
\hline
\end{tabular}

**Significant at the 0.01 level.

Figure 6.16 shows the seasonal changes in basin-scale flows resulting from the urban development scenarios. Again, the pattern of increased flows for the development scenario and decreased flows for the conservation scenario is clear. The relative magnitude of the changes is fairly uniform across all seasons, with an average increase of approximately twenty-six percent for the development scenario and an average decrease of ten percent for the conservation scenario (Table 6.10). 


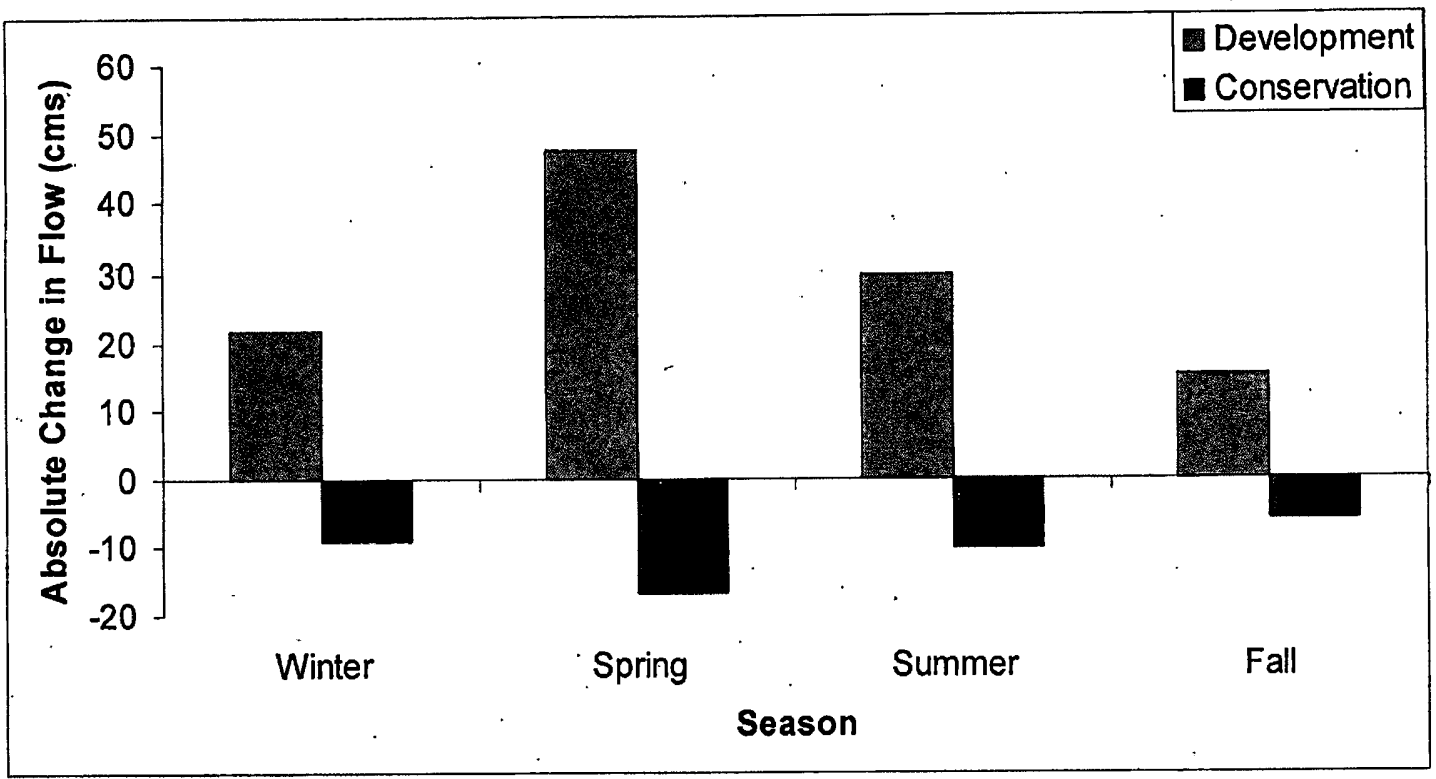

Figure 6.16: Absolute changes in seasonal flow resulting from the development and conservation land use scenarios for the Tualatin River Basin.

Table 6.10: Percent changes in seasonal flow resulting from the development and conservation land use scenarios for the Tualatin River Basin.

\begin{tabular}{|l|r|r|}
\hline Season & Development & Conservation \\
\hline Winter & $25 \%$ & $-11 \%$ \\
\hline Spring & $26 \%$ & $-9 \%$ \\
\hline Summer & $27 \%$ & $-9 \%$ \\
\hline Fall & $26 \%$ & $-10 \%$ \\
\hline Average & $26 \%$ & $-10 \%$ \\
\hline
\end{tabular}

B. Basin-Scale Extreme Hydrology

As with climate change, I created flow duration curves for the baseline, development, and conservation land use scenarios, to determine whether urban development will affect hydrologic variability in the basin. Flows are higher for the development scenario than the baseline, and lower for the conservation scenario (Figure 6.13). Fifth-percentile flows are twenty-three percent higher than baseline for the development scenario and fourteen percent lower for the conservation scenario (Table 6.11). This means that flooding is more likely to occur under the development 
scenario than present conditions and, under the conservation scenario, it is somewhat less likely to occur. The changes are significant at the 0.01 level for the development scenario, but not for the conservation scenario (Table 6.12).

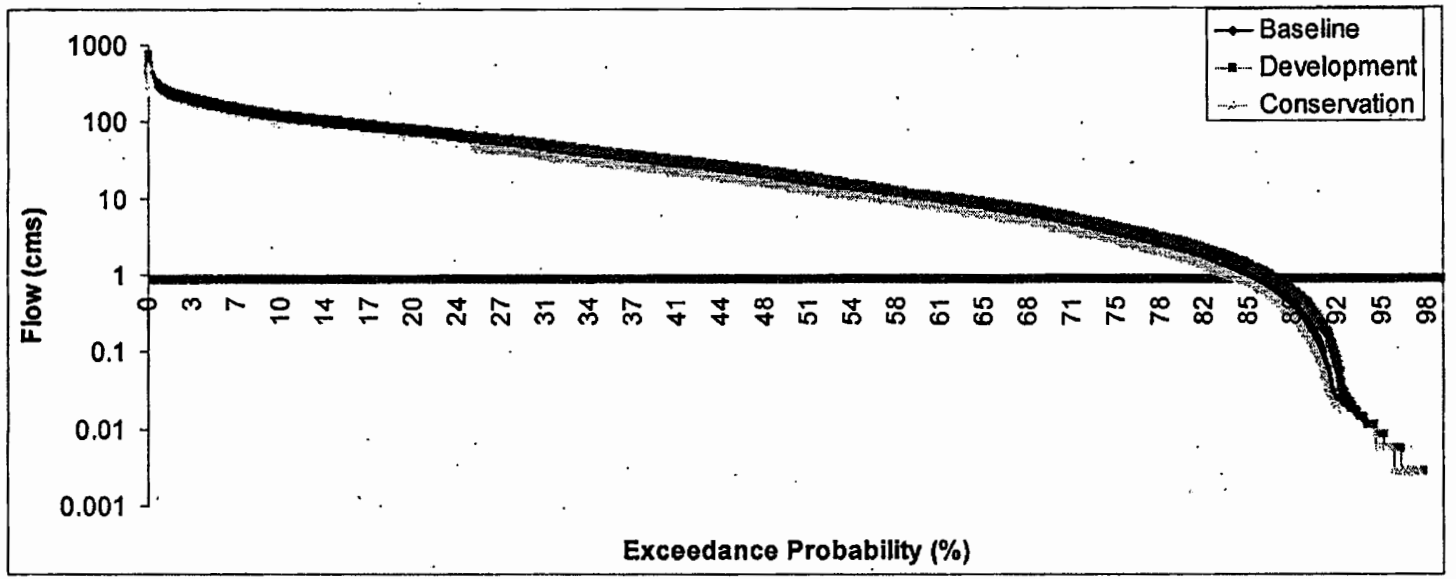

Figure 6.17: Flow duration curves for the baseline, development, and conservation land use scenarios.

Table 6.11: Percent changes in five-percent highest flows resulting from the development and conservation land use scenarios.

\begin{tabular}{|l|r|}
\hline Scenario & $\begin{array}{l}\text { Change in High } \\
\text { Flow }\end{array}$ \\
\hline Development & $23 \%$ \\
\hline Conservation & $-14 \%$ \\
\hline
\end{tabular}

Table 6.12: Results of two-tailed $t$-test for significance of changes in five-percent highest flows compared to the baseline for development and conservation land use scenarios.

\begin{tabular}{|l|l|}
\hline Scenario & $t$ \\
\hline Development & $-3.30^{\star *}$ \\
\hline Conservation & 1.71 \\
\hline
\end{tabular}

**Significant at the 0.01 level.

C. Basin-Scale Flow Partitioning

Figure 6.18 shows the partitioning of runoff into surface and groundwater . flows under the baseline, development, and conservation land use scenarios.

Groundwater flows are higher than baseline for the conservation scenario, and lower than baseline for the development scenario. This is in line with the overall pattern of 
hydrological changes in the basin, with increased wetland area providing a source of flows in the conservation scenario, while the higher impervious surface area of the development scenario limits groundwater recharge.

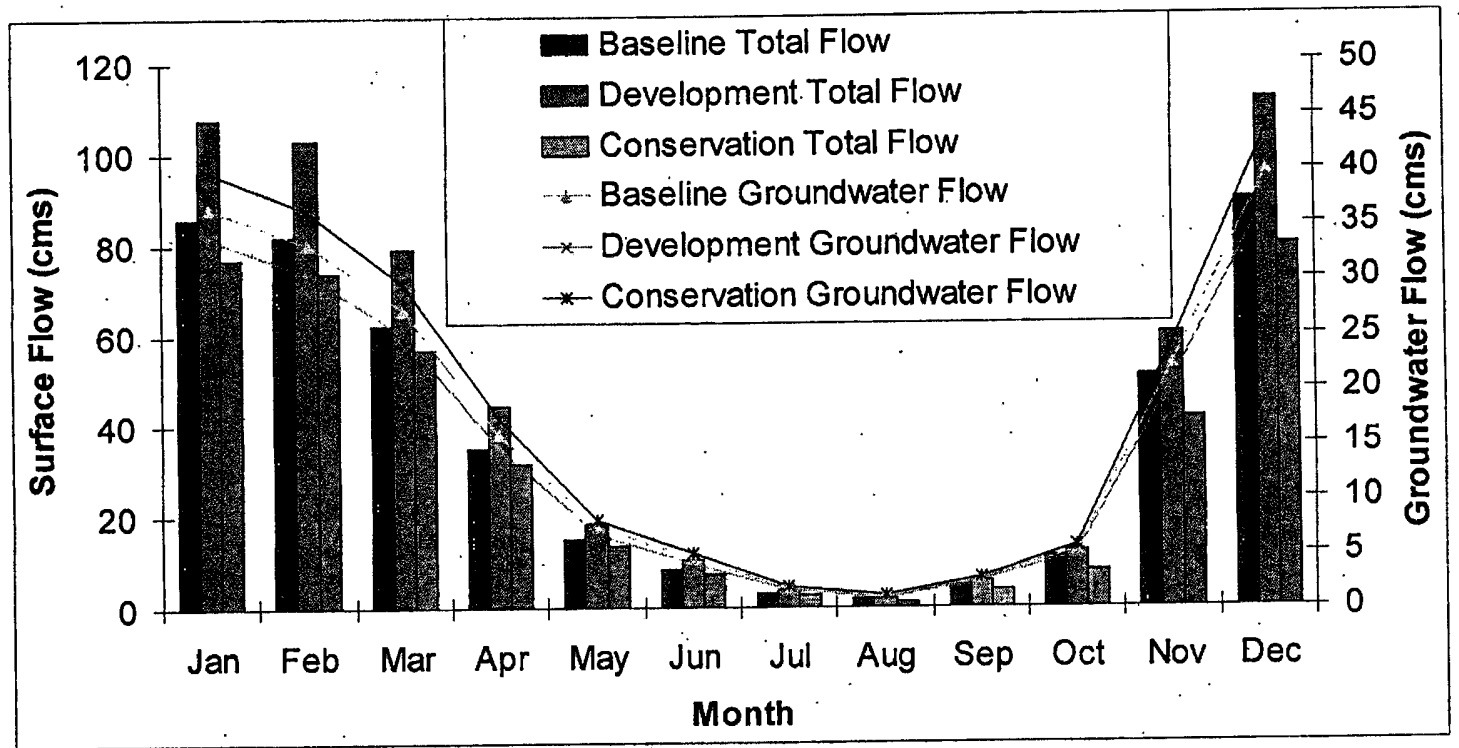

Figure 6.18: Surface and groundwater flows for the baseline, development, and conservation land use scenarios.

\section{Sub-Basin Impacts}

The hydrologic changes resulting from urban development in the two separately modeled sub-basins are substantially different from those in the TRB as a whole. In the Upper Tualatin River sub-basin, both land use scenarios include substantial increases in monthly flow, particularly the development scenario, as a result of the increase in urban area (Figure 6.19). Average monthly flows more than double under the development scenario and increase by approximately fifty-four percent under the conservation scenario (Table 6.13), which are higher-magnitude changes than those at the basin scale. Figure 6.20 shows these changes at the seasonal scale. The relative magnitude of the changes is fairly uniform across seasons for the 
conservation scenario, but much higher in spring and summer for the development scenario (Table 6.14). The reason that runoff increases under the conservation scenario in the Upper Tualatin River sub-basin, while. it decreases at the scale of the entire TRB, may be that there is actually a net loss of wetlands in the Upper Tualatin (Figure 6.21). The changes in flow are significant for both scenarios at the 0.01 level (Table 6.15).

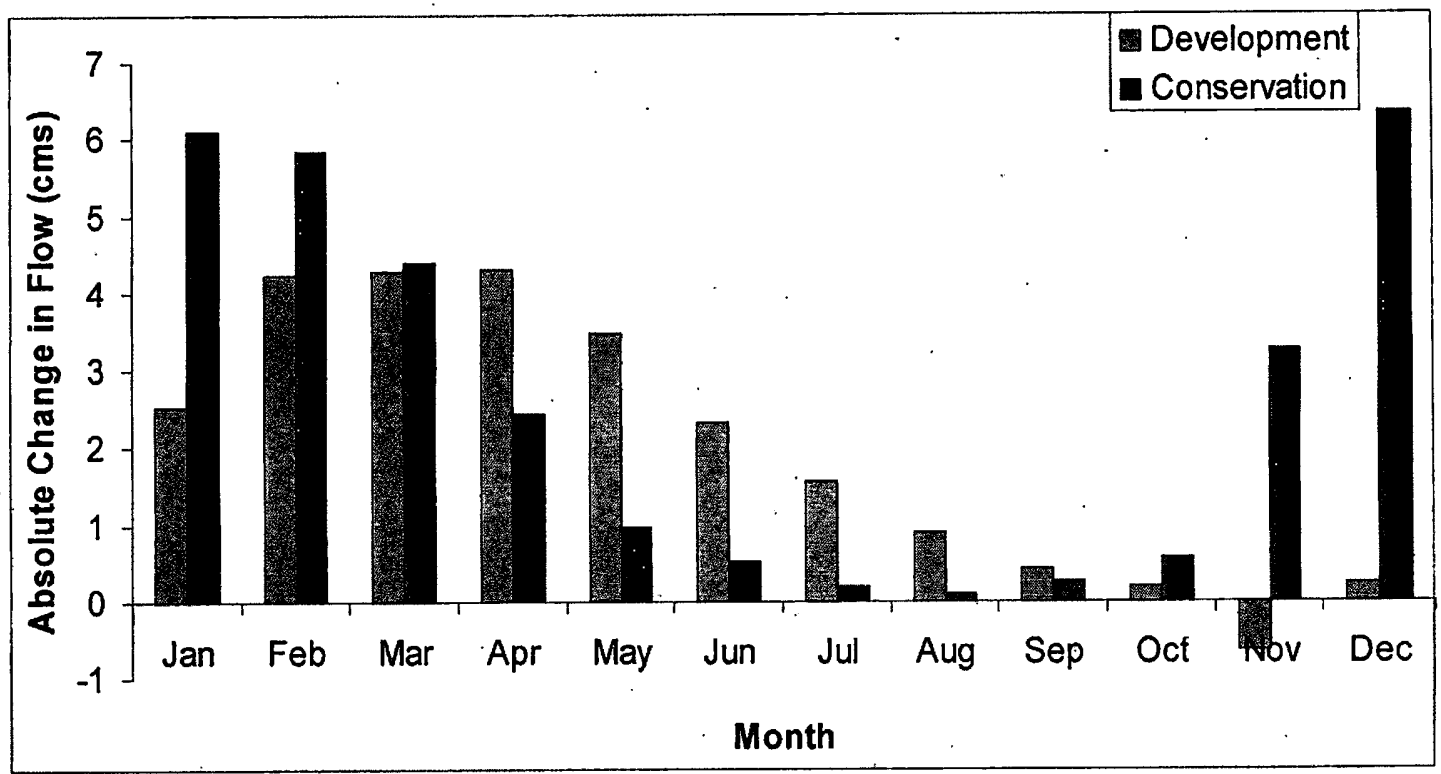

Figure 6.19: Absolute changes in monthly flow resulting from the development and conservation land use scenarios for the Upper Tualatin River sub-basin. 
Table 6.13: Percent changes in monthly flow resulting from the development and conservation land use scenarios for the Upper Tualatin River sub-basin.

\begin{tabular}{|l|r|r|}
\hline Month & Development & Conservation \\
\hline January & $22 \%$ & $53 \%$ \\
\hline February & $38 \%$ & $53 \%$ \\
\hline March & $52 \%$ & $53 \%$ \\
\hline April & $95 \%$ & $53 \%$ \\
\hline May & $193 \%$ & $54 \%$ \\
\hline June & $248 \%$ & $55 \%$ \\
\hline July & $515 \%$ & $60 \%$ \\
\hline August & $601 \%$ & $57 \%$ \\
\hline September & $93 \%$ & $54 \%$ \\
\hline October & $17 \%$ & $52 \%$ \\
\hline November & $-10 \%$ & $53 \%$ \\
\hline December & $2 \%$ & $53 \%$ \\
\hline Average & $155 \%$ & $54 \%$ \\
\hline
\end{tabular}

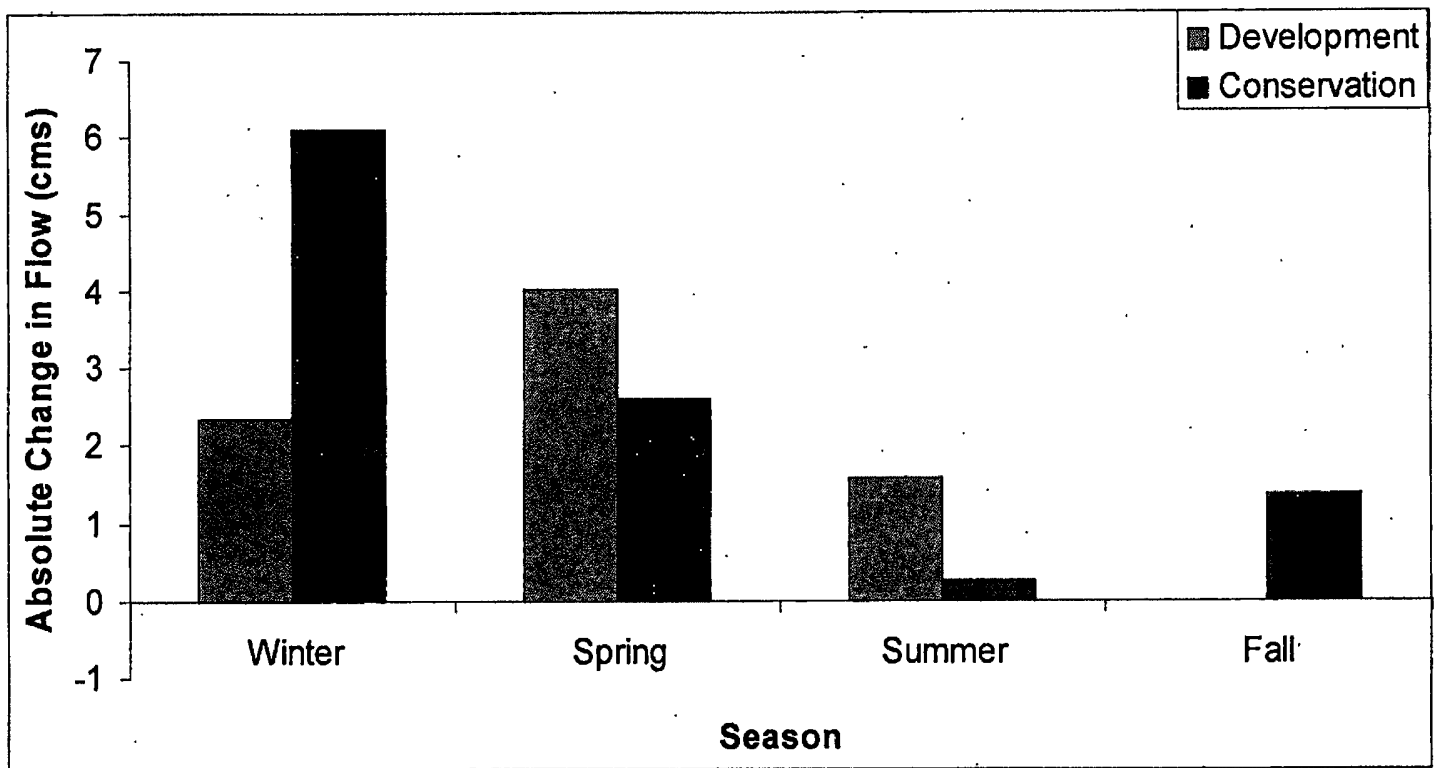

Figure 6.20: Absolute changes in seasonal flow resulting from the development and conservation land use scenarios for the Upper Tualatin River sub-basin.

Table 6.14: Percent changes in seasonal flow resulting from the development and conservation land use scenarios for the Upper Tualatin River sub-basin.

\begin{tabular}{|l|r|r|}
\hline Season & Development & Conservation \\
\hline Winter & $21 \%$ & $53 \%$ \\
\hline Spring & $113 \%$ & $53 \%$ \\
\hline Summer & $455 \%$ & $57 \%$ \\
\hline Fall & $33 \%$ & $53 \%$ \\
\hline Average & $155 \%$ & $54 \%$ \\
\hline
\end{tabular}




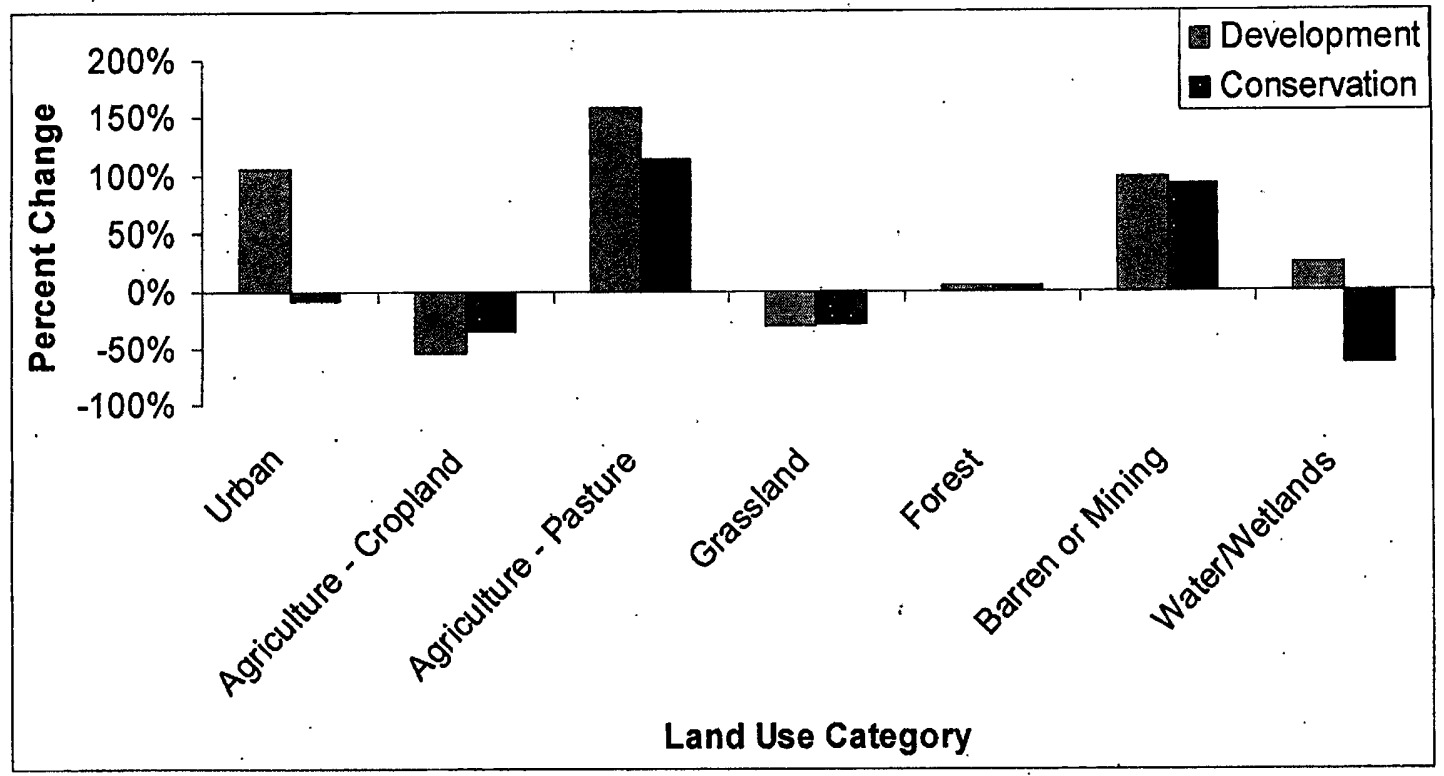

Figure 6.21: Percent changes in land use in the Upper Tualatin River sub-basin under the development and conservation scenarios.

Table 6.15: Results of two-tailed t-test for significance of changes in flow compared to the baseline for the development and conservation scenarios in the Upper Tualatin River sub-basin.

\begin{tabular}{|l|l|}
\hline Scenario & $\mathrm{t}$ \\
\hline Development & $-18.23^{* *}$ \\
\hline Conservation & $-21.19^{* *}$ \\
\hline
\end{tabular}

**Significant at the 0.01 level.

Figure 6.22 shows the changes in monthly flow resulting from the land use scenarios in the Rock Creek sub-basin. Both scenarios cause flow increases in all months, but the magnitude of the increases is much larger for the development scenario, with annual flow more than doubling, as opposed to a modest five percent average increase for the conservation scenario.(Table 6.18). As in the Upper Tualatin River sub-basin, the absolute increases are fairly uniform throughout the year for the conservation scenario, but significantly higher in summer for the development scenario (Figure 6.23, Table 6.17). The high magnitude of these changes can be explained by the increases in urban area for both scenarios, and the decrease in 
wetland area for the development scenario (Figure 6.24). The changes are significant for both scenarios at the 0.05 level (Table 6.16).

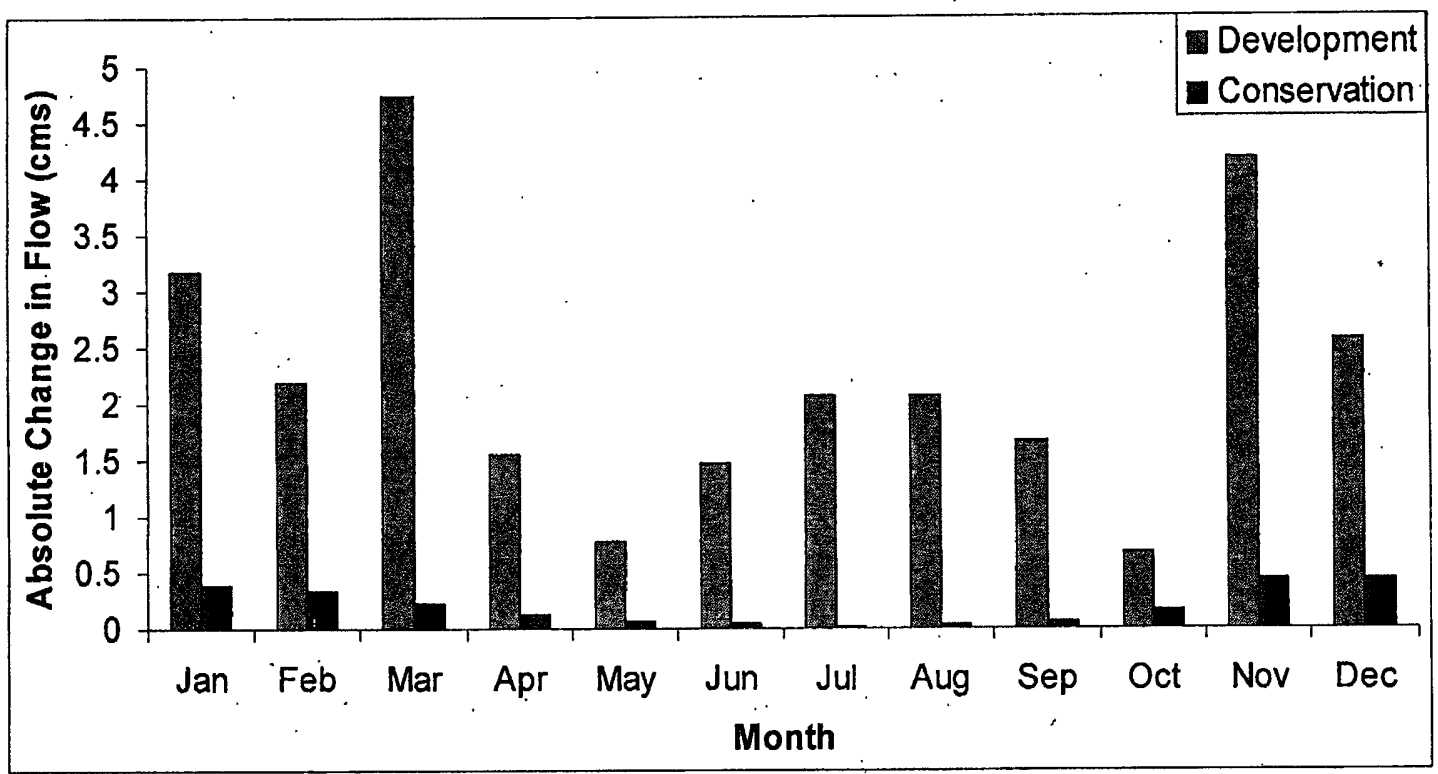

Figure 6.22: Absolute changes in monthly flow resulting from the development and conservation land use scenarios in the Rock Creek sub-basin.

Table 6.16: Percent changes in monthly flow resulting from the development and conservation land use scenarios in the Rock Creek sub-basin.

\begin{tabular}{|l|r|r|}
\hline Month & Development & Conservation \\
\hline January & $35 \%$ & $4 \%$ \\
\hline February & $26 \%$ & $4 \%$ \\
\hline March & $76 \%$ & $4 \%$ \\
\hline April & $44 \%$ & $4 \%$ \\
\hline May & $49 \%$ & $4 \%$ \\
\hline June & $159 \%$ & $5 \%$ \\
\hline July & $647 \%$ & $5 \%$ \\
\hline August & $678 \%$ & $9 \%$ \\
\hline September & $214 \%$ & $9 \%$ \\
\hline October & $38 \%$ & $9 \%$ \\
\hline November & $66 \%$ & $7 \%$ \\
\hline December & $27 \%$ & $5 \%$ \\
\hline Average & $172 \%$ & $6 \%$ \\
\hline
\end{tabular}




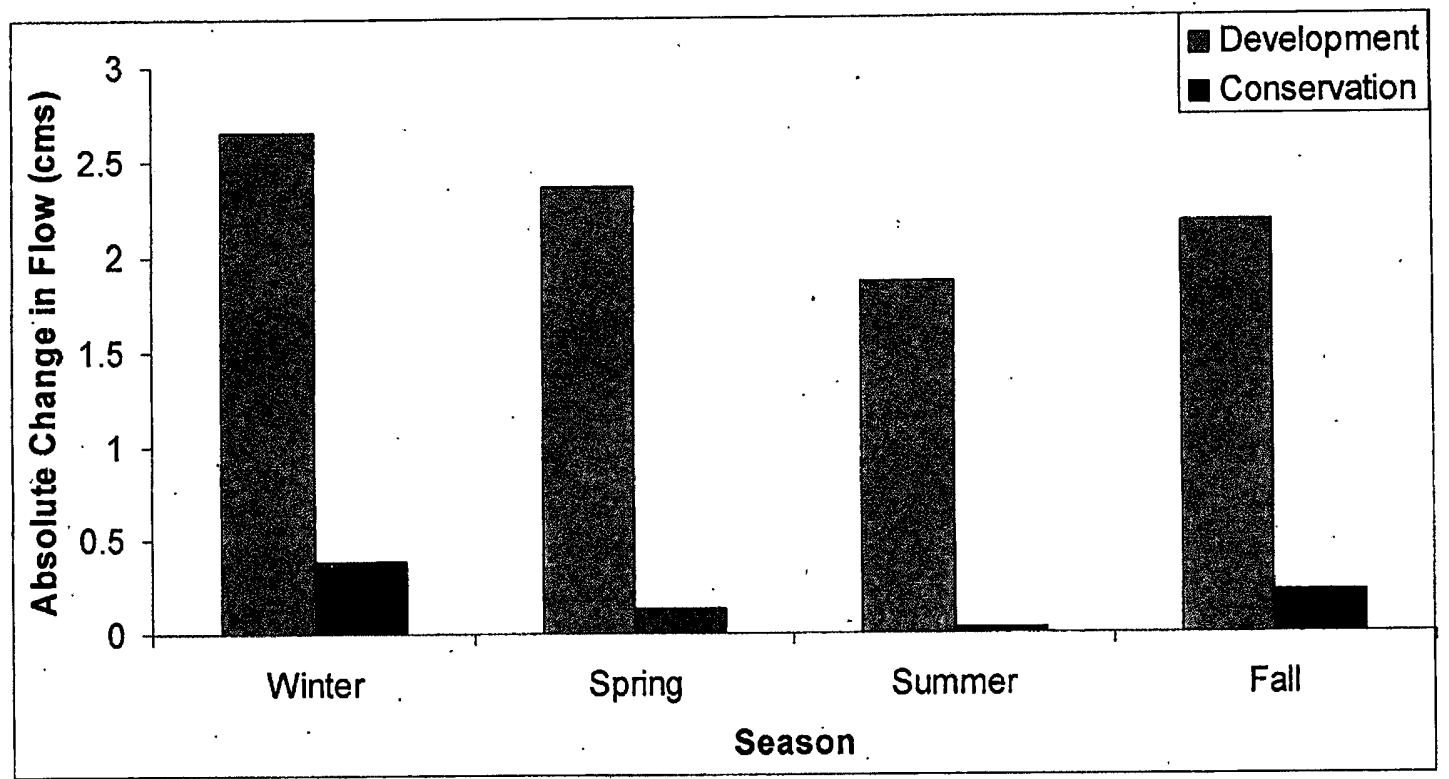

Figure 6.23: Absolute changes in seasonal flow resulting from the development and conservation land use scenarios in the Rock Creek sub-basin.

Table 6.17: Percent changes in seasonal flow resulting from the development and conservation land use scenarios in the Rock Creek sub-basin.

\begin{tabular}{|l|r|r|}
\hline Season & Development & Conservation \\
\hline Winter & $29 \%$ & $4 \%$ \\
\hline Spring & $56 \%$ & $4 \%$ \\
\hline Summer & $495 \%$ & $6 \%$ \\
\hline Fall & $106 \%$ & $8 \%$ \\
\hline Average & $172 \%$ & $6 \%$ \\
\hline
\end{tabular}




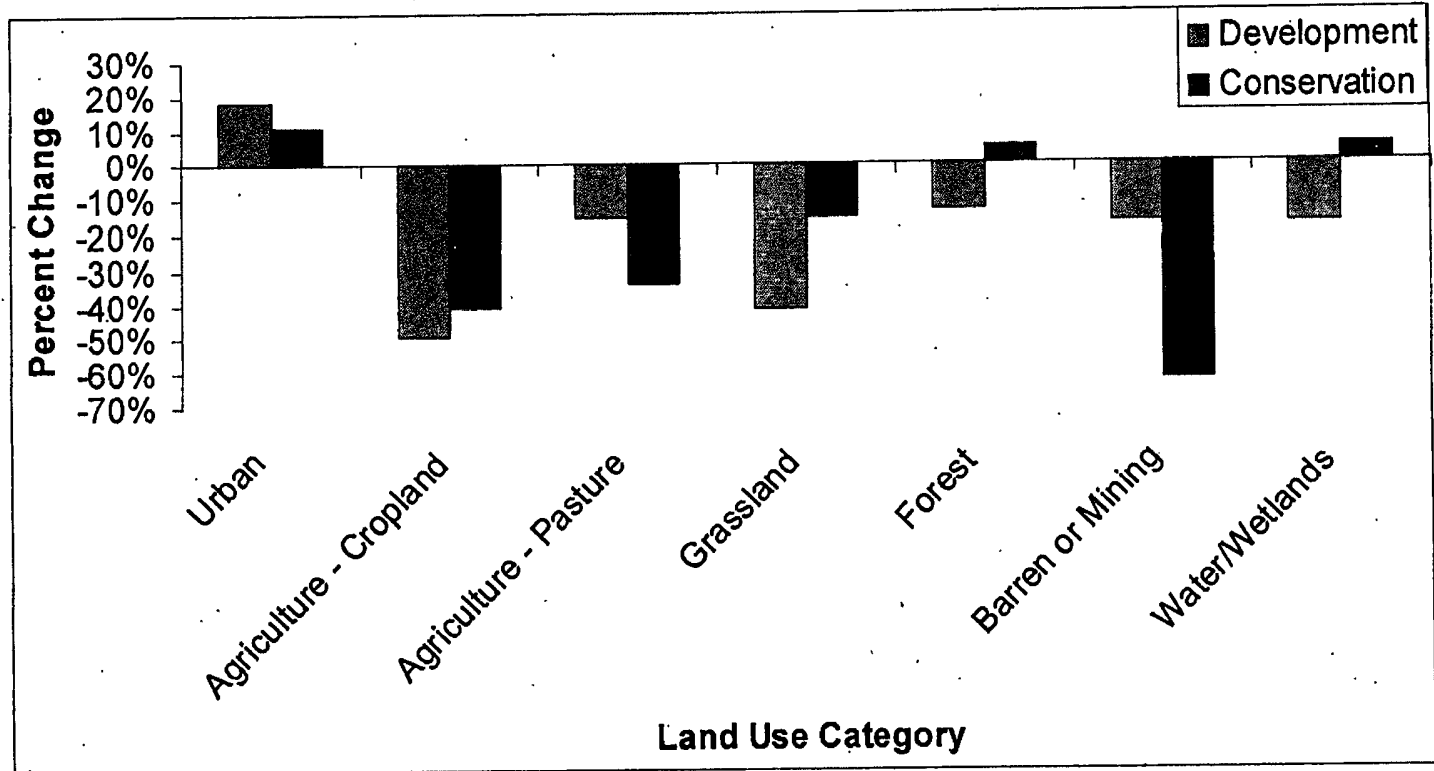

Figure 6.24: Percent changes in land use in the Rock Creek sub-basin under the development and conservation scenarios.

Table 6.18: Results of two-tailed $t$-test for significance of changes in flow compared to the baseline for the development and conservation scenarios in the Rock. Creek sub-basin.

\begin{tabular}{|l|l|}
\hline Scenario & $t$ \\
\hline Development & $-17.86^{* *}$ \\
\hline Conservation & $-2.22^{*}$ \\
\hline
\end{tabular}

*Significant at the 0.05 level.

**Significant at the 0.01 level.

3. Combined Impacts of Climate Change and Urban Development on Hydrology

\section{A. Mean Hydrology}

In addition to modeling the separate impacts of climate change and urban development on basin hydrology, I also modeled their combined impacts, since both types of changes are likely to occur in the TRB over the next several decades. I ran the hydrology model under the highest-change and lowest-change climate scenarios in combination with the development and conservation land use scenarios, for a total of four combined scenarios $[(\mathrm{HCHL}=$ high $(\mathrm{IPSL} 4 \mathrm{~B} 1)$ climate/high (development) land 
use; HCLL = high climate/low (conservation) land use; LCHL = low (CCSM3 B1) climate/high land use; $\mathrm{LCLL}=$ low climate/low land use)]. Figures 6.25 and 6.26 show the results of these combined scenarios for the 2040s and 2070s. The general pattern is the same as for the climate change scenarios, with increases in winter flow and mostly decreases in summer flow, and there are greater differences between the climate change scenarios than between the land use scenarios. This indicates that climate change is likely to more significantly impact hydrology than land use change in the TRB over the study period. For the 2040s, the increases in winter flow range from eleven percent (LCLL in February) to sixty-nine percent (HCHL in January) (Table 6.19). For the 2070s, this increases to a minimum winter increase of twelve percent (ECHL and LCLL in February) and a maximum increase of seventy-eight percent (HCHL and HCLL in January) (Table 6.20). The changes in flow are significant at the 0.01 level for all scenarios except LCLL (Table 6.21). All pairs of combined scenarios have significant differences in flows for the 2040s and 2070s, except those with the same climate scenario (Table 6.22 and 6.23). 


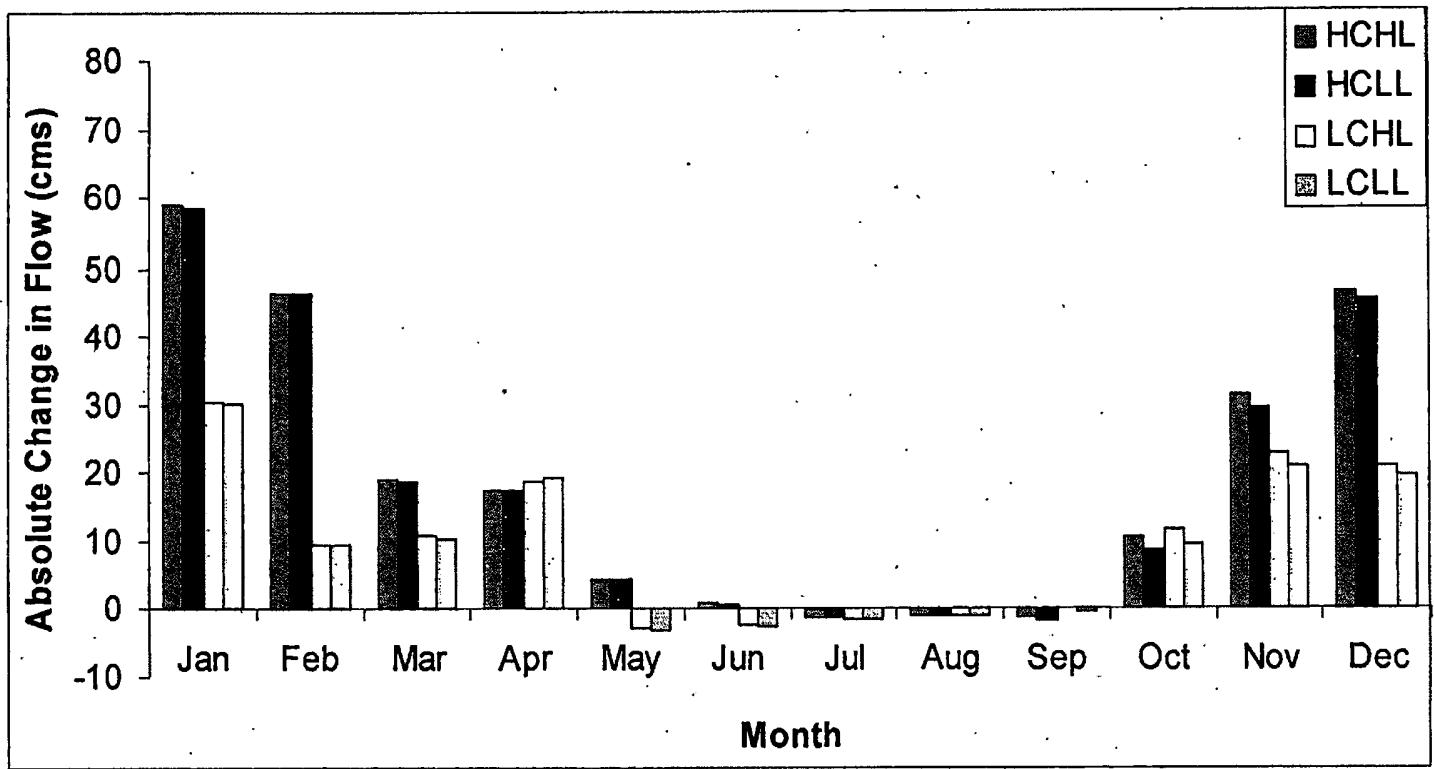

Figure 6.25: Absolute changes in monthly flow resulting from the combined climate change and urban development scenarios for the 2040s.

Note: $H C H L=$ high climate/high land use change; $H C L L=$ high climate/low land use change; $L C H L=$ low climate/high land use change; $L C L L=$ low climate/low land use change.

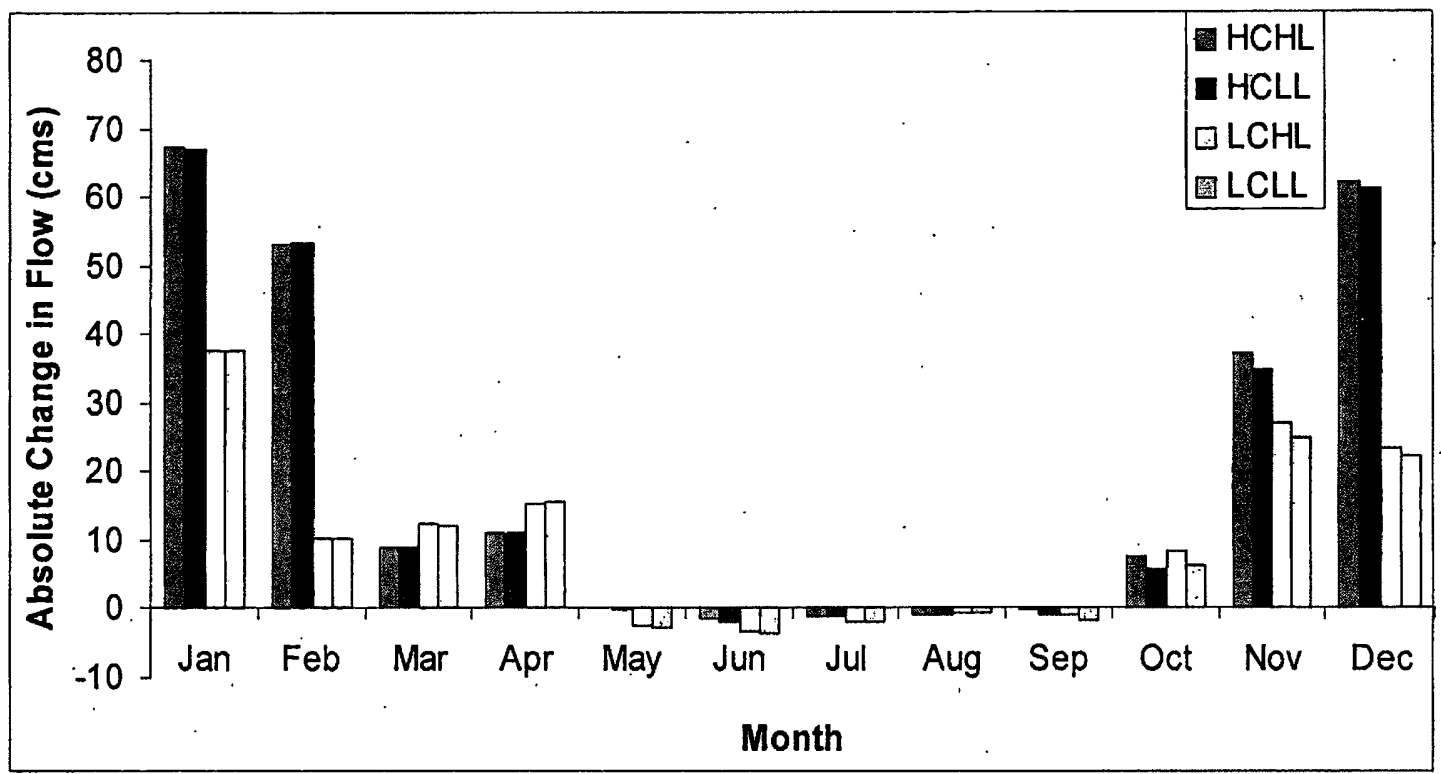

Figure 6.26: Absolute changes in monthly flow resulting from the combined climate change and urban development scenarios for the 2070s.

Note: $H C H L=$ high climate/high land use change; $H C L L=$ high climate/low land use change; $L C H L=$ low climate/high land use change; $L C L L=$ low climate/low land use change. 
Table 6.19: Percent changes in monthly flow resulting from the combined climate change and urban development scenarios for the 2040s.

\begin{tabular}{|l|r|r|r|r|}
\hline Month & HCHL & HCLL & LCHL & LCLL \\
\hline Jan & $69 \%$ & $68 \%$ & $36 \%$ & $35 \%$ \\
\hline Feb & $57 \%$ & $57 \%$ & $12 \%$ & $11 \%$ \\
\hline Mar & $30 \%$ & $30 \%$ & $17 \%$ & $17 \%$ \\
\hline Apr & $50 \%$ & $50 \%$ & $54 \%$ & $55 \%$ \\
\hline May & $30 \%$ & $28 \%$ & $-19 \%$ & $-20 \%$ \\
\hline Jun & $12 \%$ & $8 \%$ & $-27 \%$ & $-31 \%$ \\
\hline Jul & $-38 \%$ & $-41 \%$ & $-49 \%$ & $-50 \%$ \\
\hline Aug & $-47 \%$ & $-54 \%$ & $-53 \%$ & $-60 \%$ \\
\hline Sep & $-22 \%$ & $-33 \%$ & $4 \%$ & $-10 \%$ \\
\hline Oct & $93 \%$ & $77 \%$ & $101 \%$ & $84 \%$ \\
\hline Nov & $61 \%$ & $57 \%$ & $45 \%$ & $41 \%$ \\
\hline Dec & $52 \%$ & $50 \%$ & $23 \%$ & $22 \%$ \\
\hline
\end{tabular}

Table 6.20: Percent changes in monthly flow resulting from the combined climate change and urban development scenarios for the 2070s.

\begin{tabular}{|l|r|r|r|r|}
\hline Month & \multicolumn{1}{|r|}{ HCHL } & HCLL & \multicolumn{1}{l|}{ LCHL } & LCLL \\
\hline Jan & $78 \%$ & $78 \%$ & $44 \%$ & $44 \%$ \\
\hline Feb & $65 \%$ & $65 \%$ & $12 \%$ & $12 \%$ \\
\hline Mar & $14 \%$ & $14 \%$ & $20 \%$ & $19 \%$ \\
\hline Apr & $32 \%$ & $32 \%$ & $44 \%$ & $45 \%$ \\
\hline May & $1 \%$ & $0 \%$ & $-18 \%$ & $-18 \%$ \\
\hline Jun & $-19 \%$ & $-22 \%$ & $-40 \%$ & $-43 \%$ \\
\hline Jul & $-38 \%$ & $-43 \%$ & $-62 \%$ & $-64 \%$ \\
\hline Aug & $-50 \%$ & $-57 \%$ & $-35 \%$ & $-46 \%$ \\
\hline Sep & $-4 \%$ & $-18 \%$ & $-20 \%$ & $-31 \%$ \\
\hline Oct & $66 \%$ & $51 \%$ & $73 \%$ & $56 \%$ \\
\hline Nov & $73 \%$ & $68 \%$ & $53 \%$ & $49 \%$ \\
\hline Dec & $69 \%$ & $68 \%$ & $26 \%$ & $25 \%$ \\
\hline
\end{tabular}

Table 6.21: Results of two-tailed t-test for significance of changes in flow compared to the baseline for the four combined climate change and urban development scenarios.

\begin{tabular}{|l|r|r|}
\hline Scenario & 2040 & 2070 \\
\hline HCHL & $-19.88^{\star \star}$ & $-22.35^{\star \star}$ \\
\hline HCLL & $-19.49^{\star \star}$ & $-21.91^{\star *}$ \\
\hline LCHL & $-11.62^{\star *}$ & $-13.05^{\star \star}$ \\
\hline LCLL & -0.52 & -0.55 \\
\hline
\end{tabular}

**Significant at the 0.01 level. 
Table 6.22: Two-tailed t-test results from multiple paired comparisons of differences in flow among the four combined climate change and urban development scenarios for the 2040s, with significance assessed using false discovery rate.

\begin{tabular}{|l|l|l|l|l|}
\hline Scenarios & $H C H L$ & $H C L L$ & $L C H L$ & LCLL \\
\hline HCHL & - & 0.50 & $8.76^{*}$ & $9.37^{*}$ \\
\hline HCLL & 0.50 & - & $8.76^{*}$ & $8.90^{*}$ \\
\hline LCHL & $8.76^{*}$ & $8.76^{*}$ & - & 0.60 \\
\hline LCLL & $9.37^{*}$ & $8.90^{*}$ & 0.60 & - \\
\hline
\end{tabular}

* Significant at the 0.05 level.

Table 6.23: Two-tailed t-test results from paired multiple comparisons of differences in flow among the four combined climate change and urban development scenarios for the 2070 s, with significance assessed using false discovery rate.

\begin{tabular}{|l|l|l|l|l|}
\hline Scenarios & $\mathrm{HCHL}$ & $\mathrm{HCLL}$ & $\mathrm{LCHL}$ & $\mathrm{LCLL}$ \\
\hline $\mathrm{HCHL}$ & - & 0.57 & $9.96^{*}$ & $10.62^{*}$ \\
\hline $\mathrm{HCLL}$ & 0.57 & - & $9.43^{*}$ & $10.09^{*}$ \\
\hline LCHL & $9.96^{*}$ & $9.43^{*}$ & - & 0.65 \\
\hline LCLL & $10.62^{*}$ & $10.09^{*}$ & 0.65 & - \\
\hline
\end{tabular}

*Significant at the 0.05 level.

Figures 6.27 and 6.28 show the changes from the combined scenarios at the seasonal scale for the 2040s and 2070s. Overall, there are decreases in summer flow and increases in the other seasons. Increases in winter flow range from twenty-three (LCLL) to fifty-nine (HCHL) percent for the 2040s (Table 6.24) and twenty-seven (LCLL) to seventy-one (HCHL) percent for the 2070s (Table 6.25). 


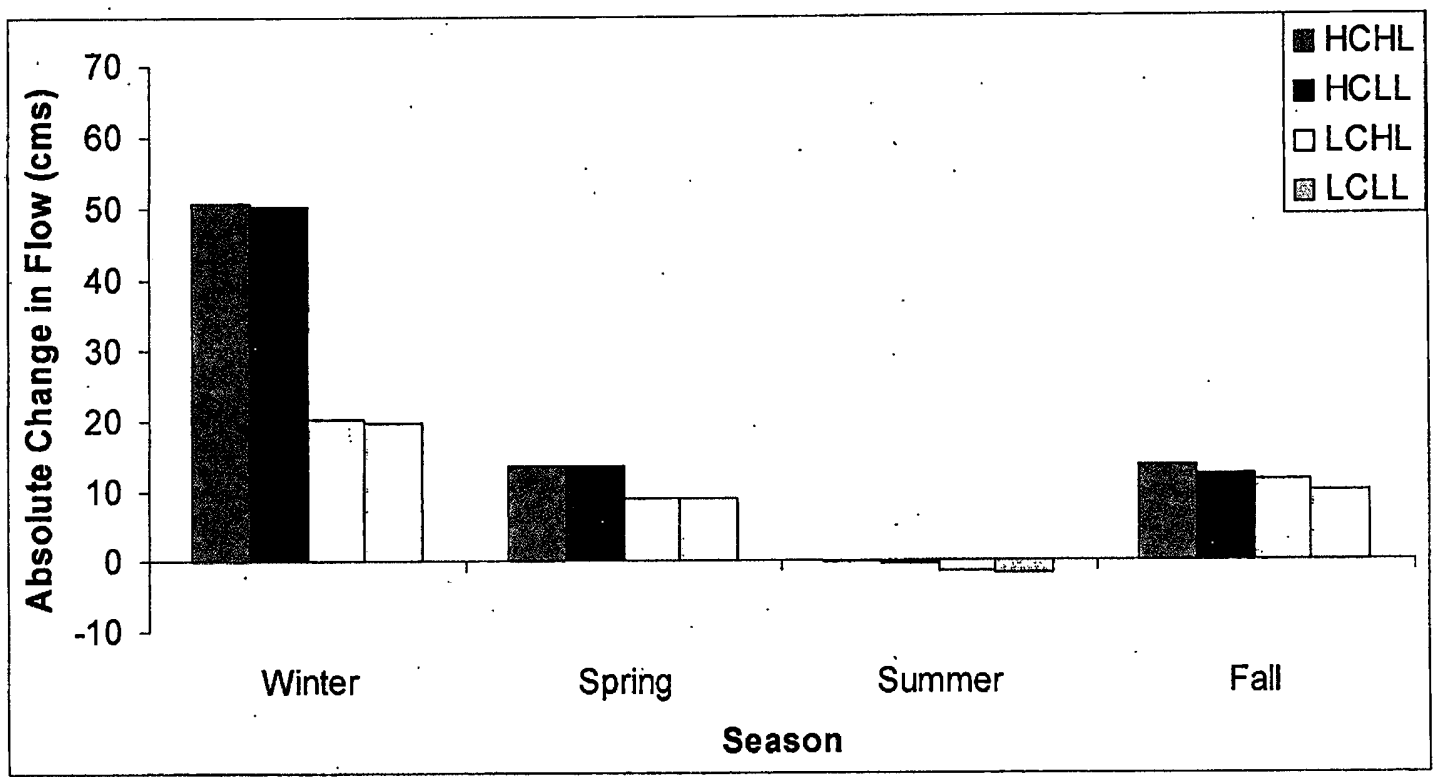

Figure 6.27: Absolute changes in seasonal flow resulting from the combined climate change and urban development scenarios for the 2040s.

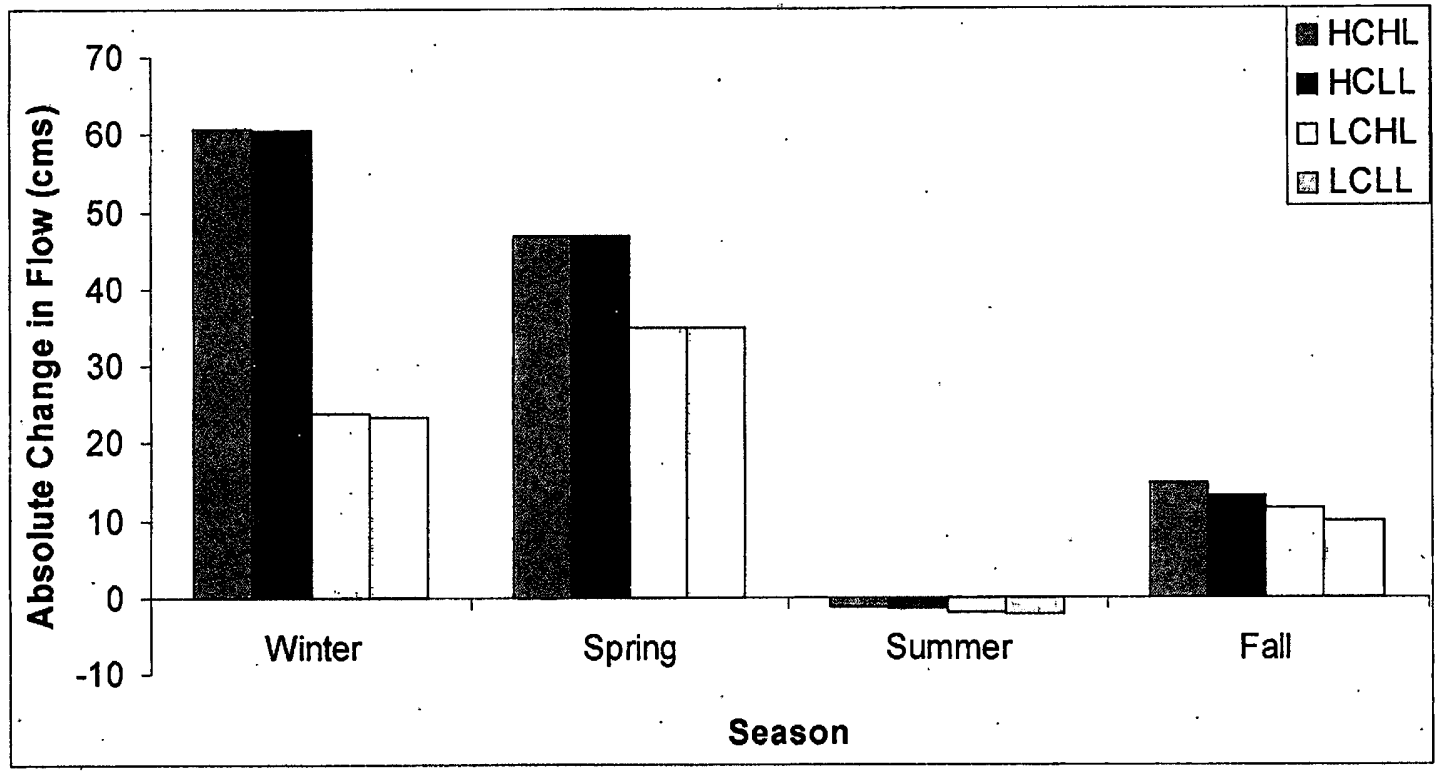

Figure 6.28: Absolute changes in seasonal flow resulting from the combined climate change and urban development scenarios for the 2070s. 
Table 6.24: Percent changes in seasonal flow resulting from the combined climate change and urban development scenarios for the 2040s.

\begin{tabular}{|l|r|r|r|r|}
\hline Season & HCHL & \multicolumn{1}{l|}{ HCLL } & \multicolumn{1}{l|}{ LCHL } & \multicolumn{1}{l|}{ LCL } \\
\hline Winter & $59 \%$ & $58 \%$ & $24 \%$ & $23 \%$ \\
\hline Spring & $36 \%$ & $36 \%$ & $24 \%$ & $24 \%$ \\
\hline Summer & $-7 \%$ & $-12 \%$ & $-35 \%$ & $-39 \%$ \\
\hline Fall & $60 \%$ & $54 \%$ & $51 \%$ & $44 \%$ \\
\hline
\end{tabular}

Table 6.25: Percent changes in seasonal flow resulting from the combined climate change and urban development scenarios for the 2070s.

\begin{tabular}{|l|r|r|r|r|}
\hline Season & HCHL & HCLL & \multicolumn{1}{l|}{ LCHL } & \multicolumn{1}{l|}{ LCLL } \\
\hline Winter & $71 \%$ & $70 \%$ & $28 \%$ & $27 \%$ \\
\hline Spring & $125 \%$ & $125 \%$ & $93 \%$ & $93 \%$ \\
\hline Summer & $-27 \%$ & $-32 \%$ & $-44 \%$ & $-48 \%$ \\
\hline Fall & $66 \%$ & $58 \%$ & $51 \%$ & $44 \%$ \\
\hline
\end{tabular}

B. Extreme Hydrology

I generated flow duration curves to examine differences in extreme flows among the four combined climate change and urban development scenarios compared to the baseline for the 2040s and 2070s (Figures 6.29 and 6.30). Under most scenarios, fifth-percentile flows more than double (Table 6.26). These changes are significant at the 0.01 level (Table 6.27). For the 2040s, significant differences exist only between HCHL and LCLL at the 0.05 level (Table 6.28), while there are no significant differences between paired scenarios for the 2070s (Table 6.29). 


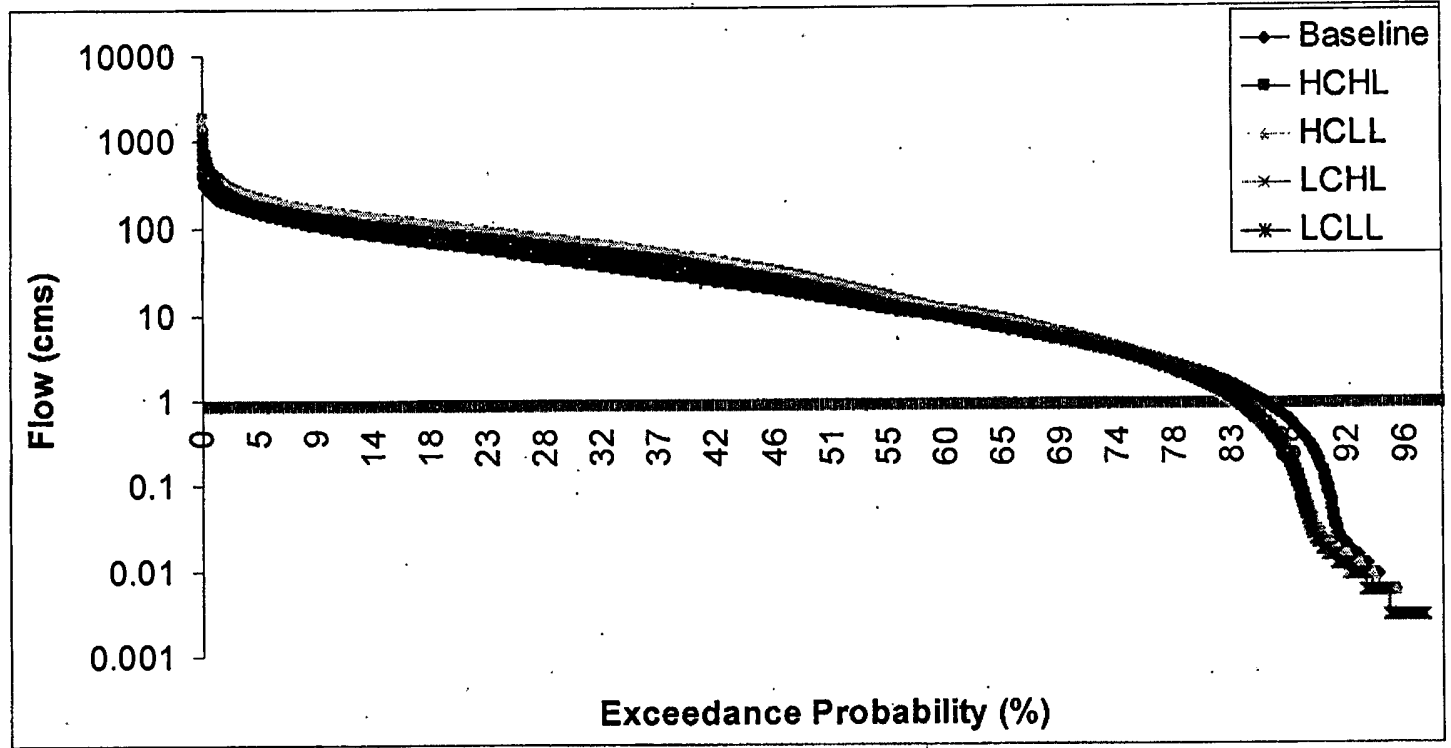

Figure 6.29: Flow duration curves for the baseline and future periods resulting from the four combined climate change and urban development scenarios for the 2040s.

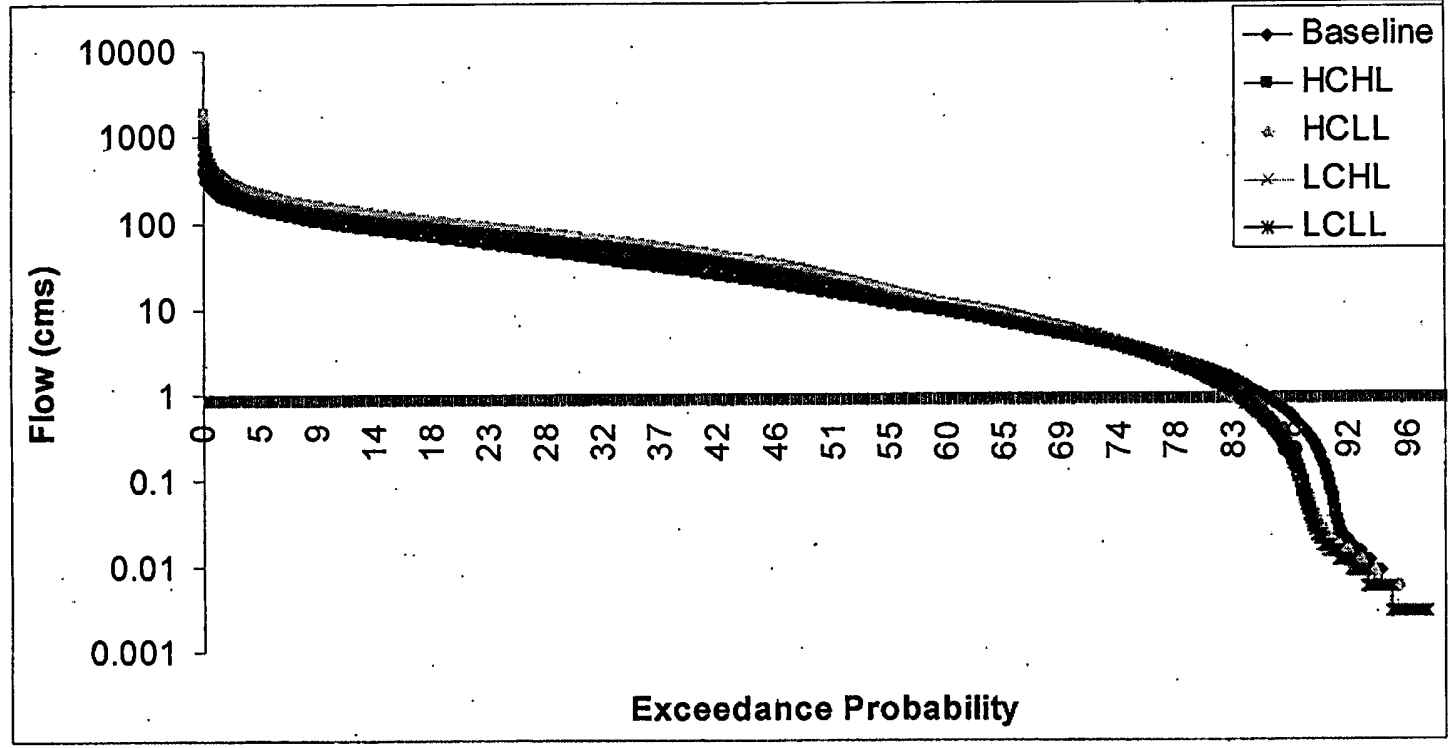

Figure 6.30: Flow duration curves for the baseline and future periods resulting from the four combined climate change and urban development scenarios for the 2070s. 
Table 6.26: Percent changes in five-percent highest flows resulting from the four combined climate change and urban development scenarios.

\begin{tabular}{|l|r|r|}
\hline Scenario & 2040 & 2070 \\
\hline HCHL & $181 \%$ & $146 \%$ \\
\hline HCLL & $178 \%$ & $143 \%$ \\
\hline LCHL & $121 \%$ & $123 \%$ \\
\hline LCLL & $87 \%$ & $120 \%$ \\
\hline
\end{tabular}

Table 6.27: Results of two-tailed t-test for significance of changes in five-percent highest flows compared to the baseline for the four combined climate change and urban development scenarios.

\begin{tabular}{|l|c|c|}
\hline Scenario & 2040 & 2070 \\
\hline HCHL & $-7.18^{* \star}$ & $-9.28^{* *}$ \\
\hline HCLL & $-7.10^{* *}$ & $-9.18^{* *}$ \\
\hline LCHL & $-7.73^{* \star}$ & $-11.66^{* \star}$ \\
\hline LCLL & $-7.46^{* \star}$ & $-11.23^{* \star}$ \\
\hline
\end{tabular}

**Significant at the 0.01 level.

Table 6.28: Two-tailed t-test results from multiple paired comparisons of differences in five-percent highest flows among the four combined climate change and urban development scenarios for the 2040s, with significance assessed using the false discovery rate.

\begin{tabular}{|l|l|l|l|l|}
\hline Scenario & $\mathrm{HCHL}$ & $\mathrm{HCLL}$ & $\mathrm{LCHL}$ & $\mathrm{LCLL}$ \\
\hline $\mathrm{HCHL}$ & - & 0.12 & 1.98 & $2.14^{*}$ \\
\hline $\mathrm{HCLL}$ & 0.12 & - & 1.84 & 1.99 \\
\hline $\mathrm{LCHL}$ & 1.98 & 1.84 & - & 0.20 \\
\hline $\mathrm{LCLL}$ & $2.14^{*}$ & 1.99 & 0.20 & - \\
\hline
\end{tabular}

*Significant at the 0.05 level.

Table 6.29: Two-tailed t-test results from multiple paired comparisons of differences in five-percent highest flows among the four combined climate change and urban development scenarios for the 2070 s, with significance assessed using the false discovery rate.

\begin{tabular}{|l|l|l|l|l|}
\hline Scenario & $H C H L$ & $H C L L$ & $L C H L$ & $L C L L$ \\
\hline$H C H L$ & - & 0.14 & 0.71 & 0.96 \\
\hline HCLL & 0.14 & - & 0.55 & 0.80 \\
\hline LCHL & 0.71 & 0.55 & - & 0.31 \\
\hline LCLL & 0.96 & 0.80 & 0.31 & - \\
\hline
\end{tabular}

C. Flow Partitioning

Figures 6.31 and 6.32 show the partitioning of total runoff into surface and groundwater flows under the baseline and four combined climate change and land use 
change scenarios for the 2040 s and 2070 s, respectively. For all four combined scenarios, groundwater flows are lower than the baseline, as a result of the increased seasonality of precipitation under climate change and the increased impervious surface area from urban development. Again, the two combined scenarios with the same climate change scenario are more similar to one another than the two with the same land use scenario.

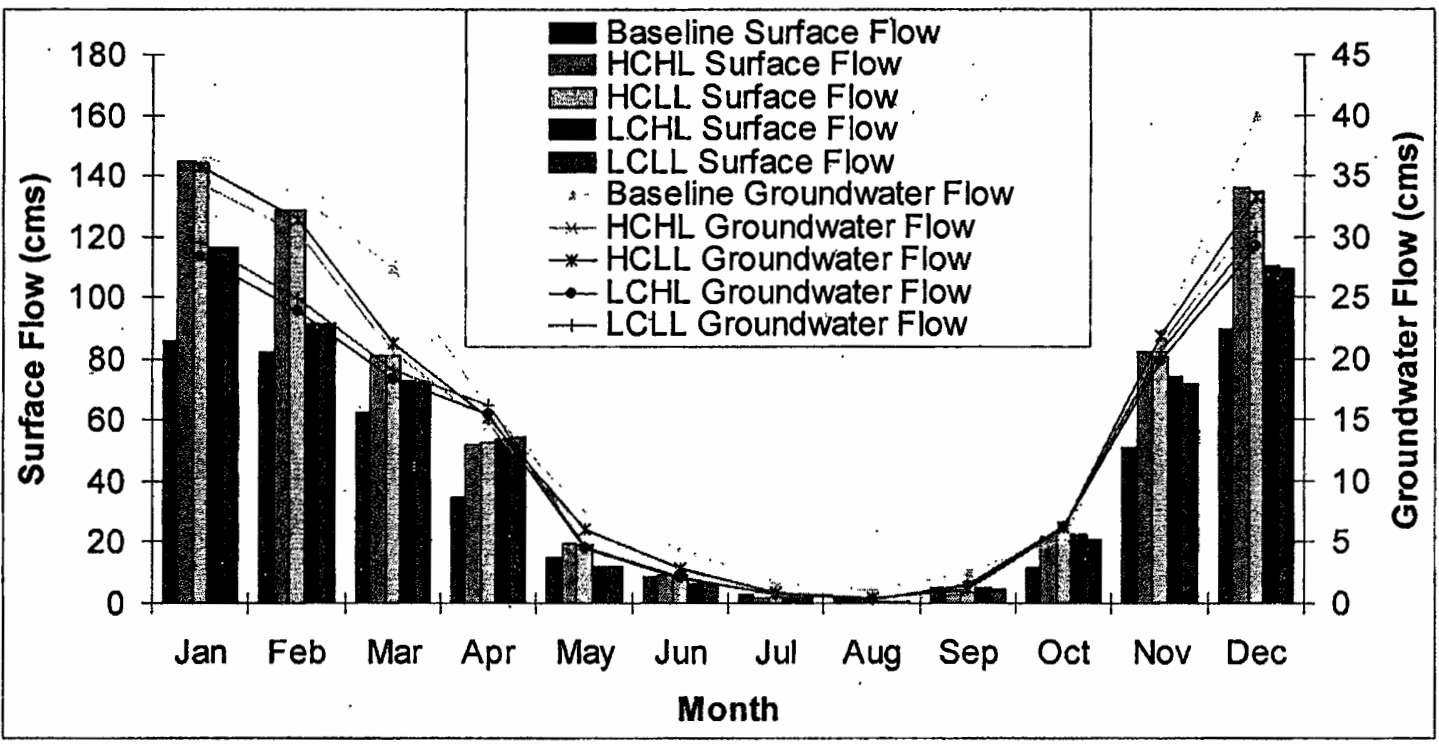

Figure 6.31: Surface and groundwater flows for the baseline and four combined climate change and urban development scenarios for the 2040s. 


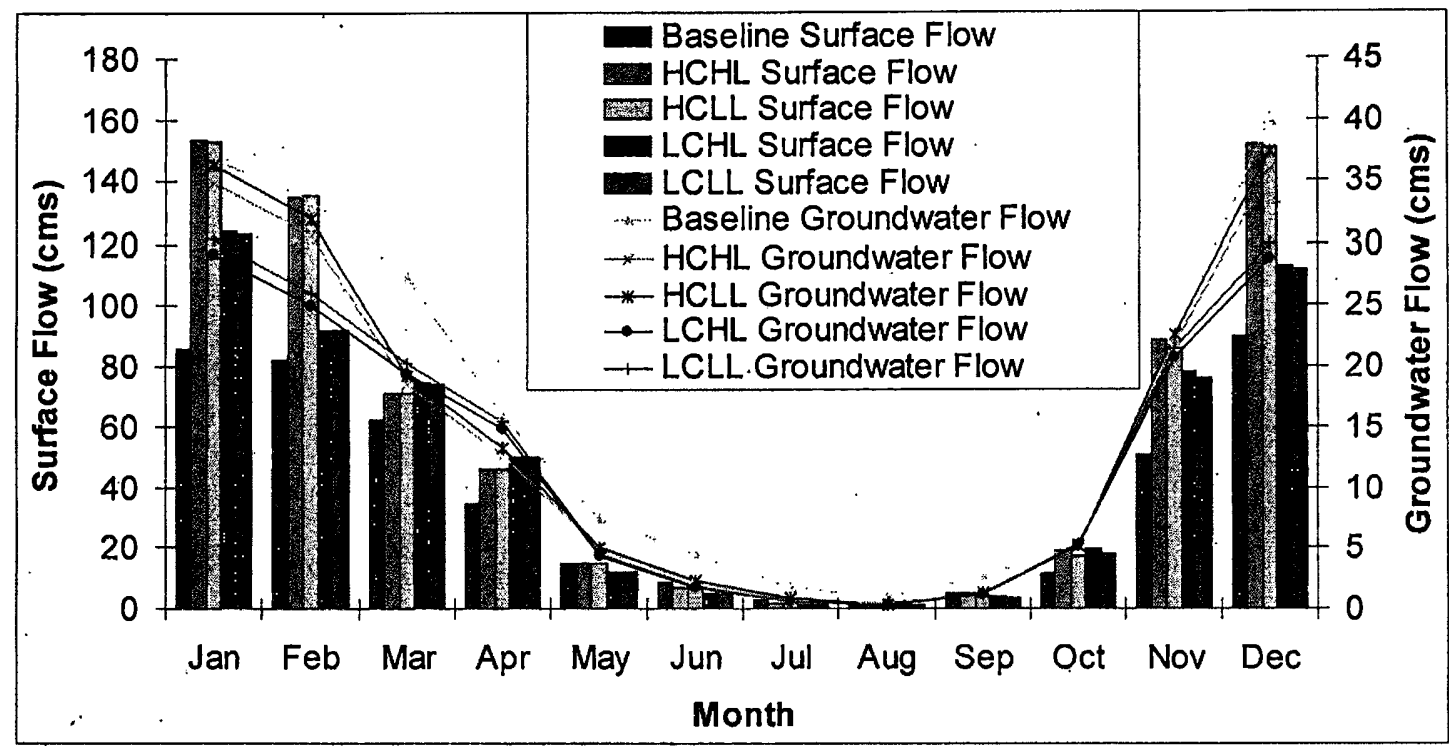

Figure 6.32: Surface and groundwater flows for the baseline and four combined climate change and urban development scenarios for the $2070 \mathrm{~s}$.

\section{Impacts of Climate Change on Sediment Loading}

The modeled impacts of climate change on suspended sediment loading closely track the hydrological changes. Figures 6.33 and 6.34 show the monthly changes in sediment loading for the 2040 s and 2070s resulting from the climate change scenarios. As with runoff, the scenarios produce different results, but the general pattern is increasing winter and decreasing summer loadings under climate change. These changes are significant at the 0.05 level for all scenarios except PCM A1B and ECHAM5 B1 (Table 6.30). 


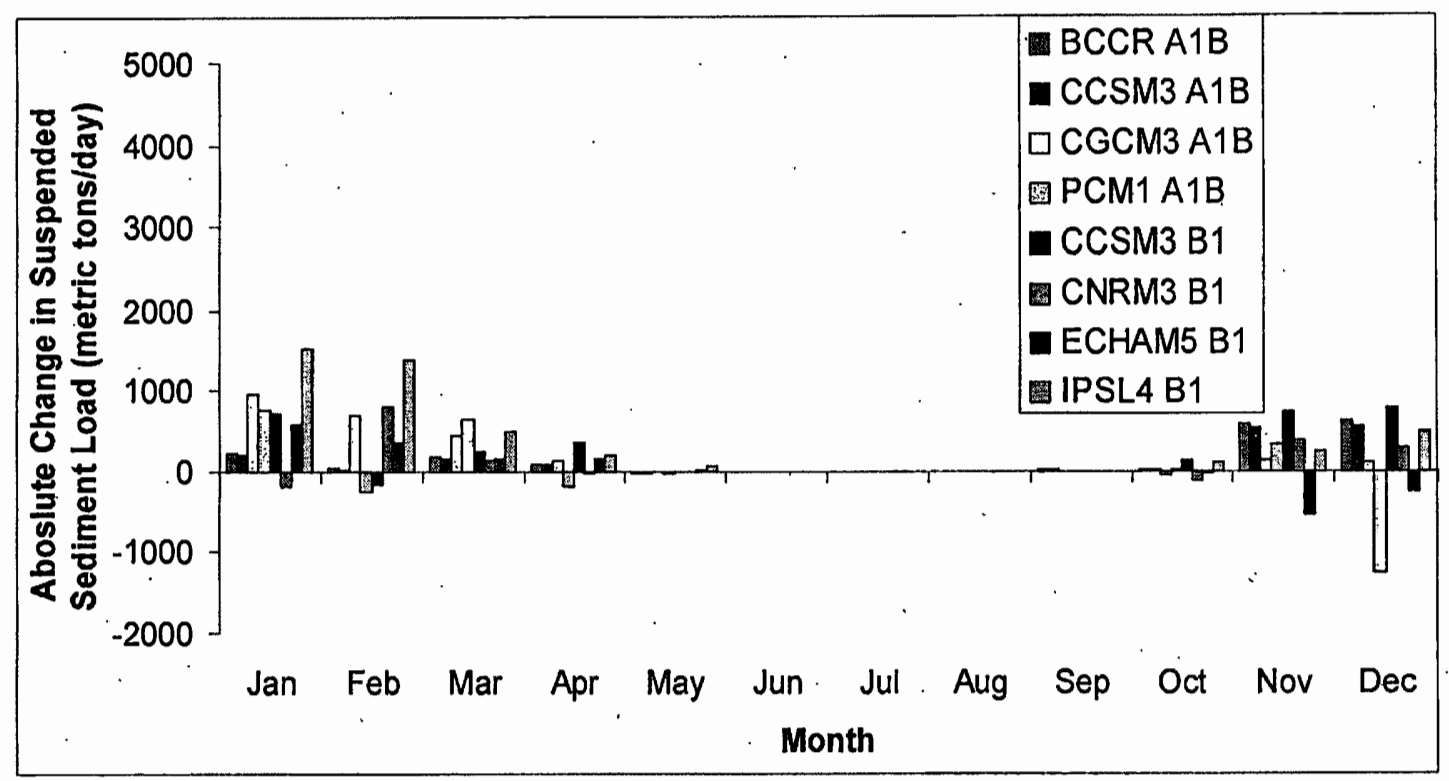

Figure 6.33: Absolute changes in monthly suspended sediment load resulting from the eight climate change scenarios for the 2040 s.

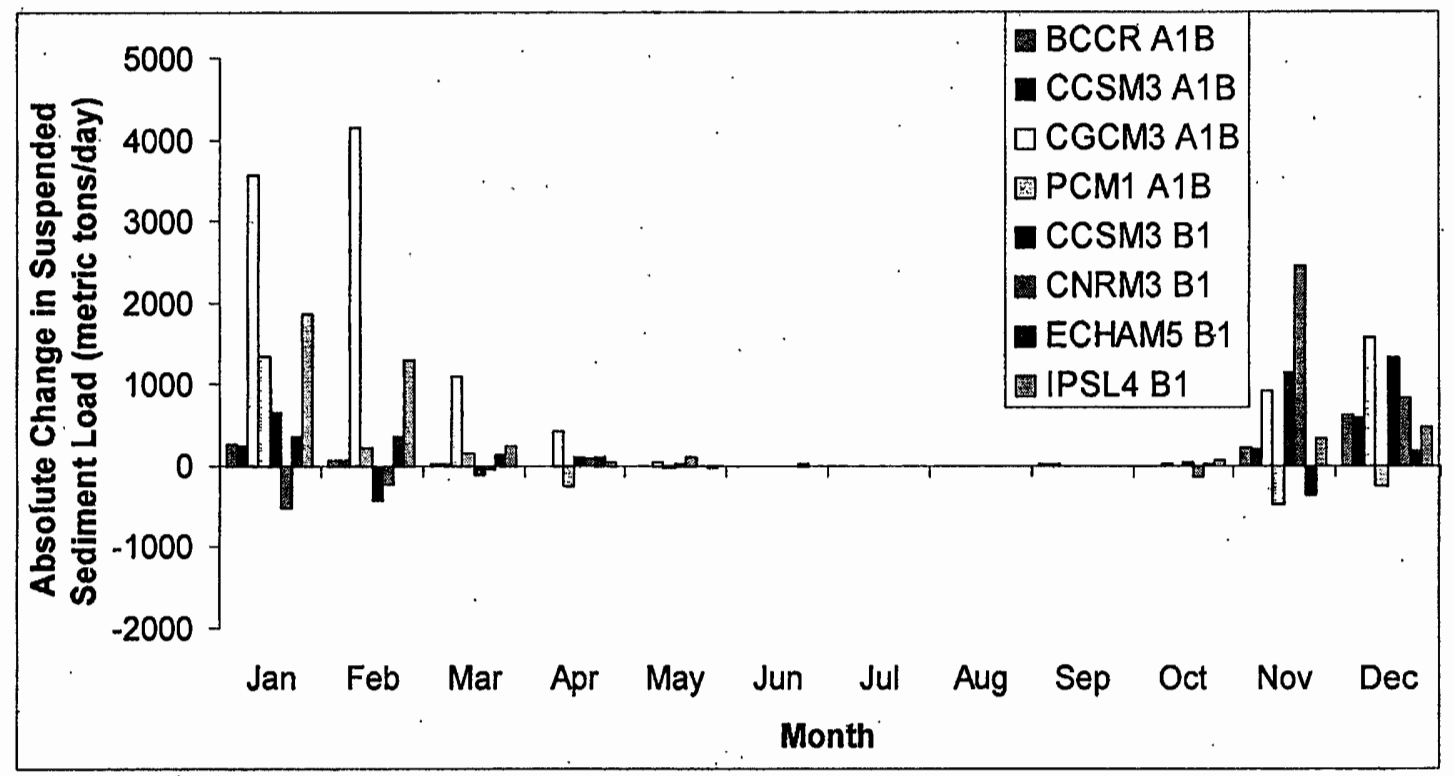

Figure 6.34: Absolute changes in monthly suspended sediment load resulting from the eight climate change scenarios for the 2070s. 
Table 6.30: Results of two-tailed t-test for significance of changes in suspended sediment load compared to the baseline for the eight climate change scenarios.

\begin{tabular}{|c|c|c|}
\hline Scenario & 2040 & 2070 \\
\hline BCCR A1B & $-6.72^{* \star}$ & $-5.43^{\star \star \star}$ \\
\hline $\operatorname{ccsin} 3 \mathrm{~A} 1 \mathrm{~B}$ & $-6.72^{\star \star *}$ & $-5.43^{\star \star}$ \\
\hline CGCM3 A1B & $-13.51^{\star \star \star}$ & $-16.77^{* \star}$ \\
\hline PCM1 A1B & -0.23 & -0.83 \\
\hline CCSM3 B1 & $-3.81^{* *}$ & $-3.85^{\star * *}$ \\
\hline CNRM3 B1 & -1.42 & $-2.26^{*}$ \\
\hline ECHAM5 B1 & -0.54 & -1.11 \\
\hline IPSL4 B1 & $-12.36^{* \star}$ & $-15.12^{* *}$ \\
\hline
\end{tabular}

*Significant at the 0.5 level.

**Significant at the 0.01 level.

Figures 6.35 and 6.36 show these changes in sediment loading for the 2040 s and 2070s at a seasonal scale. Again, the pattern of increased winter and mostly decreased summer loading is evident, with higher-magnitude changes in the 2070 s. Figure 6.37 shows the average changes for all eight scenarios. Table 6.31 shows the relative magnitude of the average changes, which for the 2040s includes a decrease in summer sediment loading of twenty-five percent and an increase in winter loading of thirty-eight percent. 


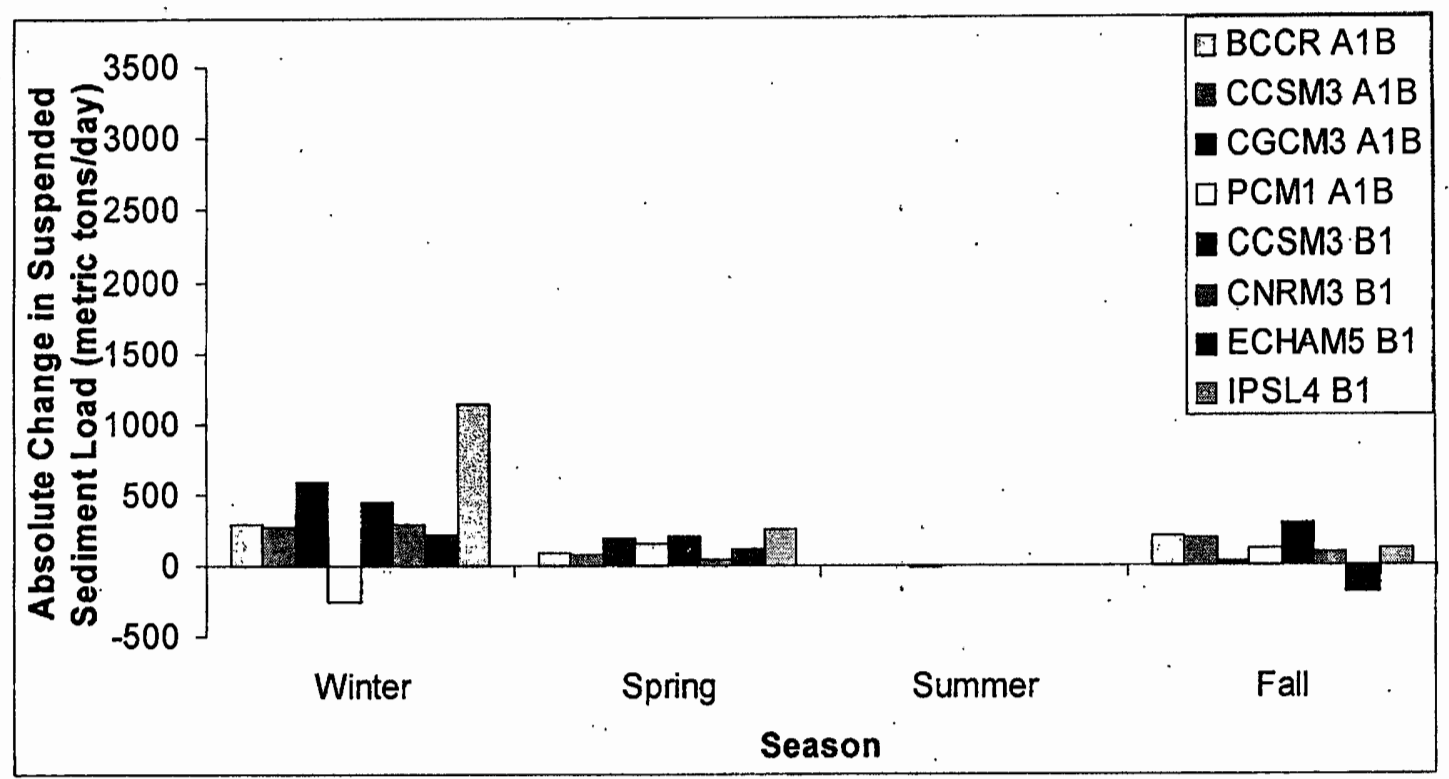

Figure 6.35: Absolute changes in seasonal suspended sediment load resulting from the eight climate change scenarios for the 2040s.

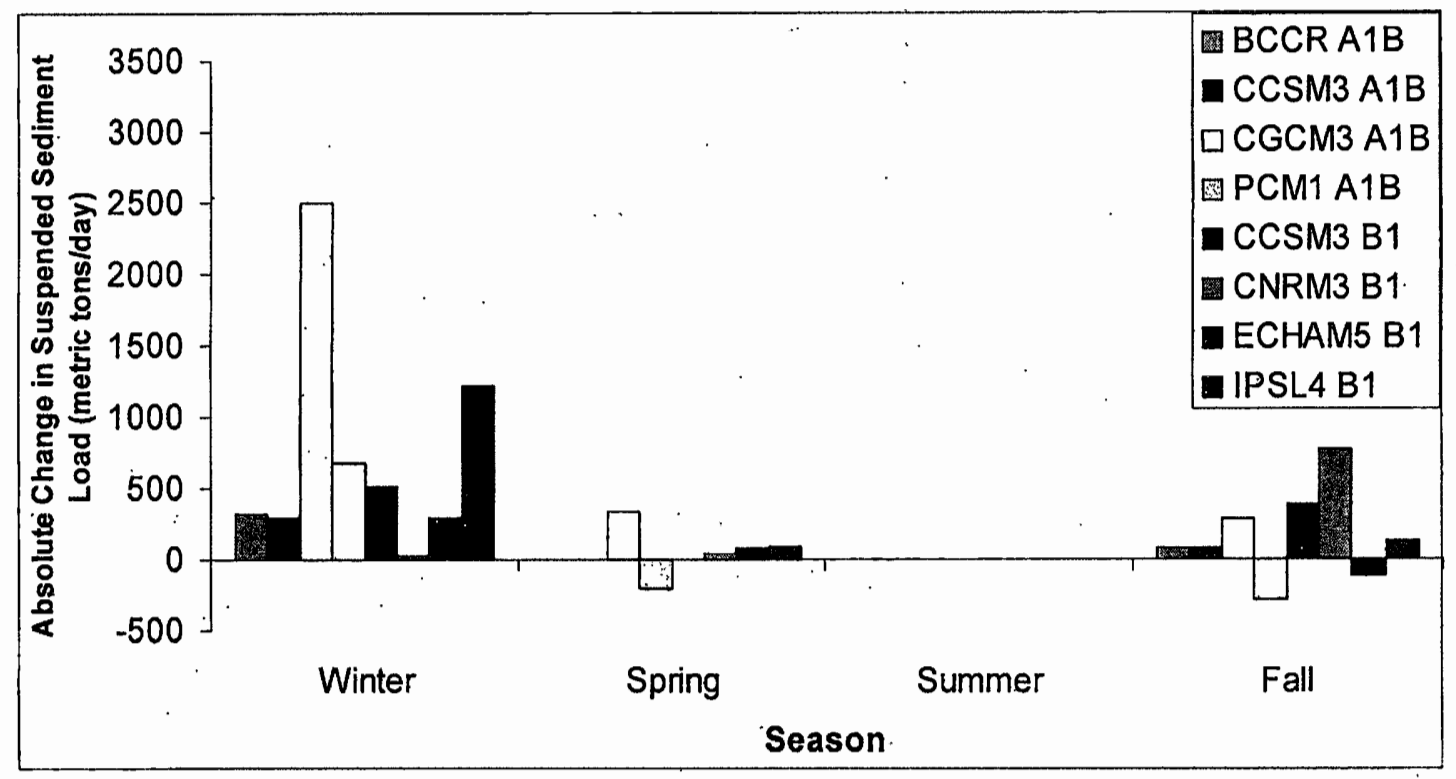

Figure 6.36: Absolute changes in seasonal suspended sediment load resulting from the eight climate change scenarios for the $2070 \mathrm{~s}$. 


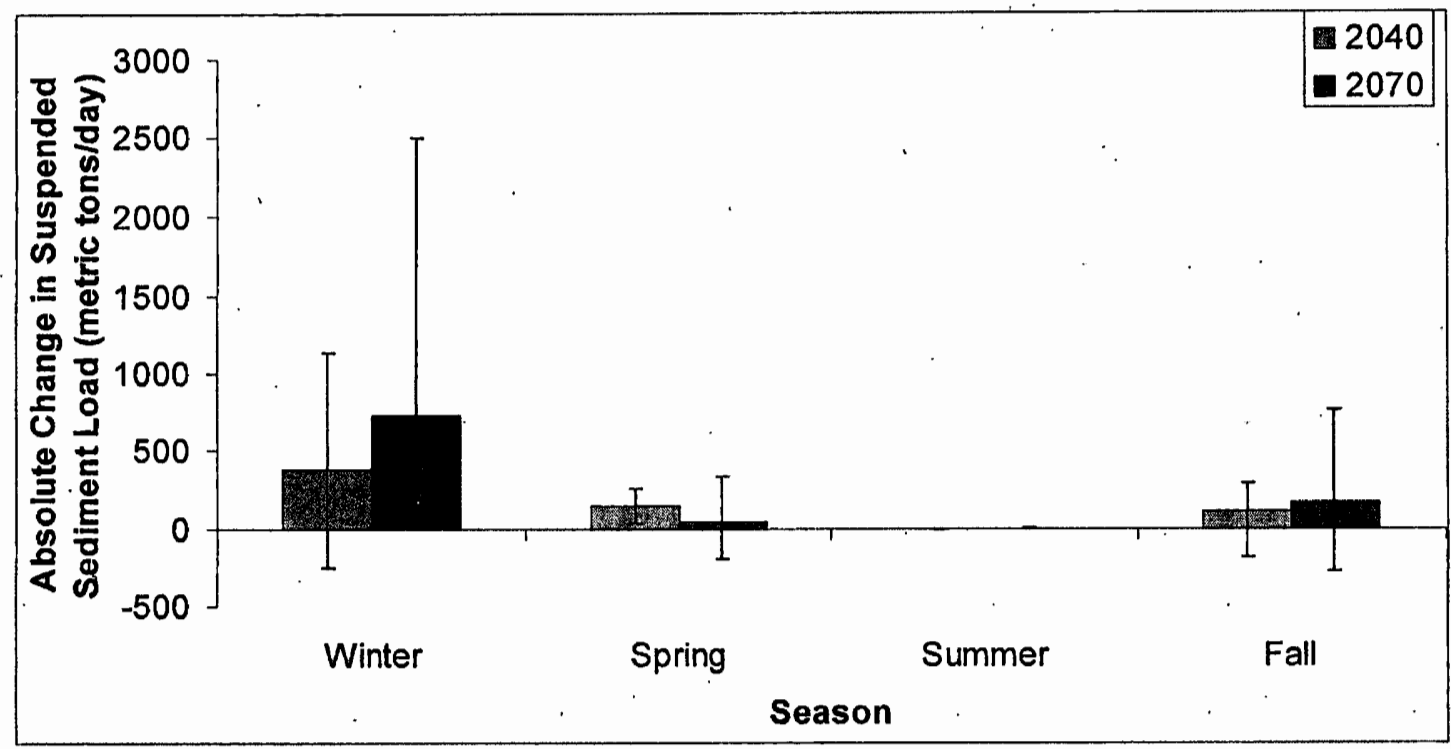

Figure 6.37: Absolute changes in seasonal suspended sediment load, averaged for all eight climate change scenarios, for the 2040s and 2070s.

Table 6.31: Percent changes in seasonal suspended sediment load, averaged for all eight climate change scenarios, for the 2040s and 2070s.

\begin{tabular}{|c|c|c|c|c|c|c|}
\hline Time & $\begin{array}{l}2040 \\
\text { Change }\end{array}$ & $\begin{array}{l}2070 \\
\text { Change }\end{array}$ & $\begin{array}{l}2040 \\
\text { Range }\end{array}$ & $\begin{array}{l}2070 \\
\text { Range }\end{array}$ & $\begin{array}{l}2040 \\
\text { Standard } \\
\text { Deviation }\end{array}$ & $\begin{array}{l}2070 \text { Standard } \\
\text { Deviation }\end{array}$ \\
\hline Winter & $38 \%$ & $81 \%$ & 2169.82 & 2884.41 & 798.78 & 971.12 \\
\hline Spring & $44 \%$ & $20 \%$ & 346.22 & 475.81 & 132.39 & 148.54 \\
\hline Sum & $-25 \%$ & $38 \%$ & 7.25 & 6.33 & 3.00 & 2.61 \\
\hline Fall & $60 \%$ & $600 \%$ & 728.47 & 1387.27 & 255.39 & 460.56 \\
\hline
\end{tabular}

\section{Impacts of Urban Development on Sediment Loading}

As with the climate change scenarios, the response of suspended sediment loading to the land use scenarios is similar to the hydrological response. Figures 6.38 and 6.39 show the modeling results of urban development impacts on sediment loading at the monthly and seasonal scales. As with basin flow, there are increases in sediment loading under the development scenario and decreases under the conservation scenario, indicating that sediment load is essentially a proxy for surface flow. As indicated in Table 6.33, the relative magnitudes of these changes average an 
eighteen percent increase for the development scenario and an eighteen percent decrease for the conservation scenario. The changes are significant at the 0.05 level or higher for both scenarios (Table 6.32).

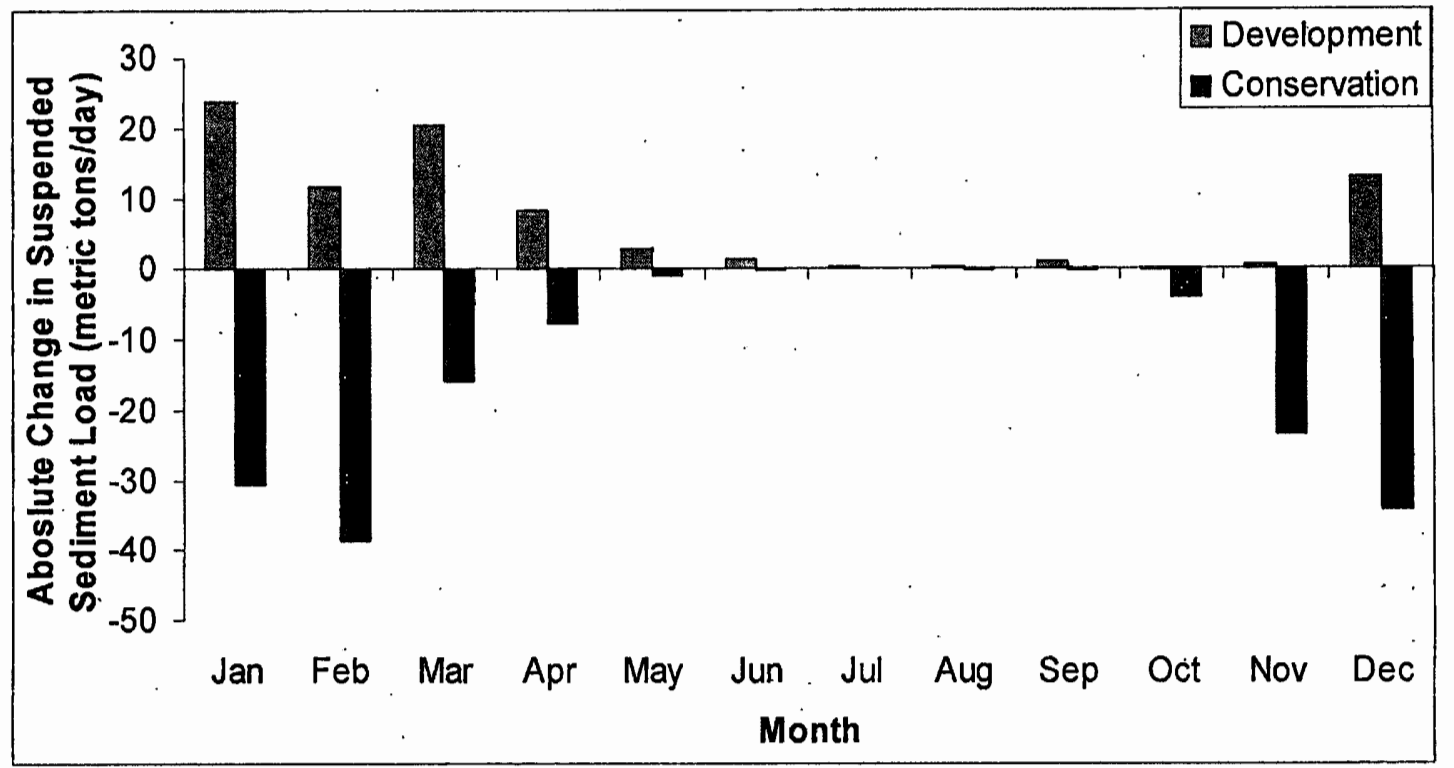

Figure 6.38: Absolute changes in monthly suspended sediment load resulting from the development and conservation land use scenarios.

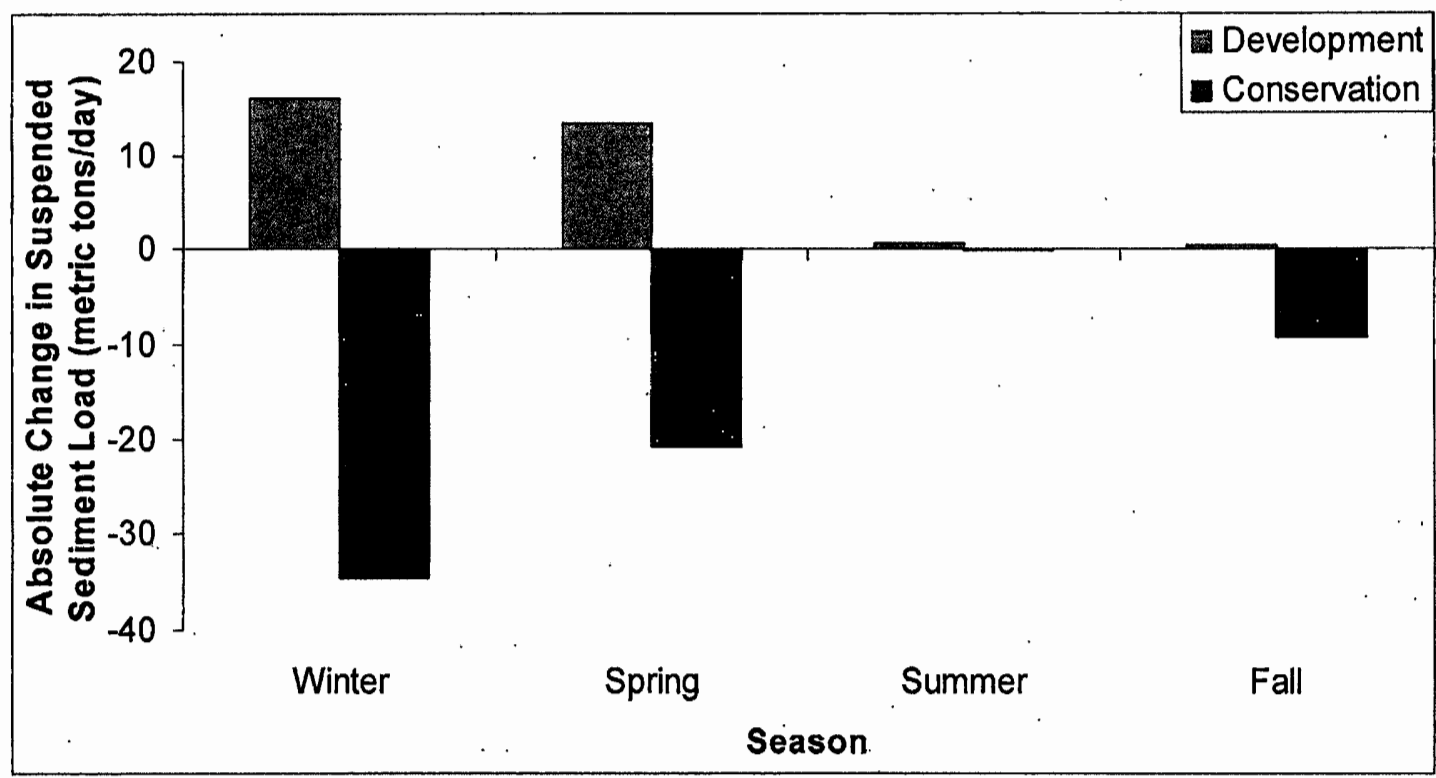

Figure 6.39: Absolute changes in seasonal suspended sediment load resulting from the development and conservation land use scenarios. 
Table 6.32: Percent changes in seasonal suspended sediment load resulting from the development and conservation land use scenarios:

\begin{tabular}{|l|r|r|}
\hline Season & Development & Conservation \\
\hline Winter & $9 \%$ & $-18 \%$ \\
\hline Spring & $11 \%$ & $-17 \%$ \\
\hline Summer & $53 \%$ & $-8 \%$ \\
\hline Fall & $1 \%$ & $-28 \%$ \\
\hline Average & $18 \%$ & $-18 \%$ \\
\hline
\end{tabular}

Table 6.33: Results of two-tailed t-test for significance of changes in suspended sediment load compared to the baseline for the development and conservation scenarios.

\begin{tabular}{|l|l|}
\hline Scenario & $t$ \\
\hline Development & $-2.53^{*}$ \\
\hline Conservation & $5.21^{* \star}$ \\
\hline
\end{tabular}

*Significant at the 0.05 level.

**Significant at the 0.01 level.

\section{Combined Impacts of Climate Change and Urban Development on Sediment}

\section{Loading}

Figures 6.40 and 6.41 show the modeled changes in sediment loading resulting from the combined climate change and urban development scenarios for the 2040s and 2070s. Sediment loading increases in all months, except for decreases in summer loading under most scenarios. As can be seen in Figures 6.42 and 6.43, the high climate change scenarios generally have greater increases in sediment loading than either of the low climate change scenarios, indicating that climate change is more likely than urban development to impact future sediment dynamics in the basin. Tables 6.34 and 6.35 indicate that the magnitude of the increases is significant, with a doubling or more of sediment loading for most scenarios, while the summer decreases are more modest. The changes are significant for all scenarios at the 0.01 level (Table $6.36)$. 


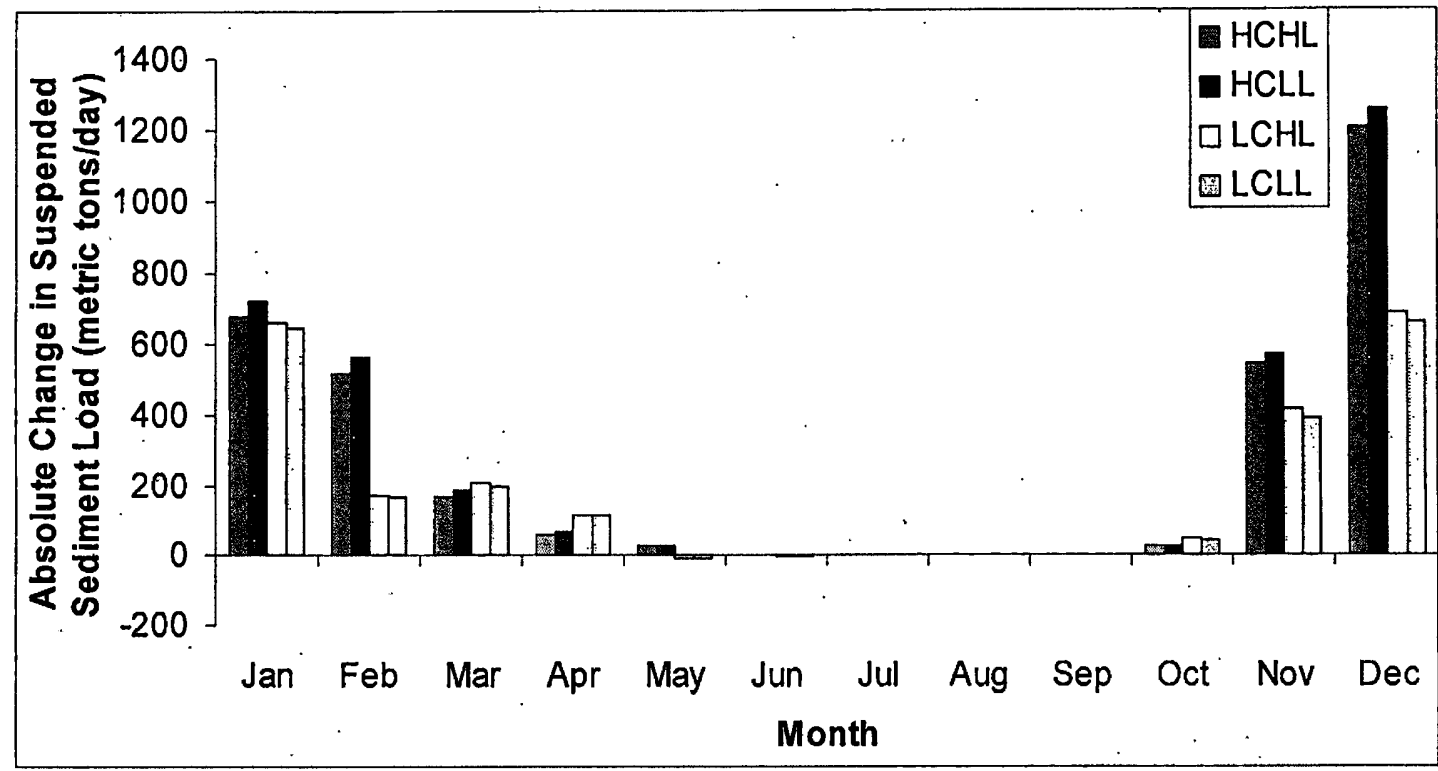

Figure 6.40: Absolute changes in monthly suspended sediment load resulting from the combined climate change and urban development scenarios for the 2040s.

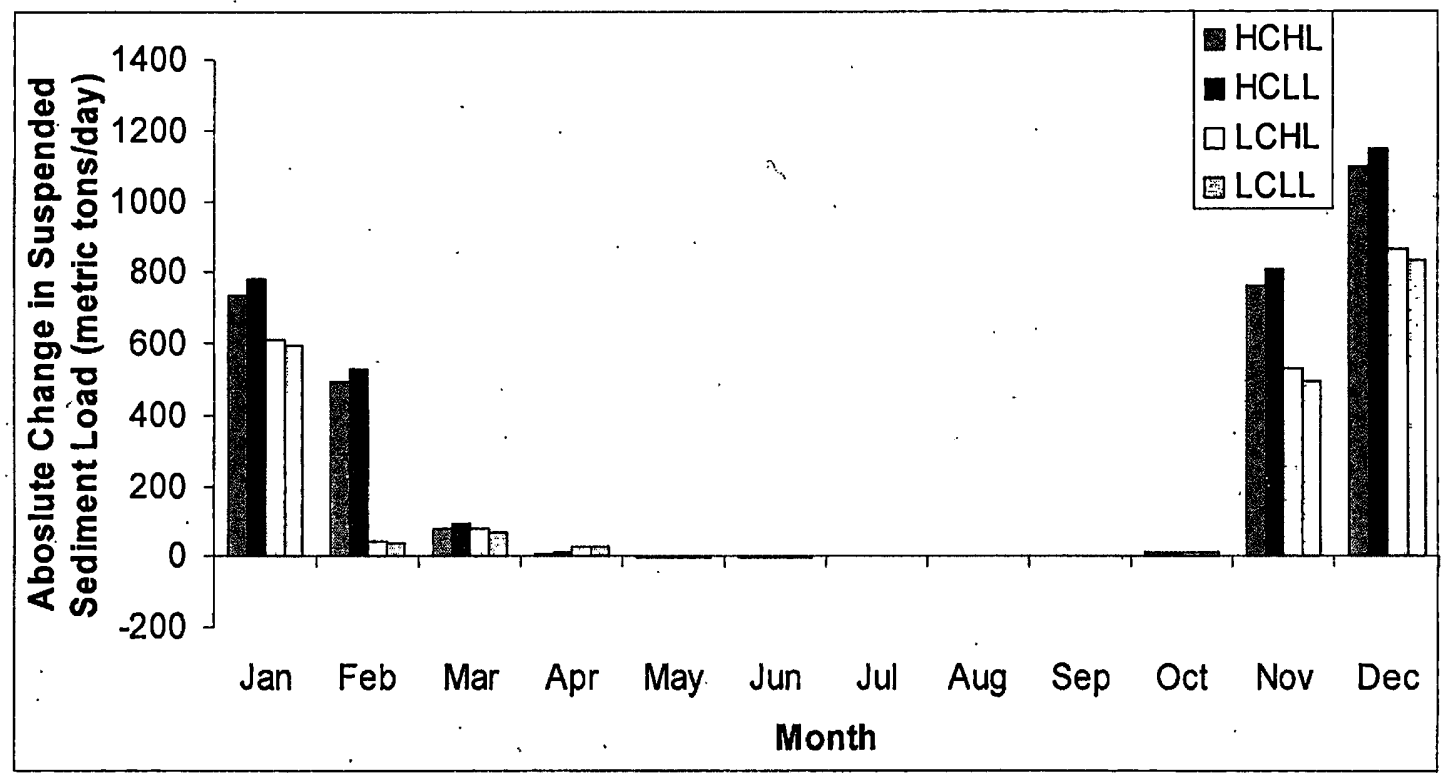

Figure 6.41: Absolute changes in monthly suspended sediment load resulting from the combined climate change and urban development scenarios for the 2070s. 


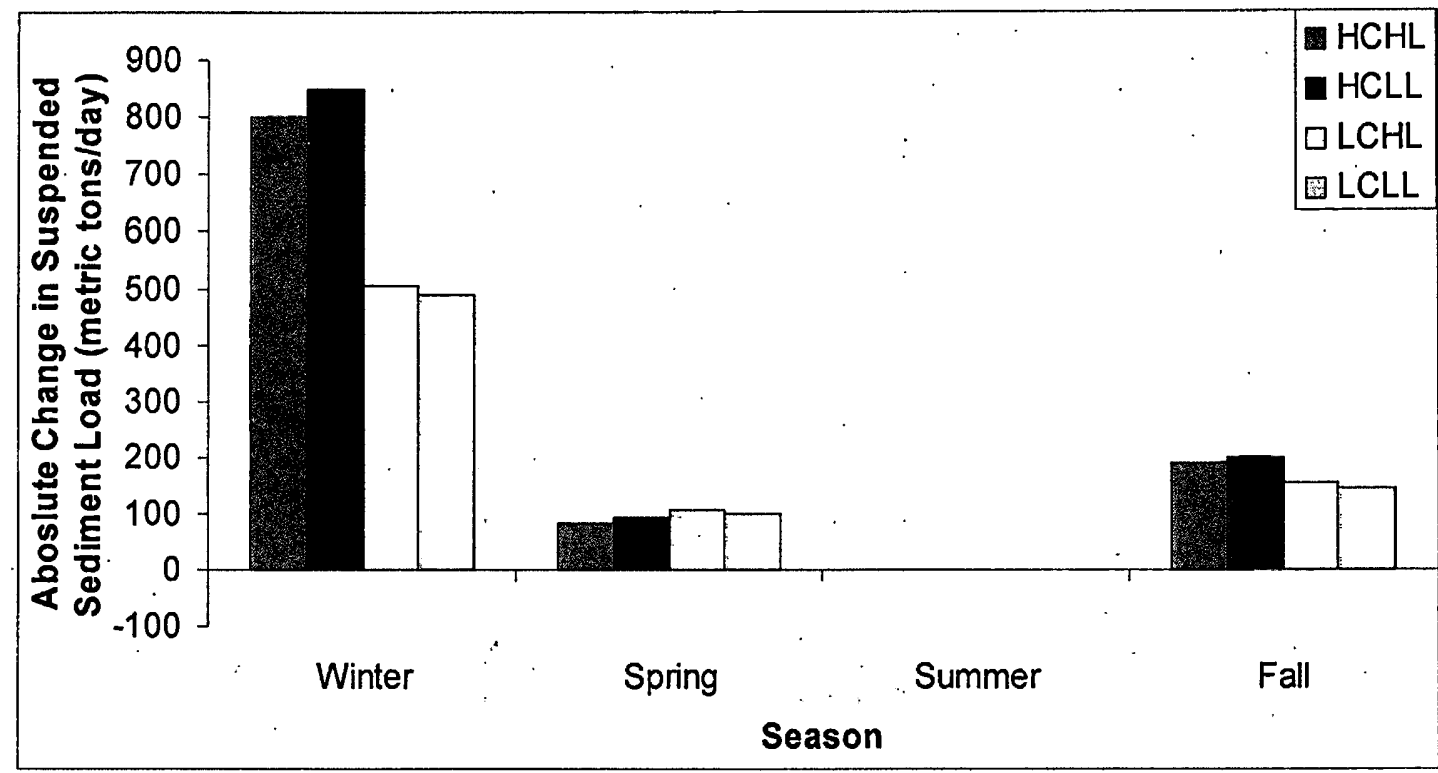

Figure 6.42: Absolute changes in seasonal suspended sediment load resulting from the combined climate change and urban development scenarios for the 2040s.

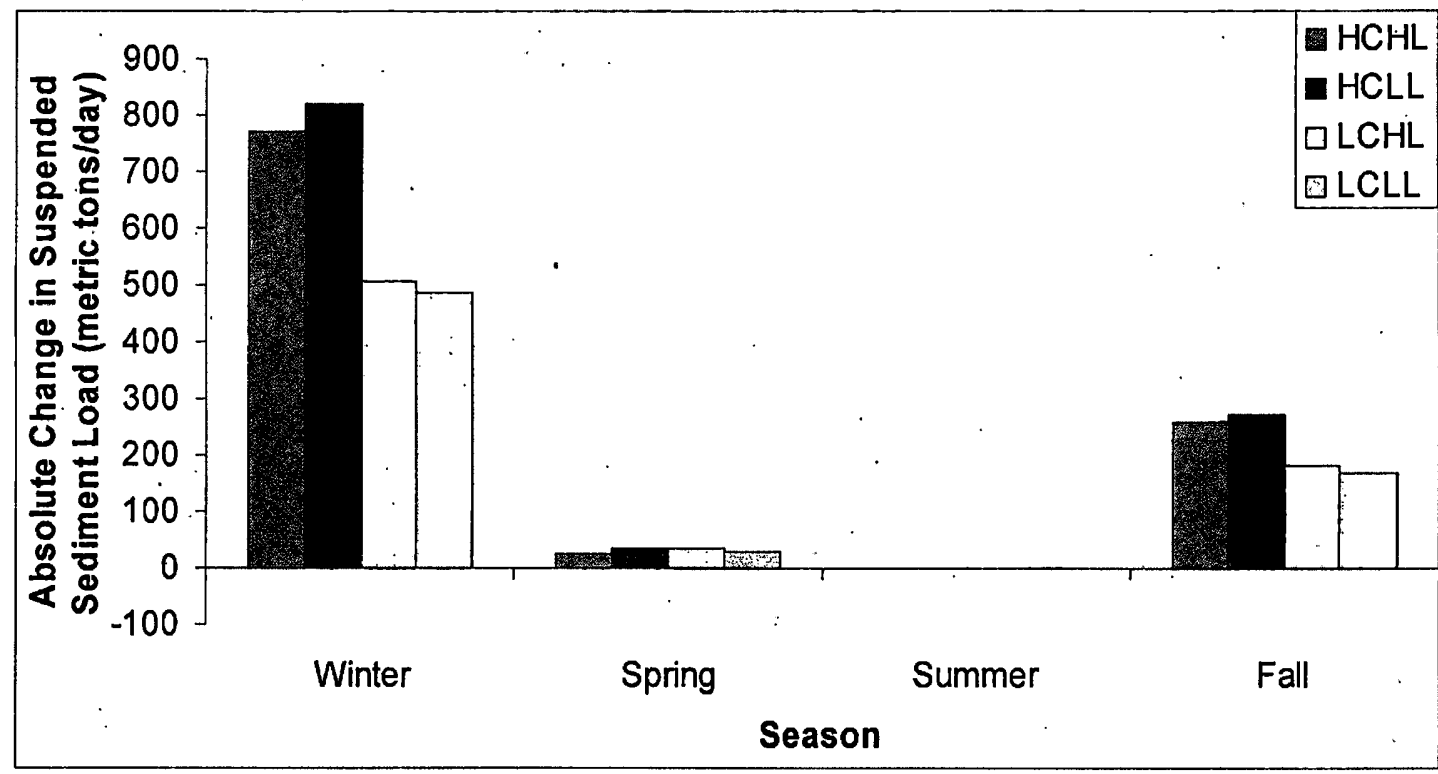

Figure 6.43: Absolute changes in seasonal suspended sediment load resulting from the combined climate change and urban development scenarios for the 2070s. 
Table 6.34: Percent changes in seasonal suspended sediment load resulting from the combined climate change and urban development scenarios for the 2040s.

\begin{tabular}{|l|r|r|r|r|}
\hline Season & \multicolumn{1}{|r|}{ HCHL } & \multicolumn{1}{l|}{ HCLL } & LCHL & \multicolumn{1}{l|}{ LCLL } \\
\hline Winter & $425 \%$ & $451 \%$ & $270 \%$ & $261 \%$ \\
\hline Spring & $129 \%$ & $146 \%$ & $164 \%$ & $156 \%$ \\
\hline Summer & $54 \%$ & $49 \%$ & $-61 \%$ & $-67 \%$ \\
\hline Fall & $569 \%$ & $595 \%$ & $460 \%$ & $430 \%$ \\
\hline
\end{tabular}

Table 6.35: Percent changes in seasonal suspended sediment load resulting from the combined climate change and urban development scenarios for the 2070s.

\begin{tabular}{|l|r|r|r|r|}
\hline Season & \multicolumn{1}{|c|}{ HCHL } & \multicolumn{1}{|c|}{ HCLL } & LCHL & \multicolumn{1}{l|}{ LCLL } \\
\hline Winter & $410 \%$ & $436 \%$ & $269 \%$ & $259 \%$ \\
\hline Spring & $41 \%$ & $53 \%$ & $53 \%$ & $47 \%$ \\
\hline Summer & $-52 \%$ & $-59 \%$ & $-77 \%$ & $-81 \%$ \\
\hline Fall & $769 \%$ & $812 \%$ & $537 \%$ & $503 \%$ \\
\hline
\end{tabular}

Table 6.36: Results of two-tailed $t$-test for significance of changes in suspended sediment load compared to the baseline for the four combined climate change and urban development scenarios.

\begin{tabular}{|l|r|r|}
\hline Scenario & 2040 & 2070 \\
\hline HCHL & $-14.07^{* *}$ & $-16.97^{* *}$ \\
\hline HCLL & $-14.37^{* *}$ & $-17.35^{* *}$ \\
\hline LCHL & $-13.26^{* *}$ & $-13.55^{* *}$ \\
\hline LCLL & $-13.20^{* *}$ & $-13.43^{* *}$ \\
\hline
\end{tabular}

\section{Impacts of Climate Change on Nutrient Loading}

\section{A. Nitrate Loading}

HSPF has the capability to simulate loading of dissolved organic nitrogen (DIN), ammonium $\left(\mathrm{NH}_{4}{ }^{+}\right)$, and nitrate $\left(\mathrm{NO}_{3}{ }^{-}\right)$. I chose nitrate as the nitrogen species to model, because I had more observed data for this parameter with which to calibrate the model than for the other constituents. I modeled the impacts of climate change on nitrate loading in the TRB. As indicated by Figures $6.4 \overline{4}$ and 6.45 , there is significant variability in the nitrate loading response among the climate change scenarios. At the seasonal scale, most scenarios result in increased winter loading and decreases in the other seasons (Figures 6.46 and 6.47), essentially following the hydrological changes. 
This pattern can be more clearly seen in the seasonal average changes among the eight scenarios (Figure 6.48). By the 2070s, there is a decline in summer loading of approximately forty percent and a more than doubling of winter loading (Table 6.37). The changes are significant at the 0.05 level for all scenarios except CCSM3 A1B (Table 6.38).

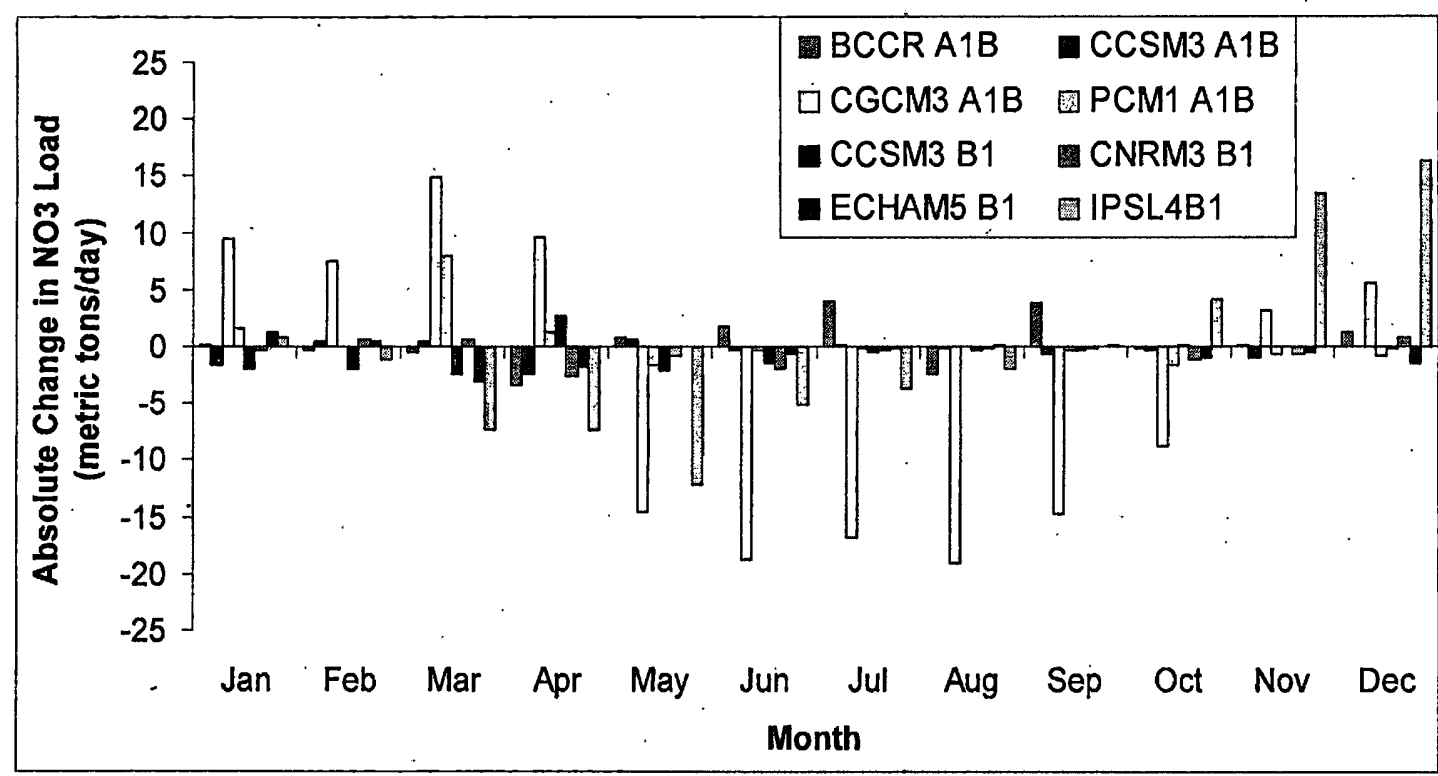

Figure 6.44: Absolute changes in monthly nitrate load resulting from the eight climate change scenarios for the 2040s. 


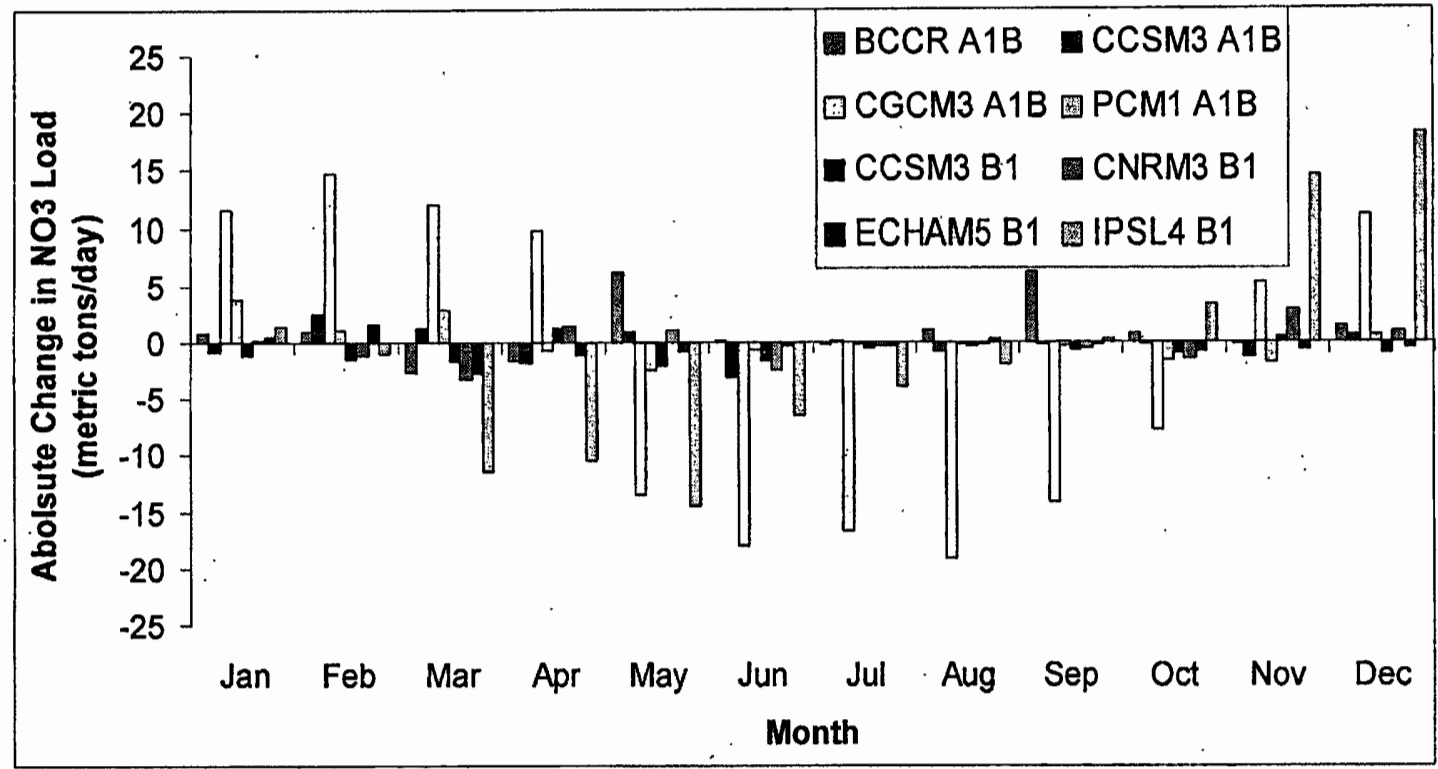

Figure 6.45: Absolute changes in monthly nitrate load resulting from the eight climate change scenarios for the 2070s.

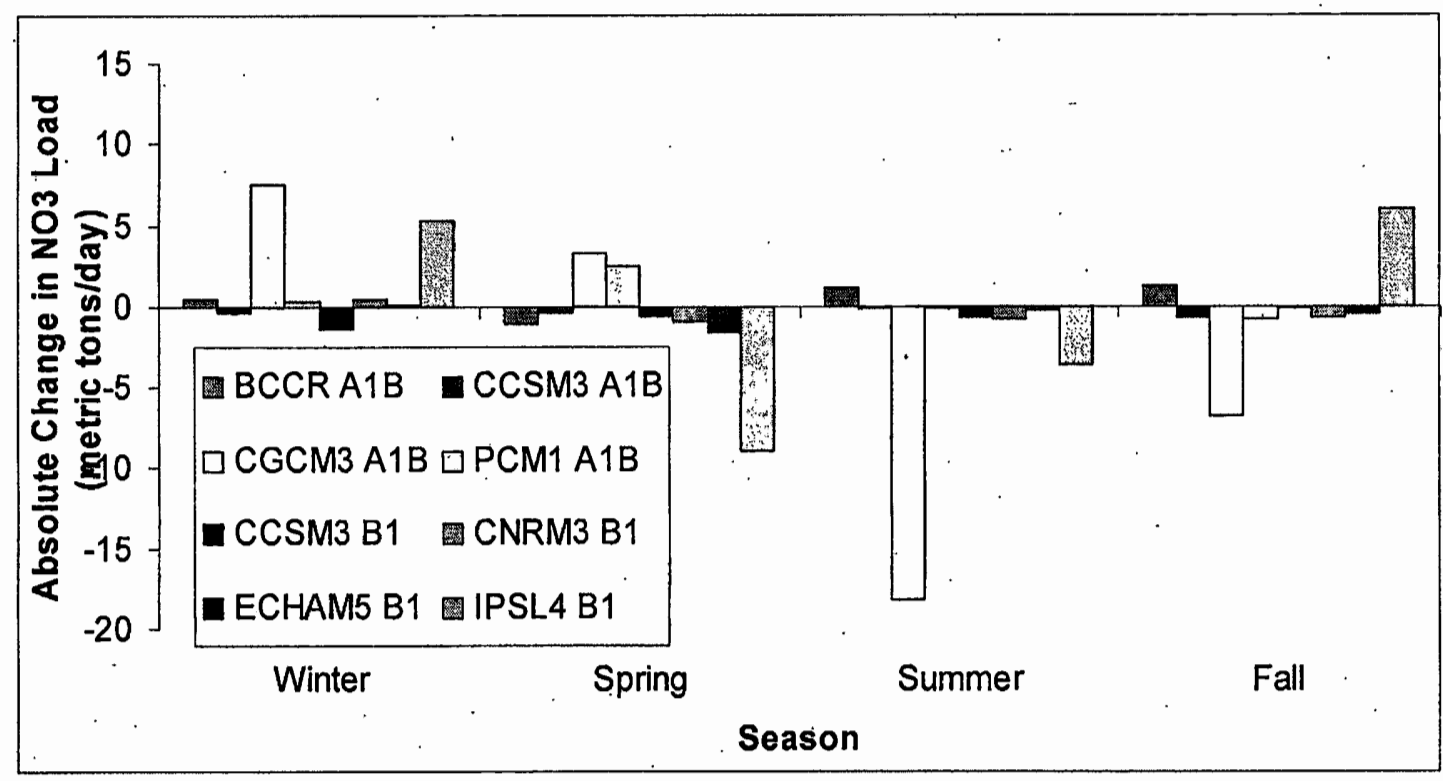

Figure 6.46: Absolute changes in seasonal nitrate load resulting from the eight climate change scenarios for the 2040s. 


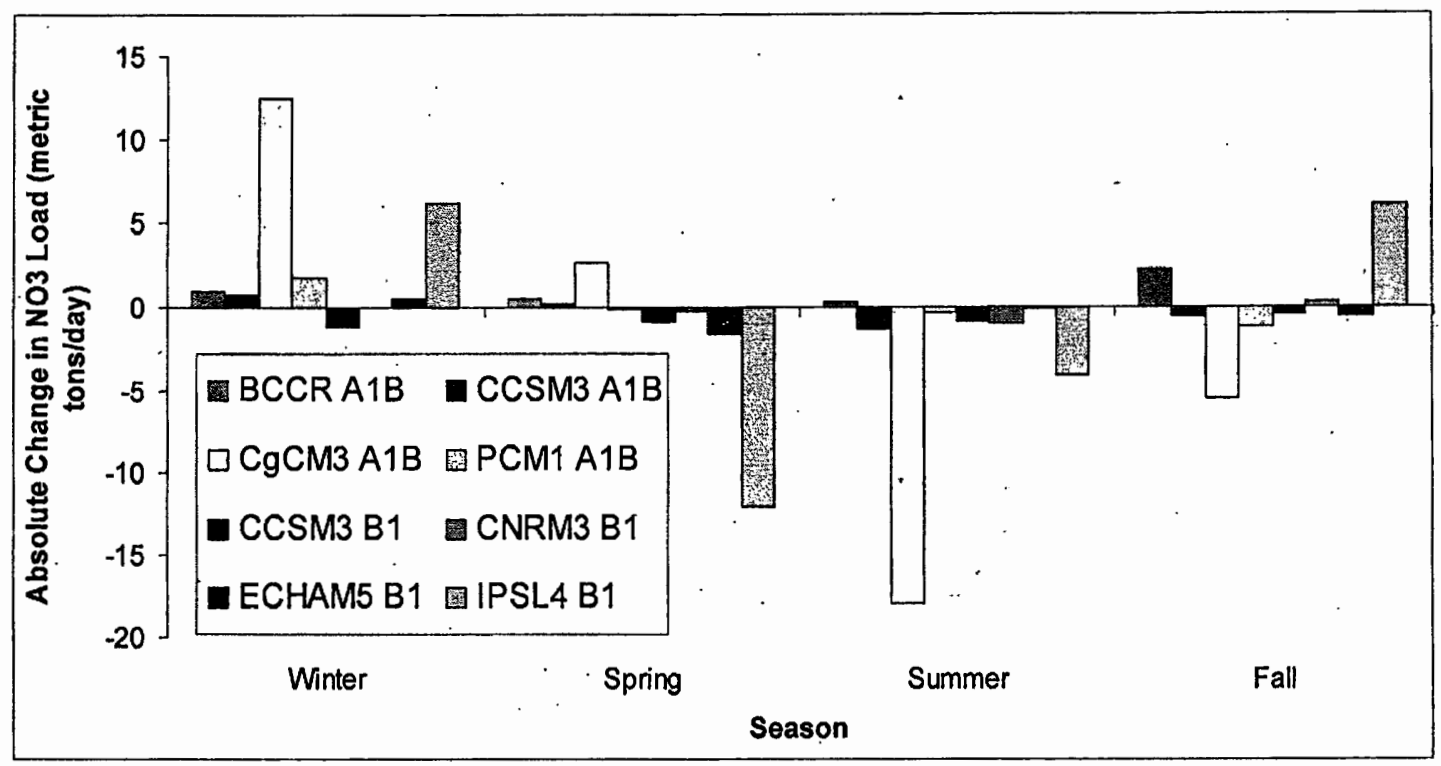

Figure 6.47: Absolute changes in seasonal nitrate load resulting from the eight climate change scenarios for the 2070s.

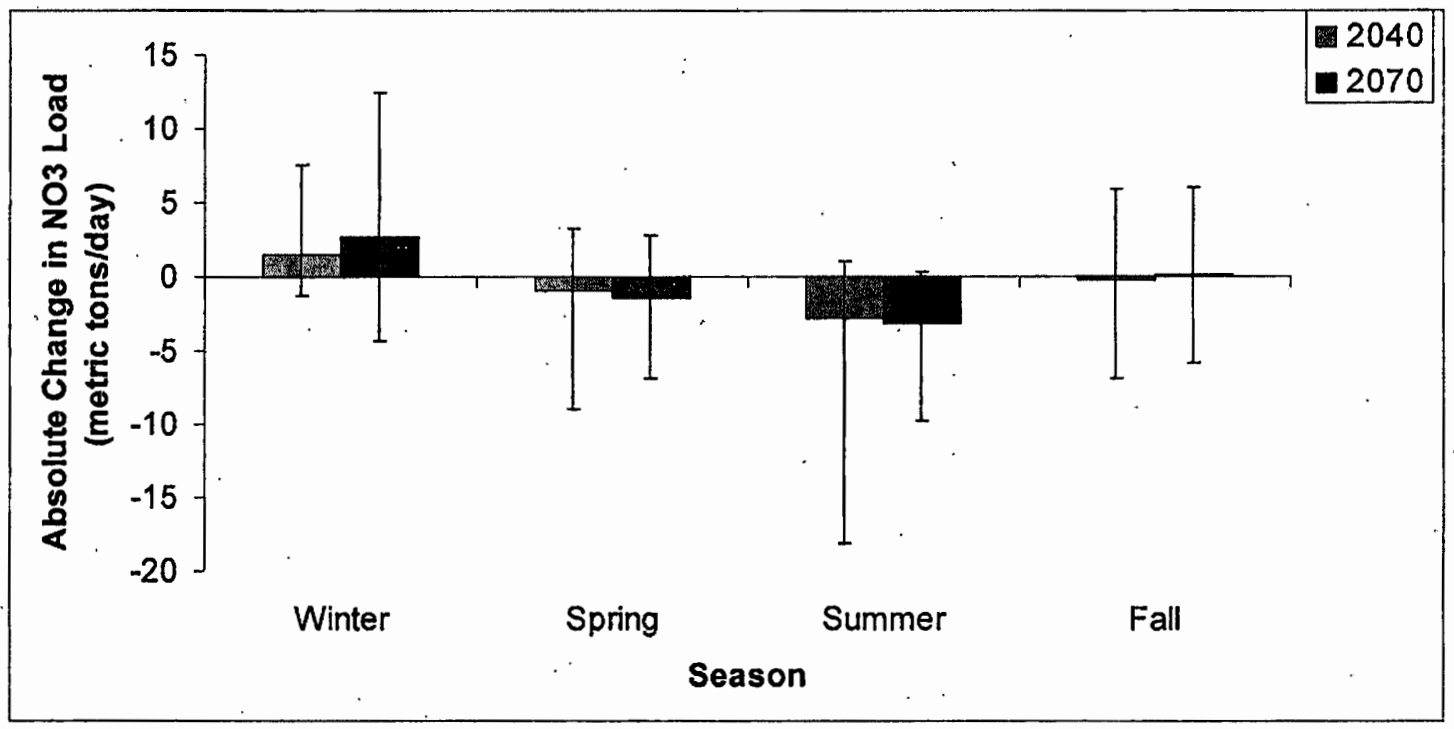

Figure 6.48: Absolute changes in seasonal nitrate load, averaged for all eight climate change scenarios, for the 2040s and 2070s. 
Table 6.37: Percent changes in seasonal nitrate load, averaged for all eight climate change scenarios, for the 2040s and 2070s.

\begin{tabular}{|l|r|r|}
\hline Season & 2040 & 2070 \\
\hline Winter & $149 \%$ & $179 \%$ \\
\hline Spring & $-4 \%$ & $-5 \%$ \\
\hline Summer & $-35 \%$ & $-41 \%$ \\
\hline Fall & $290 \%$ & $295 \%$ \\
\hline
\end{tabular}

Table 6.38: Results of two-tailed t-test for significance of changes in nitrate load compared to the baseline for the eight climate change scenarios.

\begin{tabular}{|l|r|c|}
\hline Scenario & 2040 & 2070 \\
\hline BCCR A1B & -1.12 & $-2.99^{* *}$ \\
\hline CCSM3 A1B & 1.11 & 0.58 \\
\hline CGCM3 A1B & $12.82^{* *}$ & $7.59^{* *}$ \\
\hline PCM1 A1B & $-2.04^{*}$ & -0.39 \\
\hline CCSM3 B1 & $3.04^{* \star}$ & $3.78^{* *}$ \\
\hline CNRM3 B1 & $2.30^{*}$ & 0.97 \\
\hline ECHAM5 B1 & $2.54^{*}$ & $2.01^{*}$ \\
\hline IPSL4 B1 & 1.22 & $4.06^{* *}$ \\
\hline
\end{tabular}

*Significant at the 0.05 level.

**Significant at the 0.01 level.

\section{B. Orthophosphate Loading}

Changes in orthophosphate loading closely track changes in flow and sediment loading. Figures 6.49 and 6.50 show the general pattern of increases in winter and decreases in summer. Figures 6.51 and 6.52 show these changes at the seasonal scale. The averaged changes among all scenarios include increases in winter and fall and decreases in summer orthophosphate loading (Figure 6.53). The relative magnitude of the changes reaches a winter increase of twenty-six percent and a summer decrease of nine percent (Table 6.39). The changes are significant at the 0.05 level or higher for all scenarios except CCSM3 A1B and B1 and ECHAM5 B1 (Table 6.40). 


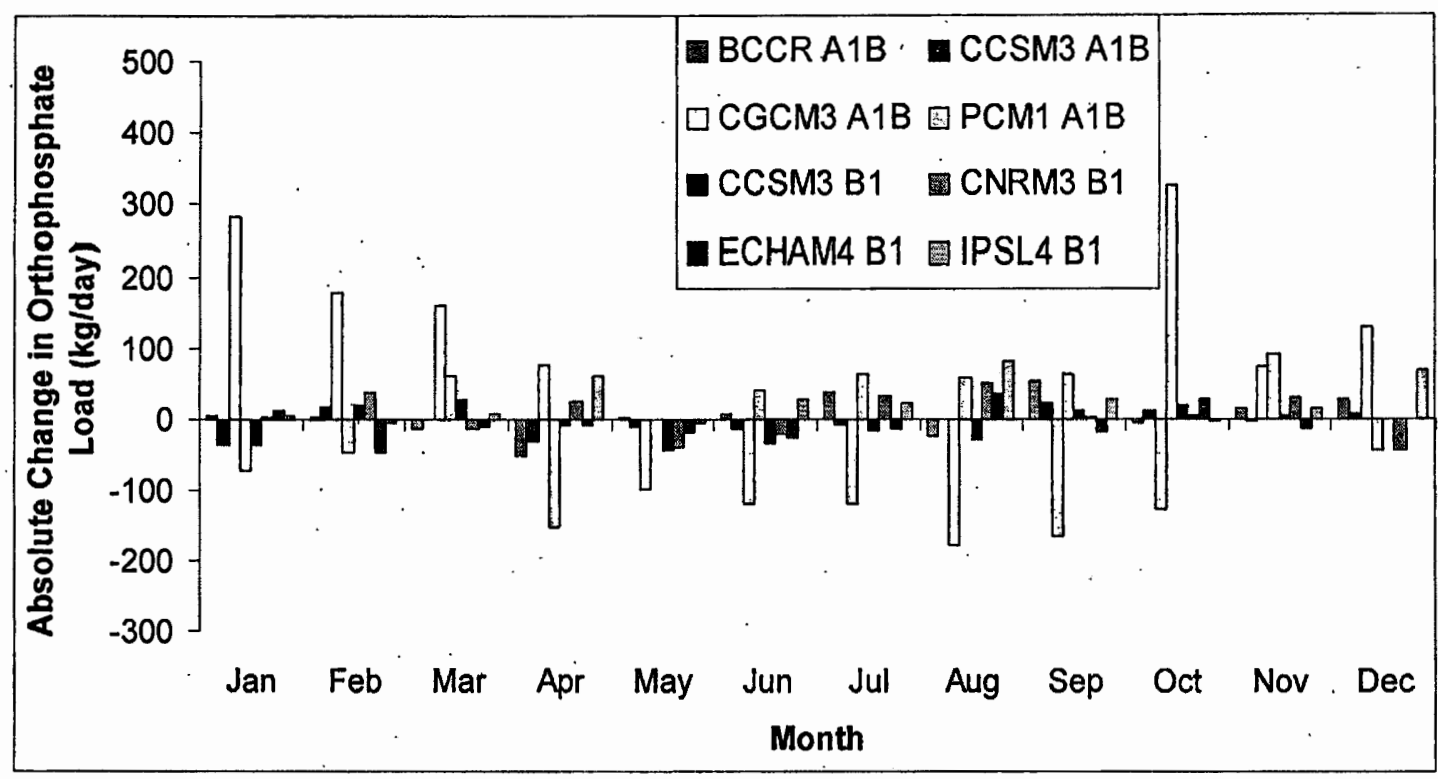

Figure 6.49: Absolute changes in monthly orthophosphate load resulting from the eight climate change scenarios for the 2040s.

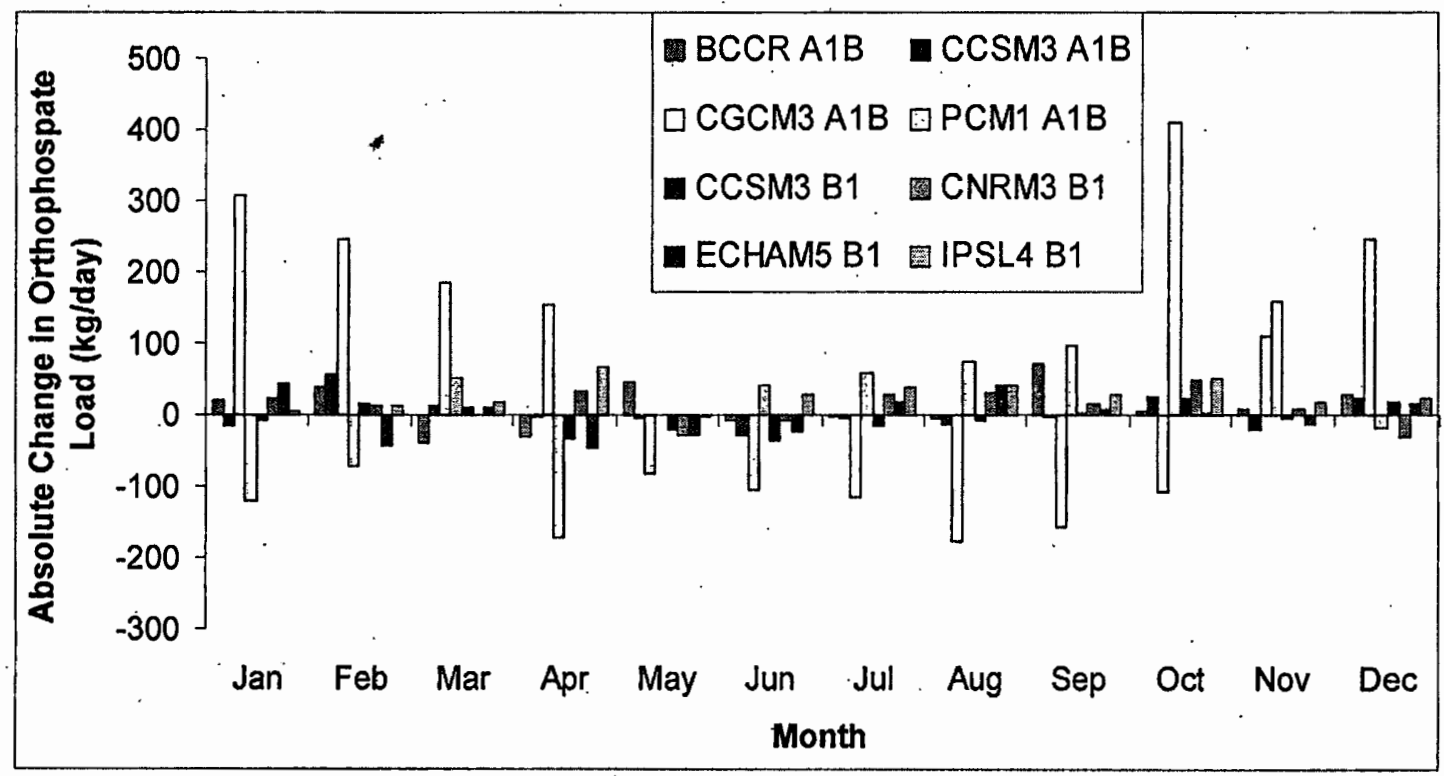

Figure 6.50: Absolute changes in monthly orthophosphate load resulting from the eight climate change scenarios for the 2070s. 


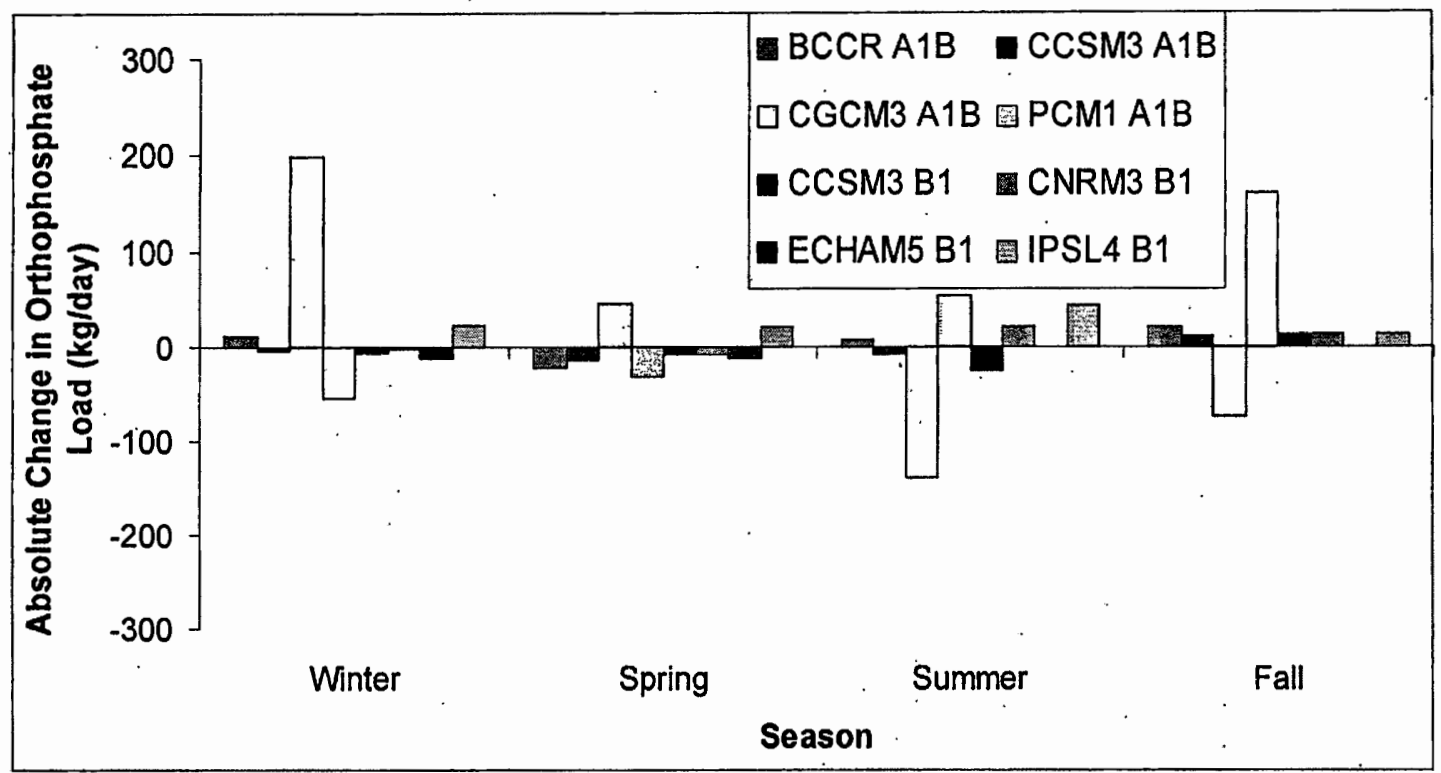

Figure 6.51: Absolute changes in seasonal orthophosphate load resulting from the eight climate change scenarios for the 2040s.

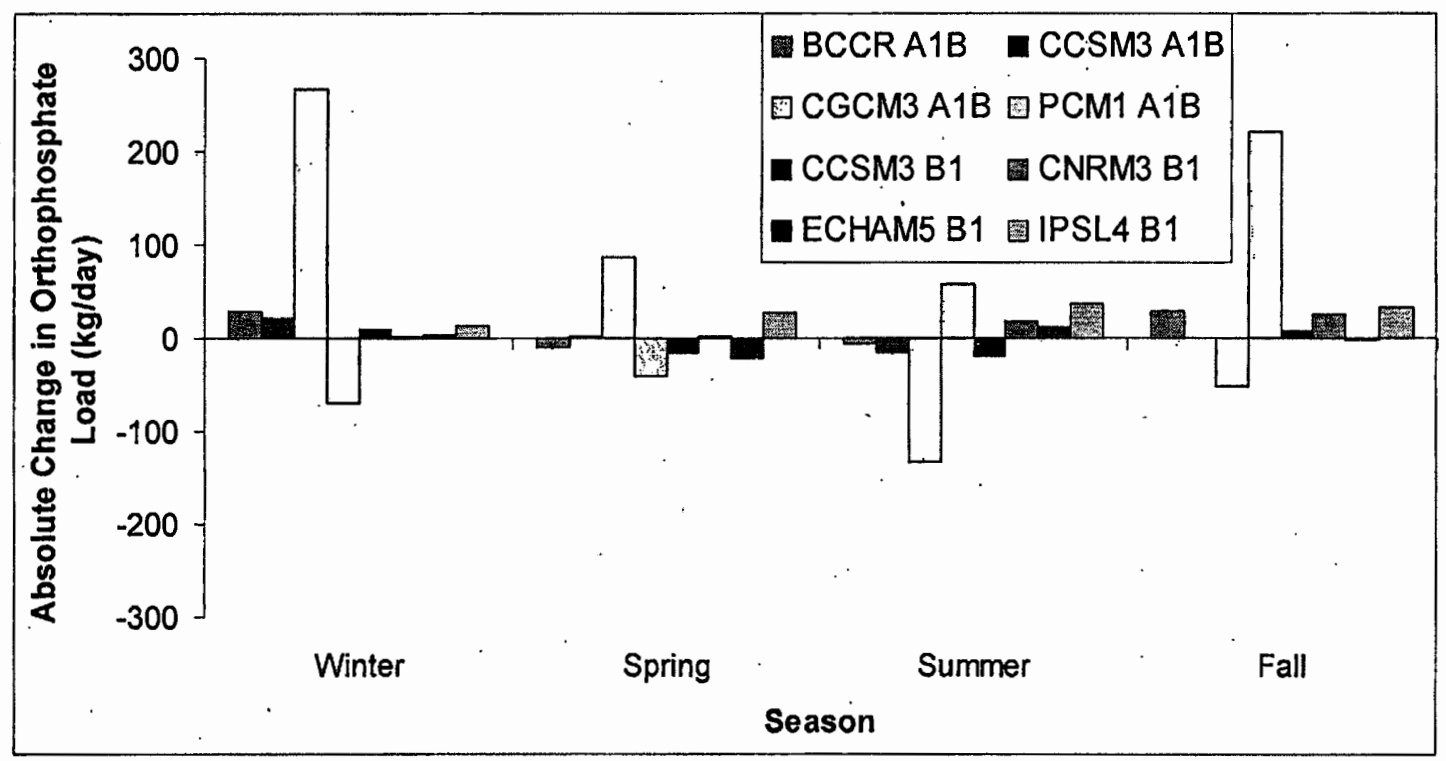

Figure 6.52: Absolute changes in seasonal orthophosphate load resulting from the eight climate change scenarios for the 2070 s. 


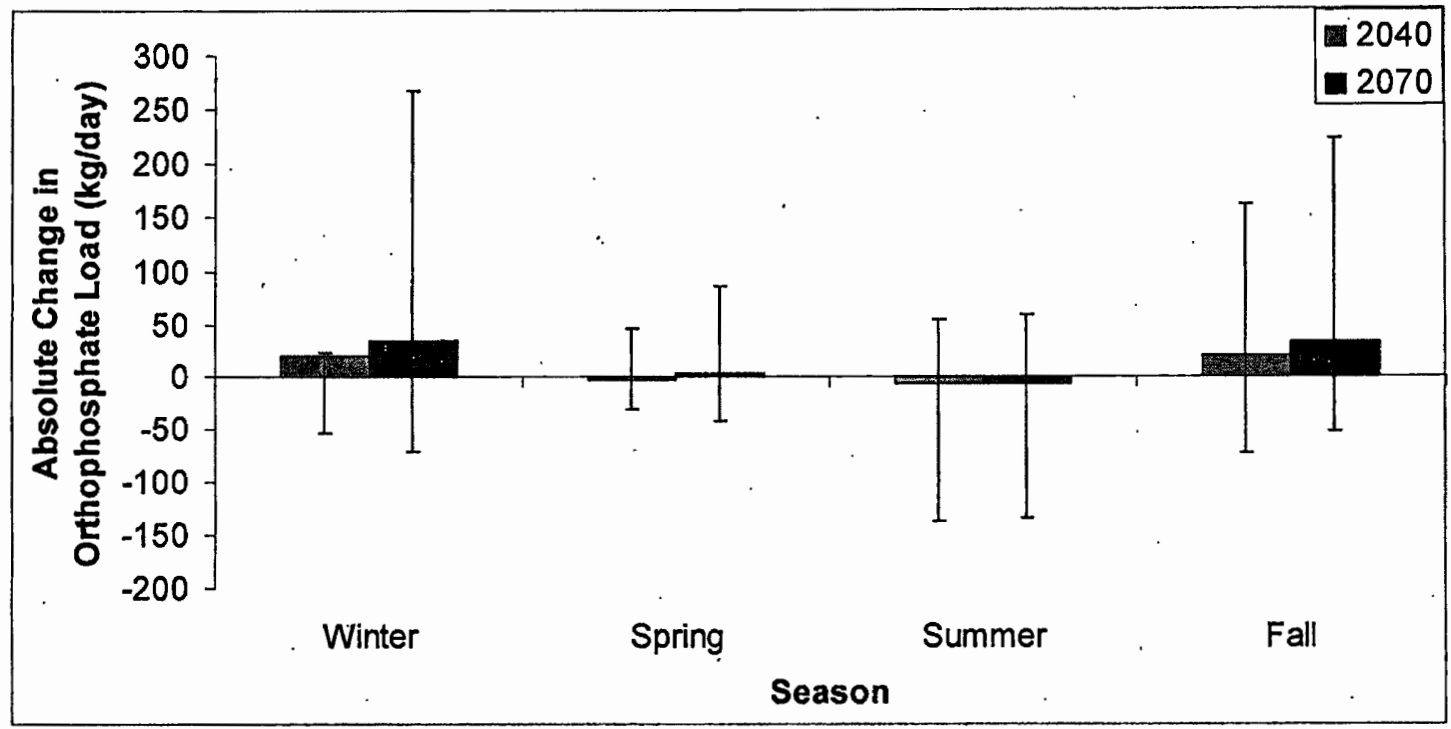

Figure 6:53: Absolute changes in seasonal orthophosphate load, averaged for all eight climate change scenarios, for the 2040s and 2070s.

Table 6.39: Percent changes in seasonal orthophosphate load, averaged for all eight climate change scenarios, for the 2040s and 2070s.

\begin{tabular}{|l|r|r|}
\hline Season & 2040 & 2070 \\
\hline Winter & $16 \%$ & $26 \%$ \\
\hline Spring & $-2 \%$ & $4 \%$ \\
\hline Summer & $-8 \%$ & $-9 \%$ \\
\hline Fall & $43 \%$ & $62 \%$ \\
\hline
\end{tabular}

Table 6.40: Results of two-tailed t-test for significance of changes in orthophosphate load compared to the baseline for the eight climate change scenarios.

\begin{tabular}{|l|r|r|}
\hline Scenario & 2040 & \multicolumn{1}{|c|}{2070} \\
\hline BCCR A1B & -1.31 & $-2.79^{* *}$ \\
\hline CCSM3 A1B & 0.92 & -0.57 \\
\hline CGCM3 A1B & $-2.28^{*}$ & $-11.81^{* \star}$ \\
\hline PCM1 A1B & $3.70^{* *}$ & 1.46 \\
\hline CCSM3 B1 & 1.88 & 1.48 \\
\hline CNRM3 B1 & -1.46 & $-3.02^{* *}$ \\
\hline ECHAM5 B1 & 1.58 & 0.32 \\
\hline IPSL4 B1 & $-6.48^{* *}$ & $-7.12^{* *}$ \\
\hline
\end{tabular}

*Significant at the 0.05 level.

**Significant at the 0.01 level. 


\section{Impacts of Urban Development on Nutrient Loading \\ A. Nitrate Loading}

The patterns of nitrate loading under the land use scenarios differ greatly from the changes in hydrology or in other water quality constituents. In most months, nitrate loading significantly declines under both scenarios, most likely because of a loss of cropland, which is the major source of nitrate export in the basin (Figure 6.54). Figure 6.55 shows these declines at the seasonal scale. The average annual decline has a magnitude of approximately twenty-two percent under the development scenario and forty-three percent under the conservation scenario (Table 6.41). The changes are significant at the 0.01 level for both scenarios (Table 6.42).

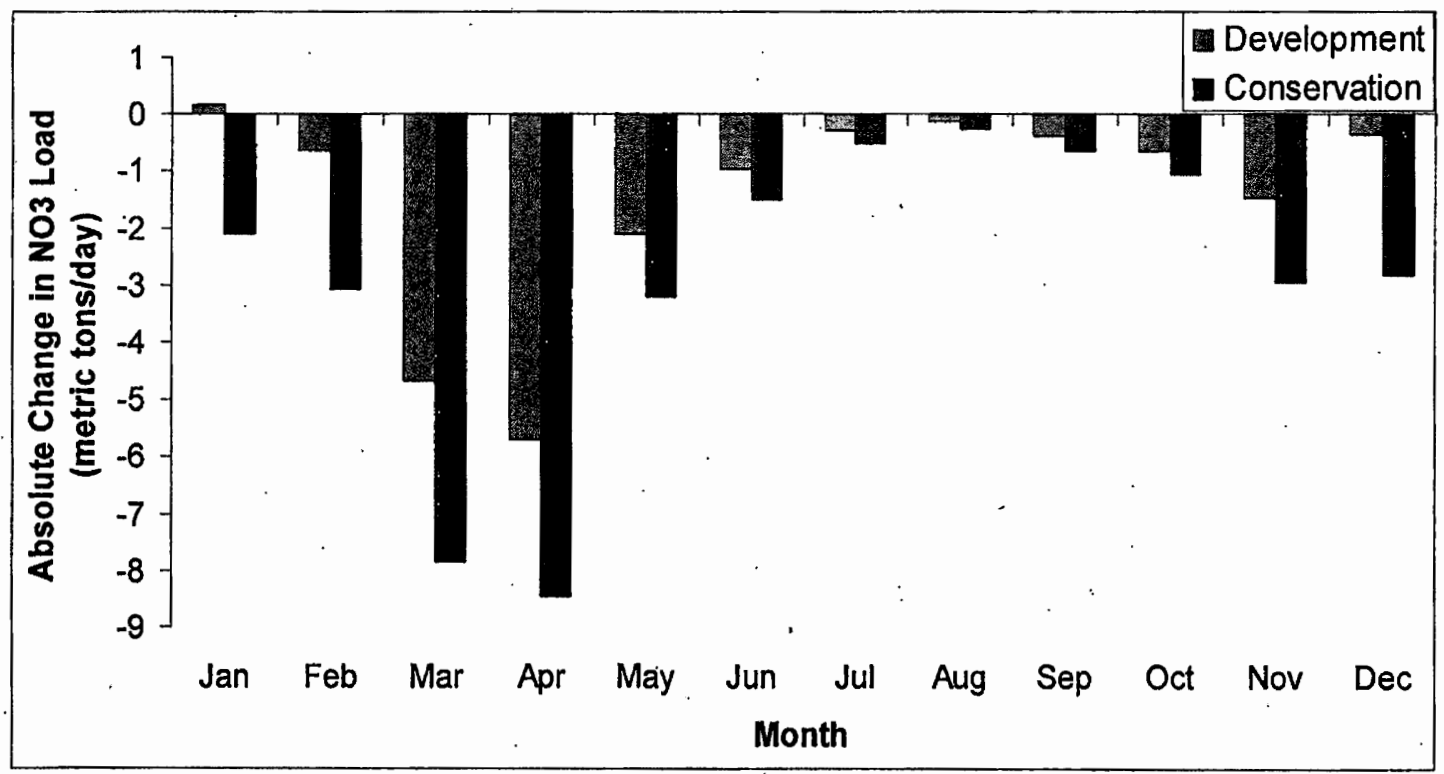

Figure 6.54: Absolute changes in monthly nitrate load resulting from the development and conservation land use scenarios. 


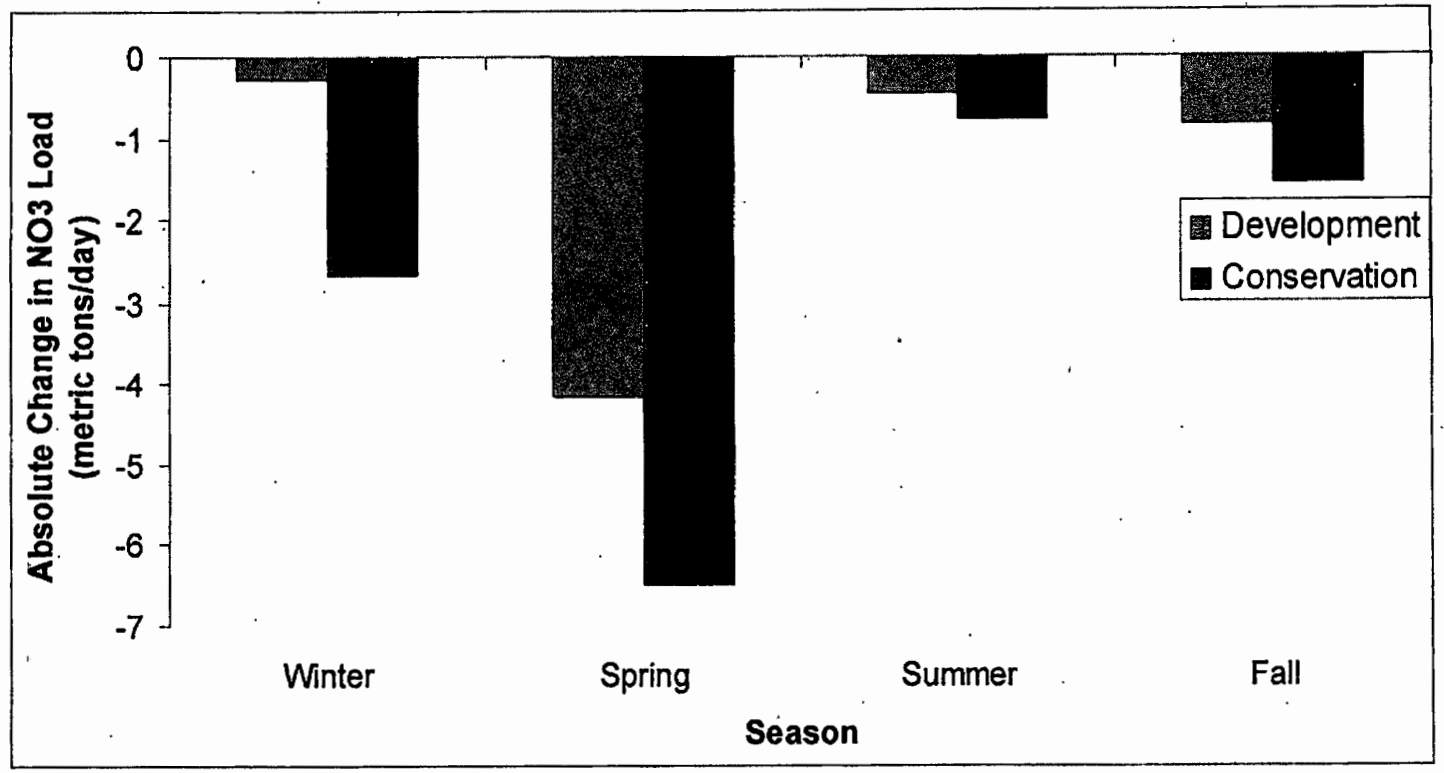

Figure 6.55: Absolute changes in seasonal nitrate load resulting from the development and conservation land use scenarios.

Table 6.41: Percent change in seasonal nitrate load resulting from the development and conservation land use scenarios.

\begin{tabular}{|l|r|r|}
\hline Season & Development & Conservation \\
\hline Winter & $-3 \%$ & $-30 \%$ \\
\hline Spring & $-30 \%$ & $-46 \%$ \\
\hline Summer & $-28 \%$ & $-49 \%$ \\
\hline Fall & $-27 \%$ & $-48 \%$ \\
\hline Average & $-22 \%$ & $-43 \%$ \\
\hline
\end{tabular}

Table 6.42: Results of two-tailed t-test for significance of changes in nitrate load compared to the baseline for the development and conservation scenarios.

\begin{tabular}{|l|l|}
\hline Scenario & $t$ \\
\hline Development & $11.52^{\star \star}$ \\
\hline Conservation & $24.84^{\star \star}$ \\
\hline
\end{tabular}

${ }^{* *}$ Significant at the 0.01 level.

B. Orthophosphate Loading

The modeled changes in orthophosphate resulting from the land use scenarios are similar to the projected changes in flow and sediment loading. Figures 6.56 and 6.57 show these changes at the monthly and seasonal scales, with significant decreases in orthophosphate loading under the conservation scenario and smaller increases under 
the development scenario, as a result of the hydrological changes. The average annual increase for the development scenario is approximately seven percent, and the average decrease under the conservation scenario is thirty-two percent (Table 6.43). The changes are significant at the 0.01 level for the conservation scenario only (Table 6.44).

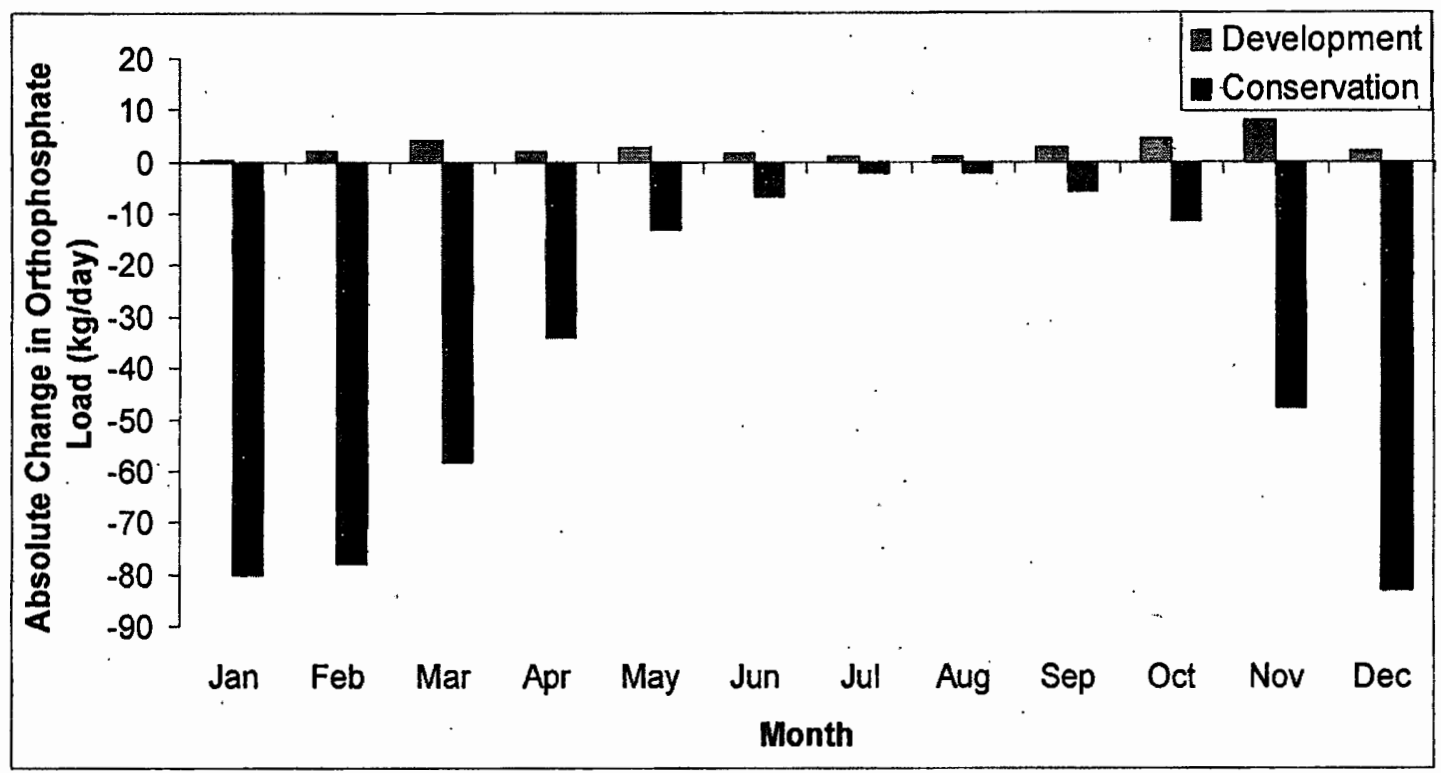

Figure 6.56: Absolute changes in monthly orthophosphate load resulting from the development and conservation land use scenarios. 


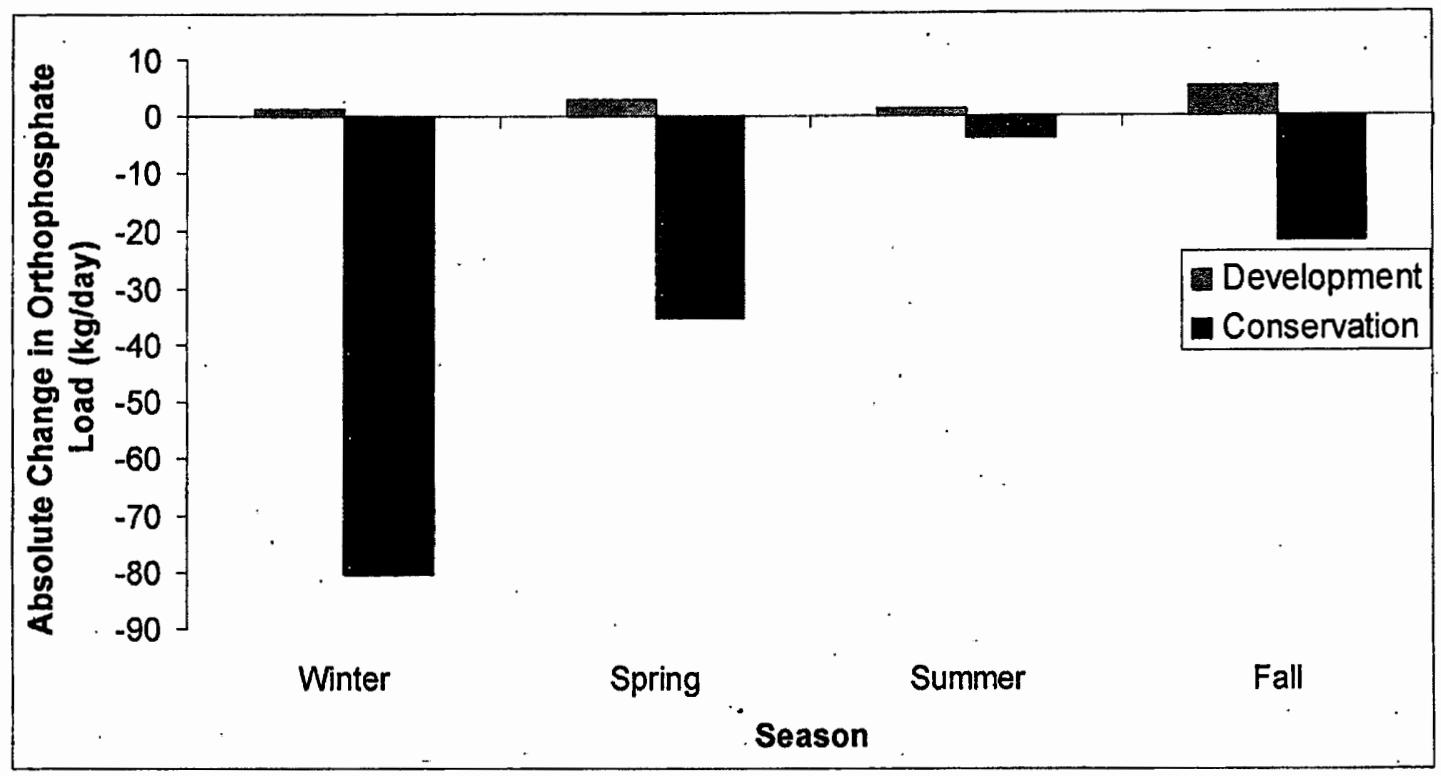

Figure 6.57: Absolute changes in seasonal orthophosphate load resulting from the development and conservation land use scenarios.

Table 6.43: Percent changes in seasonal orthophosphate load resulting from the development and conservation land use scenarios.

\begin{tabular}{|l|r|r|}
\hline Season & Development & Conservation \\
\hline Winter & $1 \%$ & $-31 \%$ \\
\hline Spring & $3 \%$ & $-30 \%$ \\
\hline Summer & $14 \%$ & $-33 \%$ \\
\hline Fall & $12 \%$ & $-34 \%$ \\
\hline Average & $7 \%$ & $-32 \%$ \\
\hline
\end{tabular}

Table 6.44: Results of two-tailed t-test for significance of changes in orthophosphate load compared to the baseline for the development and conservation scenarios.

\begin{tabular}{|l|c|}
\hline Scenario & $t$ \\
\hline Development & -1.13 \\
\hline Conservation & $17.21^{* *}$ \\
\hline **Significant at the 0.01 level.
\end{tabular}

9. Combined Impacts of Climate Change and Urban Development on Nutrient

Loading

\section{A. Nitrate Loading}

The patterns of change for the combined impacts of climate change and urban development on nutrient loading are more similar to those for climate change alone 
than to land use change alone. Generally, nitrate loading increases in the winter and decreases in the summer under the combined scenarios (Figures 6.58 and 6.59). Again, there are more difference between the high- and low-change climate scenarios than between the two land use scenarios, suggesting that climate change may be a more important determinant of changes in nitrate loading than urban development (Figures 6.60 and 6.61). For the 2040s, the winter increase reaches forty-five percent and the summer decrease reaches sixty-three percent for HCLL (Table 6.45), while in the 2070 s the winter increase reaches up to fifty-two percent and the summer decrease is sixty-six percent (Table 6.46). The changes are significant at the 0.05 level or higher for all scenarios (Table 6.47).

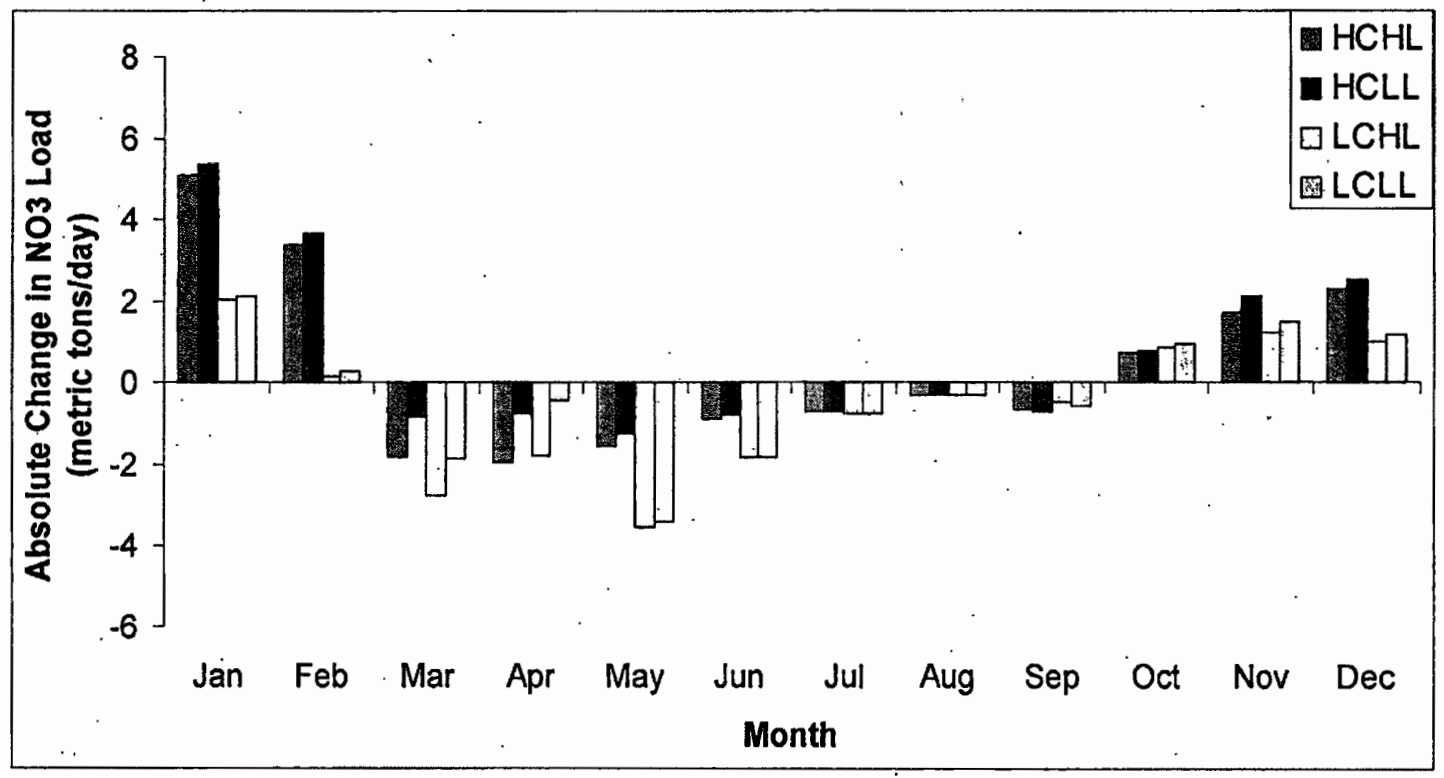

Figure 6.58: Absolute changes in monthly nitrate load resulting from the combined climate change and urban development scenarios for the 2040s. 


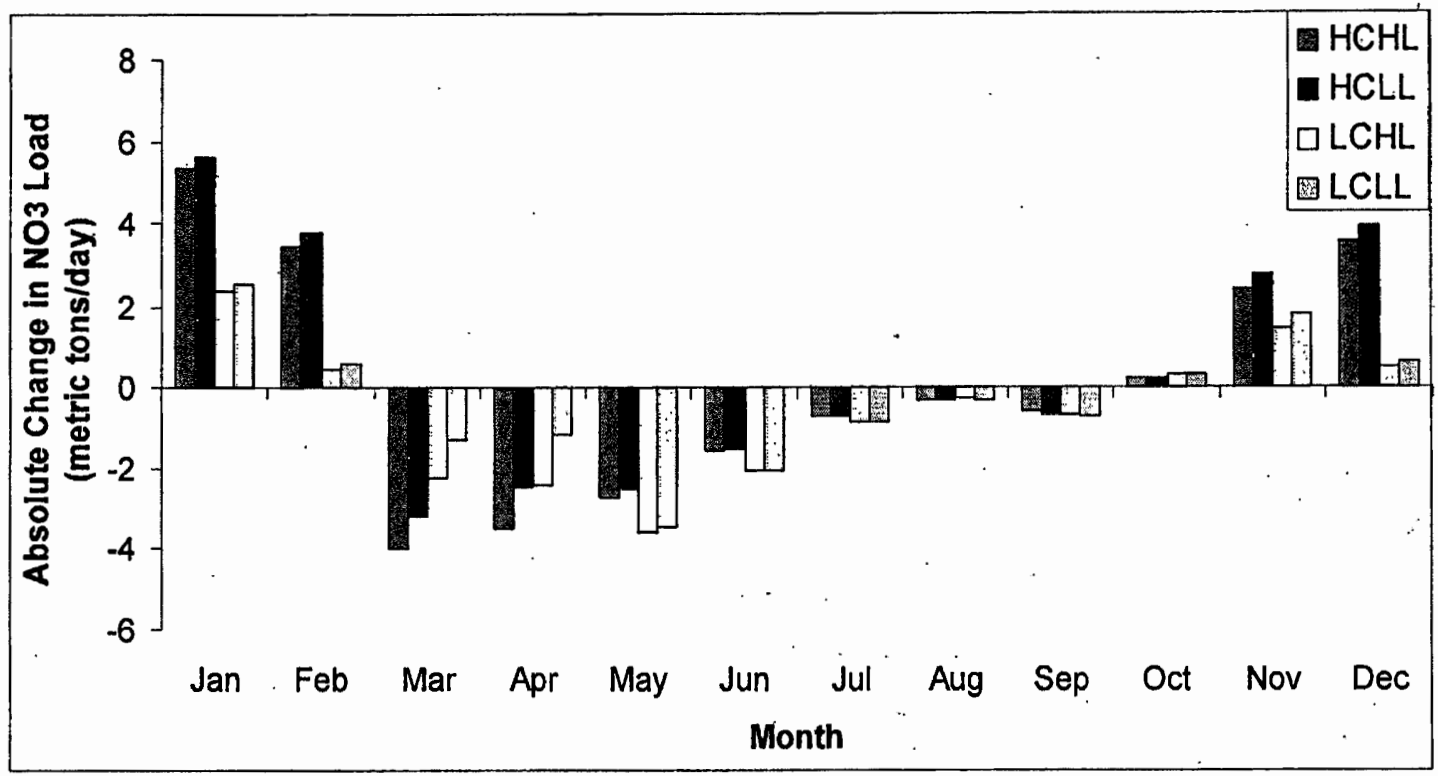

Figure 6.59: Absolute changes in monthly nitrate load resulting from the combined climate change and urban development scenarios for the $2070 \mathrm{~s}$.

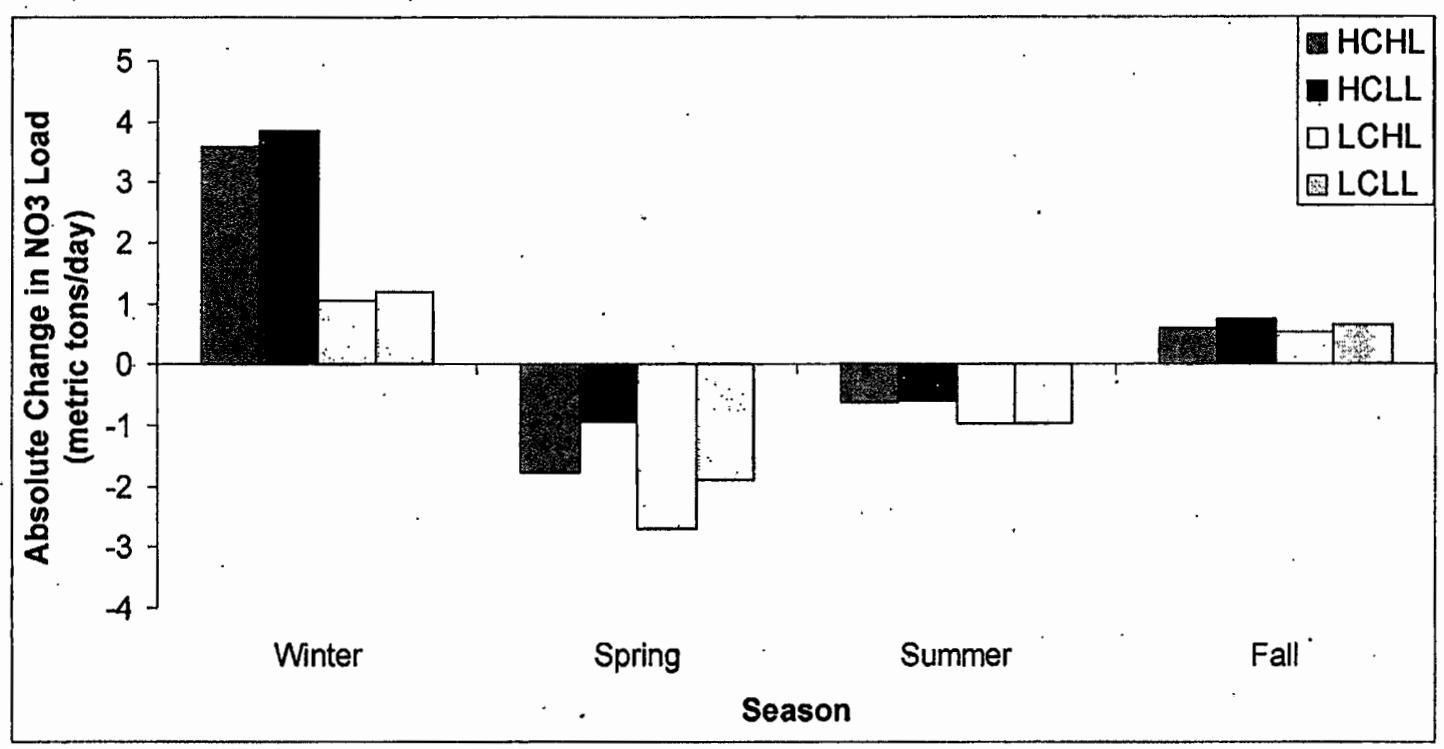

Figure 6.60: Absolute changes in seasonal nitrate load resulting from the combined climate change and urban development scenarios for the 2040s. 


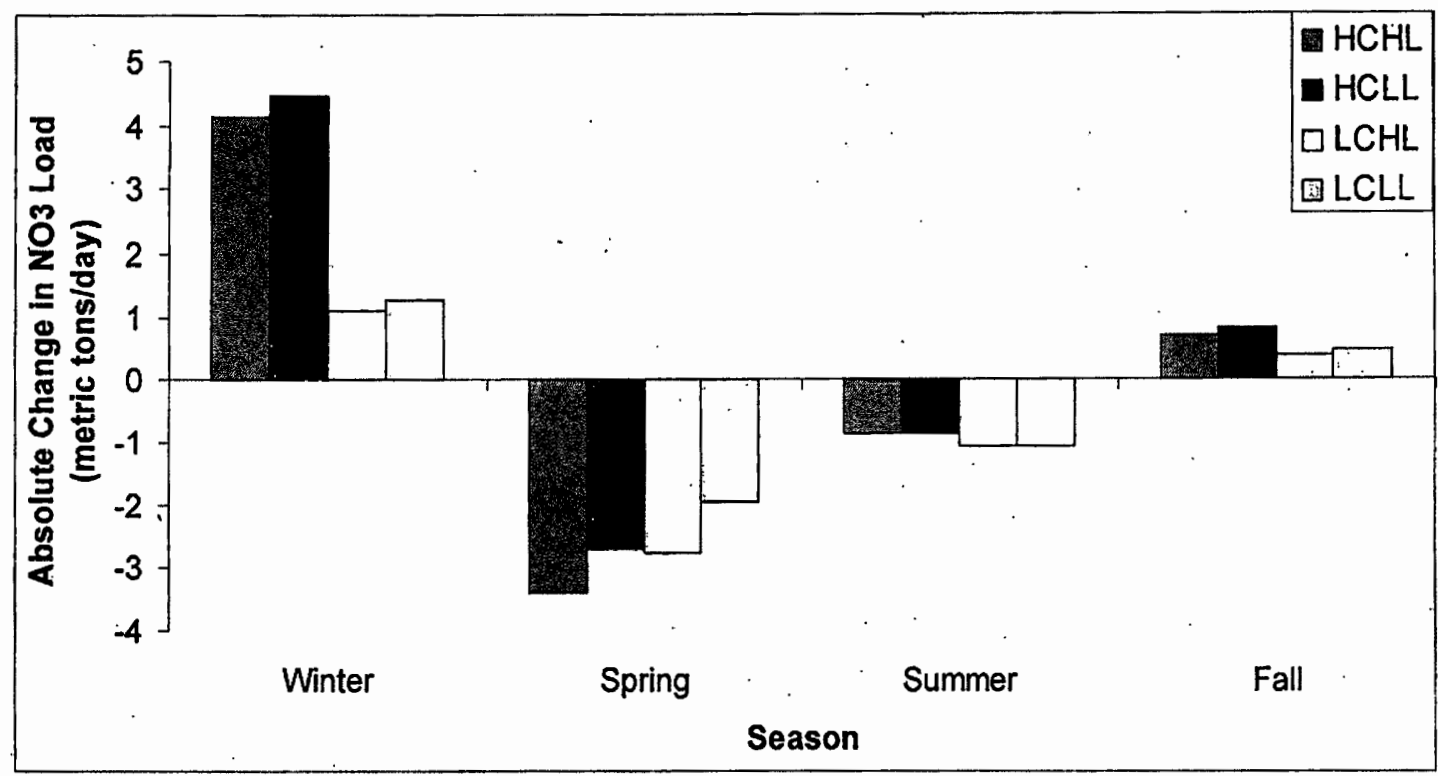

Figure 6.61: Absolute changes in seasonal nitrate load resulting from the combined climate change and urban development scenarios for the 2070s.

Table 6.45: Percent changes in seasonal nitrate load resulting from the combined climate change and urban development scenarios for the 2040s.

\begin{tabular}{|l|r|r|r|r|}
\hline Season & \multicolumn{1}{|c|}{ HCHL } & HCLL & LCHL & \multicolumn{1}{l|}{ LCLL } \\
\hline Winter & $42 \%$ & $45 \%$ & $13 \%$ & $15 \%$ \\
\hline Spring & $-15 \%$ & $-9 \%$ & $-26 \%$ & $-21 \%$ \\
\hline Summer & $-61 \%$ & $-63 \%$ & $-59 \%$ & $-62 \%$ \\
\hline Fall & $1 \%$ & $2 \%$ & $6 \%$ & $7 \%$ \\
\hline
\end{tabular}

Table 6.46: Percent changes in seasonal nitrate load resulting from the combined climate change and urban development scenarios for the 2070s.

\begin{tabular}{|l|r|r|r|r|}
\hline Season & \multicolumn{1}{|l|}{ HCHL } & HCLL & LCHL & LCLL \\
\hline Winter & $48 \%$ & $52 \%$ & $14 \%$ & $16 \%$ \\
\hline Spring & $-28 \%$ & $-23 \%$ & $-27 \%$ & $-22 \%$ \\
\hline Summer & $-60 \%$ & $-63 \%$ & $-63 \%$ & $-66 \%$ \\
\hline Fall & $-1 \%$ & $0 \%$ & $-6 \%$ & $-6 \%$ \\
\hline
\end{tabular}

Table 6.47: Results of two-tailed t-test for significance of changes in nitrate load compared to the baseline for the four combined climate change and urban development scenarios.

\begin{tabular}{|l|c|r|}
\hline Scenario & 2040 & 2070 \\
\hline HCHL & $-3.17^{\star \star}$ & -0.94 \\
\hline HCLL & $-5.29^{\star \star}$ & $-3.07^{\star \star}$ \\
\hline LCHL & $3.92^{\star \star}$ & $4.67^{\star \star}$ \\
\hline LCLL & 1.91 & $2.57^{\star}$ \\
\hline
\end{tabular}

*Significant at the 0.05 level.

**Significant at the 0.01 level. 


\section{B. Orthophosphate Loading}

The changes in orthophosphate load resulting from the combined scenarios generally follow those resulting from climate change. There are decreases in the summer and increases in the other months (Figures 6.62 and 6.63). Figures 6.64 and 6.65 show these changes at the seasonal scale. In the $2040 \mathrm{~s}$, the maximum winter increase in orthophosphate loading is approximately fifty percent and the maximum summer decrease is thirty-nine percent (Table 6.49). In the 2070s, this range increases to a maximum winter increase of fifty-six percent and a maximum summer decrease of forty-three percent (Table 6.48). The changes are significant at the 0.01 level for all scenarios (Table 6.50).

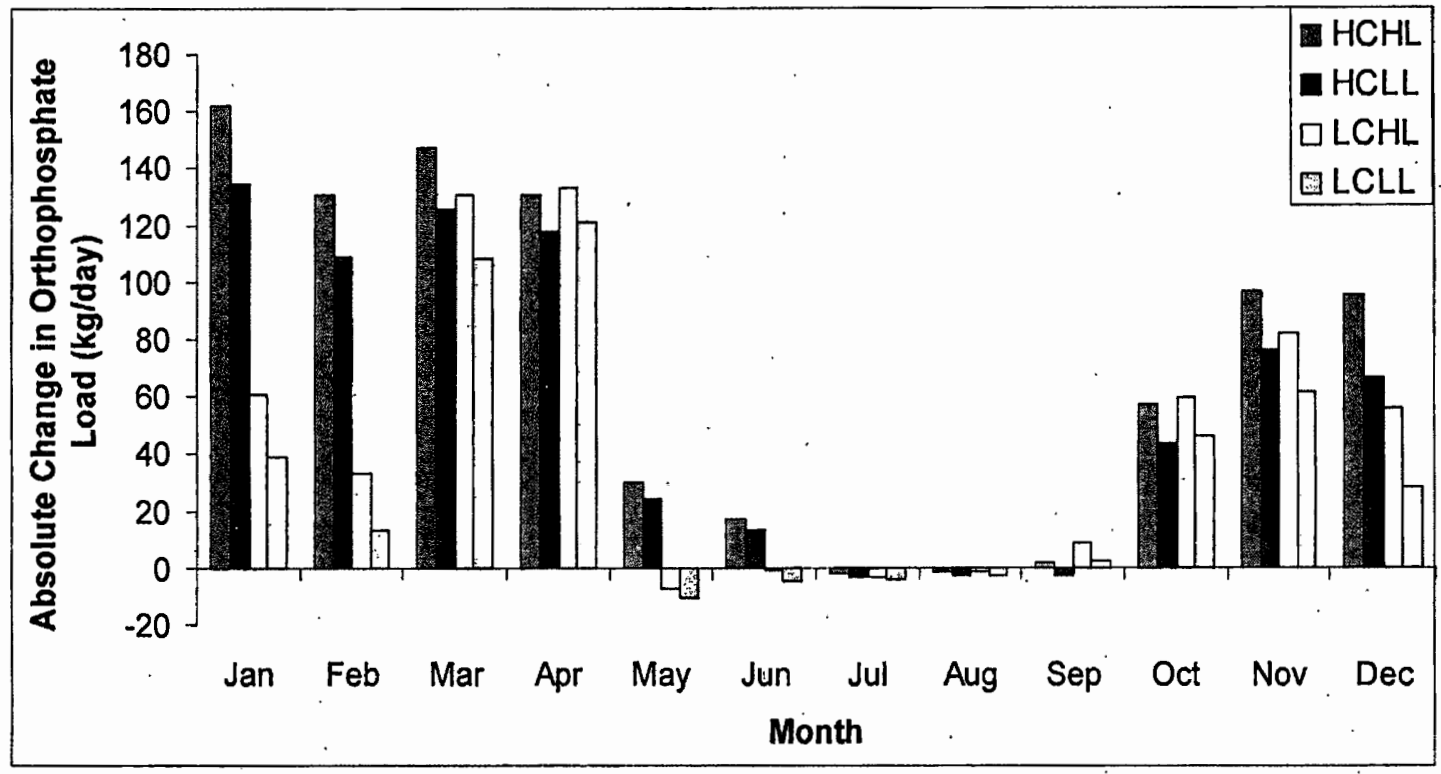

Figure 6.62: Absolute changes in monthly orthophosphate load resulting from the combined climate change and urban development scenarios for the 2040s. 


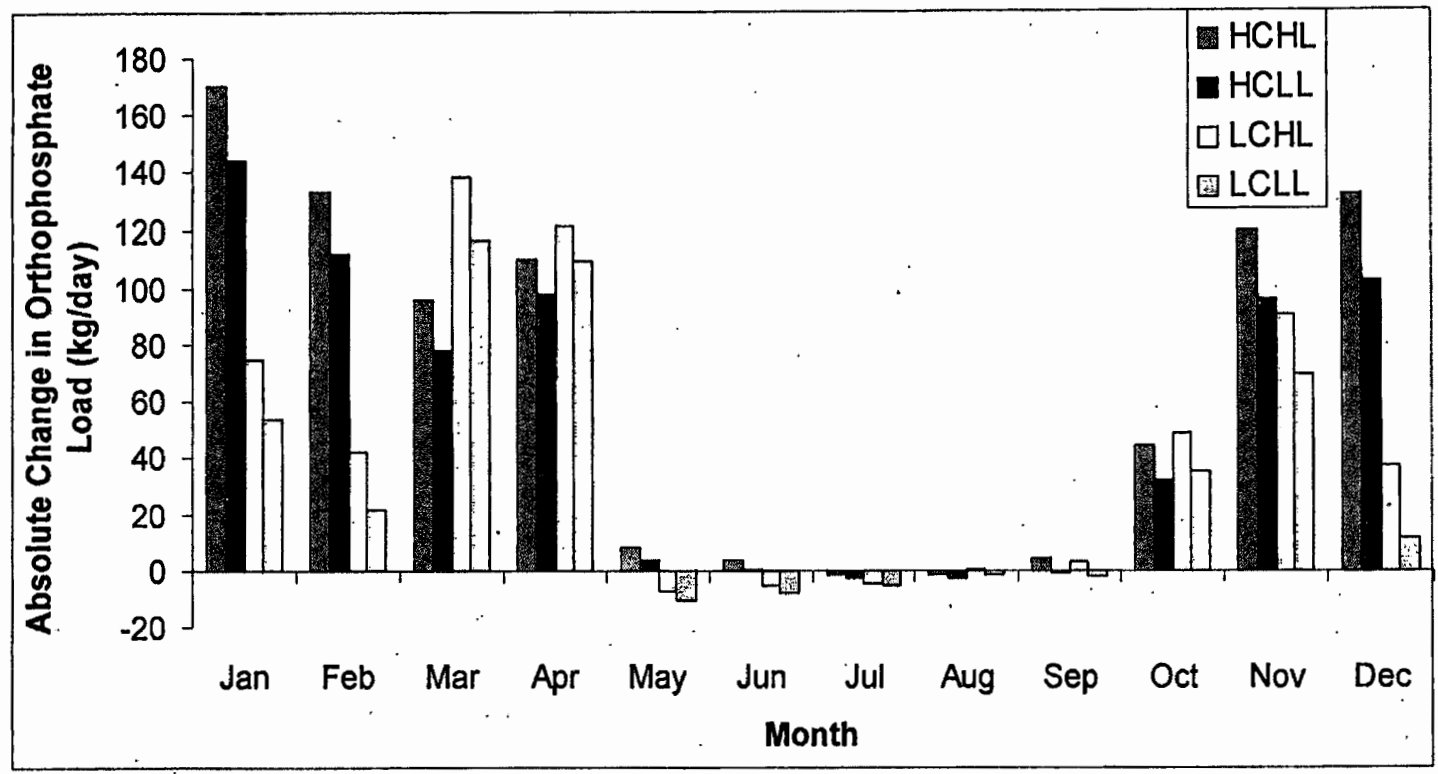

Figure 6.63: Absolute changes in monthly orthophosphate load resulting from the combined climate change and urban development scenarios for the 2070s.

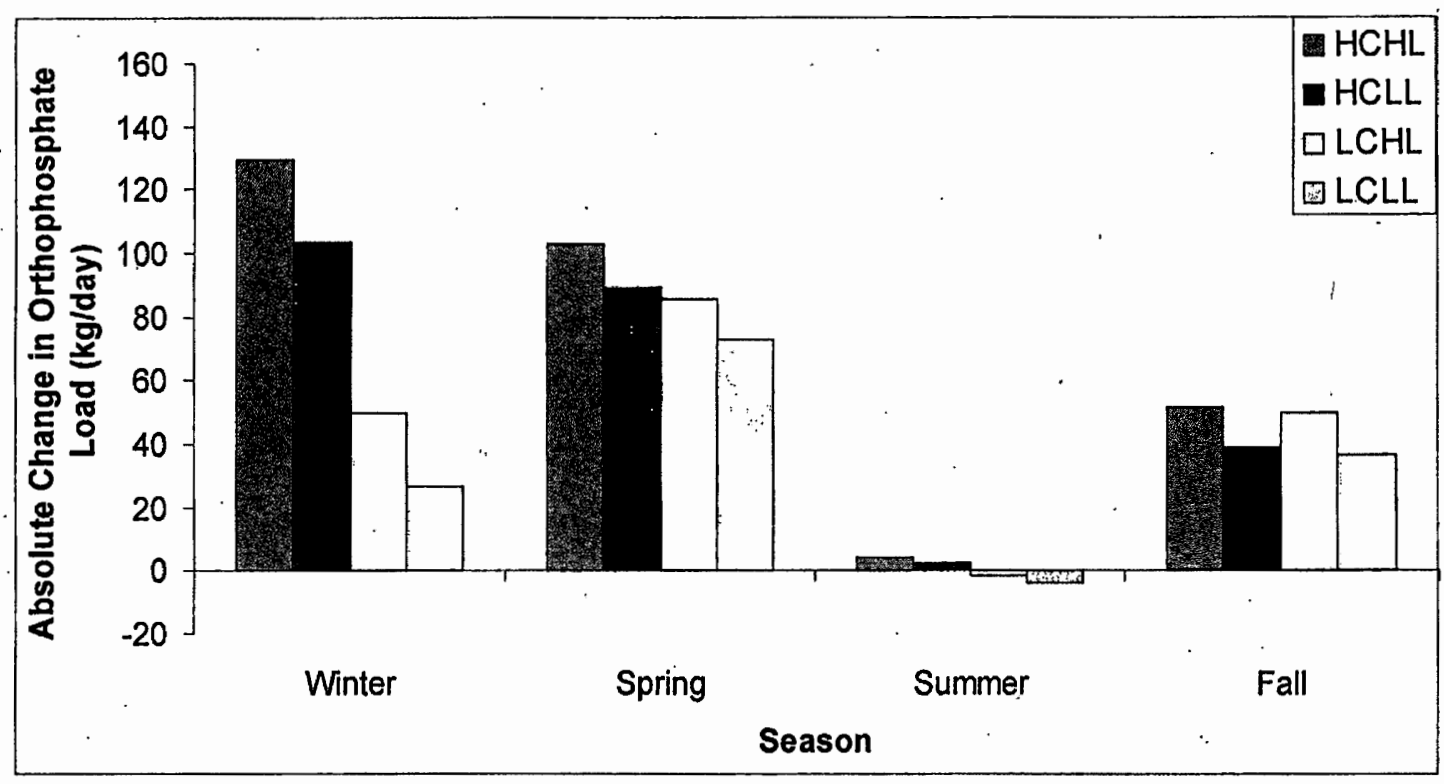

Figure 6.64: Absolute changes in seasonal orthophosphate load resulting from the combined climate change and urban development scenarios for the $2040 \mathrm{~s}$. 


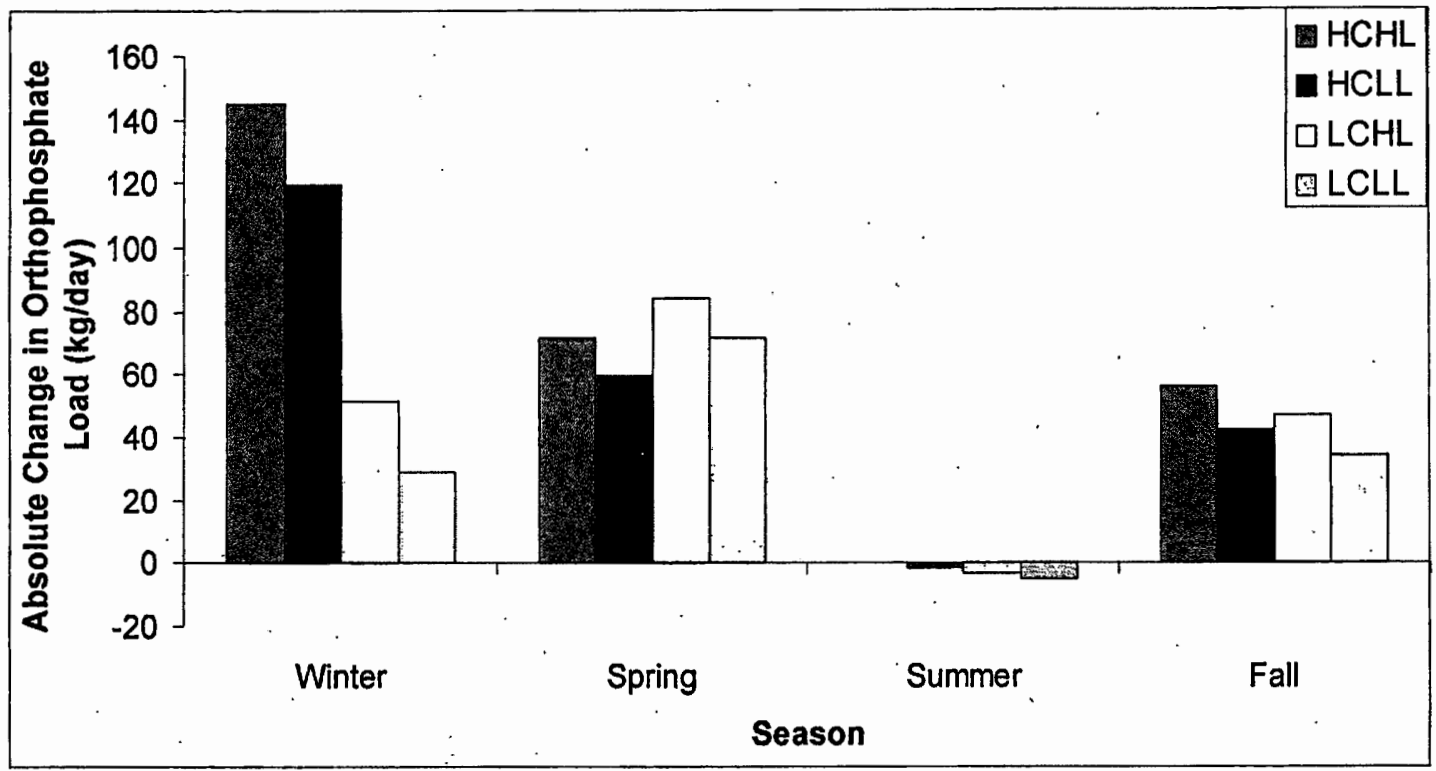

Figure 6.65: Absolute changes in seasonal orthophosphate load resulting from the combined climate change and urban development scenarios for the 2070s.

Table 6.48: Percent changes in seasonal orthophosphate load resulting from the combined climate change and urban development scenarios for the 2040s.

\begin{tabular}{|l|r|r|r|r|}
\hline Season & \multicolumn{1}{|r|}{ HCHL } & \multicolumn{1}{|l|}{ HCLL } & \multicolumn{1}{l|}{ LCHL } & \multicolumn{1}{l|}{ LCLL } \\
\hline Winter & $50 \%$ & $40 \%$ & $19 \%$ & $10 \%$ \\
\hline Spring & $88 \%$ & $76 \%$ & $57 \%$ & $47 \%$ \\
\hline Summer & $9 \%$ & $-8 \%$ & $-23 \%$ & $-39 \%$ \\
\hline Fall & $82 \%$ & $55 \%$ & $95 \%$ & $65 \%$ \\
\hline
\end{tabular}

Table 6.49: Percent changes in seasonal orthophosphate load resulting from the combined climate change and urban development scenarios for the 2070s.

\begin{tabular}{|l|r|r|r|r|}
\hline Season & \multicolumn{1}{|c|}{ HCHL } & \multicolumn{1}{|c|}{ HCLL } & LCHL & \multicolumn{1}{l|}{ LCLL } \\
\hline Winter & $56 \%$ & $46 \%$ & $20 \%$ & $11 \%$ \\
\hline Spring & $56 \%$ & $45 \%$ & $55 \%$ & $45 \%$ \\
\hline Summer & $-9 \%$ & $-27 \%$ & $-26 \%$ & $-43 \%$ \\
\hline Fall & $79 \%$ & $51 \%$ & $74 \%$ & $47 \%$ \\
\hline
\end{tabular}

Table 6.50: Results of two-tailed $t$-test for significance of changes in orthophosphate load compared to the baseline for the four combined climate change and urban development scenarios.

\begin{tabular}{|l|r|r|}
\hline Scenario & 2040 & 2070 \\
\hline HCHL & $-22.97^{* \star}$ & $-24.03^{* \star}$ \\
\hline HCLL & $-19.65^{\star \star}$ & $-20.28^{\star *}$ \\
\hline LCHL & $-15.61^{\star \star}$ & $-16.73^{* \star}$ \\
\hline LCLL & $-11.93^{* \star}$ & $-12.68^{* \star}$ \\
\hline
\end{tabular}

**Significant at the 0.01 level. 


\section{VII: DISCUSSION}

\section{Impacts of Climate Change on Hydrology}

The modeling results from this study found that climate change is likely to significantly affect water resources in the TRB during the twenty-first century, with potential average increases in winter flow of ten percent and summer decreases of thirty-seven percent by the 2070 s. These results are similar to the findings of Franczyk and Chang (2009), who used the Soil and Water Assessment Tool (SWAT), driven by a downscaled ECHAM5 A1B scenario and a range of synthetic scenarios, including an increase in mean monthly temperature of 2 or $4^{\circ} \mathrm{C}$ and increases in mean winter precipitation and decreases in mean summer precipitation of ten or twenty percent, to model impacts of climate change on runoff in the Rock Creek Basin for the 2040s. The findings in this study are also in line with those of Mote et al. (2003), who used four GCMs, with temperature increases ranging from 1.5 to $3.2^{\circ} \mathrm{C}$ and precipitation changes ranging from -2 to +22 percent, to drive the Variable Infiltration Capacity (VIC) model to predict changes in the flows of the Columbia River, and found winter increases of up to twenty-two percent and summer decreases of six percent for the entire Columbia Basin. The magnitude of the flow changes found in the present research is greater than that found for the Columbia River Basin because of the TRB's smaller area and the greater range of climate scenarios and longer study period used. A study with a more similarly-sized rain-fed basin in a marine west coast climate, the Upper Campbell River in British Columbia, whose flows were modeled using the University of British Columbia (UBC) Watershed Model under the CGCM 
A1 climate scenario, with a temperature increase of 3.5 to $4.1^{\circ} \mathrm{C}$ and an annual precipitation increase of about thirteen percent, resulted in a seventy-one percent increase in winter flows and a fifty-nine percent decrease in summer flows (Loukas et al. 2002b). While much attention is often given to impacts of climate change in snowmelt-dominated basins, the results of all these studies indicate that changes can be significant in rain-fed basins as well, because of changing precipitation patterns and higher evapotranspiration. Hamlet and Lettenmaier (2007) found that the diminished snowpack is likely to decrease flood risk in snowmelt-dominated basins under climate change, because these basins will lose their primary source of spring flow, while transient and rain-fed basins show a wide range of responses, often including an increase in flood risk, particularly in winter and spring.

These types of hydrological changes are particularly significant in regions like the Pacific Northwest that have pronounced seasonal variability of precipitation and therefore of water availability. The results of this study suggest that the TRB will experience lower low flows and higher high flows in the future as a result of climate change. These findings are in agreement with those for other midlatitude basins. In a study of six United Kingdom basins, Arnell (2003b), using a lumped conceptual hydrological model driven by the UKCIP98 climate scenario, which includes temperature increases of 0.78 to $2.08^{\circ} \mathrm{C}$ and precipitation decreases of five to twentyfive percent, found that the magnitude of the ninety-fifth percentile flow may decline by up to fifty percent by the 2080 s. Other studies have focused on predicted changes in high flows resulting from climate change. For example, Milly et al. (2002) 
statistically modeled impacts of quadrupling atmospheric carbon dioxide concentrations on the flows of twenty-nine large river basins around the world. This study found large changes in the one-hundred-year flood magnitude for several large river basins in northwestern North America, including an increase of fifteen percent for the Yukon River and seventeen percent for the Fraser River.

Changes in hydrological variability may be more significant for water resource management than changes in mean hydrology. While annual basin runoff may not change much (for the 2070 s composite climate change scenario compared to the baseline, $t=-2.00$, which is not significant), amplified seasonality of flows can prove problematic in areas like the TRB. The basin has already experienced problems with damaging flooding, notably during the spring of 1996, and regularly suffers from summer low flows that degrade the river's ecological and aesthetic value through high water temperatures and poor water quality (Boeder and Chang 2008). The results of this study indicate that such problems are likely to worsen as a result of climate change and land use change. Increased hydrologic variability poses a challenge for water resource managers, who have traditionally relied on the concept of stationarity, the assumption that the probability distribution of climatic and hydrological variables does not change over time (Milly et al. 2008). In light of climate change, there have been calls for a new paradigm in water resource management to accommodate the future of potentially increased variability. The institutional conservatism of many water resource management agencies and the long lifespan of much water 
infrastructure, however, represent significant obstacles to incorporating climate change impacts into water resource management in the near term.

\section{Impacts of Urban Development on Hydrology}

The modeled changes in land use in this study resulted in an average increase in basin runoff of twenty-one percent under the development scenario and an average decrease of sixteen percent under the conservation scenario. The results from the development scenario are similar to those of Tang et al. (2005), who modeled a mesoscale Michigan basin using the Long-Term Hydrologic Impact Assessment (L-THIA) model and found an increase in runoff of about twenty-five percent under a scenario of urban sprawl in which basin urban area increases from less than five percent to eleven to twenty percent, depending on the sub-basin. In the TRB, the urban area increases from nearly seventeen to over twenty-six percent in the development scenario. In the conservation scenario, meanwhile, urban area increases to only nineteen percent, while the water and wetlands category increases from less than one percent to nearly two percent, because of wetland restoration activities. These differences explain why the development scenario results in an increase in basin runoff while the conservation scenario causes a decrease, and illustrates the importance of land use policies in managing basin hydrology.

In the Upper Tualatin River sub-basin, both land use scenarios caused a significant increase in flow. In the Rock Creek sub-basin, the development scenario caused a large increase in basin runoff, while the conservation scenario only slightly increased flow. This latter change is similar to that found by Franczyk and Chang 
(2009), who used scenarios of up to a fourteen percent increase in urban land cover in their SWAT modeling study of the Rock Creek sub-basin. In this study, urban land use increased from sixty-one to seventy-two percent under the development scenario and to sixty-seven percent under the conservation scenario. In the Upper Tualatin River sub-basin, meanwhile, urban land use increased from two to five percent under the development scenario and decreased slightly under the conservation scenario.

The sensitivity of hydrological response to urban development is typically nonlinear (Dunne and Leopold 1978). That is, the same percent increase in urban area may have a smaller effect in an already highly urban basin than in a relatively undeveloped basin (Nirupama and Simonovic 2007). While I did not conduct a sensitivity analysis in this study, some tentative conclusions about threshold levels of basin urban development can be made based on the modeling results. First, the subbasin with the largest overall changes in runoff is the Upper TRB, which has the lowest initial urban area (two percent), as well as higher elevations and steeper slope than the rest of the basin. Because this basin is largely undeveloped, it may be more sensitive than the urban basins to any increase in impervious surface area, because it has not reached the threshold level of urban development. The basin with the smallest overall response to the land use change scenarios was the TRB as a whole, even though the percent increase in urban area under the development scenario (nine percent) is similar to that for the Rock Creek sub-basin (eleven percent). This is most likely a result of the difference in the water and wetlands category between the land use scenarios for the two basins; in the TRB, an increase in wetland area partially 
ameliorates some of the increased runoff associated with urban development, while wetland area decreases in the Rock Creek sub-basin under the development scenario. Because the development and conservation scenarios are based on the same population growth assumptions, the very different hydrological results they generate illustrate that the type of growth policies we choose to pursue - sprawling urban growth or compact sustainable development - can significantly influence basin hydrology.

\section{Combined Impacts of Climate Change and Urban Development on Hydrology}

The modeling results from the combined climate change and urban development scenarios suggest that these two changes will jointly increase winter flow by up to seventy-one percent and decrease summer flow by up to forty-eight percent by the 2070 s. These changes are similar in pattern, but greater in magnitude, compared to the combined climate change and land use change modeling results of Franczyck and Chang (2009) for the Rock Creek Basin, in which there was a maximum of a twenty-four percent increase in runoff. The larger changes found for the TRB are likely the result of this study's greater range of climate change scenarios and longer time period, as well as differences in spatial scale and hydrologic models used for impact assessment.

In comparison to the urban development scenarios alone, the combined scenarios generally predict larger changes in runoff. Additionally, the combined high climate change scenarios tend to be more similar to one another than the combined high land use change scenarios. These differences suggest that the climate change scenarios have more significant impacts than the land use change scenarios on the 
hydrology of the TRB over the study period. Barlage et al. (2002), Chang (2003), and Franczyk and Chang (2009) also found that basin hydrology is more sensitive to climate change than land use change.

The combined scenarios also generally predict higher increases in winter runoff and higher decreases in summer runoff than the climate change scenarios alone. The results of this study, then, indicate that urban development will exacerbate the problems of increased seasonal variability in flows caused by climate change. This is because the greater impervious surface area associated with urban development means a higher proportion of rainfall becomes surface runoff rather than groundwater recharge, thus increasing the overall flashiness of the basin. The reduced infiltration may lead ultimately deplete aquifers, which are an important source of cool water during the summer dry period. While some of this groundwater recharge can be made up by increased winter precipitation, the higher-intensity storms projected under climate change scenarios can overwhelm the infiltration capacity of the soil, leading to increased surface runoff and flooding. Urban development may therefore contribute to the increased seasonality of hydrology in the TRB associated with climate change.

Examining the separate and combined potential impacts of climate change on basin hydrology leads to a consideration of the dynamics of climate change mitigation and adaptation. Mitigation refers to steps taken to prevent climate change from occurring, such as reducing greenhouse gas emissions or increasing carbon storage. Adaptation, in the context of climate change, is the process of deliberately taking actions, such as increasing reservoir storage or instituting water conservation policies, 
to reduce the harm caused by anticipated climate change. There is often a tension between these two types of action, with mitigation being seen as proactive and adaptation as primarily reactive. While mitigation of greenhouse gas concentrations is clearly necessary to reduce the severity of climate change in the future, adaptation is also necessary, particularly at the local scale, because the inertia of the climate system means that some climate change in unavoidable as a result of past emissions (Nelson et al. 2007). One way to reconcile mitigation and adaptation is to recognize their differing scales of implementation. Because the atmosphere is a global system, greenhouse gas emissions from any source in the world contribute to the problem, so coordinated global action is necessary for successful mitigation. The impacts of climate change, however, are highly place-specific, and therefore so are the actions needed for adaptation. The TRB is likely to be affected by climate change during the twenty-first century, regardless of any international mitigation efforts, but local and regional policymakers have a far greater degree of control over how water resource management in the basin adapts to climate change impacts. The modeling results of . this study, which show substantial differences in hydrological response between development-oriented and conservation-oriented urban growth, suggest that one potentially powerful way to adapt to climate change impacts in the TRB is to plan for compact development with preservation and restoration of natural vegetation and wetlands. An urban development pattern similar to that in the conservation land use scenario used in this study may partially ameliorate some of the winter flooding and summer low-flow conditions projected to result from climate change in the basin. 


\section{Sediment and Nutrient Loading}

The modeling results of this study indicate that suspended sediment and orthophosphate loads are highly dependent on flow in the TRB, and changes in the loadings of these water quality constituents resulting from climate change and urban development are likely to closely track hydrological changes. Because increased flow cản affect water quality through non-linear flushing or dilution effects, however, increased load does not necessarily imply higher concentrations of pollutants, nor does reduced load entail lower concentrations. The strong relation between flow and sediment and orthophosphate load is in line with what one would expect, because sediment loading is controlled largely by erosion and scour by surface runoff, and orthophosphate tends to adsorb to soil particles and so is highly correlated with sediment. Under climate change, winter suspended sediment load increases by an average of eighty-one percent under the climate change scenarios. This is a highermagnitude change than the average ten percent increase in winter flow, indicating that the relation between flow and sediment loading is nonlinear. As a result of urban development, modeled suspended sediment load increases by an average eighteen percent under the development scenario and decreases by eighteen percent under the conservation scenario. These changes closely track the hydrological changes of an average twenty-one percent increase in flow under the development scenario and a sixteen percent decrease under the conservation scenario. Unlike with climate change, the magnitude of the increase in sediment load is not greater than the magnitude of the increase in flow, probably because the increase in impervious surface area associated 
with the development scenario depletes the source of sediment for export. The nonlinear response of sediment loading is again evident in the combined scenarios, in which winter suspended sediment loading more than doubles while summer loading decreases by up to eighty-one percent by the 2070 s, compared to an increase in winter flow of up to seventy-one percent and a decrease in summer flow of up to forty-eight percent.

Under the climate change scenarios, winter orthophosphate load increases by an average of twenty-six percent and summer load decreases by an average of nine percent by the 2070 s, changes which are consistent with the pattern of hydrological change, and also with the results of Arheimer et al. (2005), who modeled a fifty percent increase in total phosphorus transport in a Swedish basin under climate change. The orthophosphate response to land use change is also similar to the hydrological response, with an average seven percent increase under the development scenario and a thirty-two percent decrease under the conservation scenario. The combined scenario results also closely track those for hydrology and suspended sediment, with up to a fifty-six percent increase in winter load and a forty-three percent decrease in summer load by the 2070 s.

There is more variability in the nitrate modeling results, probably because nitrate load is less affected by surface runoff flushing effects than sediment and orthophosphate are. Nevertheless, the general pattern of response to climate change still holds, with a projected doubling of winter nitrate load and an average decrease of forty-one percent in summer load by the 2070s. Bouraoui et al. (2004) modeled 
increases in winter nutrient transport nearly as large (up to eighty-five percent) as a result of climate change in a Finnish basin. Imhoff et al. (2007), in contrast, found only a ten percent increase in total nitrogen loads caused by climate change in a Maryland watershed, probably because that study examined changes only at the annual rather than the seasonal scale. Nitrate load is likely to decrease in the summer not only because of diminished flow, but also because of vegetation uptake during the growing season. The decreases in nitrate loads under the urban development scenarios are likely to be the result of loss of agricultural cropland from the baseline of seventeen percent to eight percent under the development scenario and ten percent under the conservation scenario. Agricultural land exports more nitrate than any other land use type in the basin, although this study did not explicitly consider fertilizer applications. When the climate change and land use scenarios are combined, the results are similar to those for hydrology, with up to a fifty-two percent increase in winter nitrate load and a sixty-six percent decrease in summer load by the 2070 s. As with hydrology, the dominant pattern of change in water quality parameters under climate change and urban development is increased seasonality. It is likely that the combination of higher-intensity precipitation and higher impervious surface area will flush significant amounts of pollutants into TRB streams during winter ștorms, and the lower summer flows will reduce the capacity for dilution. Existing water quality problems in the basin, therefore, may worsen over the twenty-first century, although the impacts can be somewhat ameliorated by conservation-oriented land use planning. 


\section{Caveats}

There is a considerable amount of uncertainty in the results of any modeling study. The first major type of uncertainty is inherent in the climate impact analysis process. Studies have shown that the most significant source of uncertainty in the climate impact modeling chain is the General Circulation Model (GCM) (Graham et al. 2007). Because GCMs model extremely complex interactions among the atmosphere, oceans, and land surface, and they differ in the physical assumptions upon which they are based, their simulated forcings in response to a given increase of greenhouse gas concentrations vary. One way to avoid GCM biases in climate impact analysis is to use a variety of GCMs and generate a range of possible results, which is the approach taken in this study.

Another major source of uncertainty in climate impact studies is the choice of emission scenario used to drive the GCM. The Intergovernmental Panel on Climate Change (IPCC) emission scenarios are based on assumptions about global population growth, economic development, energy use, and technology, which are impossible to verify in advance. As with GCMs, one way to address this uncertainty is to use multiple emission scenarios to generate a range of possible results, which was done in this study. There is also a question of whether emissions scenarios are in line with the urban development scenarios. Using a high-development land use scenario in combination with a low-emission scenario, for example, may possibly be unrealistic.

The next source of uncertainty in the modeling chain is in the downscaling from GCM output to a scale appropriate for hydrological modeling. A variety of 
statistical and dynamic downscaling techniques are available, each with its own benefits and drawbacks. In this study, statistical downscaling produced a grid of climate inputs at a sufficiently fine spatial resolution for hydrological modeling at the basin scale. Because only one downscaling technique was used, however, it is impossible to quantify the uncertainty introduced by the downscaling.

Finally, there is uncertainty in the hydrological model itself. While HSPF has been used extensively for scenario modeling of both runoff and water quality, it has limitations. The most fundamental of these is that, like any physically-based model, it requires calibration so that the user can ensure that it is reasonably reproducing observed flow in the study basin. While the model evaluation statistics indicate relatively strong goodness-of-fit to observed data for flow, sediment, and orthophosphate, this is not a guarantee that the model's predictions for future scenarios are accurate. Whenever a hydrological model is run outside the parameters for which it was validated, it is possible that the results are spurious changes caused by overtuning of the model during calibration (Beven 2008). Comparison of multiple evaluation statistics, such as coefficient of determination and Nash-Sutcliffe model efficiency, is recommended to avoid over-estimating the accuracy of the model results, which is the approach that was taken in this study.

While the above caveats apply to any climate impact or hydrological modeling study, more specific limitations of this study must also be addressed. For one, additional assumptions are necessitated by the use of land use scenarios. These scenarios make assumptions about population growth and zoning laws in the basin, 
and results based on them are only as valid as those assumptions. Also, HSPF does not model the impacts of sustainable stormwater management technologies, which are increasingly being implemented in the TRB and may significantly affect flow in urban areas.

Additional uncertainty is introduced by this study's use of HSPF as a water quality model. Water quality is dependent on flow, so sediment and nutrient load estimates encompass all of the uncertainty associated with a hydrological model, plus additional uncertainty specific to the water quality modules. Because HSPF is primarily a runoff model, it has fewer adjustable parameters for calibration of water quality than of flow. This was particularly a problem for nitrate, for which I was unable to calibrate enough parameters to achieve a sufficiently high goodness-of-fit. Nitrate may be influenced more by subsurface processes and vegetation dynamics, neither of which HSPF explicitly simulates, than by surface flow. HSPF also does not dynamically adjust channel width, slope, or other geomorphic parameters, which affects its ability to model changes in both flow and water quality. In particular, the inability of the model to simulate channel widening and deepening as discharge increases may result in overestimates of average flow. Furthermore, although HSPF is capable of modeling point source as well as nonpoint source pollution, I did not incorporate potential changes in point sources because of lack of data, and instead assumed that point sources will remain the same in the future.

Finally, this study is based entirely on scenario modeling, which is the process of assuming that, given certain future conditions, outcomes will change accordingly. I 
did not perform a sensitivity analysis, which would allow me to, for example, estimate how much flow will increase for a given percent increase in precipitation or impervious surface area. A limitation of this study, therefore, is that the results are valid only inasmuch as the climate change and urban development scenarios used actually occur. 


\section{VIII: CONCLUSIONS}

This study examined the impacts of climate change and urban development on water resources in the TRB. I used the Hydrologic Simulation Program - Fortran (HSPF), part of the Better Assessment Science Integrating Point and Nonpoint Sources (BASINS) modeling system, to project the potential impacts on basin hydrology and sediment and nutrient loading resulting from a series of separate and combined scenarios of climate change and urban development. The model evaluation statistics indicate high goodness-of-fit for the calibrated hydrology, suspended sediment, and orthophosphate models compared to observed data. Projected impacts of climate change include higher winter flows, lower summer flows, increased hydrologic variability, increases in winter sediment and nutrient loading, and decreases in summer sediment and nutrient loading. At the basin scale, the development land use scenario results in increased runoff, increased sediment and orthophosphate loads, and decreased nitrate loads, while the conservation scenario produces decreased runoff and decreased sediment and nutrient loads. The combined climate change and urban development scenarios generally produce hydrological and water quality results that track the results from climate change alone, suggesting that the water resource impacts from climate change are more significant than those from land use change in the TRB over the study period, although this needs to be confirmed with a sensitivity analysis. The development and conservation scenarios do differ in their hydrological and water quality outcomes, however, thus representing a potential 
opportunity for local adaptation to climate change by pursuit of sustainable urban development.

The main contribution of this research is as a case study application of the HSPF model in a meso-scale urban basin in the Pacific Northwest. It is one of the few studies to model changes in both water quantity and quality resulting from both climate change and urban development. Most existing research focuses on only one type of change or one type of impact, no doubt because of the difficulty involved in selecting multiple scenarios, calibrating and validating several different models, and evaluating and comparing the results. It is important, however, to assess the combined influence of climate change and urban development in basins like the Tualatin, because both changes are likely to occur during the coming century and because the two types of change may amplify or ameliorate one another's effects. Understanding the relative importance of climate change and urban development in determining future conditions is important for water resource management, because local policymakers have more control over land use policy than global climate policy. Furthermore, much of the existing research has focused on only the hydrological changes resulting from climate change and urban development, but water quality is also likely to be affected by these changes, as this study demonstrates. By modeling basin response to the potential range of future conditions, this study provides a comprehensive view of the types of challenges likely to be faced by water resource managers in the TRB over the twenty-first century, and provides an example that may be followed in other basins. 
While this research represents an initial effort of characterizing basin response to future changes as fully as possible, great potential exists to improve and expand upon the current study. One way to do this is to experiment with different scenarios. For example, while this study used downscaled General Circulation Model (GCM) output, use of synthetic scenarios is an alternative type of climate impact analysis. Synthetic scenarios with a range of absolute temperature increases and percent increases and decreases in precipitation would allow for the estimation of sensitivity thresholds, or how much a given change in a climate variable affects a given hydrological or water quality variable. A similar approach could be used for estimating sensitivity to urban development, with synthetic land use scenarios representing incremental increases in impervious surface area. An advantage of the sensitivity analysis approach is that it would allow for direct comparison of the climate change and urban development scenarios, so that it would be possible to definitively state which type of change is more significant in the basin. It would also allow for identification of thresholds of climate change and urban development, or levels of change that have ecologically significant results.

Another way to expand upon the current study would be to include more water quality parameters. Climate change and urban development are likely to affect not only suspended sediment, orthophosphate, and nitrate loads, but also temperature, dissolved oxygen, other nutrient species, and other ecologically significant water quality constituents. These variables can be modeled in HSPF or, perhaps more reliably, with a water quality model. Also, adding current and potential future point 
sources of pollutants and best management practices would undoubtedly improve the simulation of water quality in the basin. The water quality analysis could be further improved.by inclusion of changes in concentrations, rather than merely loads, of constituents, because this measure has greater ecological significance.

An obvious way to expand this study would be to repeat the analysis in other basins. In particular, it might be instructive to model impacts of climate change and urban development in a similarly-sized basin that is dominated by snowmelt. It is likely that the climate change impacts would differ in such a basin, because of the increased sensitivity to winter temperature and the importance of the spring snowmelt peak in maintaining summer flows, but it is unclear whether there would be any difference in a higher-elevation basin's sensitivity to land use change, or in how water quality is affected by hydrological changes.

Finally, there is potential to build upon this research by more explicitly considering the impacts on water resource management in the basin. Because the Tualatin River provides drinking water for several large and growing cities, it is important to understand the size of the population that can be served by TRB withdrawals in a future of climate change, given changes in water supply and demand. The changes in the amount of water that can be provided to basin residents resulting from different management actions, such as increasing reservoir storage, installing water-efficient appliances in homes and businesses, and restricting outdoor water use, could be examined through the use of a water management model. This would 
provide management agencies and other policy-makers in the basin with the information needed for effective long-term planning.

As concurrent climate change and urban development progress in the TRB, water resources will be affected in both their quantity and quality. Despite the significant uncertainty involved, hydrological modeling studies, such as this one, are useful for projecting the likely direction and magnitude of these changes so that water resource managers are prepared to adapt. This work is necessary in order to ensure that the economic, aesthetic, recreational, and ecological values of river basins will continue to be provided in the future. 


\section{REFERENCES}

Akhtar, M.A, N. Ahmad, and M.J. Booij. 2008. The impact of climate change on the water resources of Hindukush-Himalaya-Karakorum region under different glacier coverage scenarios. Journal of Hydrology 355:148-163.

Al-Abed, N., and M. Al-Sharif. 2008. Hydrological modeling of Zarqa River Basin, Jordan, using the Hydrological Simulation Program - Fortran (HSPF) model. Water Resource Management 22:1203-1220.

Albek, M., Ü.B. Öğütveren, and E. Albek. 2004. Hydrological modeling of Seydi Suyu watershed (Turkey) with HSPF. Journal of Hydrology 285:260-271.

Alberti, M., D. Booth, K. Hill, B. Coburn, C. Avolio, S. Coe, and D. Spirandelli. 2007. The impact of urban patterns on aquatic ecosystems: An empirical analysis in Puget lowland sub-basins. Landscape and Urban Planning 80:345-361.

Alcamo, J., M. Flörke, and M. Märker. 2007. Future long-term changes in global water resources driven by socio-economic and climatic changes: Hydrological Sciences 52:247-275.

Almeida, C.A., S. Quintar, P. González, and M.A. Mallea. 2007. Influence of urbanization and tourist activities on the water quality of the Potrero de Ios Funes River (San Luis - Argentina). Environmental Monitoring and Assessment 133:459-465.

Anderson, J.R., E.E. Hardy, J.T. Roach, and R.E. Witmer. 1976. A land use and land cover classification system for use with remote sensor data. Washington, DC: United States Government Printing Office.

Andreásson, J., S. Bergström, B. Carlsson, L.P. Graham, and G. Lindström. 2004. Hydrological change: Climate change impact simulations for Sweden. Ambio 33:228-234.

Arheimer, B., J. Andréasson, S. Fogelberg, H. Johnsson, C.B. Pers, and K. Perrson. 2005. Climate change impact on water quality: Model results from southern Sweden. Ambio 34:559-566.

Arnell, N.W. 2000. Thresholds and response to climate change forcing: The water sector. Climatic Change 46:305-316.

Arnell, N.W. 2003a. Effects of IPCC SRES emission scenarios on river runoff: A global perspective. Hydrology and Earth System Sciences 7:619-641. 
Arnell, N.W. 2003b. Relative effects of multi-decadal climatic variability and changes in the mean and variability of climate due to global warming: Future streamflows in Britain. Journal of Hydrology 270:195-213.

Arnell, N.W. 2004. Climate change and global water resources: SRES emissions and socio-economic scenarios. Global Environmental Change 14:31-52.

Atasoy, M., R.B. Palmquist, and D.J. Phaneuf. 2006. Estimating the effects of urban residential development on water quality using microdata. Journal of Environmental Management 79:399-408.

Bae, D., I.W. Jung, and H.Chang. 2008. Potential changes in Korean water resources estimated by high-resolution climate simulation. Climate Research 35:213-226.

Barlage, M.J., P.L. Richards, P.J. Sousounis, and A.J. Brenner. 2002. Impacts of climate change and land use change on runoff from a Great Lakes watershed. Journal of Great Lakes Research 28:568-582.

Barnett, T.P., J.C. Adam, and D.P. Lettenmaier. 2005. Potential impacts of a warming climate on water availability in snow-dominated regions. Nature 438:303-309.

Barnett, T.P., D.W. Pierce, H.G. Hidalgo, C. Bonfils, B.D. Santer, T. Das, G. Bala, A.W. Wood, T. Nozawa, A.A. Mirin, D.R. Cayan, and M.D. Dettinger. 2008. Human-induced changes in the hydrology of the western United States. Science 319:1080-1083.

Beighley, R.E., T. Dunne, and J.M. Melack. 2008. Impacts of climate variability and land use alterations on frequency distributions of terrestrial runoff loading to coastal waters in southern California. Journal of the American Water Resources Association 44:63-74.

Beven, K. 2008. Measurement, models, management and uncertainty: The future of hydrological science. IAHS-AISH Publication 323:139-147.

Bicknell, B.R., J.C. Imhoff, J.L. Kittle, Jr., T.H. Jobes, and A.S. Donigian, Jr. 2001. Hydrological Simulation Program - Fortran: HSPF version 12 user's manual. Mountain View, CA: Aqua Terra Consultants.

Boeder, M., and H. Chang. 2008. Multi-scale analysis of oxygen demand trends in an urbanizing Oregon watershed, USA. Journal of Environmental Management $87: 567-581$. 
Bouraoui, F., B. Grizzetti, K. Granlund, S. Rekolainen, and G. Bidoglio. 2004. Impact of climate change on the water cycle and nutrient losses in a Finnish catchment. Climatic Change 66:109-126.

Cao, W., W.B. Bowden, T. Davie, and A. Fenemor. 2008. Modelling impacts of land cover change on critical water resources in the Motueka River catchment, New Zealand. Water Resource Management 10:107-121.

Chang, H. 2003. Basin hydrologic response to changes in climate and land use: The Conestoga River Basin, Pennsylvania. Physical Geography 24:222-247.

Chang, H. 2004. Water:quality impacts of climate and land use changes in southeastern Pennsylvania. Professional Geographer 56:240-257.

Chang, H., B.M. Evans, and D.R. Easterling. 2001. The effects of climate change on stream flow and nutrient loading. Journal of the American Water Resources Association 37:973-986.

Chen, J., X. Li, and M. Zhang. 2005. Simulating the impacts of climate variation and land-cover changes on basin hydrology: A case study of the Suomo Basin. Science in China Series D: Earth Sciences 48:1501-1509.

Choi, W., and B.M. Deal. 2008. Assessing hydrological impact of potential land use change through hydrological and land use change modeling for the Kishwaukee River basin (USA). Journal of Environmental Management 88:1119-1130.

Christensen, N.S., A.W. Wood, N. Voisin, D.P. Lettenmeier, and R.N. Palmer. 2004. The effects of climate change on the hydrology and water resources of the Colorado River Basin. Climatic Change 62:337-363.

Chung, E., and K.S. Lee. 2009. Prioritization of water management for sustainability using hydrologic simulation model and multicriteria decision making techniques. Journal of Environmental Management 90:1502-1511.

Conway, T.M. 2007. Impervious surface as an indicator of $\mathrm{pH}$ and specific conductance in the urbanizing coastal zone of New Jersey, USA. Journal of Environmental Management 85:308-316.

Cunderlik, J.M., and S.P. Simonovic. 2005. Hydrological extremes in a southwestern Ontario river basin under future climate conditions. Hydrological Sciences 50:631-654. 
Cuo, L., D.P. Lettenmaier, M. Alberti, and J.E. Richey. 2009. Effects of a century of land cover and climate change on the hydrology of the Puget Sound basin. Hydrological Processes 23:907-933.

Davis Todd, C.E., A.M. Goss, D. Tripathy, and J.M. Harbor. 2007. The effects of landscape transformation in a changing climate on local water resources. Physical Geography 28:21-36.

Dibike, Y.B., and P. Coulibaly. 2005. Hydrologic impact of climate change in the Saguenay watershed: Comparison of downscaling methods and hydrologic models. Journal of Hydrology 307:145-163.

Dettinger, M.D., D.R. Cayan, M.K. Meyer, and A.E. Jeton. 2004. Simulated hydrologic responses to climate variations in the Merced, Carson, and American river basins, Sierra Nevada, California, 1900-2099. Climatic Change 62:283-317.

Diaz-Ramirez, J.N., L.R. Perez-Alegria, and W.H. McAnally. 2008. Hydrology and sediment modeling using BASINS/HSPF in a tropical island watershed. Transactions of the ASABE 51:1555-1565.

Donigian, A.S., Jr., B.R. Bicknell, and J.C. Imhoff. 1995. Hydrological Simulation Program - Fortran. In Computer models of watershed hydrology, ed. V.P. Singh. Littleton, CO: Water Resources Publications.

Donigian, A.S., Jr., and J.C. Imhoff. 2002. From the Stanford model to BASINS: 40 years of watershed modeling. Mountain View, CA: Aqua Terra Consultants.

Ducharne, A., C. Baubion, N. Beaudoin, M. Benoit, G. Billen, N. Brisson, J. Garnier, H. Kieken, S. Lebonvallet, E. Ledoux, B. Mary, C. Mignolet, X. Poux, E. Sauboua, C. Schott, S. Théry, and P. Viennot. 2007. Long-term perspective of the Seine River system: Confronting climatic and direct anthropogenic changes. Science of the Total Environment 375:292-311.

Dunne, T., and L. Leopold. 1978. Water in environmental planning. New York: W.H. Freeman and Company.

Eckhardt, K., and U. Ulbrich. 2003. Potential impacts of climate change on groundwater recharge and streamflow in a central European low mountain range. Journal of Hydrology 284:244-252.

Evans, J., and S. Schreider. 2002. Hydrological impacts of climate change on inflows to Perth, Australia. Climatic Change 55:361-393. 
Fowler, H.J., C.G. Kilsby, and J. Stunell. 2007. Modelling the impacts of potential future climate change on water resources in north-west England. Hydrology and Earth System Sciences 11:1115-1126.

Franczyk, J., and H. Chang. 2009. The effects of climate change and urbanization on the runoff of the Rock Creek basin in the Portland metropolitan area, Oregon, USA. Hydrological Processes 23:805-815.

Frei, A., R.L. Armstrong, M.P. Clark, and M.C. Serreze. 2002. Catskill Mountain water resources: Vulnerability, hydroclimatology, and climate-change sensitivity. Annals of the Association of American Geographers 92:203-224.

Fujihara, Y., K. Tanaka, T. Watanabe, T. Nagano, and T. Kojiri. 2008. Assessing the impacts of climate change on the water resources of the Seyhan River Basin in Turkey: Use of dynamically downscaled data for hydrologic simulations. Journal of Hydrology 353:33-48.

Göncü, S., and E. Albek. 2008. Modeling climate change impacts on suspended and dissolved water quality constituents in watersheds. Fresenius Environmental Bulletin 17:1501-1510.

Graham, L.P. 2004. Climate change effects on river flow to the Baltic Sea. Ambio $33: 235-241$.

Graham, L.P., S. Hagemann, S. Jaun, and M. Beniston. 2007. On interpreting hydrological change from regional climate models. Climatic Change 81:97122.

Hamlet, A.F., and D.P. Lettenmaier. 2007: Effects of $20^{\text {th }}$ century warming and climate variability on flood risk in the western U.S. Water Resources Research 43:W06427.

Harrison, P.A., P.M. Berry, C. Henriques, and I.P. Holman. 2008. Impacts of socioeconomic and climate change scenarios on wetlands: Linking water resource and biodiversity meta-models. Climatic Change 90:113-139.

Hayashi, S., S. Murakami, M. Watanabe, and X. Bao-Hua. 2004. HSPF simulation of runoff and sediment loads in the Upper Changiiang River Basin, China. Journal of Environmental Engineering 130:801-815.

Herron, N., R. Davis, and R. Jones. 2002. The effects of large-scale afforestation and climate change on water allocation on the Macquarie River catchment, NSW, Australia. Journal of Environmental Management 65:369-381. 
Hunter, H.M., and R.S. Waiton. 2008. Land-use effects on fluxes of suspended sediment, nitrogen and phosphorus from a river catchment of the Great Barrier Reef, Australia. Journal of Hydrology 356:131-146.

Huntington, T.G. 2006. Evidence for intensification of the global water cycle: Review and synthesis. Journal of Hydrology 319:1-4.

Im, S., K.M. Brannan, S. Mostaghimi, and S.M. Kim. 2003. Comparison of HSPF and SWAT models performance for runoff and sediment yield prediction. Journal of Environmental Science and Health: Part A Toxic/Hazardous Substances and Environmental Engineering 42:1561-1570.

Imhoff, J.C., J.L. Kittle Jr., M.R. Gray, and T.E. Johnson. 2007. Using the Climate Assessment Tool (CAT) in U.S. EPA BASINS integrated modeling system to assess watershed vulnerability to climate change. Water Science and Technology 56:49-56.

Intergovernmental Panel on Climate Change (IPCC). 2000. Special report on emissions scenarios. The Hague: GRID-Arendal.

Iskra, I., and R. Droste. 2008. Parameter uncertainty of a watershed model. Canadian Water Resources Journal 33:5-22.

Jeon, J.H., C.G. Yoon, K.W. Jung, and J.H. Jang. 2007. HSPF-Paddy simulation of water flow and quality for the Saemangeum watershed in Korea. Water. Science and Technology 56:123-130.

Jha, M.K. 2005. Hydrologic modeling and climate change study in the Upper Mississippi River Basin using SWAT. Ph.D. dissertation, Department of Civil Engineering, Iowa State University.

Kay, A.L., R.G. Jones, and N.S. Reynard. 2006. RCM rainfall for UK flood frequency estimation. II: Climate change results. Journal of Hydrology 318:163-172.

Kim, J. 2005. A projection of the effects of the climate change induced by increased $\mathrm{CO}_{2}$ on extreme hydrologic events in the western U.S. Climatic Change $68: 153-168$.

Kim, S.M., B.L. Benham, K.M. Brannan, R.W. Zeckoski, and J. Doherty. 2007. Comparison of hydrologic calibration of HSPF using automatic and manual methods. Water Resources Research 43:W1402.

Kleinen, T., and G. Petschel-Held. 2007. Integrated assessment of changes in flooding probabilities due to climate change. Climatic Change 81:283-312. 
Knowles, N., and D.R. Cayan. 2004. Elevational dependence of projected hydrologic changes in the San Francisco estuary and watershed. Climatic Change 62:319336.

Kumagai, M., K. Ishikawa, and J. Chunmeng. 2002. Dynamics and biogeochemical significance of the physical environment in Lake Biwa. Lakes and Reservoirs: Research and Management 7:345-348.

Kundzewicz, Z.W., L.J. Mata, N.W. Arnell, P. Döll, P. Kabat, B. Jiménez, K.A. Miller, T. Oki, Z. Sęn, and I.A. Shiklomanov. 2007. Freshwater resources and their management. In Climate change 2007: Impacts, adaptation and vulnerability. Contribution of Working Group II to the Fourth Assessment Report of the Intergovernmental Panel on Climate Change. Eds. M.L. Parry, O.F. Canziani, J.P. Palutikof, P.J. van der Linden; and C.E. Hanson. Cambridge, UK: Cambridge University Press.

Kundzewicz, Z.W., U. Ulbrich, T. Brücher, D. Graczyk, A. Krüger, G.C. Leckebusch, L. Menzel; I. Pińkswar, M. Radziejewski, and M. Szwed. 2005. Summer floods in central Europe - climate change track? Natural Hazards 36:165-189.

Laroche, A., J. Gallichand, R. Lagacé, and A. Pesant. 1996. Simulating atrazine transport with HSPF in an agricultural watershed. Journal of Environmental Engineering 122:622-630.

Legates, D.R., and G.J. McCabe, Jr. 1999. Evaluating the use of "goodness-of-fit" measures in hydrologic and hydroclimatic model validation. Water Resources Research 35:233-241.

Lehner, B., P. Döll, J. Alcamo, T. Henrichs, and F. Kaspar. 2006. Estimating the impact of global change on flood and drought risks in Europe: A continental, integrated analysis. Climatic Change 75:273-299.

Loukas, A., L. Vasiliades, and N.R. Dalezios. 2002a. Potential climate change impacts on flood producing mechanisms in southern British Columbia, Canada using the CGCMA1 simulation results. Journal of Hydrology 259:163-188.

Loukas, A., L. Vasiliades, and N.R. Dalezios. 2002b. Climatic impacts on the runoff generation processes in British Columbia, Canada. Hydrology and Earth System Sciences 6:211-227.

Manabe, S., P.C.D. Milly, and R. Wetherald. 2004. Simulated long-term changes in river discharge and soil moisture due to global warming. Hydrological Sciences 49:625-642. 
Maximov, I.A. 2003. Integrated assessment of climate and land use change effects on hydrology and water quality of the Upper and Lower Great Miami River. Ph.D. dissertation, Department of Geography, University of Cincinnati.

Meyer, L.D., and W.H. Wischmeier. 1969. Mathematical simulation of the processes of soil erosion by water. Transactions of the American Society of Agricultural Engineering 12:754-762.

McBride, G.B. 2005. Using statistical tests for water quality management: Issues, problems, and solutions. Hoboken, NJ: Wiley-Interscience.

Menzel, L., and G. Bürger. 2002. Climate change scenarios and runoff response in the Mulde catchment (Southern Elbe, Germany). Journal of Hydrology 267:53-64.

Milly, P.C.D., R.T. Wetherald, K.A. Dunne, and T.L. Delworth. 2002. Increasing risk of great floods in a changing climate. Nature 415:514-517.

Milly, P.C.D., K.A. Dunne, and A.V. Vecchia. 2005. Global pattern of trends in streamflow and water availability in a changing climate. Nature 438:347-350.

Milly, P.C.D., J. Betancourt, M. Falkenmark, R.M. Hirsch, Z.W. Kundzewicz, D.P. Lettenmeier, and R.J. Stouffer. 2008. Stationarity is dead: Whither water management? Science 319:573-574.

Mimikou, M.A., E. Baltas, E. Varanou, and K. Pantazis. 2000. Regional impacts of climate change on water resources quantity and quality indicators. Journal of Hydrology 234:95-109.

Morrison, J., M.C. Quick, and M.G.G. Foreman. 2002. Climate change on the Fraser River watershed: Flow and temperature projections. Journal of Hydrology 263:230-244.

Mote, P.W., E.A. Parson, A.F. Hamlet, W.S, Keeton, D. Lettenmaier, N. Mantua, E.L. Miles, D.W. Peterson, D.L. Peterson, R. Slaughter, and A.K. Snover. 2003. Preparing for climatic change: The water, salmon, and forests of the Pacific Northwest. Climatic Change 61:45-88.

Murdoch, P.S., J.S. Baron, and T.L. Miller. 2000. Potential effects of climate change on surface-water quality in North America. Journal of the American Water Resources Association 36:347-366. 
Nasr, A., M. Bruen, P. Jordan, R. Moles, G. Kiely, and P. Byrne. 2007. A comparison of SWAT, HSPF and SHETRAN/GOPC for modelling phosphorus export from three catchments in Ireland. Water Research 41:1065-1073.

National Resource Conservation Service (NRCS). 2001. STATSGO Soils Dataset, Oregon. Accessed 5/7/2008. <http://www.brc.tamus.edu/swat/doc_databasessoils.html>.

Nelson, D.R., W.N. Adger, and K. Brown. 2007. Adaptation to environmental change: Contributions of a resilience framework. Annual Review of Environment and Resources 32:395-419.

Nirupama, N., and S.P. Simonovic. 2007. Increase of flood risk due to urbanisation: A Canadian example. Natural Hazards 40:25-41.

Nohara, D., A. Kitoh, M. Hosaka, and T. Oki. 2006. Impact of climate change on river discharge projected by multimodel ensemble. Journal of Hydrometeorology 7:1076-1089.

O'Hara, J.K. and K.P. Georgakakos. 2008. Quantifying the urban water supply impacts of climate change. Water Resource Management 22:1477-1497.

Oki, T., and S. Kanae. 2006. Global hydrological cycles and world water resources. Science 313:1068-1072.

Oregon Climate Service (OCS). 2008. Zone 2 - Climate Data Archives. Accessed 5/7/2008. http://ocs.orst.edu/index.html.

Oregon Department of Environmental Quality (ODEQ). 1998. Oregon's final 1998 water quality limited streams: 303(d) list. Oregon Department of Environmental Quality, Salem, Oregon.

Oregon Secretary of State (OSOS). 2008. Oregon Blue Book. Accessed 12/5/2008. $<$ http://bluebook.state.or.us/>.

Palmer, R.N., E. Clancy, N. T. VanRheenen, and M.W. Wiley. 2004. The impacts of climate change on the Tualatin River Basin water supply: An investigation into projected hydrologic and management impacts. Clean Water Services: Hillsboro, Oregon.

Palmer, T.N., and J. Räisänen. 2002. Quantifying the risk of extreme seasonal precipitation events in a changing climate. Nature 415:512-514. 
Payne, J.T., A.W. Wood, A.F. Hamlet, R.N. Palmer, and D.P. Lettenmeier. 2004. Mitigating the effects of climate change on the water resources of the Columbia River Basin. Climatic Change 62:233-256.

Regonda, S.K., B. Rajagopalan, M. Clark, and J. Pitlick. 2005. Seasonal cycle shifts in hydroclimatology over the western United States. Journal of Climate 18:372384.

Ribarova, I., P. Ninov, and D. Cooper. 2008. Modeling nutrient pollution during a first flood event using HSPF software: Iskar River case study, Bulgaria. Ecological Modelling 211:241-246.

Rose, S. 2007. The effects of urbanization on the hydrochemistry of base flow within the Chattahoochee River Basin (Georgia, USA). Journal of Hydrology 341:4254.

Rose, S., and N.E. Peters. 2001. Effects of urbanization and streamflow in the Atlanta area (Georgia, USA): A comparative hydrological approach. Hydrological Processes 15:1441-1457.

Salathé, Jr., E.P., P.W. Mote, and M.W. Wiley. 2007. Review of scenario selection and downscaling methods for the assessment of climate change impacts on hydrology in the United States Pacific Northwest. International Journal of. Climatology 27:1611-1621.

Samaniego, L., and A. Bárdossy. 2006. Simulation of the impacts of land use/cover and climatic changes on the runoff characteristics at the mesoscale. Ecological Modelling 196:45-61.

Sarooshian, S., and V.K. Gupta. 1995. Model calibration. In Computer models of watershed hydrology, ed. V.P. Singh. Highlands Ranch, CO: Water Resources Publications.

Sharma, U.C. 2003. Impact of population growth and climate change on the quantity and quality of water resources in the northeast of India. IASH-AISH Publication 281:349-357.

Stewart, I.T., D.R. Cayan, and M.D. Dettinger. 2004. Changes in snowmelt runoff timing in western North America under a "business as usual" climate change scenario. Climatic Change 62:217-232.

Tague, C., G. Grant, M.. Farrell, J. Choate, and A. Jefferson. 2008. Deep groundwater mediates streamflow response to climate warming in the Oregon Cascades. Climatic Change 86:189-210. 
Tang, Z., B.A. Engel, B.C. Pijanowski, and K.J. Lim. 2005. Forecasting land use change and its.environmental impact at a watershed scale. Journal of Environmental Management 76:35-45.

Thodsen, H. 2007. The influence of climate change on stream flow in Danish rivers. Journal of Hydrology 333:226-238.

Tong, S.T.Y., and W. Chen. 2002. Modeling the relationship between land use and surface water quality. Journal of Environmental Management 66:377-393.

Tu, J., Z. Xia, K.C. Clarke, and A. Frei. 2007. Impacts of urban sprawl on water quality in eastern Massachusetts, USA. Environmental Management 40:183200.

Tualatin River Watershed Council (TRWC). 1999. Tualatin River watershed action plan. Tualatin River Watershed Council, Hillsboro, Oregon.

U.S. Census Bureau (USCB). 2007. 2007 Population estimates. United States Census Bureau, Washington, DC.

U.S. Environmental Protection Agency (USEPA). 2000. BASINS technical note 6: Estimating hydrology and hydraulic parameters for HSPF. Washington, D.C.

U.S. Environmental Protection Agency (USEPA). 2001. Better assessment science integrating point and nonpoint sources: BASINS version 3.0 user's manual. Washington, D.C.

U.S. Environmental Protection Agency (USEPA). 2006. BASINS technical note 8: Sediment parameter and calibration guidance for HSPF. Washington, D.C.

U:S. Environmental Protection Agency (USEPA). 2008. Multi-Resolution Land Characteristics Consortium (MRLC). Accessed 12/5/2008. $<$ http://www.epa.gov/mrlc/>.

U.S. Geological Survey (USGS). 2004. National Elevation Dataset (NED) 1/3 Arc Second. Accessed 5/8/2008. $<$ http://seamless.usgs.gov/Website/Seamless/products/3arc.asp $>$.

U.S. Geological Survey (USGS). 2006. 8-Digit Hydrologic Unit Code Boundaries. Accessed 5/8/2008. <http://water.usgs.gov/GIS/huc.html $>$.

U.S. Geological Survey (USGS). 2008a. USGS Surface-Water Data for Oregon. Accessed 12/5/2008. < http://waterdata.usgs.gov/or/nwis/sw/>. 
U.S. Geological Survey (USGS). 2008b. Tualatin River Basin Water Quality Assessment. Accessed 12/5/2008.

< http://or.water.usgs.gov/tualatin/pn356.html>.

VanRheenen, N.T., A.W. Wood, R:N. Palmer, and D.P. Lettenmeier. 2004. Potential implications of PCM climate change scenarios for Sacramento-San Joaquin River Basin hydrology and water resources. Climatic Change 62:257-281.

Varanou, E., E. Gkouvatsou, E. Baltas, and M. Mimikou. 2002. Quantity and quality integrated catchment modeling with use of soil and water assessment tool model. Journal of Hydrologic Engineering 7:228-244.

Vörösmarty, C.J., P. Green, J. Salisbury, and R.B. Lammers. 2000. Global water resources: Vulnerability from climate change and population growth. Science 289:284-288.

Wang, L. 2006. Investigating impacts of natural and human-induced environmental changes on hydrological processes and flood hazards using a GIS-based hydrological/hydraulic model and remote sensing data. Ph.D. dissertation, Department of Geography, Texas A\&M University.

Wang, P., and L.C. Linker. 2006. A correction of DIN uptake simulation by Michaelis-Menton saturation kinetics in HSPF watershed model to improve DIN export simulation, Environmental Modelling and Software 21:45-60.

Waters, D., W.E. Watt, J. Marsalek, and B.C. Anderson. 2003. Adaptation of a storm drainage system to accommodate increased rainfall resulting from climate change. Journal of Environmental Planning and Management 46:755-770.

Watts, G. 1997. Hydrological modelling in practice. In Contemporary hydrology: Towards holistic environmental science, ed. R. Wiley. Chichester, UK: John Wiley \& Sons.

Wegglarczyk, S. 1998. The interdependence and applicability of some statistical quality measures for hydrological models. Journal of Hydrology 206:98-103.

Whitehead, P.G., R.L. Wilby, R.W. Battarbee, M. Kernan, and A.J. Wade. 2009. A review of the potential impacts of climate change on surface water quality. Hydrological Sciences Journal 54:101-123. 
Wilby, R.L., P.G. Whitehead, A.J. Wade, D. Butterfield, R.J. Davis, and G. Watts. 2006. Integrated modelling of climate change impacts on water resources and quality in a lowland catchment: River Kennet, UK. Journal of Hydrology 330:204-220.

Wood, A.W., L.R. Leung, V. Sridhar, and D.P..Lettenmeier. 2004. Hydrologic implications of dynamical and statistical approaches to downscaling climate model outputs. Climatic Change 62:189-216.

Xu, C. 1999. From GCMs to river flow: A review of downscaling methods and hydrologic modelling approaches. Progress in Physical Geography 23:229249. 